UNIVERSIDAD POLITECNICA DE VALENCIA

Departamento de Ingeniería Cartográfica, Geodesia y Fotogrametría

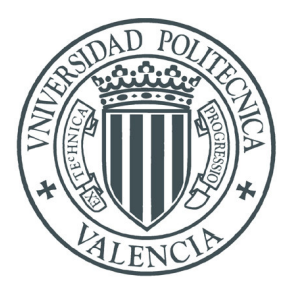

\title{
ESTUDIO DE TÉCNICAS BASADAS EN LA TRANSFORMADA WAVELET Y OPTIMIZACIÓN DE SUS PARÁMETROS PARA LA CLASIFICACIÓN POR TEXTURAS DE IMÁGENES DIGITALES
}

TESIS DOCTORAL

Presentada por:

Alfonso Fernández Sarría

Director:

Dr. D. Luis Ángel Ruiz Fernández

Valencia, febrero de 2007 
Hubo árboles antes que fubiera libros, y acaso cuando acaben los libros continúen los árboles. Y tal vez llegue la humanidad a un grado de cultura tal que no necesite ya de libros, pero siempre necesitará de los árboles y entonces abonará los árboles con libros.

Miguel de Unamuno 
1. Introducción 1

1.1. Problemática y líneas de trabajo existentes ....................................5

1.2. Contenido de la tesis......................................................... 8

2. Antecedentes sobre Análisis de Texturas 9

2.1. Definición de textura........................................................

2.2. Objetivos del estudio de texturas ......................................... 13

2.3. Las texturas en las imágenes de la superficie terrestre.........................14

2.4. Estado del arte en el análisis de texturas: metodologías y aplicaciones ....17

2.4.1. Métodos estadísticos .............................................. 17

2.4.2. Métodos estructurales o geométricos ................................ 18

2.4.3. Métodos basados en modelos ........................................... 19

2.4.4. Enfoque mediante transformadas ......................................20

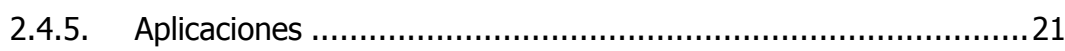

2.5. Observaciones sobre los métodos de análisis de texturas .......................38

3. Objetivos 43

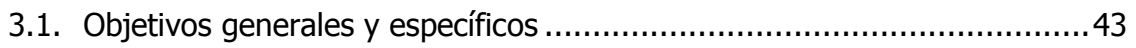

4. La Transformada Wavelet 47

4.1. Introducción a la Teoría Wavelet: historia y definiciones.......................47

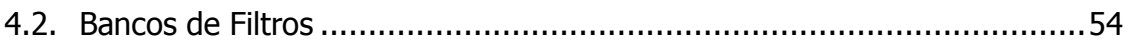

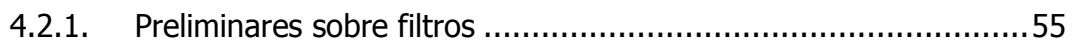

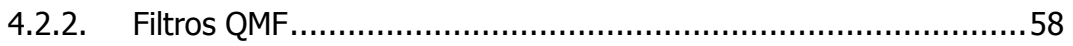

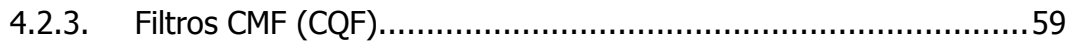

4.2.4. Filtros Ortonormales..................................................60

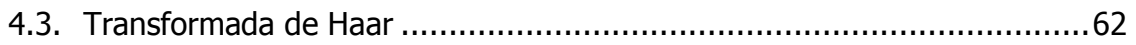

4.3.1. Transformada de Haar a nivel 1 .....................................6 62 


\section{$\underline{\text { ÍNDICE }}$}

4.3.2. Transformada de Haar de niveles sucesivos...........................63

4.3.3. Transformada wavelet de Haar ..........................................6 64

4.4. La Transformada Wavelet Continua Unidimensional (CWT) .................66

4.5. Propiedades de la Transformada Wavelet ................................. 70

4.6. Transformada Wavelet frente a Transformada de Fourier ...................73

4.7. Modelos de aplicación de la Transformada Wavelet..............................76

4.7.1. La Transformada Wavelet Discreta ....................................77

4.7.2. Análisis Multiresolución ..................................................... 81

4.7.3. Wavelet Frames Discreta (DWF) .................................. 86

4.7.4. Otras transformadas redundantes.................................... 88

4.7.4.1. Algoritmo "à trous"

4.7.4.2. Algoritmo "shift4".................................................. 90

4.7.4.3. Transformada Wavelet Packet .................................. 91

4.7.5. La Transformada Wavelet Rápida (FWT) .................................99

4.7.6. Bases Ortonormales Wavelet Bidimiensionales....................... 95

4.7.7. Transformada Wavelet Rápida en dos dimensiones. ...................96

$\begin{array}{ll}\text { 5. Datos de trabajo } & 103\end{array}$

5.1. Tipologías de las superficies .............................................. 103

5.1.1. Zonas urbanas y peri-urbanas ......................................... 104

5.1.2. Zonas rurales mediterráneas ....................................... 108

5.1.3. Zonas agrícolas......................................................... 114

5.1.4. Zonas de montaña con vegetación natural ...........................116

5.1.5. Zonas de montaña mixtas............................................... 121

6. Metodología de los ensayos realizados 127

6.1. Preprocesado de las imágenes de partida .................................... 129

6.1.1. Correcciones geométricas ............................................ 129

6.1.2. Correcciones radiométricas ....................................... 129

6.1.3. Elaboración de mosaicos................................................. 130

6.2. Análisis de las diferentes variables de textura ................................ 131 
6.2.1. Índices estadísticos de primer orden ..................................... 131

6.2.2. Índices estadísticos de segundo orden .................................. 133

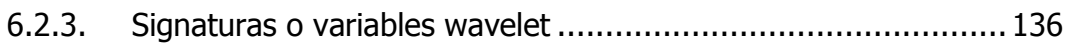

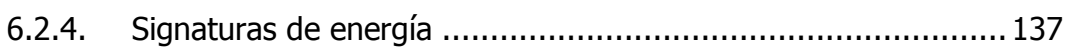

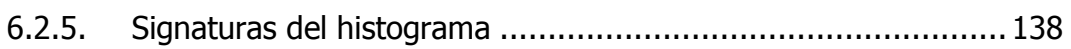

6.2.6. Filtros de energía textural o de Laws ..................................... 139

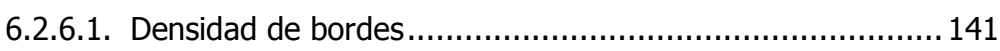

6.2.7. Filtros de Gabor ............................................................. 143

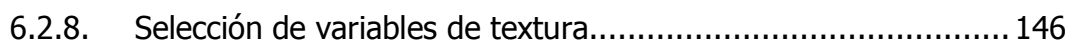

6.3. Determinación de los parámetros metodológicos globales ..................... 147

6.3.1. Determinación de la resolución espacial óptima ......................... 148

6.3.2. Determinación de la resolución radiométrica óptima..................150

6.3.3. Determinación del mejor vecindario de cálculo de textura.......... 152

6.3.4. Algoritmos de aplicación de la Transformada Wavelet ............... 153

6.3.4.1. Aplicación práctica de los algoritmos ................................ 153

6.3.5. Niveles de descomposición de la Transformada Wavelet........... 155

6.3.6. Aplicación de la Transformada Wavelet Rápida: implementación

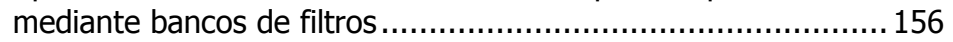

6.3.6.1. Familias de funciones wavelet empleadas en los cálculos ... 158

6.3.6.2. Wavelet de Haar ........................................................... 160

6.3.6.3. Wavelet Daubechies ......................................................... 161

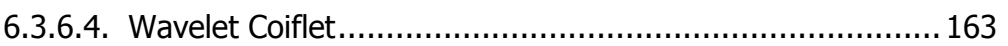

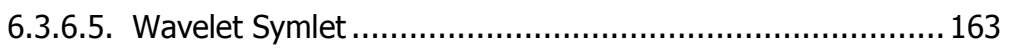

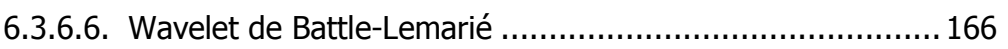

6.3.6.7. Wavelet de Shannon......................................................... 166

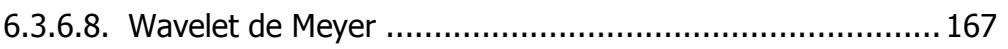

6.3.6.9. Esquema de trabajo aplicado mediante bancos de filtros.... 167

6.3.7. Selección de parámetros asociados a las funciones wavelet ...... 169

6.3.8. Método de clasificación empleado......................................... 170

6.3.9. Evaluación de las clasificaciones............................................ 174

6.4. Tratamiento post-clasificación de las zonas de bordes.......................... 175

6.4.1. Segundas varianzas............................................................. 177 
6.4.2. Bordes de la media ................................................ 178

6.4.3. Filtros de Canny.......................................................... 179

6.4.4. Bordes de la clasificación inicial .................................. 181

7. Resultados experimentales y discusión 183

7.1. Introducción y justificación ...................................................... 183

7.2. Análisis de variables de textura ................................................ 184

7.2.1. Eficiencia de las variables estadísticas de $1^{\mathrm{er}}$ y $2^{\circ}$ orden y derivadas del histograma: energía y asimetría

7.2.2. Eficiencia de otras variables de textura: filtros wavelet, Gabor

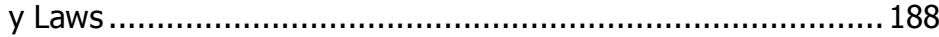

7.3. Análisis de parámetros metodológicos ........................................... 191

7.3.1. Determinación de la resolución espacial óptima ..................... 191

7.3.2. Determinación de la mejor resolución radiométrica .................. 196

7.3.3. Vecindario óptimo de cálculo de variables de textura................ 198

7.3.4. Ensayos sobre el algoritmo empleado para el cálculo de la Transformada Wavelet ............................................ 200

7.3.5. Niveles y familias empleadas en la Transformada Wavelet ........ 201

7.4. Verificación global de las variables y parámetros óptimos obtenidos ...... 204

7.4.1. Datos de partida para las pruebas ..................................... 205

7.4.2. Verificación de los grupos de variables texturales......................206

7.4.3. Verificación de todas las familias de funciones wavelet..............207

7.5. Tratamiento post-clasificación de las zonas frontera.......................... 212

7.6. Discusión de los resultados................................................. 215

8. Conclusiones y líneas futuras $\quad 219$

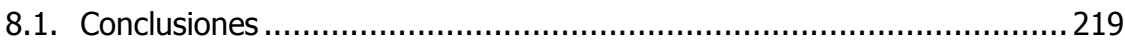

8.2. Posibles líneas futuras de investigación........................................ 223

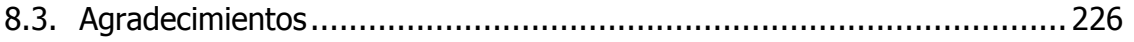

$\begin{array}{ll}\text { 9. Referencias bibliográficas } & 227\end{array}$ 
ÍNDICE

10. Anejos

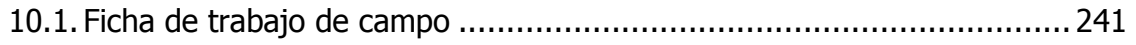

10.2. Coeficientes de los bancos de filtros ........................................ 243

10.3. Listado de rutinas programadas ............................................ 245 


\section{LISTADO DE TABLAS}

Tabla 4-1: $\quad$ Relaciones entre los filtros para distintos bancos de filtros .................................... 58

Tabla 5-1: Características técnicas de la plataforma comercial QuickBird................................... 104

Tabla 5-2: Especificaciones técnicas de la imagen QuickBird pancromática de Valencia............. 105

Tabla 5-3: Especificaciones técnicas de la imagen QuickBird pancromática de Menorca............. 109

Tabla 6-1: Ventanas de filtros de tres vecindarios............................................................. 140

Tabla 6-2: Coeficientes de la función wavelet Meyer3 …...................................................... 154

Tabla 7-1: $\quad$ Fiabilidades del productor para cada grupo de variables sobre las dos imágenes ..... 186

Tabla 7-2: $\quad$ Fiabilidades globales para cada grupo de variables de la MCNG sobre 4 imágenes... 188

Tabla 7-3: $\quad$ Fiabilidades globales para cada grupo de variables sobre las dos imágenes.............. 188

Tabla 7-4: $\quad$ Fiabilidades del productor para cada grupo de variables sobre las dos imágenes ..... 189

Tabla 7-5: Varianza para cada mosaico de cada clase a diferentes resoluciones ....................... 192

Tabla 7-6: Entorno agrícola de Daimiel considerando diferentes vecindarios de cálculo ............. 193

Tabla 7-7: Entorno de montaña con vegetación natural de Espadán ....................................... 194

Tabla 7-8: $\quad$ Resultados de la varianza local de niveles de intensidad para 2 imágenes a distintas resoluciones espaciales y empleando varios vecindarios............................. 195

Tabla 7-9: $\quad$ Resultados de la clasificación de ámbitos agrícolas ............................................... 196

Tabla 7-10: Fiabilidad global al clasificar las 8 variables de textura de la MCNG de cada resolución ................................................................................................. 197

Tabla 7-11: Fiabilidades globales en cada imagen y resolución radiométrica .............................. 197

Tabla 7-12: Fiabilidades del productor de cada clase y con cada vecindario a $5 \mathrm{~m}$ de resolución . 198

Tabla 7-13: Fiabilidades globales de las clasificaciones para distintos vecindarios ...................... 199

Tabla 7-14: Fiabilidad global y parámetro Kappa de las variables extraídas de los detalles de

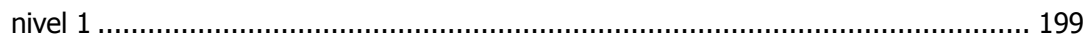

Tabla 7-15: Resultados de clasificación para 3 imágenes sobre las que se han aplicado 3

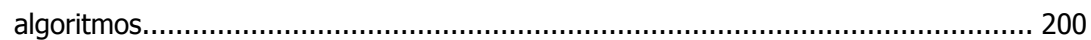

Tabla 7-16: Fiabilidades globales para cada grupo de variables sobre las dos imágenes.............. 203

Tabla 7-17: Fiabilidades globales para cada grupo de variables sobre las dos imágenes............. 203

Tabla 7-18: Fiabilidades globales para cada grupo de variables sobre las dos imágenes.............. 203

Tabla 7-19: $\quad$ Fiabilidades del productor $y$ usuario por clases $y$ funciones wavelet......................... 204

Tabla 7-20: Fiabilidades globales sobre el mosaico agrícola para varias funciones wavelet......... 204

Tabla 7-21: Fiabilidades globales para cada grupo de variables .............................................. 206

Tabla 7-22: Fiabilidades globales para cada wavelet, área de estudio y grupo de variables ........ 208

Tabla 7-23: Fiabilidades globales para cada clasificación .................................................. 213

Tabla 10-1: Coeficientes de los filtros de la familia de funciones Daubechies............................. 243

Tabla 10-2: Coeficientes de los filtros de la familia de funciones Coiflet6.................................... 243

Tabla 10-3: Coeficientes de los filtros de la familia de funciones Coiflet12 ............................... 244

Tabla 10-4: Coeficientes de los filtros de la familia de funciones Coiflet18 ................................. 244

Tabla 10-5: Coeficientes de los filtros de la familia de funciones Coiflet24 ................................ 244

Tabla 10-6: Coeficientes de los filtros de la familia de funciones Symlet.................................... 244

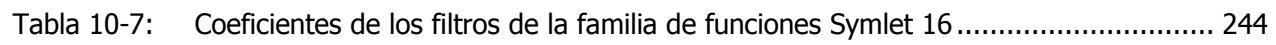

Tabla 10-8: Coeficientes de los filtros de la función Battle-Lemarié 6 ........................................ 245

Tabla 10-9: Coeficientes de los filtros de la función Shannon 7............................................. 245

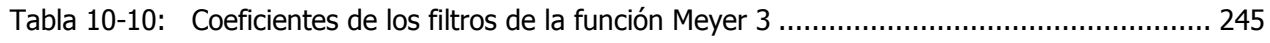




\section{LISTADO DE FIGURAS}

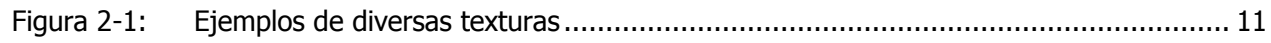

Figura 2-2: Textura propia de cada elemento y del total del conjunto ........................................ 12

Figura 2-3: $\quad$ Algunas texturas de la base Brodatz, 1966 ........................................................... 12

Figura 2-4: $\quad$ Diversos ejemplos de texturas presentes en imágenes del territorio ........................... 16

Figura 2-5: Esquema de descomposición de Porter y Canagarajah (1996) .................................... 33

Figura 4-1: Operador Laplaciano del Gaussiano ................................................................... 50

Figura 4-2: Banco de filtros de dos bandas o canales unidimensionales aplicado en análisis y

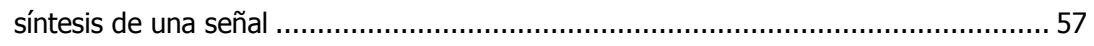

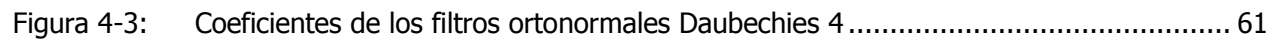

Figura 4-4: Diferentes funciones wavelet con variaciones en la traslación y escala .......................68

Figura 4-5: Dos señales unidimensionales, periódica (izquierda) y no periódica (derecha) ............ 75

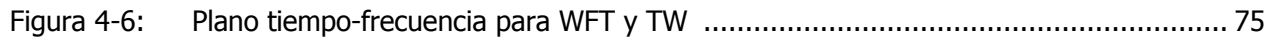

Figura 4-7: Tiling espacio frecuencia para Fourier y Wavelet ................................................... 76

Figura 4-8: Ejemplo de la modificación de una imagen por desplazamiento................................. 89

Figura 4-9: $\quad$ Algoritmo "à trous" aplicado sobre una imagen de partida $\mathrm{I}_{0}$ e imágenes

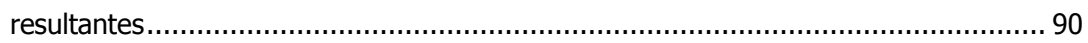

Figura 4-10: Esquema de procedimiento del algoritmo shift4............................................... 91

Figura 4-11: Esquema de descomposición de la transformada wavelet packet ............................. 91

Figura 4-12: Descomposición de los coeficientes de aproximación en el nivel j+1 ......................... 94

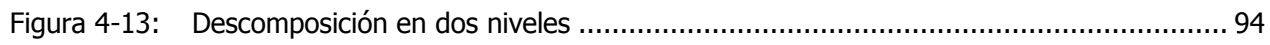

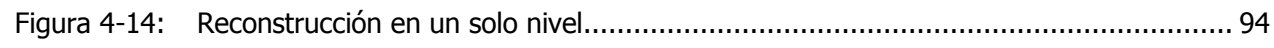

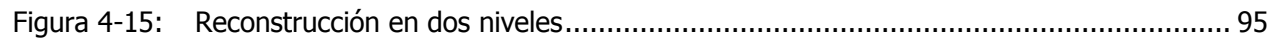

Figura 4-16: Banco de filtros de descomposición en dos niveles y dos dimensiones ...................... 99

Figura 4-17: Banco de filtros de descomposición bidimensional ................................................... 99

Figura 4-18: Descomposición de una imagen en 4 subimágenes de tendencia y fluctuaciones..... 100

Figura 4-19: Banco de filtros de reconstrucción en dos dimensiones .......................................... 101

Figura 4-20: Esquema del análisis multiresolución para la obtención de aproximaciones y

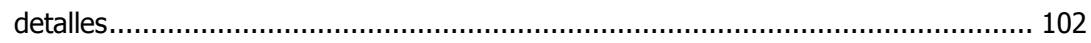

Figura 5-1: $\quad$ Fragmento de la imagen multiespectral QuickBird de Valencia ................................ 105

Figura 5-2: Fragmento de la imagen multiespectral y detalle equivalente en la imagen pancromática ............................................................................................ 106

Figura 5-3: Mosaico de la imagen pancromática remuestreada a $1.7 \mathrm{~m}$ por píxel ........................ 107

Figura 5-4: $\quad$ Muestras de las clases analizadas en la zona metropolitana de Valencia ................. 108

Figura 5-5: Diversos ejemplos de las cubiertas presentes en la isla de Menorca, área del Mitjorn ....................................................................................................... 111

Figura 5-6: Ejemplos de las clases definidas en la imagen de Menorca .................................... 112

Figura 5-7: Diversos detalles de la imagen de Menorca, color natural, pancromática y falso color IR ............................................................................................ 113

Figura 5-8: $\quad$ Mosaico de partida a resolución espacial de 2 metros por píxel .............................. 115

Figura 5-9: Texturas finas (las 6 primeras) y gruesas (el resto) a una resolución de $60 \mathrm{~cm} \ldots \ldots . . .115$

Figura 5-10: Texturas finas (las 6 primeras) y gruesas (el resto) a una resolución de $2 \mathrm{~m}$............. 116

Figura 5-11: Muestra del área de estudio de texturas en zona montañosa (Espadán) .................. 117

Figura 5-12: 4 ejemplos de las cubiertas presentes en la Sierra Espadán, Castellón .................... 118 


\section{LISTADO DE FIGURAS}

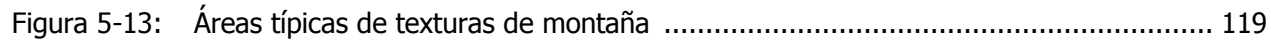

Figura 5-14: Mosaico de fotogramas aéreos del área montañosa de Espadán ............................. 120

Figura 5-15: Clases definidas sobre el mosaico de la zona montañosa de Espadán ..................... 121

Figura 5-16: 4 ejemplos de las cubiertas presentes en el área montañosa de Ayora, Valencia .... 122

Figura 5-17: Mosaico de fotogramas aéreos de la zona montañosa mixta de Ayora ..................... 123

Figura 5-18: Clases definidas en la imagen Ayora .................................................................. 124

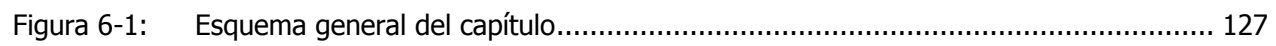

Figura 6-2: Esquema general de los ensayos metodológicos............................................... 128

Figura 6-3: Esquema de las verificaciones globales ........................................................... 128

Figura 6-4: Construcción de la matriz de co-ocurrencias de niveles de gris .............................. 133

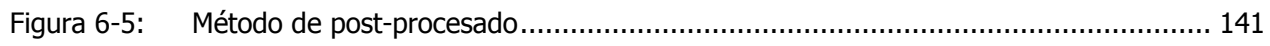

Figura 6-6: Fragmento de la imagen original y de cinco de las características texturales

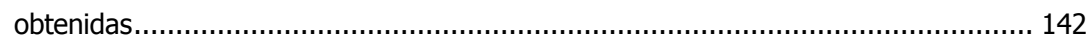

Figura 6-7: $\quad$ Orientaciones y frecuencias radiales de un banco de filtros de Gabor....................... 143

Figura 6-8: Parte real (izquierda) e imaginaria (derecha) de un filtro de Gabor.......................... 144

Figura 6-9: Comparativa de distintas resoluciones radiométricas............................................. 151

Figura 6-10: 3 tipos de cubiertas reales: cítricos, urbano desordenado e industrial. ..................... 152

Figura 6-11: Imagen y su descomposición a nivel 2 en detalles y aproximaciones ....................... 156

Figura 6-12: Funciones scaling y wavelet de Haar................................................................ 161

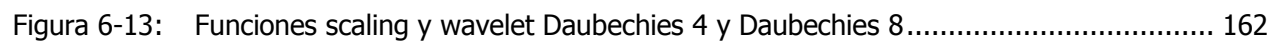

Figura 6-14: Relación gráfica entre los coeficientes de los 4 filtros de un banco de filtros ortonormales, concretamente los de la función Daubechies 4.............................. 162

Figura 6-15: Funciones scaling y wavelet Coiflet 6, Coiflet 12 , Coiflet 18 y Coiflet $24 \ldots \ldots \ldots \ldots . . . . . . .164$

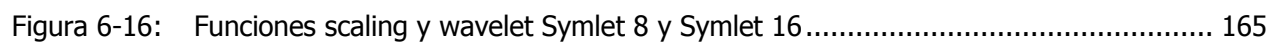

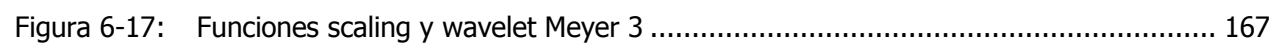

Figura 6-18: Flujo de tareas para aplicar la transformada wavelet discreta en 3 niveles ............... 168

Figura 6-19: Distribución de las funciones de densidad de probabilidad con 2 clases y una variable ................................................................................................. 172

Figura 6-20: Ejemplo de la incorrecta asignación de clases en una zona frontera entre 2 clases .. 176

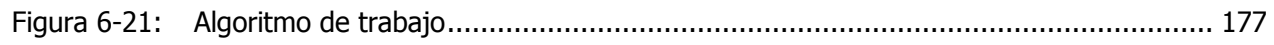

Figura 6-22: Modelo de definición de bordes basado en segundas varianzas .............................. 178

Figura 6-23: Modelo de definición de bordes basado en filtros de gradiente sobre la media ......... 179

Figura 6-24: Modelo de definición de bordes basado en filtros de Canny.................................. 180

Figura 6-25: Modelo de definición de bordes basado en la clasificación de las variables wavelet.. 181

Figura 7-1: Esquema de procedimientos a realizar ................................................................ 183

Figura 7-2: $\quad$ Fiabilidades globales para cada grupo de variables sobre todas las imágenes........... 186

Figura 7-3: Fiabilidades del productor para cada grupo de variables sobre la imagen de

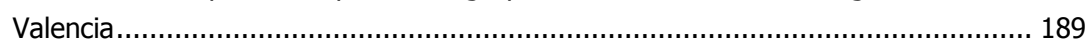

Figura 7-4: Fragmentos de la clasificación con todas las variables en la zona forestal ................ 190

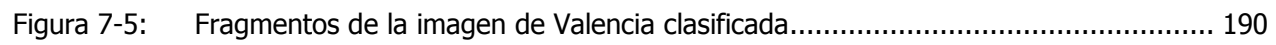

Figura 7-6: Efecto de bordes en un fragmento de la imagen de Ayora clasificada ..................... 191

Figura 7-7: Evolución de la media de la varianza para cada resolución y vecindario .................... 193

Figura 7-8: Fiabilidad global de diferentes clasificaciones a las resoluciones analizadas ............. 196 


\section{LISTADO DE FIGURAS}

Figura 7-9: Evolución de la fiabilidad global de las clasificaciones con cada vecindario .............. 199 Figura 7-10: Ejemplo de la descomposición Wavelet con la función Daubechies 4 hasta nivel 3... 201

Figura 7-11: Esquema del procesado global tras la definición de parámetros y variables............. 205

Figura 7-12: Fiabilidades globales sobre la imagen de Valencia ............................................... 209

Figura 7-13: Fiabilidades globales sobre la imagen de Menorca ................................................. 209

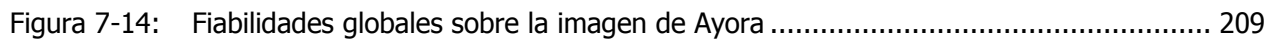

Figura 7-15: Fiabilidades globales sobre la imagen de Espadán ............................................... 210

Figura 7-16: Ejemplos de las clasificaciones con todas las variables en Valencia ......................... 211

Figura 7-17: Ejemplos de las clasificaciones con todas las variables en Menorca.......................... 211

Figura 7-18: Fragmento de la imagen de Ayora con las muestras para los ensayos de bordes..... 212

Figura 7-19: Evolución de la fiabilidad global para cada clasificación y zona .............................. 213

Figura 7-20: Fragmento de la imagen pancromática original y comparación de la clasificación. ... 214

Figura 7-21: Ejemplos de la presencia de elementos dispersos en las clasificaciones.................... 216

Figura 7-22: Efecto de bordes en las transiciones entre texturas ............................................. 217

\section{GLOSARIO}

CMF: Conjugate Mirror Filter

CQF: $\quad$ Conjugate Quadrature Filtres

CWT: Continuous Wavelet Transform

DWT: Discrete Wavelet Transform

DWF: Discrete Wavelet Frames

FFT: $\quad$ Fast Fourier Transform

FIR: $\quad$ Finite Impulse Response

FWT: Fast Wavelet Transform

GMRF: Gauss Markov Random Filed

IDWT: Inverse Discrete Wavelet Transform

IFWT: Inverse Fast Wavelet Transform

IIR: Infinite Impulse Response

MCNG: Matriz de Coocurrencias de Niveles de Gris

MRA: Multi-Resolution Analysis

MRF: $\quad$ Markov Random Field

QMF: Quadrature Mirror Filters

TW: Transformada Wavelet 


\section{Resumen}

El análisis y la gestión del territorio requieren el empleo de información captada por sensores aéreos o espaciales en forma de imágenes digitales. La caracterización de los elementos presentes en ellas se puede enfocar tanto estudiando la información espectral como la espacial, es decir, sus formas, tamaños, distribución de sus niveles de gris, etc. La caracterización de texturas consiste en su análisis ya que son indicativas de las diferentes clases temáticas o cubiertas del territorio. En el presente trabajo se abordan técnicas de análisis de texturas para clasificar diversos tipos de cubiertas del medio físico, basándonos en imágenes de distintas fuentes. Esas imágenes representan cubiertas vegetales arbóreas naturales (Sierra de Espadán), cubiertas mixtas de vegetación natural y cultivos (Menorca y Valle de Ayora) y zonas agrícolas de tipología hortícola fuertemente antropizadas en el área peri-urbana de Valencia.

El análisis de texturas puede enfocarse desde diversos puntos de vista, bien estadísticos, estructurales, basados en modelos, basados en transformadas, etc. Dada la buena respuesta de algunos métodos estadísticos y las características específicas que presenta la Transformada Wavelet, se pretende determinar los rasgos texturales de unas imágenes mediante los dos métodos. En cuanto a estas variables, se han estudiado los estadísticos de $1^{\mathrm{er}}$ orden, los de $2^{\circ}$ orden de la matriz de co-ocurrencias de niveles de gris y algunos obtenidos a partir del histograma.

La transformada wavelet presenta un buen comportamiento a la hora del estudio de la relación espacio-frecuencia, al basarse en funciones matemáticas que cortan datos o señales en diferentes componentes de frecuencia y estudian cada uno de ellos con una resolución ajustada a su escala. La transformada se pone en práctica mediante bancos de filtros paso alto y paso bajo bidimensionales formados por los coeficientes de las funciones que permiten obtener la información de altas y bajas frecuencias en la imagen. Son varios los parámetros que se han analizado en esta transformada, como diversas familias y soportes, estructuras o algoritmos de aplicación, niveles o escalas de descomposición, etc.

Los resultados obtenidos muestran que es importante seleccionar adecuadamente las variables texturales y parámetros específicos de la transformada wavelet. Las variables de textura derivadas de esta transformada se comportan bien en casi todas las superficies. Complementan a las estadísticas de la imagen pancromática y permiten obtener buenas clasificaciones de las diferentes cubiertas del territorio, tanto en entornos urbanos como agrícolas y forestales, donde es importante diferenciar entre tipos de cubiertas y densidades de ocupación. La transformada complementa mejor a los métodos estadísticos en estas clases más homogéneas y menos separables y permite conseguir buenas fiabilidades. También se han diseñado una serie de rutinas para reducir el efecto de bordes de la clasificación que se han mostrado efectivas. 


\section{Abstract}

The land management and analysis requires the use of information acquired as digital images by aerial or spatial sensors. The characterization of landscape elements can be focused studying either the spectral or spatial information, that is, their shapes, sizes, grey levels distribution, etc. The objective of texture analysis is to study the spatial information and distribution of grey levels in order to classify the images. In the present work, an analysis of textures is carried out for classifying different types of landscapes using aerial and satellite images containing different coverages to determine the most suitable variables. These images depict natural forest covers in mountain environments (Sierra de Espadán), mixed covers of natural vegetation and crops (Menorca and Valle de Ayora) and horticulture crops, anthropic and peri-urban areas of Valencia.

The analysis of textures can be focused from several points of view: statistical, structural, based on models, transform-based, etc. Given the good results obtained using some statistical methods and the good perspectives that present the Wavelet Transform, we applied these two methods in order to determine the textural patterns of a set of images. The analysed variables are the first and second order statistics of the Grey Level Co-occurrences Matrix (GLCM), and others obtained from the histogram.

The Wavelet Transform presents a good behaviour in the study of the spacefrequency relation. It is based on mathematical functions that decompose data or signals in different frequency components, that are studied with a resolution adapted to their particular scale. The wavelet functions allow the design of filter banks that are applied first along the rows with a dyadic downsampling, and then along the columns with a second downsampling with the same dyadic factor, obtaining the information of high and low frequencies of the image. Several parameters are analysed in this transform, such as the families and supports, algorithms of application, levels and scales of decomposition, etc.

The results obtained in the present work show the importance of a suitable selection of the textural variables and the specific parameters of the Wavelet Transform to be used. There is also an important improvement in the accuracy of the classification using the variables obtained from this transform. In urban, agricultural and forest environments is very important to differentiate between kinds of coverages and densities of occupation. For this objective, the textural variables obtained from the wavelet transform complete the statistical variables of the panchromatic image. This method is more suitable when the classes are homogeneous and not very separable, yielding better results. On the other hand, the border effect is reduced by means of some algorithms for extraction and analysis of the external areas of the different textures. 


\section{Resum}

L'anàlisi i gestió del territori requereix l'ocupació d'informació captada per sensors aeris o espacials en forma d'imatges digitals. La caracterització dels elements presents en elles es pot enfocar tant estudiant la informació espectral com l'espacial, és a dir, les seues formes, grandàries, distribució dels seus nivells de gris, etc. La caracterització de textures consisteix en analitzar aquestes al ser indicatives de les diferents classes temàtiques o cobertes del territori. En el present treball s'aborda una anàlisi de textures per a classificar certes porciones del medi físic de diferent naturalesa, en forma d'imatges de diversos tipus de cobertes i de distintes fonts. Aquestes imatges es caracteritzen per presentar cobertes vegetals arbóries naturals (Serra d'Espadà), cobertes mixtes de vegetació natural i cultius (Menorca i la Vall d'Ayora) i zones agrícoles de tipologia hortícola fortament antropitzades en l'àrea peri-urbana de València.

L'anàlisi de textures pot enfocar-se des de diversos punts de vista, bé estadístics, estructurals, basats en models, basats en transformades, etc. Donada la bona resposta d'alguns mètodes estadístics i les característiques de la Transformada Wavelet, es pretén determinar els trets texturals d'unes imatges mitjançant els dos mètodes. Respecte a aquestes variables, s'han estudiat els estadístics de $1^{\text {er }}$ ordre i de second ordre de la matriu de co-ocurrències de nivells de gris i alguns obtinguts a partir de l'histograma.

La transformada wavelet presenta un bon comportament per a l'estudi de la relació espai-freqüència, al basar-se en funcions matemàtiques que tallen dades o senyals en diferents components de freqüència i estudien cadascun d'ells amb una resolució ajustada a la seua escala. Aquesta transformada es posa en pràctica mitjançant bancs de filtres bidimensionales formats pels coeficientes de les funcions que permeten obtenir així la informació d'altes i baixes freqüències en la imatge. Són varis els paràmetres que es poden analitzar en aquesta transformada, com diverses famílies i suports, estructures o algoritmes d'aplicació, nivells o escales de descomposició, etc.

Els resultats obtinguts mostren que és important seleccionar adequadament les variables texturals i paràmetres específics de la transformada wavelet. Les variables de textura derivades d'esta transformada es comporten bé en quasi totes les superfícies. Complementen a les estadístiques de la imatge pancromàtica i permeten obtindre bones classificacions de les diferents cobertes del territori, tant en entorns urbans com agrícoles $i$ forestals, on és important diferenciar entre tipus de cobertes i densitats d'ocupació. La transformada complementa millor als mètodes estadístics en estes classes més homogènies $i$ menys separables $i$ permet aconseguir bones fiabilitats. També s'han dissenyat una sèrie de rutines per a reduir l'efecte de bords de la classificació que s'han mostrat efectives. 


\section{Agradecimientos}

Los resultados del presente documento son el fruto de largo tiempo de trabajo y de investigación. En este ámbito, me encuentro adscrito al grupo de investigación denominado "Cartografía Geoambiental y Teledetección" del Departamento de Ingeniería Cartográfica, Geodesia y Fotogrametría de la Universidad Politécnica de Valencia. Una de las líneas de desarrollo de este grupo es la centrada en el análisis de texturas, campo en el que se enmarca esta tesis. Por ello, me gustaría manifestar mi público agradecimiento a los compañeros del grupo de investigación que de una manera u otra me han dado su apoyo, su consejo, su ayuda y su ánimo. A todos ellos, y especialmente a mi director de tesis, muchas gracias.

Por otro lado no podría olvidar a los amigos que sin tener relación ninguna con la temática del trabajo, me han prestado su ayuda en algún momento de esta etapa.

A mis padres, por haberme enseñado tantas cosas, entre ellas a trabajar duro.

Y por último, agradecer la paciencia de María José, que ha sabido aguantar todos mis malos momentos y darme ánimo y apoyo para superarlos. 


\section{Capítulo I}

\section{Introducción}

La confección de mapas, planos y cualquier otro tipo de documento cartográfico ha experimentado importantes cambios en las últimas décadas con la evolución de técnicas ya clásicas como la fotogrametría, o con la aparición de otras novedosas como la detección remota desde plataformas espaciales que orbitan alrededor del planeta. El imparable desarrollo de los sistemas informáticos y electrónicos ha redundado en la técnica aeroespacial de forma muy notable, al punto de que actualmente se comienzan a plantear aplicaciones cartográficas para los datos suministrados por los satélites. El análisis de la información espacial suministrada por sensores aerotransportados o implementados en plataformas espaciales nos permite tener una visión clara, directa, real y actualizada de la realidad de dicha información, es decir, de los tipos de cubiertas existentes, de su distribución, densidad, avance o retroceso, estado de salud o crecimiento (en el caso de vegetación), etc. Por ello, es en el campo de la cartografía temática donde la teledetección se convierte en una piedra angular para la gestión, tratamiento y explotación de toda esa ingente cantidad de información.

Cualquier estudio del medio físico o humano que nos rodea no puede enfocarse con esperanza de éxito si no se considera la detección remota como fuente de abundantes y precisos datos, ya que la combinación de información espectral y espacial que aportan las imágenes permite aplicar gran cantidad de procesos y rutinas para generar modelos derivados, extraer resultados y conclusiones, etc.

Los sistemas disponibles en la actualidad para la obtención de información con fines cartográficos suministran casi en su totalidad dicha información en formato digital, en forma de imágenes, bien sean fotogramas aéreos o bien imágenes de satélite. Estos dos tipos de datos son los más frecuentemente empleados por su alto rendimiento y su buena 
relación calidad - precio frente a datos tomados en campo por métodos considerados como "clásicos" (topografía clásica, GPS, ...)

Las imágenes digitales son capturadas por dispositivos especiales, como cámaras digitales fotográficas o de vídeo, sensores electrónicos, escáner u otros, y son almacenadas como ficheros que, en el fondo, son una representación de una matriz rectangular, cada uno de cuyos elementos es el valor del píxel, también conocido como nivel digital (ND). Tanto se puede hablar de imágenes con niveles de gris, monobanda o pancromáticas, como de imágenes multibanda, multiespectrales 0 en color, al representarse ésta mediante una combinación de tres de las bandas de la imagen multiespectral.

La imagen digital se obtiene a partir de la energía electromagnética que reflejan y/o emiten los objetos del mundo real y que es recibida por el dispositivo de captura, distribuyéndola sobre un filtro de muestreo. La respuesta del filtro es la matriz rectangular resultante, cuyos elementos son los valores de los niveles digitales que se atribuyen a cada unidad de información o píxel. Dichos niveles digitales son una expresión de la cantidad de energía electromagnética que el sensor recibe. A la hora de realizar esa transformación, es necesario decidir la cantidad de información que se atribuye a cada píxel. Esta cantidad de información se mide en número de bits por píxel. Se pueden obtener imágenes binarias (1 bit) u otras con mayor rango de niveles digitales, siendo la cuantización con 8 bits (valores comprendidos entre 0 y 255) de las más habituales. Por lo que respecta al tamaño de la imagen, dependerá de la resolución espacial (según la precisión de los detectores del sensor), del número de bandas espectrales, de sus dimensiones (número total de píxeles, o número de filas y número de columnas de la matriz) y de la cantidad de bits que se asocie a cada píxel.

La obtención de cartografía temática mediante el procesado digital de imágenes es una práctica habitual cuando se cuenta con información espectral suficiente para poder asignar a cada píxel una de las clases informacionales previamente definidas. Este proceso de clasificación de imágenes está condicionado, por un lado, por la disponibilidad de imágenes con la información espectral lo suficientemente diversa y, por otro, porque las imágenes presenten una resolución espacial con el detalle necesario para poder abordar con éxito el problema de la discriminación de clases temáticas planteado. En otras ocasiones, la heterogeneidad espectral de las clases definidas hace ineficaces los métodos de procesado basados únicamente en el estudio píxel a píxel de la información espectral, requiriéndose un análisis del contexto espacial o vecindario de cada píxel dentro del cual se pueda caracterizar la distribución espacial de la función de intensidad de una o varias bandas espectrales. Así, la perspectiva espacial permite extraer características que 
proporcionan información sobre la textura, forma o tamaño de los vecindarios u objetos en la imagen. Desde este enfoque cobran especial interés las técnicas de análisis de texturas, mediante las cuales se describe la distribución de niveles de gris relativa al vecindario de cada píxel calculando variables estadísticas que describan propiedades como la variabilidad, el contraste, valor medio, etc. y que permitan obtener nuevas imágenes o bandas de textura que puedan utilizarse de forma aislada o combinadas con bandas espectrales para clasificar las imágenes originales.

En lo que respecta a aplicaciones concretas, el uso de la teledetección en la caracterización de la vegetación forestal, tanto en la identificación de especies como en la clasificación zonal por densidades de vegetación, está tomando cada vez mayor relevancia debido al desarrollo, perfeccionamiento y validación de las técnicas de análisis, así como a la disponibilidad de sensores con mayores capacidades espaciales, espectrales y radiométricas. En entornos forestales, las técnicas de clasificación multiespectral de imágenes ofrecen resultados coherentes cuando las clases objeto de estudio son unidades homogéneas desde el punto de vista estructural y espectral, siempre que la respuesta espectral de cada clase sea lo suficientemente específica. Este es el típico caso de zonas de montaña con predominio de bosques densos, con presencia casi exclusiva de una especie y crecimiento uniforme y alternancia de praderas, tal y como ocurre en muchas zonas de montaña del norte de la península con explotaciones forestales y ganaderas con carácter más bien intensivo. Por el contrario, los ecosistemas de montaña mediterráneos presentan mayor variedad estructural y botánica, debido a los rasgos climáticos de menor y más desigual reparto en el régimen de precipitaciones, pero también a la pérdida de masa forestal localizada, provocada por las recurrencias de incendios forestales, creando agrupaciones de árboles o pequeños bosquetes de menor densidad, con proliferación de zonas con alternancia espacial de matorral y árboles dispersos. Otro factor de variabilidad lo introducen ciertas prácticas culturales, como la creación de terrazas para aprovechamiento agrícolas (olivos, almendros,...). En estas zonas resulta más complejo el problema de la clasificación de imágenes mediante métodos exclusivamente espectrales, por lo que se requiere información sobre su estructura espacial, la cual puede obtenerse mediante técnicas de análisis de texturas.

El mismo planteamiento anterior podría ampliarse a cualquier otro tipo de superficie presente en el terreno, si bien cada una de ellas presentará ciertas particularidades propias que requerirán un enfoque específico. Es en esta situación donde se han de poner en juego todos los conocimientos específicos en función del objetivo global buscado.

Entendida una imagen digital como una matriz bidimensional de píxeles, la información que contiene puede ser espectral o espacial. Profundizando un poco más en 
este último tipo, para representar la información contenida en ella se pueden emplear además:

- Composiciones de frecuencias, entendidas como magnitudes de los cambios en los niveles digitales entre píxeles.

- Representaciones multiescala, que explican la imagen como una jerarquía de imágenes de diferentes resoluciones.

Para lograr esta segunda estructura son varios los métodos propuestos, destacando las estructuras en árbol (Quadtrees ${ }^{1}$ ) y las piramidales, que descomponen la imagen como una secuencia de subimágenes de resoluciones decrecientes. Es científicamente aceptado que la percepción natural de las imágenes como suavizadas o rugosas consiste en la diferenciación de patrones globales, formados por la repetición de subpatrones locales, bien sea de forma determinada o bien aleatoria. Para captar esa suavidad o rugosidad de las imágenes, el proceso visual humano analiza los objetos con resoluciones adaptadas a su tamaño. Pues bien, las representaciones piramidales se asemejan mucho a este proceso natural de la visión humana. Son varias las implementaciones de esta estructura piramidal, destacando la basada en funciones gaussianas y la basada en wavelets (Agustí et al., 2003).

Además de los métodos anteriores, existen otros englobados bajo la denominación "análisis de texturas" los cuales se basan en considerar una imagen como una distribución de niveles digitales, de la cual se pueden realizar caracterizaciones más centradas en aspectos morfológicos y extraer parámetros propios de forma, densidad, variación, tamaño, agrupaciones, etc. Estos métodos se pueden aplicar desde varios enfoques, como son el estadístico, el frecuencial, el estructural o geométrico y el basado en transformadas.

Los análisis de texturas principalmente empleados en la actualidad se basan en la extracción de los estadísticos de $1^{\text {er }}$ orden del histograma de la imagen o bien en la extracción de los estadísticos de $2^{\circ}$ orden, conocidos como características de texturas de la matriz de co-ocurrencias de niveles de gris (MCNG). Otros autores complementan esos estudios con el empleo de algunos filtros específicos de energía, filtros de Gabor o con la aplicación de transformadas en el dominio de la frecuencia como la transformada de Fourier, por ejemplo.

\footnotetext{
${ }^{1}$ Un Quadtree es una estructura de almacenamiento y manejo eficiente para imágenes basada en la descomposición sucesiva de la imagen en cuatro cuadrantes pudiendo ser una descomposición recursiva del espacio. Los 4 cuadrantes son las subimagenes de lado mitad del inicial y correspondientes a los cuartos NW, NE, SW y SE. Los Quadtrees también son utilizados para diferentes tipos de datos como son puntos, curvas, superficies y volúmenes (González y Woods, 2002).
} 
A principios de los años 80 diversos autores, básicamente Morlet y Grossman a los cuales se les añadirían posteriormente algunos referentes como Mallat y Daubechies, comenzaron a aplicar una transformación novedosa sobre señales unidimensionales y por extensión sobre señales bidimensionales con objetivos básicos como la compresión de dichas señales o la eliminación del ruido presente en ellas. Dicha transformación es conocida como Transformada Wavelet y sus aplicaciones actuales se han extendido en el campo de las imágenes digitales.

\subsection{Problemática y líneas de trabajo existentes}

Una de las aplicaciones finales más comunes, junto a otras, en una rutina de trabajo con imágenes digitales suele ser la de conseguir una clasificación o asignación de valores temáticos a cada uno de los píxeles que conforma la imagen. En el caso de imágenes de satélite, dicho objetivo se traduce en la identificación lo más automática posible de las diferentes cubiertas que se encuentran en la zona representada por dicha imagen, de tal forma que se pueda hacer cualquier tipo de estudio posterior sobre esa imagen clasificada.

Este objetivo ha sido abordado por muchos autores de tal manera que se puede hablar de un abanico importante de clasificadores, desde los no paramétricos más básicos hasta los más complejos como redes neuronales y árboles de decisión pasando por los más empleados como el de máxima probabilidad, sin olvidar los automáticos o semiautomáticos, en los que la participación del operador es mínima. Cada uno de ellos implica la definición de una serie de parámetros básicos y genera resultados que no siempre son óptimos y que deben ser considerados en el marco de los fines específicos y datos disponibles.

La clasificación a partir de la información multiespectral por sí sola puede ser suficiente en determinados casos. En otros, el empleo de las características de textura obtenidas de la imagen, junto a su propia información espectral, mejora sensiblemente los resultados obtenidos y justifica todas las rutinas necesarias para obtener esas características texturales. Pero en este punto se debe plantear una pregunta importante: ¿cuándo se puede decir que en una imagen se aprecian texturas? El concepto de textura, entendida como la distribución de los niveles digitales en la imagen, puede llevar a pensar que en una imagen pueden existir un gran número de ellas o no existir ninguna. En este último escenario, no tienen sentido los métodos que se verán en capítulos siguientes, pero 
por suerte, en la mayor parte de las imágenes naturales se puede encontrar, más o menos definidas, una cierta variedad de texturas.

La homogeneidad interna de las texturas es otro aspecto a considerar. Es importante tener en cuenta que es normal una variabilidad interna natural de los elementos de las imágenes y que puede hacer pensar en diferentes texturas, cuando en realidad eso sería erróneo. Por ejemplo, una parcela de cultivo de cítricos en línea, orientados al norte y con árboles de $2 \mathrm{~m}$ de diámetro tiene la misma textura que otra con cítricos en línea, orientados al noreste y con ejemplares de $3 \mathrm{~m}$ de diámetro y así ha de ser considerado en cualquier método de tratamiento (comportamiento conocido como invarianza a la rotación).

El trabajo con información digital en formato raster permite variar la escala de trabajo, es decir, modificar la resolución espacial mediante técnicas de remuestreo. La textura es una propiedad de cualquier superficie perceptible solo cuando es observada desde la distancia apropiada o con la resolución ajustada a la dimensión de los objetos que la conforman. Dado que la textura es muy dependiente de la escala a la que se trabaje, se podrían encontrar diferentes patrones espaciales en una misma imagen a diferentes escalas. Por ello, es importante definir la escala correcta de análisis como el equilibrio necesario para que todas las superficies presenten características de textura perceptibles y cuantificables. Tampoco se puede olvidar que en determinadas ocasiones puede ser interesante analizar la relación existente entre la resolución espacial y las dimensiones de las imágenes para optimizar los tiempos y capacidades de cálculo, sin perder fiabilidad en los resultados obtenidos.

Muy directamente relacionada con la escala, y por tanto con el tamaño del píxel, se encuentra la dimensión del vecindario de cálculo de texturas. Ciertas texturas deben ser analizadas con un vecindario mayor para captar todas sus características (como zonas urbanas), mientras que otras permiten emplear vecindarios menores (como áreas de cultivos o de vegetación natural). Es evidente la relación entre tamaño de píxel y de vecindario, ya que para una misma superficie, un píxel mayor requerirá un vecindario menor y viceversa.

Existen diferentes métodos de caracterización de texturas, tal y como se verá en el siguiente capítulo, pero cualquiera de ellos debe considerar de la mejor forma posible la variabilidad de texturas que puede existir en una misma imagen y a una escala considerada. La correcta selección del método de análisis es un tema muy importante ya que los resultados pueden cambiar de forma sensible y las comparaciones entre métodos así lo corroboran.

Lo que la mayor parte de los métodos reseñados no realiza bien es el tratamiento de las zonas periféricas de las texturas, de las fronteras entre ellas, las comúnmente 
conocidas como bordes. Es frecuente que las variables de textura en estos píxeles sean incorrectas, y por lo tanto la clasificación posterior también lo será, debido a la influencia de los píxeles de una textura vecina sobre los de otra.

Uno de los métodos que más recientemente se han introducido en el estudio de las texturas se basa en la aplicación de la transformada wavelet. Dada la importancia práctica que día a día va teniendo esta transformada en multitud de ensayos, el presente trabajo también pretende indagar en su aplicación sobre imágenes de la superficie terrestre para mejorar los procesos de clasificación por texturas.

Esta herramienta presenta buenas expectativas debido a varios aspectos. En primer lugar, se trata de una transformada matemática con una base teórica sólida y lo suficientemente versátil para permitir su aplicación de diversas maneras, bien de forma unidimensional o bidimensional, sobre señales continuas o discretas, según modelos redundantes o simples, etc. Al poder realizar descomposiciones de una imagen de entrada en grupos de información a diferentes escalas (multiresolución) permite extraer la información que más pueda interesar para analizar las texturas, las altas frecuencias horizontales, verticales o diagonales, las bajas frecuencias, en diferentes niveles o resoluciones, etc. Pero no solamente se limita a descomponer una imagen sino que permite su reconstrucción sin pérdida de información, pero permitiendo realizar tareas de compresión se datos, o de eliminación de ruido, o de realce de información u otras, en la fase intermedia entre la descomposición y la reconstrucción.

Otra peculiaridad de esta transformada es que puede ser implementada computacionalmente mediante bancos de filtros discretos, lo cual permite su desarrollo en lenguajes de programación y su personalización por parte del investigador, sin dejar de perder por ello su capacidad de enlace con otros métodos de análisis de texturas. Dado que es una herramienta relativamente joven (apenas 25 años) su ámbito de aplicación es muy amplio y en continua expansión, dadas sus capacidades demostradas en muchos campos de la ciencia y la técnica.

Pese a todo lo anteriormente comentado, la aplicación de esta transformación en imágenes reales, como fotogramas aéreos o imágenes espaciales es muy reducida en la bibliografía, ya que la comunidad científica se centra en estudios de texturas de imágenes con claros patrones geométricos, como las de la base de imágenes Brodatz (1965) o las propias de la base Vision Texture del MIT (1995), al generar buenos resultados y ser de aplicación en ciertas tareas industriales. 


\subsection{Contenido de la tesis}

Además del presente capítulo I de introducción, se estructura esta tesis en los siguientes:

- En el capítulo II se hace una definición de los antecedentes en el análisis de texturas, estudiando sus objetivos, entendiendo cómo son las texturas reales de la superficie terrestre y comparando diferentes metodologías de estudio.

- El capítulo III se dedica a definir los objetivos del presente trabajo de investigación.

- En el capítulo IV se expone la historia, los trabajos previos, los fundamentos de la teoría wavelet y de la transformada del mismo nombre, así como diferentes modelos de aplicación, algunos de los cuales han sido analizados en esta tesis.

- En el capítulo $\mathbf{V}$ se especifican cuáles son los datos de partida, su origen, sus características técnicas y el tipo de cubiertas naturales que presentan.

- En el capítulo VI se especifica la metodología de trabajo empleada en la tesis, partiendo del preprocesado de las imágenes originales, continuando con el análisis de las diferentes variables de textura consideradas y determinando los parámetros metodológicos globales, para terminar con propuestas planteadas para minimizar el error de clasificación en las zonas de borde.

- En el capítulo VII se detallan los resultados más relevantes de los ensayos realizados según la metodología propuesta en el capítulo anterior, así como una discusión de ellos.

- En el capítulo VIII se detallan las conclusiones extraídas y se definen las líneas futuras de investigación.

- En los dos últimos capítulos, IX y $\mathbf{X}$, se detallan las referencias empleadas a lo largo de todo este trabajo y se adjuntan algunos materiales o contenidos complementarios como anejos. 


\section{Capítulo II}

\section{Antecedentes sobre análisis de texturas}

El análisis de texturas está basado en el empleo de diversos métodos, estadísticos, filtrados, transformadas, etc. para calcular índices cuantitativos que describan la distribución de niveles de gris o niveles digitales en una imagen, proporcionando información espacial útil para cualquier tarea posterior de clasificación, segmentación, recuperación de imágenes en bases de datos, síntesis de texturas, etc. Pero para entender todo esto mejor, previamente se debe conocer la definición de textura, los tipos presentes en imágenes del territorio y las aplicaciones existentes en la actualidad.

\subsection{Definición de textura}

Para poder entender en qué consiste un estudio de textura es necesario aclarar qué se entiende por ese término, aunque se puedan presentar diferencias sutiles en su definición en función del campo de estudio específico. En el tratamiento de imágenes, son muchas las definiciones adoptadas si bien todas son muy coincidentes en la idea a expresar. Algunas de las más comunes son las siguientes:

- $\quad$ "Textura es un atributo que presenta la distribución espacial de los niveles de gris de una determinada región"(IEEE Standard 610.4)

- $\quad$ "El término textura se refiere, en general, a la repetición de elementos básicos llamados texels. Cada texel contiene varios píxeles, cuya ubicación puede ser periódica, quasi-periódica o aleatoria. Las texturas naturales son generalmente 
aleatorias, mientras que las artificiales son a menudo deterministas o periódicas. Una textura puede ser gruesa, fina, suave, granulada, rugosa, regular, irregular, lineal, etc."(Jain, 1989).

- $\quad$ "El concepto textura se refiere a la distribución espacial de las variaciones de niveles de gris o de colores en una imagen" (Shatadal et al., 1991).

- $\quad$ "De manera intuitiva, puede decirse que es un descriptor que da una medida de propiedades como suavidad, heterogeneidad o regularidad" (González y Woods, 2002).

- $\quad$ "Se entiende por textura un conjunto de características de una escena como son su rugosidad, homogeneidad, contraste, regularidad, direccionalidad o granulosidad, entre otras, las cuales se conocen como propiedades texturales" (Haralick y Saphiro, 1992).

- $\quad$ "Se puede definir la textura como el patrón visual homogéneo y repetitivo que se observa en cierto tipo de materiales como telas, piedras, madera,..." (de la Escalera, 2001).

- "Las texturas son patrones visuales complejos compuestos de entidades 0 subpatrones, que tienen similares características de brillo, color, forma, tamaño, etc." (Materka y Strzelecki, 1998). Por ello una textura puede ser considerada como una porción de la imagen de similares propiedades.

- $\quad$ "Puede definirse la textura como la variación del contraste entre píxeles vecinos, o, dicho de otra forma, la variabilidad local de la reflectancia dentro de una unidad que a mayor escala se puede considerar como homogénea"(Sánchez, 2003).

Aparte de las definiciones, que no dejan de ser formas de expresar una misma idea, es importante destacar algunos aspectos importantes al hablar de texturas, como son su rugosidad o suavidad, sus patrones, su escala, sus bordes, su resolución, etc. Estas propiedades pueden ser observadas sobre los ejemplos de texturas de la figura 2-1.

En cuanto a la rugosidad, una textura se considera rugosa si la diferencia entre los valores máximos y los mínimos es grande y si la distancia entre su posición es importante respecto a las dimensiones del filtro empleado en el análisis. Por el contrario, una textura se define como suave si las diferencias entre máximos y mínimos son pequeñas y su separación también. Las texturas en una imagen cuantificarán esas diferencias entre niveles de gris, es decir, el contraste, definirán el tamaño de la ventana dentro de la cual se producirán cambios y ponderarán la direccionalidad o la falta de ella. 


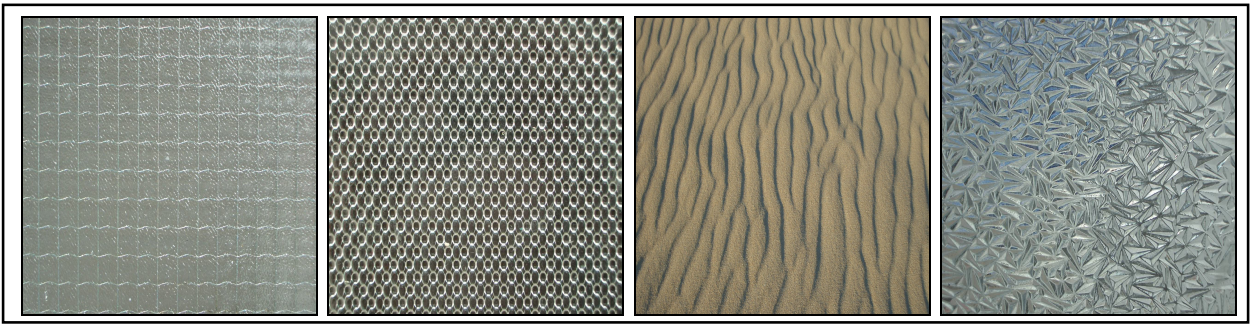

Figura 2-1. Ejemplos de diversas texturas.

Un elemento textural o una determinada textura se puede entender como la combinación de primitivas de niveles de gris, o regiones que poseen ciertas propiedades de nivel de gris, y la disposición espacial de dichas primitivas, que puede ser totalmente aleatoria o bien presentar una relación estructural con otras primitivas vecinas (Ruiz, 1999). Si las primitivas de nivel de gris son de pequeñas dimensiones y su interacción con otras primitivas es muy localizadas se puede hablar de microtexturas; por el contrario, si son de dimensiones mayores y forma definida y están organizadas de forma regular se les denomina macrotexturas. Se deduce de esto uno de los principios fundamentales en el análisis de texturas: una misma superficie observada a una determinada escala puede presentar un aspecto distinto si se analiza a otra escala sensiblemente diferente, es decir, la textura es muy dependiente de la escala a la que se analice.

Directamente relacionada con la escala se encuentra la variable resolución de la imagen, hasta tal punto que se puede afirmar (Shatadal et al., 1991) que la textura es una propiedad de cualquier superficie pero solo cuando es observada desde la distancia apropiada o con la resolución ajustada a la dimensión de los objetos que la conforman. Un ejemplo puede ser una imagen urbana, la cual a una resolución alta (pequeño tamaño de píxel) puede presentar un patrón de textura diferente al que se observaría si tuviese un tamaño de píxel mayor (menor resolución). Se puede decir que la textura contiene importante información sobre la disposición estructural de las superficies que puede ser útil para su discriminación.

Los límites entre diferentes objetos de las imágenes es lo que generalmente se define como "bordes". Los bordes de estructuras en imágenes a veces son las características más importantes analizadas en un proceso de reconocimiento de patrones espaciales. Pero el concepto de borde puede no ser entendido de la misma forma en diferentes imágenes. De forma genérica se puede decir que un borde es un punto o lugar de la imagen donde la intensidad tiene transiciones marcadas (Mallat, 1989). Pero no todas esas transiciones o variaciones han de ser siempre bordes, pueden ser transiciones internas de un mismo elemento. Por ejemplo, en un muro construido por ladrillos, los bordes pueden ser o bien los límites de cada ladrillo que forma el muro (con lo que la textura de cada ladrillo sería diferente a la del muro), o bien el límite del muro en su 
conjunto, en cuyo caso la textura sería la del conjunto del muro (figura 2-2). Se vuelve a reafirmar la idea de que la discriminación de texturas y bordes en una imagen depende en gran medida de la escala de análisis.

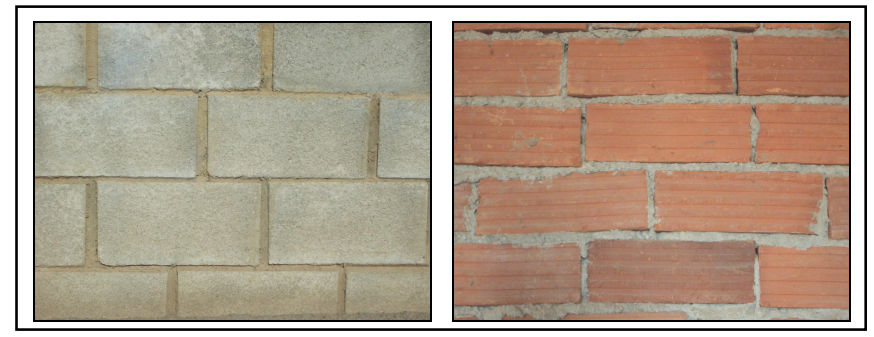

Figura 2-2. Textura propia de cada elemento y del total del conjunto.

Por lo que respecta a las propiedades de una textura y la discriminación entre ellas a partir de sus propiedades estadísticas, las regiones homogéneas de una imagen generalmente tienden a tener el mismo nivel de gris promedio, el cual es diferente del de otras regiones en la imagen. Se puede decir con ello que la segmentación de imágenes se basa en el tono promedio, si bien surge inmediatamente el hecho de que no siempre el problema es tan sencillo ya que diferentes partes de una imagen pueden tener el mismo nivel de gris medio y tener diferentes distribuciones espaciales de dichos niveles, es decir, ser visualmente diferentes y tener diferentes texturas (James, 1987).

Son varias las colecciones de texturas existentes en el entorno científico-técnico, destacando por su mayor difusión la elaborada por Brodatz en 1965, de la que se adjuntan algunas muestras en la figura 2-3, y la elaborada por el Media Laboratory del MIT y conocida como "VisTex"( Vision Texture, Massachusetts Institute of Technology, 1995).

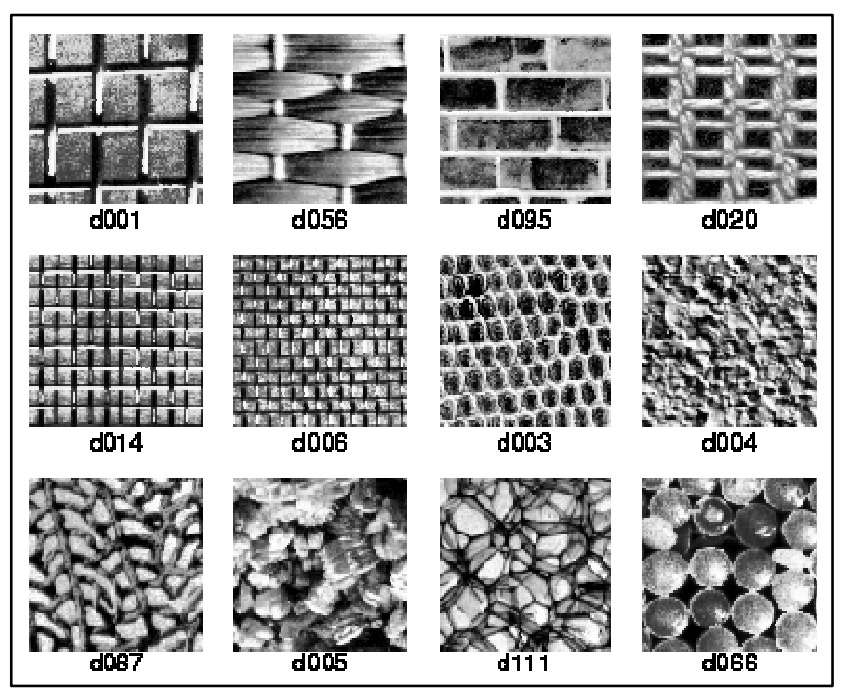

Figura 2-3. Algunas texturas de la base Brodatz (1965). 


\subsection{Objetivos del estudio de texturas}

El objetivo central del análisis de las texturas presentes en una imagen es básicamente extraer las características de las mismas, de manera que se pueda identificarlas de forma inequívoca y proceder a su segmentación o clasificación. Este objetivo final puede ser variado, según diversos autores. Haralick (1973) y Haralick y Shapiro (1992) establecen que son tres las finalidades de un análisis de texturas:

1) Clasificación de texturas: para determinar a cuál de un número determinado de clases físicamente definidas pertenece una región de textura homogénea. Se ha de tener en cuenta que las texturas homogéneas en las imágenes naturales no siempre son frecuentes, por lo que el problema consiste en clasificar una imagen o un fragmento de ella dentro de un número determinado de clases cualitativas conocidas previamente. Es, básicamente, en este objetivo en el que se ubica el presente trabajo.

2) Generar modelos de textura a partir de otra original mediante técnicas de generación o síntesis de modelos de textura que emulan a las naturales, que puedan servir de referencia para otras y ser empleadas en procesos de modelización gráfica por ordenador.

3) Delimitar en una imagen aquellas zonas que posean texturas diferentes. Se trataría de un problema de segmentación de imágenes o también llamado de discriminación de texturas, en el que se segmentaría una imagen de texturas en regiones, cada una correspondiente a una textura perceptualmente homogénea.

Otros autores establecen objetivos complementarios a los anteriores en un proceso de análisis textural (Materka y Strzelecki, 1998):

4) Extracción de características que permitan describir numéricamente sus propiedades de textura. Al conjunto de descriptores extraído de una textura dada se le denomina vector de características de textura. Se emplean generalmente los estadísticos de primer orden y los estadísticos de segundo orden. Si bien se pueden obtener un número considerable de dichos descriptores, en la mayoría de las aplicaciones es muy interesante el obtener un vector con aquellas características más discriminantes para diferenciar texturas.

5) Generación de formas a partir de texturas, para reconstruir superficies geométricas tridimensionales a partir de la información de texturas.

Otro posible objetivo podría ser el identificado por Chien-Chang y Chaur-Chin (1999): 
6) Intentar reconocer de qué imagen inicial proviene un fragmento de imagen dado, tarea designada como recuperación de texturas, o bien encontrar una textura dada en una base de imágenes.

Por lo que respecta a los campos donde se puede aplicar el análisis textural, se podría decir que las principales aplicaciones del análisis de texturas son (Randen, 1997):

1. Teledetección.

2. Tratamiento de imágenes médicas.

3. Procesos industriales de control de producción.

4. Segmentación de documentos para separar áreas de texto de aquellas que incorporan imágenes o gráficos.

5. Búsqueda en las bases de datos de imágenes para una recuperación rápida de determinados patrones.

6. Generación y síntesis de formas a partir de texturas.

7. Reconocimiento de formas por sistemas que emplean análisis espectrales.

\subsection{Las texturas en las imágenes de la superficie terrestre}

Toda la diversidad de elementos que se encuentran sobre la superficie terrestre forman el conjunto de las llamadas cubiertas superficiales. Dichas cubiertas se pueden considerar de dos tipos desde el punto de vista de su origen o naturaleza, bien sean naturales o antrópicas. En cualquiera de los dos tipos, se considera que forman mosaicos con distribuciones más o menos regulares y homogéneas, dando lugar en su conjunto a lo que se puede definir como imágenes de la superficie terrestre. Sobre estas imágenes y analizados desde la perspectiva cenital que introduce la proyección cónica de los sistemas captadores de información (sensores aerotransportados o plataformas espaciales) se pueden encontrar patrones repetitivos y de carácter geométrico (cultivos con marco de plantación geométrico, núcleos urbanos con planeamiento urbanístico) o bien aleatorios, como pueden ser las zonas de vegetación natural con diversas especies arbóreas o arbustivas, con varios niveles de densidad, con distribución irregular de esas especies, etc. 
Por ello se pueden encontrar texturas con patrones geométricos muy diferentes y siempre dependientes de la escala, como se aprecia en la figura 2-4, en la que las resoluciones espaciales son variables para poder apreciar en las muestras las características de cada una de ellas. Se puede realizar una agrupación según su geometría o irregularidad o bien se pueden agrupar en función del tipo de superficie que describan. De esta última manera, podemos encontrar (figura 2-4) texturas propias de:

- Entornos urbanos: áreas industriales (a) en las que las naves industriales tienen muchas similitudes; las áreas urbanas antiguas (b) en las que no hay geometría aparente ni en trazado de las calles ni en la forma de las edificaciones; los ámbitos urbanos de ensanche urbanístico programado (c) con calles paralelas y perpendiculares entre sí que definen manzanas de grandes dimensiones; urbanizaciones con arbolado (c) donde existe una dispersión de edificaciones entremezcladas con vegetación; urbanizaciones nuevas sin vegetación (e).

- Zonas forestales propias de entornos montañosos: las áreas forestales de alta densidad arbórea ( $f$ ); superficies en las que la masa arbórea tiene una densidad media ( $\mathrm{g}$ ); las zonas de vegetación forestal abierta $(\mathrm{h})$ donde hay pocos árboles entremezclados con vegetación arbustiva o herbácea; superficies de alta densidad de matorrales (i) o bien de escasa vegetación arbustiva (j); los entornos montañosos de repoblación forestal $(k)$ en los que se aprecian los surcos resultantes de la roturación por maquinaria pesada para la repoblación.

- Áreas de cultivos de secano: las plantaciones de almendros (I) donde el marco de plantación cuadrado es bastante repetitivo si bien presenta diferentes orientaciones; los cultivos de olivos en parcelas irregulares $(\mathrm{m})$ donde la disposición de los árboles muestra una ausencia de geometría; las áreas de cereal recolectado ( $n$ ) en las que se aprecian líneas paralelas correspondientes a los restos de las máquinas cosechadoras; cultivos implantados en bancales a mitad de las laderas (ñ) sin tamaño o disposición constantes; las parcelas "cercadas" por muros de piedra seca y con presencia de árboles y arbustos dispersos en Menorca (o).

- Áreas de cultivos de regadío: plantaciones de cítricos ( $p$ ) donde se diferencian árboles individuales con marco de plantación cuadrado o en diamante y tamaños variables; los cítricos pueden presentar una linealidad evidente $(q) \circ$ bien tener una heterogeneidad en el tamaño de los árboles $(r)$ por reconversiones de variedades, enfermedades, etc.; las parcelas de huerta (s) de pequeñas dimensiones y con cubierta vegetal muy heterogénea por la variedad de cultivos. 


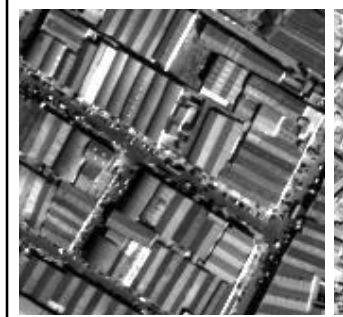

a)

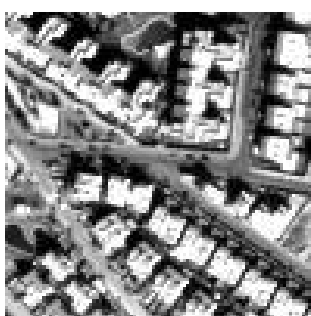

e)

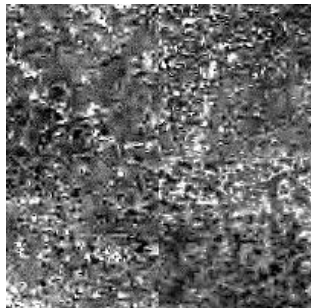

i)

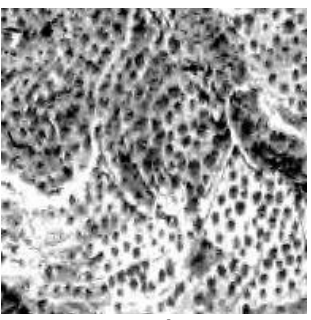

m)

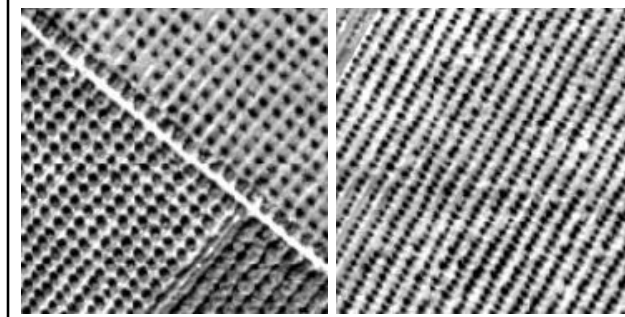

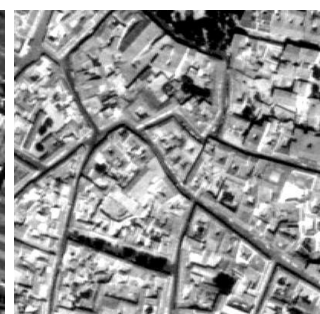

b)

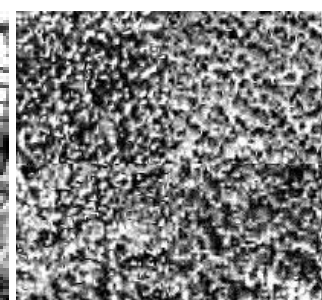

f)

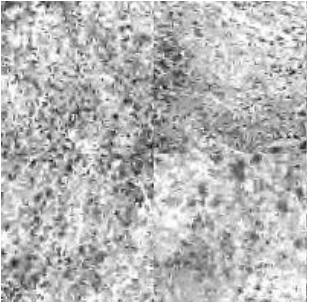

j)

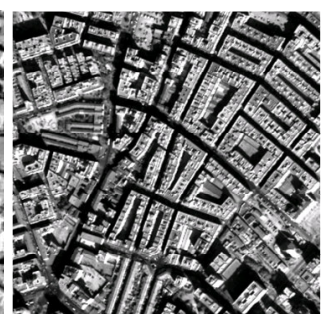

c)

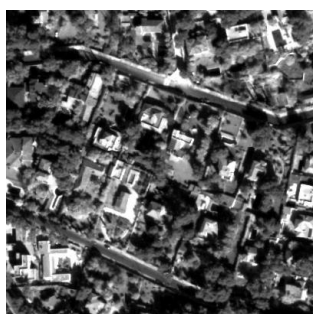

d)

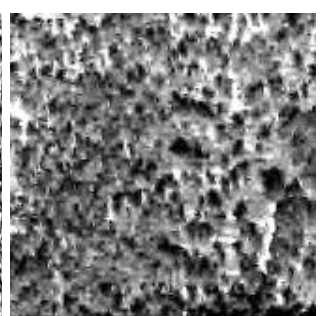

g)

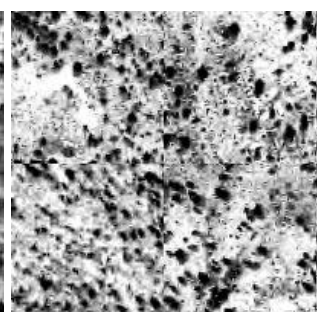

h)

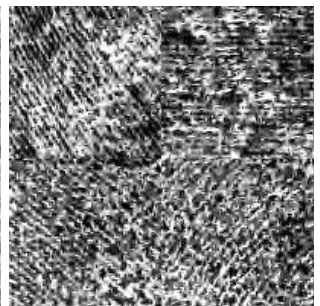

k)

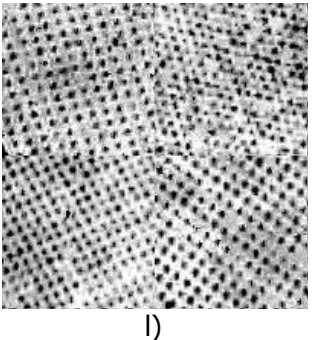

I)

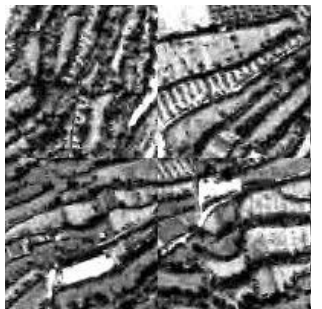

ก̃)

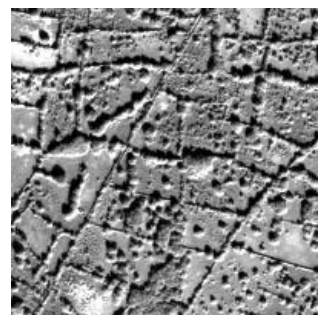

o)

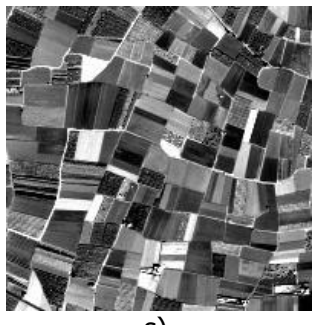

s)

Figura 2-4. Diversos ejemplos de texturas presentes en imágenes del territorio (elaboración propia a partir de fotogramas aéreos e imágenes de satélite). 


\subsection{Estado del arte en el análisis de texturas: Metodologías y aplicaciones}

Son varias las propuestas de clasificación de los métodos de análisis de texturas. Por ejemplo, Haralick en 1979 realizó un repaso a varias aproximaciones al estudio de texturas, desde las estadísticas como funciones de autocorrelación, transformadas ópticas, transformadas digitales, densidad de bordes de las texturas, elementos estructurales, coocurrencia de niveles de gris y modelos de autorregresión; hasta los modelos estructurales de textura como son los centrados en primitivas complejas y sus relaciones espaciales.

Otros autores hacen una simplificación de ellos. Riou (1997) divide los procesos de cálculo de operadores de textura aplicados en imágenes en métodos estadísticos y métodos estructurales. En los métodos estadísticos, la textura es considerada como la distribución de niveles de gris de una imagen y la información textural puede ser obtenida de la matriz de co-ocurrencias de niveles de gris. En los métodos estructurales, la textura se considera como el reflejo de un patrón básico o primitivo que se repite de tal forma que puede ser estudiado mediante el análisis de Fourier. Los operadores de textura existentes pueden no ser los más indicados para el estudio de imágenes de bajo contraste en las que las texturas son bastante homogéneas. Si se realiza un filtrado previo se puede difuminar la información textural pese a que se realcen los contrastes por los que este autor también propone técnicas híbridas entre los métodos estadísticos y los estructurales, consistentes en el empleo de análisis de Fourier adaptado a esas imágenes de bajo contraste por baja reflectancia.

Revisiones más recientes (Zhang y Tan, 2002, Sánchez, 2003) de los métodos de análisis de textura, particularizados para el caso de las texturas invariantes (no afectadas por la traslación, rotación, perspectiva, punto de vista, etc.) establecen los métodos estadísticos, estructurales y basados en modelos como los tres grandes grupos.

Como se comprueba y aunque no exista unanimidad en cuanto a la relación de métodos para estudiar las texturas, la mayor parte de los autores los agrupan en 4 tipos principales: estadísticos, estructurales, basados en modelos y basados en transformadas.

\subsubsection{Métodos Estadísticos}

Estos métodos no intentan entender explícitamente la estructura jerárquica de la textura como hace el método estructural, sino que representan la textura indirectamente por las propiedades no deterministas que controlan las distribuciones y relaciones entre los 
niveles de gris de una imagen. Dicho en otras palabras, este método se basa en el cálculo de descriptores de la distribución de intensidades en la imagen, los cuales son casi constantes para cada textura. Estos descriptores estadísticos miden variaciones de niveles de gris en un vecindario y se puede hablar de los estadísticos de $1^{\mathrm{er}}$ orden, o derivados del histograma y de los estadísticos de $2^{\circ}$ orden los que más información aportan sobre una textura, es decir los extraídos de la Matriz de Co-ocurrencia de Niveles de Gris (MCNG) (Arivazhagan y Ganesan, 2003). Este tipo de descriptores son los más apropiados para clasificar o segmentar imágenes por regiones. También se podría citar la función de autocorrelación de la imagen, empleada para evaluar tanto la regularidad como la finura o rugosidad de la textura (Randen, 1997, Epifanio, 2002).

En Zhang y Tan (2002) se detallan otros métodos estadísticos como son:

- Gráficos polares (polar plots) y polarogramas.

- $\quad$ Estadísticas texturales en los bordes.

- Expansión armónica.

- Métodos óptico-digitales.

- Estadísticos de orden alto.

- $\quad$ Momentos invariantes.

- Métodos de distribución de características.

Los métodos estadísticos, basados en características de textura como orientación, frecuencia espacial o contraste, han demostrado ser muy útiles (Maillard, 2003) para clasificar regiones homogéneas en las imágenes y por ello también a veces se les denomina "métodos basados en características" (feature-based method).

\subsubsection{Métodos Estructurales o Geométricos}

Consiste en entender una textura como una serie de primitivas (microtexturas) y una jerarquía de orden espacial (macro textura) de esas primitivas. Para describir la textura se deben definir por tanto las primitivas, su tamaño y sus formas (o calcular sus propiedades estadísticas), así como sus reglas de localización espacial (Materka y Strzelecki, 1998, Maillard, 2003). La ventaja de este método es que proporciona una buena descripción simbólica de la imagen, indicando si una imagen presenta o no textura, si bien es un método más útil para procesos de síntesis que para tareas de análisis. Randen, (1997) cita otro procedimiento como es el de la división en polígonos de Voronoi 
de cara a extraer las características estructurales, mientras que Zhang y Tan (2002) citan otros 4 métodos estructurales para el caso de texturas invariantes:

- Perímetro y compactación de las primitivas.

- Histograma invariante.

- Descriptores topológicos.

- $\quad$ Descomposición morfológica.

En cuanto a este último, Jiang (1999) especifica una serie de parámetros morfológicos extraíbles de cada textura para su caracterización geométrica:

- Área: cantidad de píxeles.

- $\quad$ Perímetro.

- Compactación: cuadrado del perímetro dividido por el área.

- $\quad$ Eje mayor de la elipse ajustada alrededor del núcleo.

- $\quad$ Eje menor de la elipse ajustada alrededor del núcleo.

- $\quad$ Diámetro mayor del objeto.

- Diámetro menor del objeto.

- Forma: diámetro mínimo dividido entre diámetro máximo.

- Dimensión fractal del objeto.

- Factor de simetría que calcula la simetría a lo largo del centro de gravedad del objeto.

- Diferencia de longitudes entre las líneas perpendiculares desde el eje mayor al límite del objeto.

\subsubsection{Métodos basados en Modelos}

Estos métodos (Epifanio, 2002) se basan en la construcción de un modelo, cuyos parámetros estimados sobre unas subimágenes tipo describirán las cualidades de la textura. Se emplean características derivadas de un modelo multiresolución autorregresivo (Mao y Jain, 1992, Zhang y Tan, 2002), fractales y modelos estocásticos como los campos aleatorios de Markov, Gibbs o Wold (Zhang y Tan, 2002) para interpretar una imagen de textura mediante modelos de generación de imágenes y modelos estocásticos 
respectivamente (Materka y Strzelecki, 1998, Maillard, 2003). Los parámetros de ese modelo son estimados y empleados para el análisis de imágenes.

Al emplear un campo aleatorio de Markov gaussiano (Arivazhagan y Ganesan, 2003) se está caracterizando la relación estadística entre un píxel y sus vecinos. El modelo estocástico resultante consta de un número de parámetros igual al tamaño de la máscara de vecindad usada.

También se puede hablar de modelos de campo aleatorio LogNormal (una distribución LogNormal es una distribución continua en la cual el logaritmo de una variable tiene una distribución normal).

El análisis de texturas o su descripción basada en fractales muestra la correlación existente entre la dimensión fractal de una textura y su rugosidad o tosquedad (coarseness). La propiedad de auto-similitud implica que la dimensión fractal de una imagen es independiente de la escala. El modelo basado en fractales se considera útil para modelar ciertas texturas naturales si bien también puede ser empleado para análisis de texturas y su discriminación.

Se podrían citar otros modelos orientados al análisis invariante de las texturas (Zhang y Tan, 2002) como modelos SAR y RISAR, modelo "wold-like" y pirámides orientadas.

\subsubsection{Enfoque mediante Transformadas}

Los métodos anteriores operan sobre la señal definida en el dominio espacial, si bien puede resultar más conveniente representar la imagen en otro dominio de forma que en el nuevo dominio se facilite la extracción de determinadas características (Epifanio, 2002). Para ello se aplican procesos de filtrado o de transformación a otro espacio de trabajo, pudiendo hablar de varios métodos (Arivazhagan y Ganesan, 2003, Chien-Chang, 1999):

- Filtros en el dominio espacial, como densidad de bordes, filtros de energía, operadores no lineales y métodos basados en momentos espaciales.

- Transformada de Fourier, basada en el análisis en el dominio de la frecuencia.

- Filtros de Gabor, partiendo de la transformada de Fourier ventana cuando la función ventana es una gaussiana. 
- Transformada Wavelet, que permite analizar la frecuencia de una imagen en función de la escala.

De todas esas transformaciones, las más conocidas (Materka y Strzelecki, 1998) son las de Fourier, Gabor y wavelet (Mallat, 1989, Daubechies, 1992, Strang, 1997) y la idea básica en la que se apoyan es la de representar una imagen en un espacio cuyo sistema de coordenadas está relacionado con las características de una textura, como puedan ser frecuencia de repetición o tamaño de la textura, si bien el comportamiento de estas tres transformadas no es similar. La transformada de Fourier genera resultados pobres debido a su limitación en la localización espacial. Los filtros de Gabor realizan mejor localización espacial, pero su empleo está limitado por la resolución en la cual se pueden localizar las estructuras espaciales en las texturas naturales. Este último contratiempo lo solventa la transformada wavelet al presentar dos rasgos importantes en su aplicación:

10 Permite variar la resolución espacial y representar texturas de diversas naturalezas.

$2^{\circ}$ Hay un amplio abanico de funciones base wavelet de tal manera que cada aplicación práctica se puede realizar con la wavelet que a priori generará mejor resultado.

\subsubsection{Aplicaciones}

Tras una rápida y resumida revisión de los 4 tipos de métodos texturales, en este apartado se especifican aplicaciones concretas de ellos, bien sean empleados de forma individual o bien combinados. Los diversos investigadores en este campo han realizado diferentes aplicaciones que nos permiten tener una visión actualizada del estado del arte y de esta manera poder definir en cada caso los pasos a dar, las rutinas a aplicar, los resultados esperables, etc. A continuación se introducen algunos métodos recientes y novedosos. Se termina revisando algunas de las principales aplicaciones de la transformada wavelet.

Los métodos más empleados quizás sean los estadísticos, bien de primer o de segundo orden. Ferro (1998) parte de imágenes radar de 1 metro de resolución, calcula características de textura y realiza experimentos con diferentes ventanas de cálculos de textura. Los resultados muestran que las variables de textura incrementan las fiabilidades de acierto hasta un $80 \%$ al ser usadas junto a información espectral, si bien aparece el problema del efecto de bordes. 
Las variables de textura también pueden ser integradas junto a otros tipos de información espacial en sistemas de información geográfica (SIG) para cualquier tipo de aplicación. Stefanov et al. (2001) emplean los estadísticos de primer orden de imágenes TM para, junto a otras variables, construir un sistema que permita analizar cambios en coberturas urbanas en los estados de Arizona y Phoenix (USA). Los resultados del $85 \%$ corroboran la metodología aplicada.

La extracción de estadísticas de las imágenes se puede hacer directamente sobre ellas o bien sobre resultados de operaciones previas, como la planteada por Ojala et al. (2001), consistente en obtener las diferencias relativas de niveles de gris y extraer sus características texturales. Aplicada en clasificación y segmentación de texturas se muestra como una buena rutina frente a otras conocidas como MCNG, MRF o filtros de Gabor.

La información estadística contenida en una imagen se puede analizar sobre los histogramas, de tal manera que algunos autores (Anys y He, 1995) calculan medidas texturales de diferentes grados sobre histogramas de primer, segundo y tercer orden. El objetivo de este trabajo es evaluar la capacidad de discriminar cosechas a partir de datos radar mediante la extracción de variables texturales de los citados histogramas. Para cada uno de los histogramas destacan algunas variables: para el de primer grado la media; para el de segundo grado el contraste y para el de tercer grado la variable "énfasis de los valores altos". Estas variables mejoran el resultado final de la clasificación en casi un $10 \%$.

Una ventaja de los métodos estadísticos es que son insensibles a la presencia de ruido gaussiano en imágenes. En particular, los parámetros estadísticos de tercer orden son los menos afectados por cualquier distribución simétrica de ruido y los que presentan una mayor capacidad de caracterizar señales no gaussianas. Murino et al. (1998) diseñan un método para clasificar texturas afectadas por ruido con diferentes distribuciones y con un bajo ratio señal-ruido, es decir, imágenes muy afectadas por ruido. De sus ensayos sobre imágenes de la base Brodatz y su comparación con técnicas estadísticas de segundo orden concluyen que la metodología propuesta es bastante eficiente (sobre todo en presencia de bajos ratios señal-ruido) y mejor que aquellas.

También se pueden encontrar referencias a aplicaciones de algoritmos de segmentación de texturas basados en momentos (Tuceryan, 1994). Los momentos en una pequeña ventana de imágenes binarias que contienen texturas con estadísticas de segundo orden similares o con imágenes en niveles de gris se han mostrado bastante útiles para su segmentación.

Las variables de textura, junto a otras, pueden ser empleadas a veces para establecer comparaciones entre tipos de imágenes para un objetivo específico. Haack y Bechdol (2000) calculan variables de textura de segundo orden, analizan el tamaño de la ventana de cálculo de textura, aplican filtrados previos a la extracción de ellas y 
suavizados post-clasificación, para comparar el comportamiento de imágenes TM y radar (SIR-C) en la clasificación de ámbitos forestales en el este de África. La variable varianza, una ventana de $13 \times 13$, los filtrados previos y el suavizado post-clasificación se muestran como buenos parámetros de trabajo para conseguir resultados óptimos, en cualquiera de los dos tipos de imágenes.

De todas las variables estadísticas que se pueden extraer de una imagen, las de la MCNG son de las más discriminantes pero no todas contribuyen de igual manera al resultado final. Ruiz (1997) aplica análisis discriminante paso a paso y análisis de componentes principales sobre esas variables para conseguir fiabilidades globales de hasta casi el $90 \%$. Esto refleja la importancia de una correcta elección de variables.

Los métodos estadísticos se pueden aplicar a la clasificación de zonas vegetales a partir de imágenes Landsat TM. Ruiz et al. (1998) proponen una metodología basada en métodos estadísticos para mejorar la diferenciación de esas cubiertas usando datos estadísticos de las texturas obtenidas de fotogramas aéreos de alta resolución. Para ello, definen las clases de vegetación a partir de sus diferencias texturales obtenidas de la MCNG, tres indicadores de energía textural y un factor de bordes. La selección de los parámetros óptimos como niveles de gris, tamaño del vecindario y distancia entre píxeles son obtenidos a partir del análisis discriminante paso a paso y de las técnicas de componentes principales, extrayendo así un grupo de muestras representativas de cada clase. Ruiz y Fdez.-Sarría (2000) integran diferentes variables derivadas de imágenes multiespectrales, fotogramas aéreos pancromáticos y MDE para clasificar zonas forestales montañosas. De la imagen multiespectral determinan índices de vegetación y emplean sus bandas; de la pancromática extraen 12 rasgos texturales (MCNG, energía y densidad de bordes) y del MDE derivan pendiente, orientación, radiación solar y modelo de insolación. La integración de todas ellas permite una clasificación combinada para determinar diferentes especies forestales y sus densidades, con unas fiabilidades del productor comprendidas entre 85 y $95 \%$.

Las áreas urbanas o de expansión urbanística también pueden se analizadas según métodos estadísticos. Así, Zhang (1999) propone realizar una clasificación multiespectral de imágenes TM y SPOT y posteriormente mejorarla mediante una MCNG modificada basada en filtrados direccionales. Sus resultados apuntan a que la fiabilidad media del usuario aumenta del orden del $46 \%$, por lo que se considera un método útil para una rápida estimación de edificios urbanos y áreas de rápido crecimiento. Córcoles et al. (2003) proponen la unión de las variables de la MCNG con otras espectrales e índices derivados para evaluar la evolución de núcleos urbanos compactos y urbanizaciones en el área metropolitana norte de la ciudad de Valencia, obteniendo fiabilidades próximas al $90 \%$ y constatando la necesidad de emplear metodologías diferentes según la tipología constructiva de cada área. Recio et al. (2003) definen una metodología para detectar y 
cartografiar los procesos de expansión urbana consistente en un análisis multiespectral y textural a partir de la MCNG y analizan la estructura del paisaje peri-urbano mediante el cálculo de hasta 29 índices que reflejan propiedades estructurales básicas como la dispersión o fragmentación, la proximidad, el tamaño y la forma de las unidades o núcleos urbanos.

Las imágenes radar (como las de ERS-1, por ejemplo) también pueden ser empleadas para caracterizar ámbitos urbanos. Dell'Acqua y Gamba (2003) investigan el uso de las medidas de textura de la MCNG para extraer información de diferentes tipologías y densidades de edificación en áreas urbanas, intentando mejorar la clasificación píxel a píxel mediante la consideración de bloques de la imagen.

Trabajando sobre imágenes con varios canales de color, Palm (2005) introduce matrices de co-ocurrencia integradas como un modelo a partir del cual se pueden extraer características para la clasificación de texturas en color, donde este parámetro es un elemento diferenciador de las texturas. Para ello, en primer lugar se definen las matrices de co-ocurrencia individuales de cada canal de color por separado y posteriormente se definen las matrices de co-ocurrencia multicanal mediante el cómputo de las ocurrencias por pares de los valores en las diferentes bandas de color. De esta última matriz se determinan las características texturales propuestas por Haralick para realizar la clasificación. Los experimentos realizados sobre texturas de la base VisText del MIT demuestran que existen patrones de color totalmente independientes de su intensidad y que al comparar las características de textura derivadas de las matrices integradas con las derivadas de niveles de gris y con el análisis de histogramas, las primeras mejoran los resultados de las clasificaciones un $20 \%$ y un $32 \%$ respecto de cada uno de los otros dos métodos. Anteriormente, Shearer y Holmes (1990) habían obtenido matrices de coocurrencia de color de cada uno de los atributos de color: intensidad, saturación y tono, calculando 11 variables de textura de cada una de ellas. Con las 33 variables consiguieron fiabilidades globales de más del $90 \%$ en la identificación de 7 tipologías de cultivos.

Los métodos estadísticos citados pueden ampliarse a enfoques geoestadísticos y más concretamente al estudio del semivariograma de la distribución de niveles de gris en el vecindario de un píxel (Carr y Pellon, 1998, Chica-Olmo, 2000, Durrieu et al., 2005). Con esto se pueden caracterizar propiedades que definen las texturas como homogeneidad, granulometría, rugosidad, regularidad y anisotropía, ampliando a las clásicas de intervalo, pie y efecto "nugget" por ejemplo. Estos autores proponen un grupo de rasgos de textura basados en ratios, integrales o derivadas de los valores extraídos del semivariograma experimental. De un análisis discrimante paso a paso deducen cuales serán las que mejor contribuyan a la clasificación de imágenes pancromáticas de alta resolución (QuickBird), reflejando sus resultados un nivel de fiabilidad del $80 \%$ partiendo tan solo de una imagen. 
La correcta caracterización de algunas texturas puede ser muy importante para cuantificar la dimensión de ciertos desastres naturales y poder establecer medidas de ayuda a la población y reconstrucción inmediatas y adecuadas. Es el caso del trabajo de Saito y Spence (2004) en el que elaboran un mapa de afección en la ciudad de Bam (Irán) tras el terremoto del 26 de diciembre de 2003. Para ello emplean como información textural la extraída del semivariograma calculado sobre una imagen pancromática, para todas las direcciones, con una separación de la unidad y un vecindario de cálculo de 9x9 píxeles. Tras completarse con la información multiespectral y clasificar, los autores encuentran que los errores de asignación en las clases temáticas vienen producidos por la dificultad de caracterizar correctamente los escombros, ya que no se ajustan a ningún patrón o distribución. Si se define mejor esta clase "escombro" se podrían obtener mayores porcentajes de acierto y menos errores por exceso o defecto.

El tratamiento de imágenes mediante técnicas de detección de bordes, filtrados y análisis de texturas puede ser mejorado mediante el empleo de ventanas de cálculo de tamaños variables en función de la escala o de la realidad de la escena. El estudio de los semivariogramas es una de las mejores técnicas para considerar esa variabilidad dimensional de la ventana geográfica de trabajo, proporcionando la mejor para cada escala. Franklin et al. (1996) demuestran, empleando semivariogramas y sobre tres ejemplos (imágenes SPOT, imágenes CASI e imágenes SAR) la mejora de las clasificaciones con fines forestales o de determinación de los usos del suelo, con fiabilidades globales entre el $75 \%$ y el $80 \%$.

Los métodos estructurales se basan en la extracción de rasgos geométricos de los patrones de textura. Wu y Linders (1999) emplean dos medidas estructurales de textura, una basada en la propia estructura o forma y otra en la complejidad de la imagen para discriminar 3 cubiertas vegetales en imágenes radar. Además realizan una comparación con las variables de la MCNG propuesta por Haralick. Los resultados muestran que las características estructurales tienen buena capacidad de discriminación y que minimizan los cálculos dentro de la ventana de trabajo.

De los diferentes niveles de gris de las imágenes se pueden derivar varios índices de textura y ser aplicados a casos tan diversos como el reconocimiento y estudio de imágenes médicas. Tal es el caso del trabajo de Dhawan et al. (1996) que mediante características estructurales de los niveles de gris clasifican tumores malignos en mamografías. Para ello emplean variables basadas en los histogramas de primer y de segundo orden y otras basadas en la descomposición wavelet. De todas ellas realizan una selección de las más discriminantes y clasifican mediante redes neuronales, obteniendo resultados bastante fiables. 
En cuanto a métodos basados en modelos, uno de ellos, aplicado a la clasificación de texturas, es el conocido como FTCM (Frame Texture Classification Method) (Skretting y Husoy, 2002). Un frame es un conjunto de vectores que caracteriza cada uno de ellos a una clase de textura. Por tanto, si se define un frame para cada textura se puede clasificar una imagen en las texturas deseadas en función de todos los frames. La clasificación se realiza buscando la mejor aproximación de unos vectores de test a los frames definidos para cada clase. Tras ser aplicado sobre nueve imágenes de prueba se obtuvieron excelentes aciertos globales y un número aproximadamente la mitad de píxeles erróneamente clasificados respecto a otros métodos. El trabajo de estos autores se basa en el publicado por Chun Zhu et al. en el año 1996 en el que presentaron el modelo FRAME, acrónimo de Filtres, Random Fields and Maximun Entropy, (filtros, campos aleatorios y máxima entropía). Se trata de un modelo de análisis y síntesis imitativa de texturas que combina la idea del filtrado, los modelos de Markov y el principio de máxima entropía.

El método basado en modelos fractales ha sido aplicado por algunos autores para segmentar imágenes de texturas en niveles de gris mediante el pre-filtrado de esas imágenes y el cálculo de sus características fractales (Kasparis et al., 2001). El empleo de esta metodología se fundamenta en que la descomposición mediante bancos de filtros considera la energía en cada banda como una característica textural, siendo un parámetro altamente dependiente de la intensidad luminosa de la imagen. Sin embargo, el utilizar características basadas en fractales se debe a que éstas reflejan mejor las propiedades de las texturas en sí y están poco influenciadas por la intensidad de la imagen. Mediante la rutina propuesta se consiguen porcentajes de acierto en la segmentación de hasta el 93\%, superior al conseguido con otras variables como filtros de Gabor y de energía (91\%).

En el análisis fractal tradicional se supone que las variaciones de iluminación y contraste no afectan de manera importante y que las texturas presentan similar rugosidad sobre un amplio número de escalas. En la realidad, esta última premisa no se cumple en muchas texturas. Muneeswaran et al. (2005) proponen un método que consiste en una extensión de las dimensiones fractales, donde el rango total de escalas es dividido en varios subrangos y las medidas fractales son extraídas de cada uno de ellos, formando vectores de características texturales.

Otra aproximación a las variables texturales de un modelo fractal es la propuesta por Turiel (2003), que intenta analizar la relevancia de todas las variables de una imagen fractal, ya que algunas propiedades de bordes o texturas son importantes para una perfecta reconstrucción en imágenes comprimidas y otras pueden ser borradas sin afectar significativamente a la calidad. 
Campisi et al. (2004) presentan un procedimiento de clasificación basado en texturas extraídas mediante un modelo, en concreto las derivadas de la función de autocorrelación espacial aplicada sobre imágenes binarias de diversas texturas tipo de la base de Brodatz (1965). Las características de textura extraídas de esa función se muestran suficientes para una buena clasificación, realizada concretamente con técnicas basadas en momentos invariantes, por lo que este procedimiento de clasificación generará resultados invariantes a la rotación de las texturas.

Epifanio (2002) considera en su tesis el problema de la clasificación de texturas y la representación eficiente de imágenes naturales (con múltiples texturas) mediante transformaciones para ser comprimidas. En las dos tareas existen dos etapas. Una primera etapa de extracción de características: por un lado descriptores de texturas y por otro lado, coeficientes obtenidos tras la transformación de la imagen a un dominio adecuado. Una segunda etapa de asignación de clase a la que pertenece (clasificación) y proceso de cuantizado con la asignación de un valor representativo según la zona de la imagen.

Uno de las metodologías que se pueden aplicar sobre imágenes de textura puede consistir en la segmentación de dichas imágenes mediante el empleo de diversos bancos de filtros Gabor (Kasparis et al., 2001). O bien evaluar su aplicación como filtros opuestos a otros bancos de filtros usados en codificación de imágenes tanto a dimensión completa (sin submuestreos) como en descomposiciones críticamente muestreadas (Randen y Husoy, 1993, 1994).

La transformada de Fourier ofrece muchas posibilidades de trabajo en aplicaciones que requieran el análisis de frecuencias espaciales y de sus orientaciones (Maillard, 2003). En cuanto a texturas, ciertas imágenes como las de zonas forestales tropicales (Riou et al., 1997) se pueden caracterizar mejor por su textura que por su respuesta espectral. El método propuesto, basado en la transformada de Fourier, no implica el filtrado de ningún tipo, lo que podría degradar la resolución de la imagen y la alteración de los patrones texturales.

Si esta transformada se aplica obteniendo el espectro de Fourier de ventanas seleccionadas dentro de diferentes tipos de vegetación (Zhang y Chaisattapagon, 1995) como cereales o pastos, se puede considerar como un buen método para analizar sus texturas.

Los resultados obtenidos por la comunidad científica al respecto de todos los métodos reseñados no son siempre uniformes, ya que los datos de partida y las formas de implementarlos no son siempre los mismos. Por ello son muchas las comparativas que se 
han realizado de cara a resaltar ventajas e inconvenientes de unos y otros en tareas específicas.

Maillard (2003) compara las variables texturales de la MCNG, del semivariograma y de la FFT. Los tres pueden ser aplicados en varios contextos de clasificación de fragmentos de imágenes de cubiertas vegetales naturales, en términos del efecto de variación dentro de la clase y variaciones entre clases. Si la MCNG se aplica correctamente, es un método muy eficiente para clasificar texturas cuando sus características son visualmente diferentes y los otros métodos no mejoran los resultados del primero. En cambio, el método del semivariograma parece ligeramente mejor que otros en el caso de texturas muy similares si bien está poco contrastado. Tanto la MCNG como el semivariograma son los mejores métodos en todos los casos, con fiabilidades entre el 65 y el $70 \%$. El método que peor se comporta de los tres en cualquier escenario es la transformada de Fourier.

Es elevado el número de sensores que nos pueden aportar imágenes digitales. Cada uno de ellos tiene aspectos técnicos diferentes y por tanto las imágenes pueden diferir en su radiometría, resolución, etc. No todas las técnicas de texturas se comportan igual frente a una misma imagen y viceversa. Carr y Pellon (1998) han realizado un estudio comparativo del comportamiento del semivariograma y la MCNG con un conjunto de 6 tipos de imágenes diferentes (SPOT HRV, Landsat TM, IRS LISS-II, Magellan S-band radar, Shuttle Imaging Radar SIR-C X-band y SIR-C L-band) en una rutina de clasificación. Los resultados obtenidos muestran que las variables texturales del semivariograma proporcionan una mayor fiabilidad que las basadas en la MCNG para las imágenes radar mientras que para las imágenes ópticas ocurre lo contrario.

Clausi y Deng (2005) estudian la posibilidad de fusionar características de textura de varios métodos, en concreto los filtros de Gabor y la MCNG, para mejorar el reconocimiento de texturas. El conjunto fusionado de características se aprovecha de la capacidad de los filtros de Gabor para capturar la información textural en las bajas y medias frecuencias y de que la MCNG extrae dicha información para las altas frecuencias. La evaluación de este conjunto fusionado de variables se realiza mediante la separabilidad de ellas y también mediante el ratio de acierto en tareas de segmentación y clasificación con todas ellas. Dicha evaluación muestra que el trabajar con todas las variables produce mejores fiabilidades que el hacerlo por separado.

La comparación de dos métodos de textura, el estadístico de la MCNG y el modelo de campos aleatorios de Gauss-Markov (GMRF) ha sido realizada por Clausi y Yue (2005) sobre un conjunto de imágenes de diferente naturaleza: imágenes sintéticas, imágenes de la base Brodatz e imágenes radar SAR de bancos de hielo marinos. La comparación se ha realizado desde el objetivo final de segmentar de forma no supervisada esas imágenes, 
pero considerando otro parámetro importante como es el tamaño del vecindario de cálculo. Los resultados obtenidos indican que el modelo GMRF requiere tamaños mayores de vecindario que MCNG para estimar de forma consistente las texturas. Sobre los tres tipos de imágenes ensayadas se ha estimado un vecindario mínimo de 32×32 para obtener características de texturas separables. Es un tamaño grande por lo que se produce un importante efecto de bordes al poder influir varias clases en un mismo vecindario a la vez. Como última conclusión, se apunta a que el contorno irregular de las clases influirá negativamente en la segmentación.

En un trabajo anterior del mismo autor (Clausi, 2001) se comparan y fusionan características texturales obtenidas por 3 métodos (MCNG, Gabor y MRF) para clasificar imágenes radar SAR de hielo marino. También considera este trabajo que desiguales cuantizaciones de los niveles de gris de la imagen podrían implicar resultados diferentes, si bien sobre las imágenes analizadas no hay diferencias remarcables. En cuanto a los grupos de variables, destaca la MCNG como la más útil, seguida por los filtros de Gabor y MRF a cierta distancia en porcentaje de acierto. Dado que las características derivadas del modelo MRF no presentan ningún tipo de correlación con las otras, la mejor agrupación de variables es la unión de MCNG y MRF, como lo corroboran los resultados.

Skretting y Husoy (2002) comparan varios métodos de clasificación (filtros QMF de tipo FIR, filtros de Daubechies, filtros de energía y MCNG) con un método propuesto llamado FTCM (Frame Texture Classification Method) (un frame es un conjunto de vectores que caracteriza cada uno de ellos a una clase de textura) y concluyen que usar un solo vector para definir el comportamiento de cada clase no genera resultados sensiblemente mejores a los otros métodos, mientras que usar varios (entre 3 y 5) vectores por textura proporciona mejores fiabilidades en la clasificación.

Trabajos como el de Chien-Chang y Chaur-Chin (1999) enfocan la discriminación de texturas de imágenes para descomponer estas últimas en diferentes espacios proyectados, los cuales corresponden a los campos receptivos de visión humana. Se comparan 4 métodos de análisis textural, como son (1) la transformada de Fourier, (2) filtros espaciales, (3) filtros de Gabor y (4) transformada wavelet. De los resultados obtenidos de la comparación de esos 4 métodos sobre un total de 600 imágenes derivadas de 6 texturas de la base Brodatz (1965) se pueden extraer algunas conclusiones: Con las 4 primeras características de textura obtenidas por cada método, el porcentaje de acierto en la identificación de la textura inicial es muy similar entre ellos y bastante alto (entre el 90 y el $98 \%$ ) si bien destaca el método de Gabor. Si el número de parámetros texturales de cada método es mayor de 7, la transformada wavelet se comienza a mostrar como más idónea por el alto porcentaje de acierto (casi del 100\%) y por su menor coste computacional y temporal. Estos mismos autores amplían la anterior comparativa a texturas sintetizadas mediante campos aleatorios de Markov (MRF). Con 2 características 
de texturas, la transformada wavelet se muestra claramente superior al resto. Cuando el número de rasgos de textura es mayor de 4, todos los métodos consiguen un casi perfecto reconocimiento si bien en coste computacional, destacan las transformadas de Fourier y wavelet.

Los métodos estadísticos dan juego para derivar nuevos métodos basados en parámetros o índices de utilidad real. Tal es el caso de los trabajos de Ganesan y Bhattacharyya (1995 y 1995), los cuales proponen una aproximación estadística que emplea un conjunto de polinomios ortogonales para describir texturas. Este método testea la presencia de microtexturas y las representa como un descriptor local llamado "pronum". La frecuencia de ocurrencia de pronums (llamada "prospectum") es el descriptor global de la textura. La aplicación de este método ha demostrado que las variaciones espaciales de las texturas han sido correctamente diferenciadas.

La investigación sobre los posibles métodos de extracción de texturas ha llevado a Strand y Taxt (1994) a proponer un método basado en la detección de extremos locales a lo largo de un conjunto de vectores direccionales en la imagen. Estos extremos son interpretados como frecuencias locales y usados para diseñar variables de textura. Este método ha sido comparado con Gabor y MCNG sobre 3 imágenes con buenos resultados.

El efecto de bordes reseñado en párrafos anteriores ha sido enfocado en diversos trabajos. Jones (1994) plantea un método de segmentación de imágenes empleando detección de bordes en las texturas. Para ello define un operador, denominado "rarity $m a p^{\prime \prime}$, que extrae altos valores en el centro de regiones homogéneas y bajos en áreas periféricas. Una segmentación jerárquica es entonces realizada mediante la búsqueda de "huecos" importantes en las salidas del operador. Lin y Huang (2004) proponen que la extracción de bordes puede mejorar las fiabilidades de clasificación de variables texturales. Para la detección de bordes proponen un método basado en redes neuronales y denominado cellular neural network implementado mediante filtros de Gabor y contrastado en imágenes sintéticas y naturales, con buenos resultados.

Uno de los métodos de análisis de texturas más utilizado en los últimos años por sus ventajas evidentes en cuanto a la localización espacio - frecuencia y su capacidad de trabajar a diferentes resoluciones es la transformada wavelet. En los párrafos siguientes se comentan algunas de las aplicaciones más comunes de dicha transformada para la caracterización de las texturas en la imagen, tanto de forma individual como combinada con otras. 
La transformada wavelet discreta descompone una imagen en un conjunto de coeficientes, tendencias y detalles, que constituyen una representación multiescala de la imagen. Una limitación importante en el análisis de texturas en una imagen es que se hace a una sola escala. Si se emplea la transformada wavelet puede extenderse ese estudio a varias escalas o resoluciones. De esa manera, la caracterización de la textura puede hacerse a partir de propiedades estadísticas calculadas en un vecindario de los coeficientes de detalles correspondientes a varias escalas, ya que, según resultados obtenidos por Giménez et al. (2004) se considera que las tendencias (obtenidas mediante promedios iterativos) no contribuyen apenas a la caracterización de texturas.

Un modelo redundante (sin submuestreos) de transformada wavelet es aplicado por Fukuda y Hirosawa (1999) para conseguir características de textura derivadas de cada subimagen invariantes a la traslación en imágenes radar. El conjunto de variables ha sido aplicado con éxito en áreas agrícolas de Holanda.

Jafari-Khouzani y Soltanian-Zadeh (2005) definen una nueva técnica de análisis de texturas que se muestra invariante a las rotaciones y utiliza la transformada wavelet y la transformada Radon (Helgason, 1980). Esta técnica emplea la transformada Radon para convertir la rotación a una traslación y entonces aplicar una transformada wavelet invariante a la traslación para extraer las características de textura. Éstas generan un espacio de características ortogonal que extraen tanto la información local como la direccional de los patrones de textura. Sobre ese espacio de características aplican un clasificador de distancia (el de los k vecinos más próximos). Los resultados muestran que esta técnica es ventajosa frente a otros métodos clásicos de análisis de texturas.

Sobre el tratamiento de bordes, Angel y Morris (2000) emplearon la transformada wavelet según el modelo de descomposición de Mallat sobre imágenes naturales en las que la presencia de gran cantidad de bordes junto a diferentes texturas hacía difícil extraer modelos de contornos y diferenciarlos. Para superar esa desventaja, estos autores propusieron un algoritmo en el que en primer lugar se creaba una representación multiescala según el modelo de descomposición wavelet de Mallat y entonces se combinaban los modelos de bordes a cada escala para crear un único modelo de contornos donde la influencia de las texturas sobre los bordes era minimizada. Sus resultados muestran que los contornos y las características de textura pueden ser discriminadas en cada escala y el modelo final de bordes es muy útil para localización y reconocimiento posteriores. Algo similar hicieron con anterioridad Gi-Mun et al. (1997) al emplear la transformada wavelet para definir un análisis multiresolución y proceder a la extracción de bordes según un ajuste entre las imágenes de baja resolución obtenidas y los píxeles de los bordes previamente interpretados. 
En otras ocasiones se pueden combinar las variables derivadas de métodos estadísticos y las de la transformada wavelet. Tal es el caso del trabajo de Arivazhagan y Ganesan (2003), que realizan una clasificación de texturas empleando tres grupos de variables, a) usando 24 características estadísticas (media y desviación estándar de cada subbanda) de la descomposición wavelet a nivel 3 empleando la función "symlet" de 20 coeficientes en cada filtro; b) usando 35 variables de la MCNG (7 de cada subbanda) de la descomposición wavelet a nivel 1 y de la imagen original; y c) una combinación de ambos grupos de variables y aplicándolo tanto sobre 20 imágenes completas de 512×512, como sobre un conjunto de subimágenes de tamaños diferentes extraídas de las completas y pertenecientes éstas a la base de imágenes típicas de texturas homogéneas o sintéticas VisTex (1995). Los resultados obtenidos muestran que el porcentaje de acierto tras la clasificación es mucho más alto al combinar las variables estadísticas y las de la MCNG de la transformada wavelet. Fdez.-Sarría et al. (2005) aplican conjuntos de variables de segundo orden obtenidas directamente de la imagen pancromática original y de las imágenes de detalle de niveles 1, 2 y 3 para clasificar tipologías de superficies urbanas y rurales y analizando varias familias de funciones wavelet, mostrando que la agrupación de todas ellas puede conseguir buenas fiabilidades globales.

Otra posible combinación de métodos es la que propone Unser (1995) donde relaciona la formulación wavelet con alguna de las transformadas en las funciones Gabor para caracterizar las texturas de una imagen.

Arivazhagan y Ganesan (2003) emplean la transformada wavelet para segmentación de imágenes comparando las características de textura obtenidas de la MCNG de la transformada wavelet discreta aplicada sobre cada bloque de 32×32 píxeles de la imagen original, calculando diferencias entre las variables de cada bloque y generando una banda de segmentación. Las imágenes de partida son tomadas del álbum de Brodatz (1965) y los resultados muestran una mejor segmentación empleando la transformada wavelet frente a otros métodos.

Muchas imágenes reales constan de una variedad de texturas suaves y rugosas y para su segmentación se necesita de un algoritmo que verdaderamente las diferencie, basándose en su dispar comportamiento frecuencial. Las texturas suaves pueden ser segmentadas usando las estadísticas de los niveles de gris en un vecindario, como media y varianza, mientras que las texturas rugosas necesitan del estudio de sus características basadas en la frecuencia espacial. Esto justifica la importancia de realizar un estudio previo a la segmentación de varias imágenes (Porter y Canagarajah, 1996). Estos autores proponen un esquema de trabajo como el de la figura 2-5, en el que tras la descomposición wavelet discreta de una imagen original, establecen si un píxel o una agrupación de píxeles presentan una textura suave o una textura rugosa. Esta asignación se realiza mediante el cálculo de la variable $\mathrm{R}$, expresada como: 


$$
R=\frac{e_{C 1}+e_{C 2}+e_{C 3}+e_{C 4}}{e_{C 5}+e_{C 6}+e_{C 7}}
$$

donde $e_{C n}$ es la energía en la subbanda $n$ de la descomposición wavelet de nivel tres, y su comparación con un umbral $T$ definido por el usuario. Si $R>T$ se considera un píxel suave y si $R \leq T$ se considera rugoso. Se considera que las subbandas $1,2,3$ y 4 (las propias del nivel 3) tienen componentes de bajas frecuencias, las subbandas 5, 6 y 7 (las propias del nivel 2) presentan componentes de medias frecuencias, mientras que la 8, 9 y 10 (las de nivel 1) engloban las altas frecuencias. Los resultados de este artículo muestran que esta metodología de trabajo es ventajosa frente a la descomposición wavelet por si sola cuando el objetivo es el de segmentar imágenes.

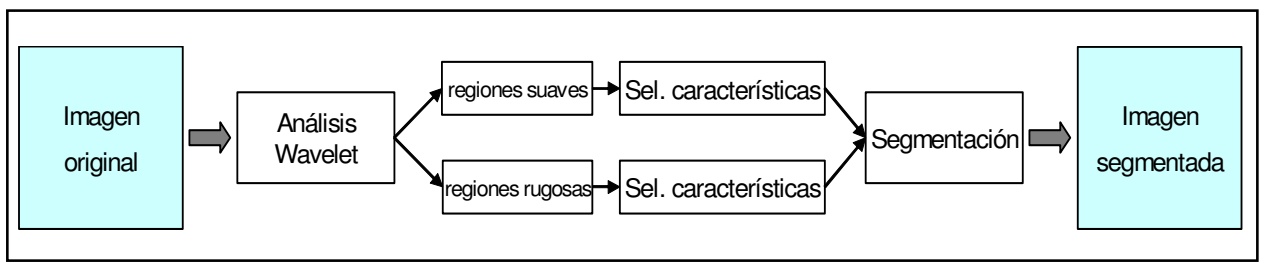

Figura 2-5. Esquema de descomposición de Porter y Canagarajah (1996).

También se puede emplear la descomposición wavelet para la transmisión de datos del terreno a través de redes de baja velocidad mediante los modelos multiresolución, aplicando dicho análisis tanto en la selección de puntos de control, como en la clasificación de texturas y la segmentación, para posteriormente generar un proceso de síntesis de texturas para la reconstrucción del modelo (Abásolo y Perales, 2003).

En lo que respecta al análisis de objetos o texturas presentes en una imagen, Antoine et al. (1992) emplean la transformada wavelet bidimensional para extraer varios parámetros descriptivos de las imágenes, buscando determinar la posición, la escala y la orientación de las estructuras presentes en una imagen.

Entendiendo que la energía de una imagen es una variable importante, Zhou et al. (2000) aplican la transformada wavelet de diversas maneras de cara a la obtención de la energía de las diferentes subbandas, ponderándola con su orden dentro del ranking de valores, es decir, trabajan con una función de distancia que es el resultado de la multiplicación de un vector de distancias de energía y otro vector de distancias ordinales.

Agustí et al. (2003) emplean la transformada wavelet como herramienta básica para caracterizar e indexar una base de datos de imágenes mediante el análisis multiresolución, aplicando diferentes tipos de wavelets a una colección de imágenes y extrayendo de ellas los vectores de características texturales que permitan implementar un sistema para la recuperación de imágenes dentro de dicha base de datos. Pese a que esta 
aplicación no tiene una valoración cuantitativa del acierto, los resultados obtenidos son aceptables en cuanto a la recuperación de la imagen de partida.

Si se aplican variaciones a la transformada wavelet clásica se pueden solventar inconvenientes que a veces se presentan de forma natural en las texturas. Para realizar una clasificación y discriminación de las texturas, es importante considerar la propiedad de invarianza a la traslación (textura estacionaria). Un cambio o movimiento entero de la señal de entrada generalmente implicará modificaciones en la transformada wavelet. Por lo que a la extracción de características respecta, este comportamiento no es adecuado, pues es de esperar que la textura sea invariante a la traslación. Para superar esta limitación, se puede realizar un análisis de la señal de entrada sobre el conjunto total de saltos posibles en la imagen aplicando la transformada discreta wavelet frame (DWF) (Unser, 1995). La caracterización de la textura se realiza mediante el cálculo de la varianza sobre un determinado vecindario.

En diversos trabajos se ha aplicado la transformada wavelet de 2 bandas (o filtros) ampliada a una transformada genérica de $M$ bandas. Entre ellos, Chitre y Dhawan (1999), la aplican al problema de la discriminación de texturas naturales de tamaños variables, sobre un conjunto de 20 de ellas y extrayendo las características de energía de cada subbanda descompuesta, para posteriormente clasificar mediante el vecino más próximo un total de 700 imágenes. La fiabilidad global máxima conseguida es del 99.5\%, evaluada mediante una serie de test estadísticos. Havlicek y Tay (2001) aplican una rutina muy similar para determinar la cantidad de texturas presentes en una imagen aplicando la misma transformada hasta nivel 3 y calculando la energía de cada subbanda.

Wang et al. (1998) proponen la extracción de las características de textura de una descomposición denominada transformada wavelet no separable bidimensional (NSWT), basada en el análisis multiresolución y el submuestreo pero con un factor de remuestreo de $\sqrt{ } 2$, con lo que se puede aplicar un mayor número de niveles de descomposición. Este remuestreo es el llamado quincunx subsampling. Tras aplicar el anterior algoritmo se procede a la selección de las características de textura de cada subbanda que se emplearán en la clasificación para formar así el vector de cualidades de cada subimagen. Son conocidas la varianza, la entropía (cantidad de desorden o dispersión) y a ellas se suman los números extremos máximo y mínimo y la entropía de dichos extremos, de cara a una clasificación de texturas. Los resultados apuntan a las medidas de los extremos como las que consiguen una mejor clasificación.

Fatemi-Ghomi (1997) plantea 4 esquemas de aplicación de la transformada wavelet sobre un conjunto de imágenes para ser segmentadas. De esos 4 esquemas y aplicando un conjunto de filtros realiza la extracción de una serie de características o variables de textura mediante lo que denomina la distancia de histograma por un lado y la 
función de correlación entre 2 puntos por otro. Estas dos medidas de la calidad del espacio de variables texturales se muestran útiles al no requerir conocimientos previos de ese espacio. La función de correlación entre dos puntos es mejor que la distancia del histograma en espacios pequeños mientras que en grandes, ocurre al revés.

Dado que son varias las familias de funciones wavelet desarrolladas, algunos autores como Muneeswaran et al. (2005) plantean combinaciones entre ellas para destacar aspectos de las texturas como características invariantes a la rotación y a la escala. Para ello definen un modelo integrado (CIF: Combined Invariant Features) formado por información derivada de funciones wavelet básicas como la gaussiana y la Mexican Hat y otras ortogonales como Daubechies. También incluyen en ese modelo características derivadas de filtros de suavizado gaussianos ponderados. La invarianza a la rotación es conseguida mediante el paquete wavelet mientras que para la invarianza al escalado emplean modelos fractales extendidos a cada escala. Los resultados obtenidos muestran que el modelo conjunto genera mejores ratios de acierto que los dos grupos de funciones wavelet por separado.

Tal y como se detalla en el capítulo IV, existen varias formas de aplicar la transformación basada en wavelet. Uno de ellos se denomina transformada wavelet en árbol o wavelet packet, aplicada por Chang y Kuo (1993) sobre un conjunto de 30 imágenes de la colección Brodatz (1965) para conseguir su clasificación. Parten de la motivación de que la transformada wavelet ordinaria se basa en la descomposición sucesiva de las subbandas de bajas frecuencias mientras que ellos afirman que la mayor parte de las texturas naturales presentan frecuencias localizadas en los canales de media frecuencia, por lo que es de esperar que se obtengan mejores resultados con la descomposición en árbol. Además realizan un análisis comparativo con otras transformadas de cara a valorar la fiabilidad de la transformada discreta del coseno (DCT), la DST (transformada discreta del seno), la DHT (Transformada Discreta de Hadamard), transformada wavelet piramidal, filtros de Gabor y filtros de Laws. Tras calcular la energía media en cada subbanda resultante y clasificar, de los resultados obtenidos se concluye que de las 3 funciones wavelet empleadas (Haar, Daubechies16 y Battle-Lemarié) ninguna de ellas destaca claramente frente al resto. También se observa que los resultados de DCT, DST, DHT y Laws son muy parecidos entre sí; que los resultados de Gabor son muy próximos a los de la descomposición wavelet piramidal y que en conjunto es la transformada wavelet packet la que genera mejores porcentajes de aciertos, si bien estos autores emplean las mismas muestras para el clasificador y para la evaluación, con lo que la significación de esos resultados ha de ser considerada en su justa medida.

La distribución de frecuencias anteriormente detallada es corroborada por otros autores como Larsen (2001), el cual concluye que las imágenes con texturas claramente 
visibles tienden a tener una distribución espectral con mayor contenido de energía, y por tanto mayor información textural, en las bandas medias.

Rajpoot (2002) también trabaja sobre el modelo wavelet packet, de cara a extraer las mejores características de texturas para clasificar. El procedimiento de trabajo consiste en aplicar la descomposición, calcular las funciones de distribución de energía de cada subbanda resultante, aplicar la distancia de Kullback-Leibler (también conocida como "entropía relativa") entre los coeficientes de la descomposición entre dos clases para seleccionar las subbandas más discriminantes y aplicar el clasificador K-means sobre ellas para obtener los resultados de la clasificación. Las conclusiones de este trabajo apuntan a que unas pocas subbandas generan mejores resultados que todo el conjunto de ellas, al ser muy discriminantes.

La aplicación de las funciones wavelet y la transformada a que dan lugar no se restringe al campo de las imágenes digitales y su análisis textural, sino que son muchos los ámbitos de aplicación y además crecientes de forma progresiva. Se podrían citar algunos:

- Astronomía

- Procesado digital de imágenes y señales

- Reconocimiento de formas

- Tratamiento de señales geofísicas

- Ingeniería nuclear

- Generación de imágenes por resonancia magnética

- Resolución de ecuaciones diferenciales parciales

- Climatología
- Acústica

- Neurofisiología

- Óptica

- Radar

- Visión humana

- Música

- Aerodinámica

- Oceanografía

De forma más específica y entrando en algunos de ellos se citan algunos de los trabajos más recientes al respecto.

En el procesado digital de imágenes y señales, aparte del ya citado análisis de texturas, son varios los problemas que las funciones wavelet ayudan a resolver. La compresión de imágenes, para ser transmitidas, codificadas, almacenadas, etc. es enfocado por varios trabajos.

El hecho de que una imagen de tamaño $\mathrm{M}$ filas y $\mathrm{N}$ columnas tenga $\mathrm{MxN}$ coeficientes wavelet, exactamente el mismo número que píxeles de la imagen inicial, es empleado en la compresión de imágenes y es la base del desarrollo de formatos de imágenes como el JPEG2000. El modelo de transformada wavelet packet es empleado en la compresión de imágenes por el FBI (Xiong y Ramchandran, 2000). Se pueden citar 
trabajos al respecto de la compresión de señales e imágenes basadas en wavelets, como los de Mulcahy (1996); Antonini et al. (1992) extrayendo y codificando la información; Cohen y Froment (1992) empleando la transformada wavelet ortonormal; Nguyen (1995) que explica la aplicabilidad de diferentes esquemas de filtrado basados en transformadas wavelet para comprimir imágenes y electrocardiogramas; Stollnitz el al. (1995) que emplean la wavelet de Haar para la compresión de imágenes y la wavelet basada en la función B-spline para desarrollar un banco de filtros B-spline y aplicarlo a edición de curvados en diferentes resoluciones y en la edición de superficies; Larsen (2001) usa máscaras binarias de detección de bordes (filtros de Sobel y umbralizado posterior) para codificar imágenes a partir de la transformada wavelet packet a varios niveles y seleccionando las subbandas de mayor relevancia en contenido de información.

Tras la compresión puede ser necesario recuperar la señal o imagen inicial. Mallat y Zhong (1992) detallan un algoritmo para reconstruir señales unidimensionales e imágenes a partir de sus puntos de variación de picos o filos, ya que éstos pueden ser detectados a partir de los máximos locales de su transformada wavelet. Serrano (2004) introduce las ideas matemáticas básicas para la aplicación de la transforma wavelet al diseño de estrategias analíticas para caracterizar los parámetros principales en señales de emisión acústica y proceder a su compresión y reconstrucción.

Las señales e imágenes pueden presentar a veces interferencias de diversa naturaleza (sistemáticas y propias del sistema captador de señales o aleatorias) que se plasman como ruido y que generalmente interesa eliminar o reducir en la medida de lo posible. Abrishami et al. (2004) presentan un método mejorado para la reducción del ruido gaussiano (o moteado o speck/e) basado en la transformada wavelet. Para ello transforman logarítmicamente las imágenes y las descomponen según el algoritmo clásico de Mallat empleando como wavelet madre la función laplaciano del gaussiano (LoG).

Si se trabaja con imágenes médicas las herramientas wavelets pueden aplicarse también para realizar un filtrado y eliminar el ruido. Pérez et al. (2001) lo consiguen hacer en una serie de imágenes médicas, mediante la implementación de un algoritmo de cálculo basado en la transformada wavelet con la base de funciones Haar. El objetivo final de este trabajo consiste en la mejora de la relación señal-ruido de imágenes mediante la aplicación de la transformada discreta wavelet 2D de Haar y la evaluación de la modificación del espectro de potencias de la imagen por la aplicación de ese método de filtrado. Bertand et al. (1992) también aplican la transformada wavelet discreta al filtrado de perfiles eléctricos en señales del cerebro con la misma finalidad.

En cuanto a climatología, Chane-Ming et al. (1997) aplican la transformación directa wavelet continua, el análisis multiresolución y la wavelets packet para estudiar las características de las ondas verticales (longitud de onda y velocidad) frente al tiempo y la 
altura de la atmósfera media (30-60 km de altura) sobre perfiles verticales de perturbación de temperaturas proporcionados por un Lidar Rayleigh.

En oceanografía, Chapron y Bliven (1992) presentan una aplicación de la transformada wavelet para obtener información instantánea en cuanto a tiempo-frecuencia de datos de altura de las olas del mar. Los resultados sirven para interpretar la dispersión en señales radar sobre diversos estados de la superficie del agua. David y Chapron (1992) aplican la transformada wavelet al análisis de señales de sonar marinas para detectar partículas marinas, sus características y su volumen. Nicolas et al. (1992) emplean un método basado en redes neuronales y wavelet packet para detectar y clasificar ruidos submarinos variables, debidos básicamente a seres vivos, intentando diferenciarlos de otros sonidos casi estacionarios o constantes como puedan ser los debidos a fenómenos oceanográficos, geológicos o humanos.

En astronomía, Graps (1995) caracteriza el comportamiento en cuanto a autosimilitudes en series temporales de datos obtenidos por sensores de rayos $X$ astronómicos con oscilaciones casi periódicas y ruido de muy baja frecuencia, aprovechando la potencia del análisis wavelet de poder procesar información a diferentes escalas. Slezak et al. (1992) describen un método para la detección automatizada y caracterización de todos los componentes estructurales presentes en un catálogo visual de galaxias, es decir, emplean la transformada wavelet para el análisis local de la distribución de galaxias.

Tsolmon (2003) plantea el empleo del análisis wavelet, mediante sus posibles tipos de transformadas, para la extracción de objetos en imágenes LIDAR, modelando las características de los objetos e intentando extraerlas mediante el análisis wavelet, para posteriormente segmentar el espacio de características mediante técnicas de clustering.

\subsection{Observaciones sobre los métodos de análisis de textura}

Quizás una de las primeras consideraciones a la hora de sacar conclusiones u observaciones sobre el estado actual de los métodos de análisis de texturas es que la mayor parte de los trabajos se han realizado sobre imágenes con texturas homogéneas o imágenes artificiales y en muy pocos casos sobre datos reales de la superficie terrestre, obteniendo resultados sobre las primeras mucho mejores que los obtenidos sobre texturas reales. Pese a que la naturaleza variable de los elementos que cubren el territorio conlleva 
una dificultad inherente, en la parte de la técnica en la que este trabajo se enmarca no tendría sentido emplear otros datos que no fuesen imágenes reales del terreno.

También se aprecia que ciertos métodos propuestos consideran algunas premisas a priori que no necesariamente se cumplen sobre todas las imágenes. Una de ellas se deduce al analizar los métodos estructurales, los cuales intentan identificar ciertos aspectos morfológicos en las primitivas de las texturas que no siempre es posible localizarlos por la propia naturaleza irregular de la textura concreta. Otra presunción se encuentra en el análisis fractal tradicional, mediante el cual se supone que las variaciones de iluminación y contraste no afectan de manera importante y que las texturas presentan similar rugosidad sobre un amplio número de escalas, cuando es evidente que a determinadas escalas se pierde la primitiva de una textura.

A la hora de realizar una clasificación y discriminación de texturas es importante considerar la propiedad de invarianza a la traslación, es decir, que una textura sea estacionaria y pueda ser discriminada tanto si está girada y/o desplazada sobre la imagen como si no. Cualquier método que se aplique ha de tener en cuenta este requisito y no todos lo cumplen, como algunos algoritmos de la transformada wavelet o algunos métodos estructurales.

Es notable el déficit de acierto en la discriminación de las zonas frontera entre superficies de diferentes texturas que demuestran prácticamente todos los métodos. Pese a que la literatura propone ciertos modelos particulares, el problema sigue estando presente y sigue siendo de compleja y no siempre precisa resolución. En el presente trabajo se proponen algunas formas de abordar este problema.

Los diversos métodos citados y considerados difieren de forma radical en muchos de sus planteamientos, en su puesta en práctica, sus requerimientos y sus resultados. Sería difícil intentar jerarquizarlos en función de su fiabilidad, por lo que no se puede decir que haya un método mejor que el resto. Hay diferentes posibilidades y la elección de uno u otro no es una decisión sencilla y directa.

Entrando más específicamente en ciertos aspectos de los métodos, se observa que los estadísticos pueden requerir de una preselección de variables para obtener buenos resultados, ya que a veces la gran cantidad de ellas puede ocasionar una disminución de los aciertos. Como aspecto positivo de este grupo de métodos se puede decir que permiten integrar variables de forma coherente con otro tipo de información geoespacial (variables topográficas derivadas de $\mathrm{MDE}$, información multiespectral, índices de vegetación, etc.).

Los métodos estadísticos también pueden ampliarse a enfoques geoestadísticos y más concretamente al estudio del semivariograma de la distribución de niveles de gris en 
el vecindario de un píxel, con lo que se consigue un conjunto de variables mayor y con más capacidades de estudio.

En la construcción de la MCNG puede tener influencia el número de niveles de gris considerado, ya que algunas características se comportan mejor con pocos niveles de gris (entropía), mientras que otras lo hacen mejor con una radiometría mas detallada (más niveles de gris) como ocurre con el momento de diferencia inverso (Clausi, 2001). Esta apreciación ha sido tenida en consideración a la hora de analizar los datos en este trabajo.

Los filtros de Gabor tienen la limitación de que no pueden resolver en su totalidad el problema de la clasificación de texturas. No son ortogonales y ello genera características redundantes en diferentes escalas e importantes correlaciones entre ellas. Además, dado que las altas frecuencias de una imagen son extraídas por filtros pequeños y las bajas por filtros grandes, su uso está más indicado para el caso de la segmentación, donde el tamaño de la ventana no está predefinido.

Comparando algunos métodos entre sí, se observa que las variables texturales derivadas de los campos aleatorios de Markov son bastante diferentes a las de Gabor y MCNG, ya que las primeras se ajustan mejor a una distribución gaussiana de los niveles de gris. No existe por tanto relación entre las variables de MRF y las de Gabor o MCNG, por lo que su empleo conjunto no apunta buenas expectativas.

De forma resumida, se puede decir que los métodos estadísticos, estructurales y basados en modelos se aplican en el dominio espacial. Pero puede ocurrir que en determinadas ocasiones interese más aplicar algún método basado en transformaciones al dominio de la frecuencia, por el hecho de que la información espacial no aporte suficiente capacidad de discriminación y sea la información frecuencial la que sí lo haga.

Es conocida la limitación de localización espacial que presenta la transformada de Fourier, generando a veces resultados poco precisos. Otras transformadas, como la de Gabor, realizan una mejor localización espacial, pero su empleo está limitado por la resolución en la cual se pueden localizar las estructuras espaciales en las texturas naturales. Esta limitación es solventada por la transformada wavelet al presentar dos rasgos importantes en su aplicación:

10 Permite variar la resolución espacial y representar texturas de diversas naturalezas.

$2^{\circ}$ Hay un amplio abanico de funciones base wavelet, de tal manera que cada aplicación práctica se puede realizar con la función que a priori genere mejor resultado. 
Si se pretende realizar una clasificación de texturas, tras haber determinado las variables texturales de una imagen, sea por el método que sea, se debe definir un clasificador que realice la asignación cualitativa a cada píxel de entrada. Son muchos los métodos de clasificación existentes y al igual que con los modelos de análisis textural, no hay uno mejor que el resto, sino que la realidad de cada situación debe condicionar la elección de uno u otro. En la mayor parte de las ocasiones se emplea el clasificador de máxima probabilidad, basado en la regla de decisión de Bayes, por su sencillez de aplicación y por sus ventajas inherentes y conocidas (Richards, 1999).

Sin embargo, lo que no debe hacerse, como a veces ocurre, es evaluar los resultados de una clasificación a partir de las mismas muestras empleadas en el entrenamiento del clasificador. Esta práctica, constatada en algunos trabajos (Chan y Kuo, 1993, Weszka et al., 1976), conlleva a obtener resultados muy buenos pero irreales y muy poco fiables o consistentes.

A modo de conclusión y dado que es algo constatado en la revisión bibliográfica llevada a cabo en el marco de este trabajo, se puede afirmar que el método estadístico de variables texturales derivadas de la MCNG es el que mejor se comporta y mejores resultados proporciona. También se aprecia que el método más novedoso y con mejores expectativas de aplicación en un gran abanico de áreas técnicas es la transformada wavelet. Estas dos evidencias son las que han marcado el hilo argumental de esta tesis: aplicación de técnicas basadas en funciones wavelet al análisis de texturas y su implementación con otras variables estadísticas, principalmente derivadas de la MCNG. 
Antes de entrar de lleno en los capítulos centrados en el fundamento teórico, metodologías de ensayos y datos empleados, es importante delimitar lo más explícitamente posible cuáles son los objetivos de este trabajo para poder entender con mayor claridad su justificación.

\subsection{Objetivos generales y específicos}

Este documento surge en el marco de los trabajos del grupo de investigación "Cartografía Geo-Ambiental y Teledetección" de la Universidad Politécnica de Valencia. Desde hace algún tiempo, una de las líneas de investigación desarrolladas ha sido la centrada en el análisis de texturas. Por otro lado, en la revisión de antecedentes sobre el estudio de texturas del capítulo anterior se aprecia que son muchos los intentos por comparar métodos de trabajo sobre determinados datos y problemas y los resultados y conclusiones no son plenamente coincidentes (incluso, a veces, son contradictorios). Con estas premisas se puede hablar de unos objetivos globales de este trabajo, prolongación de otros ya cumplidos y constatados, y de otros más específicos y particulares, que se deben considerar como elementos más concretos de ensayo y evaluación y que pretenden mejorar metodologías y procesos previos. 
La Teledetección se basa en el empleo de información suministrada por diferentes sensores en forma de imágenes digitales para la extracción de todo tipo de información directa y derivada. Una de las aplicaciones más comunes sobre esos datos consiste en la identificación lo más automática posible de las diferentes cubiertas y usos del suelo que se encuentran en dicha imagen, generando modelos temáticos en forma de imágenes clasificadas. Sin embargo, la mayor parte de los trabajos sobre texturas se han realizado sobre imágenes sintéticas que presentan texturas con muy poca variabilidad y en muy pocos casos sobre datos reales de la superficie terrestre. Esto justifica el que se busque, de forma específica, la evaluación de diversas clasificaciones sobre varios tipos de imágenes naturales, bien fotogramas aéreos digitalizados o bien imágenes de satélite de alta resolución espacial. Estos datos conllevan la dificultad propia de la naturaleza variable de los elementos que cubren el territorio, donde pueden influir en gran medida factores específicos de sus texturas como tamaños, formas, colores, especies vegetales, estado fenológico de cada especie, afección por plagas, etc.

Para llevar a cabo una clasificación, partir de la información multiespectral por sí sola puede ser suficiente en determinados casos. En otros, el empleo de las características de textura obtenidas de la imagen mejora sensiblemente los resultados obtenidos y justifica todas las rutinas necesarias para obtener esas características texturales. Esto permite introducirnos en los diferentes métodos de análisis texturales que, aplicados sobre un conjunto de imágenes raster provenientes de diferentes sensores y con desiguales características, complementan a los multiespectrales.

Conocidos son los métodos estadísticos de $1^{\mathrm{er}}$ y $2^{\circ}$ orden (ocurrencias y coocurrencias), las transformadas de Gabor y wavelet, así como los filtros de Laws. Las variables texturales de ellos derivadas se detallan con detenimiento en el capítulo metodológico, así como otras definidas a partir de los histogramas o de los propios valores de la imagen de partida. Uno de los objetivos globales de este trabajo es valorar qué métodos de análisis caracterizan mejor a las diferentes texturas y si todas las variables contribuyen de igual manera a la discriminación y clasificación de las coberturas.

Se ha observado que en en la mayor parte de los estudios revisados no se han tenido en consideración algunos parámetros metodológicos como resolución espacial o radiométrica o tamaño del vecindario, cuando se ha demostrado que en determinadas ocasiones puede ser interesante su consideración a priori. A continuación se justifica el por qué de su estudio con anterioridad a los análisis texturales:

- Los datos geo-espaciales en formato digital permiten remuestreos para modificar la resolución. Al variar el tamaño del píxel se pueden tener varias imágenes de una misma porción del terreno con diferentes patrones espaciales. Es importante 
averiguar cuál es la resolución espacial que optimiza el análisis de la mayor parte de las texturas en casos concretos. Ello se puede lograr evaluando el método de cálculo de varianza local.

- Al construir la MCNG de una imagen puede tener mucha influencia el rango radiométrico (o rango de niveles digitales), ya que algunas características se comportan mejor con pocos niveles de gris, mientras que otras lo hacen mejor con más niveles. Este hecho justifica la necesidad de determinar la resolución radiométrica óptima para un problema de clasificación concreto.

- Cada superficie tiene un patrón espacial de diferente tamaño al de otras. Un vecindario de cálculo pequeño para una textura con grandes elementos no permitirá su correcto análisis y viceversa. Es importante conocer el tamaño del vecindario óptimo para cada caso concreto.

La transformada wavelet presenta buenas perspectivas para analizar texturas al permitir variar la resolución espacial, representar texturas de diversa naturaleza a varios niveles y usar un amplio grupo de funciones base wavelet de tal manera que cada aplicación práctica se pueda realizar con la función que, a priori, genere mejor resultado. Es necesario estudiar la transformada wavelet, valorando de qué manera mejora este método de análisis a otras técnicas, qué aporta, cuando puede ser útil y cómo se debe aplicar.

Son muy pocos los ensayos realizados con diferentes tipos de transformada wavelet y posibles niveles de descomposición sobre imágenes obtenidas mediante sensores aéreos o de satélite. Tampoco se ha probado la influencia de las diferentes familias de funciones wavelet sobre dichas imágenes. Estos parámetros pueden condicionar las variables de textura derivadas. De forma más específica, se han planteado otros objetivos:

- Tal y como se ha visto en la revisión bibliográfica y se verá en el capítulo referido a las bases teóricas de la transformada wavelet, son varias las alternativas existentes para su aplicación en texturas, tanto sea en forma continua como discreta, redundante o no, etc. En el presente trabajo se pretende comparar tres métodos de aplicación de la transformada wavelet, el discreto, el algoritmo llamado "à trous" $y$ el algoritmo redundante llamado "shift4" y contrastar la capacidad de cada uno de ellos para destacar las características texturales de las imágenes.

- Dado que el comportamiento de la transformación difiere sensiblemente dependiendo de la función wavelet base considerada en los cálculos, es necesario evaluar si existe una función o familia de funciones óptima y determinar si el 
comportamiento de todas ellas es similar o si trasladan sus parámetros específicos a la textura sobre la que se apliquen. Para ello se analizan las funciones más referenciadas en la literatura y algunas otras cuyo comportamiento, a priori, apunta hacia buenos resultados.

- La transformada wavelet permite realizar descomposiciones y posteriores reconstrucciones de imágenes en un rango de escalas definido por sus propias dimensiones. En cada una de esas escalas o niveles se pueden extraer informaciones específicas sobre las texturas, tanto de altas como de bajas frecuencias, coeficientes horizontales, verticales o diagonales, etc. Se pretende contrastar cómo la información útil varía con el nivel de la transformada, cuál es el más idóneo y si se produce el mismo resultado.

- Estudio de los resultados en diferentes tipologías de cubiertas de la superficie, tanto naturales como afectadas por la acción del hombre.

Para concluir con esta definición de objetivos, reseñar que es evidente el irresuelto problema de la asignación temática en las áreas periféricas de las texturas, las zonas frontera o de bordes. Si bien hay métodos que se comportan algo mejor, la mayor parte de los procedimientos de estudio considerados muestran un porcentaje de acierto bastante reducido en su discriminación. Se pretende diseñar posibles algoritmos de trabajo que permitan minimizar el problema de la incorrecta clasificación de las zonas limítrofes entre dos clases contiguas. 


\section{Capítulo IV}

\section{La Transformada Wavelet}

Tal y como el apartado de análisis de texturas establecía, son muchas las aplicaciones de la transformada basada en funciones wavelet y algunas se relacionan de forma directa con otros métodos de extracción de características texturales.

Dada la importancia evidente de esta herramienta y las posibilidades prácticas apuntadas, se considera importante tener una noción clara de lo que es su aspecto teórico. En el presente capítulo se pretende que quede suficientemente clara toda la base teórica de esas funciones así como la forma de ser puesta en práctica mediante transformaciones. Para ello hay que empezar por lo más básico, entender qué son las funciones wavelet, conocer su historia, su relación con bancos de filtros, el primer acercamiento a la transformada realizado por Haar en 1909, la transformada base y sus propiedades y los tipos de transformada o formas de ser aplicada que pueden aparecer en la literatura específica. Estos serán, por tanto, los apartados principales de este capítulo.

\subsection{Introducción a la teoría Wavelet: historia y definiciones}

En la historia de las matemáticas, el análisis wavelet no tiene un único punto de partida sino que han sido varias ramas de desarrollo, convergentes en tiempos no demasiado lejanos. Si bien la mayor parte del trabajo fue realizado en los años 30 del siglo 
pasado, existen indicios anteriores que apuntaban a una nueva herramienta matemática por desarrollar en aquel entonces. Son los siguientes:

- Se puede decir que el punto de partida matemático que conduciría a la teoría wavelet parte de Joseph Fourier (1807), con sus teorías del análisis de frecuencia. Él afirmaba que cualquier función $f(t)$ periódica cada $2 \pi$ es el resultado de la suma ponderada de senos y cosenos siguiente:

$$
f(t)=a_{0}+\sum_{k=1}^{\infty} a_{k} \cos k \omega_{0} t+b_{k} \operatorname{sen} k \omega_{0} t
$$

Esta premisa jugó un papel esencial en la evolución de las ideas matemáticas en torno a las funciones, si bien fue denegada la publicación de sus trabajos por Lagrange, Legendre y Laplace hasta 1822 , cuando fueron finalmente publicados.

Sus teorías han sido adoptadas tal y como fueron formuladas hasta que en 1965, Cooley y Tukey desarrollaron la transformada rápida de Fourier (Fast Fourier Transform).

- Después de 1807, explorando el significado de las funciones, la convergencia de las series de Fourier y los sistemas ortogonales, los matemáticos gradualmente fueron orientándose desde la noción de análisis de frecuencia a la de análisis de escala. ¿Cómo? Construyendo una función, ajustándola en alguna medida y cambiando su escala.

La primera mención de "wavelet" aparece en el apéndice de la tesis de Alfred Haar (1909), convirtiéndose en el primer referente a las wavelets, al trabajar con funciones de soporte compacto, es decir, que se anulan fuera de un intervalo finito. Desafortunadamente la wavelet de Haar no es continuamente diferenciable, por lo que sus aplicaciones se vieron limitadas.

- En la década de 1930, varios grupos, trabajando independientemente, investigaban la representación de funciones usando bases de escala variable. Un físico llamado Paul Levy usó funciones base de escala variable de Haar mientras investigaba el movimiento Browniano. Encontró la base de Haar superior a las funciones base de Fourier para el estudio de pequeños detalles en la señal.

Otra investigación de los años 30, llevada a cabo por Littlewood, Paley y Satín se basaba en el cálculo de la energía de una función $f(x)$ :

$$
\text { energía }=\frac{1}{2} \int_{0}^{2 \pi}|f(x)|^{2} d x
$$


El cálculo producía diferentes resultados si la energía se calculaba concentrada alrededor de pocos puntos o a lo largo de un gran intervalo. Este resultado llamaba la atención de los científicos ya que esto indicaba que la energía no se conservaba. Posteriormente, los investigadores descubrieron una función que podía variar en escala conservando su energía. Este trabajo proporcionó a David Marr un algoritmo efectivo para el procesamiento numérico de imágenes a principios de los años 80 .

- En 1946, Gabor había obtenido la Short Time Fourier Transform (STFT), la cual permite analizar:

- Componentes de altas frecuencias usando pequeñas ventanas, o bien

- Componentes de bajas frecuencias usando ventanas mas anchas.

- Además de lo anterior, Gabor introdujo una familia de wavelets no ortogonales con soporte infinito basadas en las traslaciones sobre una función gaussiana (Seppälä, 2001).

- El origen de la transformada wavelet se fecha a finales de los años 70, cuando $\mathrm{J}$. Morlet (ingeniero geofísico) tenía planteados ciertos problemas:

- $\quad$ El análisis tiempo-frecuencia de señales con componentes de altas frecuencias en pequeños fragmentos de tiempo y componentes de bajas frecuencias en amplios períodos de tiempo.

- Se podía aplicar sobre esas señales la STFT por separado, pero no sobre ambas a la vez. La solución que halló usaba funciones de diferente soporte o amplitud para secciones de la señal con diferentes contenidos de frecuencia.

- Las diferentes amplitudes eran generadas por dilatación o contracción de un pequeño prototipo de señal oscilatoria. De ello proviene el nombre de wavelet, el cual se podría traducir por "pequeña onda".

- Según la teoría desarrollada por David Marr a principio de los años 80, el tratamiento de imágenes en el sistema visual humano tiene una estructura jerárquica compleja y consta de varios niveles de tratamiento. El "tratamiento de bajo nivel", proporciona una representación sobre la que se realizan las etapas posteriores del tratamiento de la información visual.

Partiendo de un análisis muy preciso de las capacidades de las células ópticas, Marr llegó a la hipótesis de que la representación proporcionada por el sistema retiniano está formada por una sucesión de diagramas efectuados a escalas diferentes, que constituyen una progresión geométrica. Esos diagramas están constituidos por líneas, denominados por Marr "zero crossings". La representación de base está relacionada 
con la detección de cambios de intensidad, y la detección de estos cambios está determinada por dos ideas:

- Los cambios de intensidad ocurren a escalas diferentes, de forma que su detección óptima exige la utilización de operadores de magnitudes diferentes.

- Un cambio súbito de intensidad da lugar a un pico o valle en la derivada primera o, equivalentemente, a un "zero crossing" en la derivada segunda.

Estas ideas sugieren que para detectar cambios de intensidad de manera eficiente se debe buscar un filtro con dos características fundamentales:

(1) Debe ser un operador diferencial.

(2) Debe poderse reescalar para actuar a cualquier escala deseada.

El operador que satisface las condiciones expuestas de forma mas satisfactoria, es el filtro $\Delta G$, donde $\Delta$ es el operador Laplaciano

$$
\Delta=\frac{\partial^{2}}{\partial_{x}^{2}}+\frac{\partial^{2}}{\partial_{y}^{2}}
$$

y G es la distribución gaussiana normal:

$$
G(x, y)=e^{-\frac{x^{2}+y^{2}}{2 \sigma^{2}}}
$$

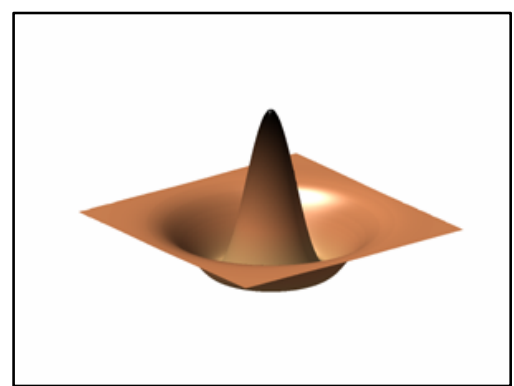

Figura 4-1. Operador Laplaciano del Gaussiano.

Tal como se observa en la figura 4-1, $\Delta G$ es un operador de simetría radial, con la forma de un sombrero mejicano ("Mexican Hat"). Partiendo de ella se define la wavelet de Marr como:

$$
\psi(x, y)=-\frac{1}{\pi}\left(1-\frac{x^{2}+y^{2}}{2}\right) e^{-\frac{x^{2}+y^{2}}{2}}
$$


La teoría de Marr, explicada sobre imágenes, permite entender el comportamiento de las funciones wavelet: Las imágenes naturales no tienen una clara estructura oscilatoria como las ondas. Al contrario, el contenido de las imágenes es una mezcla de varias texturas diferentes que definen bordes entre ellas. Los objetos pueden formar estructuras cuya identificación depende en gran medida de la escala a la que se analice la imagen. Muchas de esas estructuras son identificables a pequeñas escalas y son de bajo contraste o amplitud, mientras que otras pueden ser claras a media o gran escala por tener mayor contraste. Una representación de esas imágenes a diferentes escalas, con pequeños cambios en el contraste además de las mayores escalas permitiría un estudio más preciso de la información contenida en ellas. Esta idea se apoya en el hecho de que las imágenes tienen estadísticas muy variables en diferentes posiciones, con zonas homogéneas, bordes y zonas heterogéneas. Por contra, una imagen en el dominio wavelet, presenta estadísticas locales consistentes y constantes en cualquier parte y los coeficientes resultantes de la transformación son próximos a cero en su mayoría, lo cual representa ciertas ventajas.

- También al principio de los años 80, Grossmann (físico teórico) formalizó la transformación de Morlet e ideó la transformación inversa. Acababa de nacer la primera Transformada Wavelet. En 1984 Morlet y Grossman publican un artículo donde introducen definitivamente el término "wavelet" en el lenguaje matemático.

- Se redescubrió el trabajo de Calderón (1964) sobre análisis de armónicos de tal manera que el siguiente paso fue dado por Yves Meyer en 1984, encontrando:

- $\quad$ Similitudes entre el trabajo de Calderón (1964) y Morlet.

- $\quad$ Redundancia en la elección de las funciones base planteada por Morlet.

- Que las funciones base wavelet ortogonales tienen una mejor localización en el tiempo y en la frecuencia.

- Fueron reaplicados ciertos trabajos previos como el de J.O. Stromberg (1980) sobre las bases de funciones; y sobre todo el trabajo de Alfred Haar del año 1909 sobre bases de funciones ortogonales. En la actualidad se consideran las bases de Haar como las wavelets ortonormales más simples conocidas.

- Evolución hacia el análisis de señales discretas. En el año 1976 Croisier, Esteban y Galand desarrollaron la descomposición diádica de una señal discreta creando el Análisis Multiresolución (MRA), mediante el empleo de Quadrature Mirror Filters en forma de banco de filtros. 
- En las dos últimas décadas varios han sido los investigadores que han trabajado sobre la implementación en señales discretas. Se pueden destacar los resultados de:

- Stéphane Mallat en 1986, cuando demuestra que la base de Haar, las frecuencias de Gabor, así como muchas otras investigaciones están todas relacionadas con algoritmos basados en wavelets.

- $\quad$ Stéphane Mallat junto a Meyer (1986) sobre el análisis multiresolución y sobre la transformada wavelet discreta (DWT) y sobre algoritmos para su cálculo.

- Ingrid Daubechies, sobre discretización del tiempo y escala de la transformada wavelet, sobre los Wavelets Frames (1986) o sobre bases ortonormales wavelets de soporte compacto (1988).

- Martin Vetterli y Jelena Kovacevic, sobre wavelets y bancos de filtros (1986); sobre la reconstrucción perfecta de señales empleando bancos de filtros FIR (1988), sobre la descomposición subbanda o sobre bancos de filtros multidimensionales (1992).

- A principios del año 2000 fue presentado el nuevo estándar de codificación de imágenes JPEG2000 después de importantes esfuerzos centrados en la teoría wavelet, de tal manera que este nuevo formato se basa en el uso de bancos de filtros wavelet y un avanzado esquema de cuantización llamado EBCOT (Larsen, 2001).

- En el momento presente, la aplicabilidad de la transformada wavelet con diversas variantes es creciente en diversos campos científicos y tecnológicos.

Como se puede apreciar tanto en el estudio de antecedentes del capítulo II como en la reseña histórica anterior, han sido numerosos los autores que han trabajado con funciones y transformadas wavelet. Es fácil encontrarse con diferentes definiciones de función wavelet y de cómo se aplica y aunque el significado es básicamente el mismo en todas, existen diferencias en ellas según intenten explicar su forma ondulatoria, o su tamaño (soporte), o sus frecuencias o las descomposiciones que pueden generar. Algunas de ellas son las que se comentan en los siguientes párrafos.

Si se tiene en cuenta la forma de la función, la palabra wavelet se podría traducir al castellano por "ondículas" o mejor expresado por "onda ${ }^{1}$ pequeña", si bien se considera mejor adoptar el término anglosajón como tal y evitar traducciones que no son del todo

\footnotetext{
${ }^{1}$ Como bien es conocido, una onda es definida como una función oscilante del tiempo o del espacio, tal como una onda senoidal y algunas transformadas, como por ejemplo la transformada de Fourier, emplean funciones ondulatorias.
} 
rigurosas. Una wavelet es una "función con forma de onda y de pequeña dimensión, finita y nula fuera de un determinado intervalo". La forma de onda implica una integración a cero (oscilando por encima y por debajo del eje de abscisas $X$ ) y su tamaño pequeño implica que su amplitud decrece a medida que se aleja de su origen. También es definida como "forma de onda de duración limitada que tiene un valor medio cero" (Pajares y de la Cruz, 2001), o incluso como "pequeña onda que tiene su energía concentrada en el tiempo para servir como herramienta de análisis de fenómenos cambiantes, no estacionarios 0 variables en el tiempo" (Burrus et al., 1998).

En cuanto al soporte o dimensión de una función wavelet, se puede decir de ésta que es una "función que tiene un soporte compacto suficiente tanto en el tiempo como en el dominio de la frecuencia y presenta un comportamiento oscilatorio con una media igual a cero" (Van de Wouwer, 1998). También se puede decir que las funciones wavelet son "funciones de soporte compacto, a diferencia de las funciones base de la transformada de Fourier que tienen soporte infinito". Este soporte compacto permite a la transformada wavelet trasladar una función desde el dominio temporal hasta el dominio frecuencial (Mangin, 2001) de tal manera que posea localización frecuencial y temporal a la vez.

Analizando el contenido de frecuencia, una función wavelet es la base para "cortar datos o funciones en diferentes componentes de frecuencia y estudiar cada uno de esos componentes con una resolución ajustada a su escala" (Daubechies, 1992, Graps, 1995). Para una señal cambiante en el tiempo (como un sonido de amplitud variable) la transformada wavelet depende de dos variables: la escala (o frecuencia) y el tiempo y es un buen análisis para la localización tiempo-frecuencia. Las imágenes naturales son una mezcla de texturas suaves o de bajas frecuencias, como el cielo, la superficie del agua, superficies homogéneas y uniformes, etc., además de otras texturas más cambiantes en menor espacio, es decir, de mayores frecuencias de cambio por su cantidad de bordes. Por ello su interacción con funciones wavelet permite "capturar las altas frecuencias de zonas de bordes y las bajas de zonas mas homogéneas, agrupando la mayor parte de la energía de la imagen en una pequeña porción de los coeficientes de la transformación" (Xiong y Ramchandran, 2000).

Una propiedad importante de las funciones wavelet es su capacidad de localizar las características espectrales de una señal en el tiempo o el espacio (Materka y Strzelecki, 1998), cosa que otras transformadas (como la de Fourier) no pueden hacer. Si se desea examinar el tiempo y frecuencia de una señal de forma simultánea se puede expandir esa señal en términos de "funciones oscilatorias y localizadas en el tiempo", es decir, funciones wavelet. 
Las funciones wavelet son la base para poder aplicar el análisis o transformada del mismo nombre, la cual permite descomponer señales jerárquicamente (Stollnitz et al., 1995) y su posterior reconstrucción, además de extraer ciertos tipos de información de ellas. Las wavelet son "herramientas para la descomposición de señales, tales como imágenes en una jerarquía de resoluciones crecientes de tal manera que al considerar niveles de mayor resolución, se obtengan más y más detalles de la imagen" (Xiong y Ramchandran, 2000).

Una cualidad muy importante de las funciones wavelet es la de poder analizar una señal a diversas escalas. En el análisis wavelet, la escala juega un papel muy importante, ya que los diversos algoritmos procesan los datos en diferentes escalas y resoluciones espaciales. Si se observa una señal a una escala pequeña (poca resolución) se apreciarán únicamente aquellas entidades de mayores dimensiones. De igual manera, si se observa la misma señal a una escala grande (alta resolución) se podrán distinguir pequeños elementos o partes de la señal (Graps, 1995). Por ello, analizar una señal $f(t)$ consiste en su descomposición en una serie de versiones escaladas y trasladadas con el objetivo de representarla como la superposición de un conjunto de funciones base o wavelet escaladas y trasladadas (Pajares y de la Cruz, 2001).

Para poner en práctica el citado análisis wavelet se ha de adoptar una función wavelet prototipo llamada "wavelet madre" a partir de la cual se deriva toda una familia de versiones trasladadas y escaladas. El análisis de una señal en función del tiempo $f(t)$ se realiza desde dos puntos de vista: el análisis temporal, mediante una versión de la función madre contraída y de alta frecuencia; mientras que el análisis de frecuencias se desarrolla con una versión dilatada y de baja frecuencia. Como la citada señal original $f(t)$ puede ser representada en términos de una expansión wavelet (usando coeficientes en una combinación lineal de las funciones wavelets), las operaciones sobre los datos pueden ser realizadas empleando sólo los correspondientes coeficientes wavelet (Graps, 1995).

\subsection{Bancos de filtros}

Tal y como se detalla en el capítulo "Metodología" la forma más sencilla y frecuente de poner en práctica las propiedades que las funciones wavelet poseen para el estudio de texturas en imágenes consiste en aplicar convoluciones sobre ellas mediante filtros cuyos coeficientes son derivados de las funciones wavelet. Ese conjunto de filtros, tanto de descomposición como de reconstrucción o síntesis, se denomina banco de 
filtros y se considera oportuno conocer los rasgos básicos de ellos para poder entender cómo son puestos en práctica.

Una idea básica para procesos de filtrado es que la distribución de energía en el dominio de la frecuencia identifica a una textura. Por tanto, si el espectro de frecuencia es descompuesto en un número suficiente de subbandas, la energía de diferentes texturas serán desiguales (Randen, 1997). Aprovechando esta cualidad, se han diseñado varios tipos de bancos de filtros y entre ellos cabe citar los filtros separables de Laws (1980), los filtros circulares y en cuña (Coggins y Jain, 1985), los filtros diádicos de Gabor, los bancos de filtros críticamente muestreados para aplicar las wavelets, o los filtros que aplican la transformada discreta del coseno (DCT), por ejemplo.

\subsubsection{Preliminares sobre filtros}

Un filtro digital es una secuencia de valores que se emplea para destacar o suavizar ciertos aspectos en una señal, sea de una o dos dimensiones. En esencia, un filtro actúa sobre una señal mediante una convolución de ambos produciendo otra señal de salida diferente. El filtro es desplazado sobre la señal calculando un producto interno entre los coeficientes del filtro y aquellos de la señal sobre los que se encuentra el filtro. La representación digital de un filtro es conocida como impulse response o respuesta de impulso (o también respuesta impulsional, Mangin, 2001) y aquellos filtros que tienen un número finito de coeficientes son llamados Finite Impulse Response, filtros de respuesta de impulso finita, filtros finitos o simplemente filtros FIR. Los filtros con un número infinito de coeficientes se denominan filtros de impulso infinito, o filtros IIR. (Topiwala, 1998, Burrus et al., 1998).

Los filtros digitales pueden ser simétricos o no. Los filtros simétricos y especialmente los que tienen una forma con pico en el centro, tienen una serie de ventajas a mencionar: preservan la localización de las transiciones agudas en las señales y facilitan el tratamiento de sus bordes. Los filtros simétricos son a veces llamados de fase lineal, ya que si no lo son, su desviación es evaluada por la magnitud de desviación de su fase desde una función lineal. Además, existen dos tipos de filtros simétricos, los simétricos respecto del valor central del filtro (tienen dimensión impar) y por tanto sus coeficientes cumplen la relación $h(k)=h(-k)$, como por ejemplo el filtro de valores $(1,3,6,3,1)$; y los simétricos en mitad del filtro (dimensión par), que cumplen la relación $h(k)=h(-k-1)$, como por ejemplo $(-1,2,4,4,2,-1)$. Los filtros antisimétricos cumplen que $h(k)=-h(-k)$ o bien $h(k)=-h(-k-1)$, como por ejemplo $(1,2,3,-2,-1)$ o bien $(4,5,3,-3,-5,-4)$.

Del concepto de filtro se avanza al de banco de filtros, como conjunto de ellos que cumplen una finalidad dada. Los bancos de filtros son piezas elementales en la 
construcción de la transformada wavelet (Moulin, 2000). Un banco de filtros M-channel equivale a decir que tiene $M$ canales, es decir, se aplican M filtros (Nguyen, 1995) y el número de resultados del banco de filtros es $M$ (no significa que haya $M$ filtros distintos, sino que se aplican filtros un total de $M$ veces). A modo de ejemplo se puede adelantar que la transformada wavelet discreta diádica está basada en un banco de filtros de 2 canales.

En un banco de filtros en el que se defina un factor de remuestreo $N$ y $M$ sea el número de filtros aplicados, se pueden encontrar variedades en cuanto al número de canales (resultados). Así, el banco de filtros se puede denominar:

- Críticamente submuestreado (o máximamente dividido) si:

○ $\quad N=M$

- El número total de elementos de las subbandas es igual al número de elementos de la imagen inicial.

- No críticamente submuestreado o sobremuestreado (overcomplete u oversampled representations) (Vetterli, 1995), si:

$\circ \quad N<M$

- La expansión sobremuestreada de una señal se produce cuando se emplea un conjunto de funciones de expansión mayor de lo necesario, de tal forma que aunque esas funciones sean bases, son linealmente dependientes. Aplicar esa transformación en forma de bancos de filtros significa emplear un banco de filtros no críticamente submuestreados, es decir, un banco de $N$ filtros que tras ser aplicados son submuestreados por un factor $M$ tal que $N>M$. Con ello se cumplirá que el número resultante de todos los elementos de las subbandas es mayor al número de elementos de la imagen inicial.

El proceso de aplicar un banco de filtros es el equivalente al propuesto por González y Woods (2002) como "subband codding". Según estos autores, el subband coding es una de las formas de construir un Análisis Multiresolución (MRA), ya que una imagen se descompone en un grupo de componentes o subbandas con información particular de la imagen inicial y que pueden ser reagrupadas para reconstruir la imagen inicial sin error.

Ese objetivo se consigue procesando la señal inicial con un conjunto de filtros (banco de filtros) paso banda. Como el ancho de banda de las subbandas resultantes es 
menor del inicial, las subbandas pueden ser submuestreadas sin pérdida de información. La reconstrucción de la imagen requiere un proceso de sobremuestreo, filtrado y suma de los resultados parciales. La figura 4-2 muestra los principales componentes de un sistema de descomposición y reconstrucción con dos subbandas para $x(n)=(0,1,2,3, \ldots)$, señal unidimensional y discreta de ancho de banda limitado.

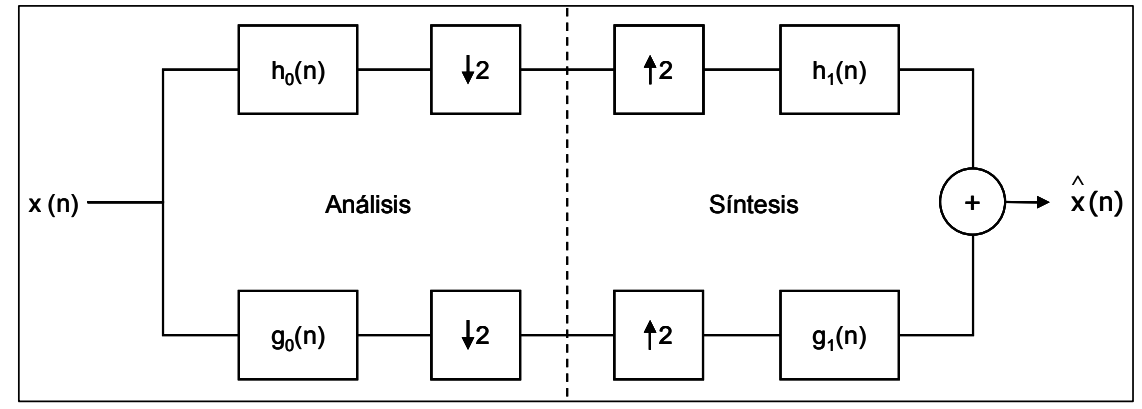

Figura 4-2. Banco de filtros de dos bandas o canales unidimensionales aplicado en análisis y síntesis de una señal.

La salida del sistema $\hat{x}(n)$ es obtenida mediante la descomposición de $x(n)$ en dos señales $y_{0}(n)$ e $y_{1}(n)$ aplicando dos filtros de análisis o descomposición $h_{0}(n)$ y $g_{0}(n)$ y un submuestreo; el posterior sobremuestreo y empleo de los filtros de síntesis o reconstrucción $h_{1}(n)$ y $g_{1}(n)$ y su combinación nos genera la señal de salida. Los filtros $h_{0}(n)$ y $g_{0}(n)$ son filtros de la mitad de ancho de banda y sus valores característicos vienen definidos por los coeficientes de un filtro de paso bajo $H_{0}$ y de paso alto $G_{0}$. El resultado del filtro de paso bajo $H_{0}$ es una aproximación de la señal de entrada, mientras que al aplicar el filtro de paso alto $G_{0}$ se obtienen las altas frecuencias o detalles de $x(n)$. De la correcta elección de los filtros $h_{0}(n), g_{0}(n), h_{1}(n)$ y $g_{1}(n)$ o alternativamente $H_{0}$, $G_{0}, H_{1}, G_{1}$, depende la reconstrucción perfecta de la señal o imagen inicial.

Cumpliendo la condición de biortogonalidad para conseguir la reconstrucción perfecta, se han logrado diferentes soluciones para que, partiendo de un filtro prototipo, el resto que conforman el banco de filtros se deriven de él. Así se pueden citar los Quadrature Mirror Filters (QMF) (Croisier, Esteban y Galand, 1976); los Conjugate Quadrature Filters (CQF) (Smith y Barnwell, 1986), también denominados por otros autores como Conjugate Mirror Filter (CMF), (Mallat, 1999, Burrus, 1998); y los filtros Ortonormales (base de la transformada wavelet rápida (FWT)), expresados en función de la transformada Z. Las relaciones fundamentales entre ellos se encuentran en la tabla 4-1.

Estos filtros son a menudo llamados filtros de energía complementaria, debido a que los dos filtros de paso bajo y los dos filtros de paso alto tienen la misma respuesta de 
frecuencia y entre los filtros paso bajo y paso alto se define la propiedad de energía complementaria siguiente, válida para todas las frecuencias:

$$
\left|h_{0}(n)\right|^{2}+\left|g_{0}(n)\right|^{2}=2
$$

siendo $h_{0}(n)$ y $g_{0}(n)$ los filtros bidimensionales de paso bajo y paso alto respectivamente (Moulin, 2000).

Además de tener energía complementaria, los filtros ortonormales cumplen con la propiedad de ortonormalidad. Esto significa que para una base de funciones ortonormal, el producto interno de cualquier función base consigo misma es la unidad.

\begin{tabular}{|l|l|l|}
\hline \multicolumn{1}{|c|}{ QMF } & \multicolumn{1}{c|}{ CMF (CQF) } & \multicolumn{1}{c|}{ Ortonormales } \\
\hline$H_{0}(z)$ & $H_{0}(z)$ & $H_{0}(z)=H_{1}\left(z^{-1}\right)$ \\
\hline$G_{0}(z)=H_{0}(-z)$ & $G_{0}(z)=z^{-1} H_{0}\left(-z^{-1}\right)$ & $G_{0}(z)=G_{1}\left(z^{-1}\right)$ \\
\hline$H_{1}(z)=H_{0}(z)$ & $H_{1}(z)=H_{0}\left(z^{-1}\right)$ & $H_{1}(z)$ \\
\hline$G_{1}(z)=-H_{0}(-z)$ & $G_{1}(z)=z H_{0}(-z)$ & $G_{1}(z)=-z^{-2 k+1} H_{1}\left(-z^{-1}\right)$ \\
\hline
\end{tabular}

Tabla 4-1: Relaciones entre los filtros para distintos bancos de filtros.

Tanto los QMF como los CMF realizan descomposiciones subbanda pero no se puede decir que sean la aplicación de la transformada wavelet, la cual se logra con los filtros ortonormales.

\subsubsection{Filtros QMF}

El efecto denominado aliasing está directamente relacionado con la densidad de muestreo de una señal, de tal manera que si una señal es muestreada con un número suficiente de valores, podrá ser reconstruida fiablemente y de forma inequívoca. Si por contra se toman pocos valores, pueden existir diferentes reconstrucciones consistentes con las muestras. Para evitar este efecto, el porcentaje de muestreo debe ser mayor o igual a un determinado umbral, llamado ratio Nyquist, el cual es el doble de la frecuencia del componente de mayor frecuencia de la señal (Ward, 2000).

Si un filtro paso bajo de descomposición $h_{0}$ utilizado es simétrico, $h_{0}(n)=h_{0}(-n)$, se les denomina filtros espejo (mirror). Si hay finitos coeficientes de $h(n)$ distintos de 
cero, entonces son filtros finitos FIR, si bien, al igual que los filtros Haar, los QMF pueden no tener una respuesta de impulso finita, es decir, puede no ser filtros FIR.

El primer esquema de descomposición subbanda (o subband coding) mediante bancos de filtros y que consigue evitar el efecto aliasing, fue propuesto por Esteban y Galand en 1977 y fue llamado Quadrature Mirror Filters (QMF) o traducido al castellano por algunos autores como "filtros espejo en cuadratura" (Colom, 2001). Consisten en un conjunto de filtros simétricos y finitos que permiten una reconstrucción adecuada de la señal inicial. Se puede resumir por tanto que los QMF permiten hacer descomposiciones de señales uni y bidimensionales en varias subbandas submuestreadas y reconstruirlas casi sin pérdida de información y sin efecto aliasing. La descomposición wavelet de una señal puede ser realizada convolucionándola con una familia de funciones derivadas de la wavelet madre, o bien usar los QMF para implementar un tipo de transformada wavelet en lugar de emplear explícitamente esa familia de funciones (Materka y Strzelecki, 1998).

Se pueden encontrar referencias al empleo de estos filtros en Randen (1997) y Randen (1999) donde se aplican los QMF en forma de filtros IIR y FIR de 8, 16 y 32 coeficientes en descomposiciones diádicas de niveles 3,4 y 5 y también como transformada wavelet packet.

Trabajando sobre los QMF, en 1984, Smith y Barnwell encontraron condiciones necesarias y suficientes para obtener filtros ortogonales de perfecta reconstrucción con una respuesta de impulso finita (FIR) y les llamaron Conjugate Mirror Filters (CMF).

\subsubsection{Filtros CMF (CQF)}

Los Conjugate Mirror Filters (CMF) son filtros ortogonales que hacen posible descomponer señales discretas en bandas de frecuencias separadas mediante bancos de filtros. Además se les considera como filtros de reconstrucción que tienen una respuesta de impulso finita (filtros con un número de coeficientes finito). Son filtros discretos cuya función de transferencia satisface la siguiente ecuación:

$$
\forall \omega \in R, \quad|\hat{h}(\omega)|^{2}+|\hat{h}(\omega+\pi)|^{2}=2 \quad \text { y } \quad \hat{h}(0)=\sqrt{2}
$$

donde se cumple que el filtro paso bajo de descomposición $h_{0}$ es igual al filtro paso bajo $h_{1}$ de reconstrucción y donde $\hat{h}(0)$ indica la transforma de Fourier de $h$ para la frecuencia $\omega=0$. Juegan un papel importante en el procesado de señales discretas, ya que hacen posible descomponer señales discretas en bandas de diferentes frecuencias mediante bancos de filtros. La condición anterior es la requerida para que se puedan generar 
wavelets ortogonales y conseguir una perfecta reconstrucción en el esquema de filtrado subbanda.

Estos filtros también son llamados Conjugate Quadrature Filters (CQF) y no solo consiguen una reconstrucción perfecta de la señal inicial sino que también eliminan el efecto aliasing al conseguirlo. Están directamente relacionados con los filtros ortonormales ya que cada base wavelet ortonormal genera un par de CQF, es decir, un esquema de filtrado y subbandas con reconstrucción exacta (Prasad, 1997).

\subsubsection{Filtros Ortonormales}

Bajo determinadas condiciones de los filtros, la transformada asociada con los bancos de filtros de descomposición y de reconstrucción es ortonormal, es decir, la energía de la imagen inicial es preservada al hacer la transformación y se consigue la reconstrucción perfecta de la señal. Cuando esa característica se cumple los filtros tienen una propiedad interesante: los filtros de reconstrucción o de síntesis son versiones invertidas en el tiempo de los filtros de análisis o descomposición (copias de modulo cruzado de los filtros de análisis con signos invertidos en algunos de sus términos); y los filtros paso alto son versiones moduladas de los filtros paso bajo.

Si se considera que $2 K$ es el tamaño o soporte del filtro, se puede observar que los filtros genéricos $H_{0}, G_{0}$ y $G_{1}$ son derivados de $H_{1}$ :

- $\quad H_{0}$ es el resultado de trasponer los términos o coeficientes de $H_{1}$.

- $\quad G_{1}$ se forma con los coeficientes traspuestos de $H_{1}$ pero cambiando el signo de los términos impares.

- $\quad H_{0}$ es el resultado de trasponer los términos o coeficientes de $G_{1}$.

Estas relaciones quedan particularizadas para sus términos individuales como:

$$
\begin{aligned}
& g_{1}(n)=(-1)^{n} \cdot h_{1}(2 K-1-n) \\
& h_{0}(n)=h_{1}(2 K-1-n) \\
& g_{0}(n)=g_{1}(2 K-1-n), \quad n=\{0, \ldots, K-1\}
\end{aligned}
$$

donde $h_{0}, g_{0}, h_{1}$ y $g_{1}$ son los coeficientes (o respuestas de impulso) de los filtros ortonormales definidos.

Las ecuaciones anteriores, relaciones fundamentales entre los filtros que conforma un banco de filtros, pueden ser explicadas por la aplicación directa e inversa de 
la transformada Z, (Topiwala, 1998), una generalización de la transformada discreta de Fourier sobre el modelo de análisis y síntesis de la figura 4-2.

Como ejemplo se pueden detallar de forma gráfica (figura 4-3) los coeficientes de los filtros ortonormales de 4 coeficientes expresados por Daubechies (1992) que claramente nos permite ver la modulación cruzada entre ellos y los cambios en los signos expresados por la ecuación (4-8).

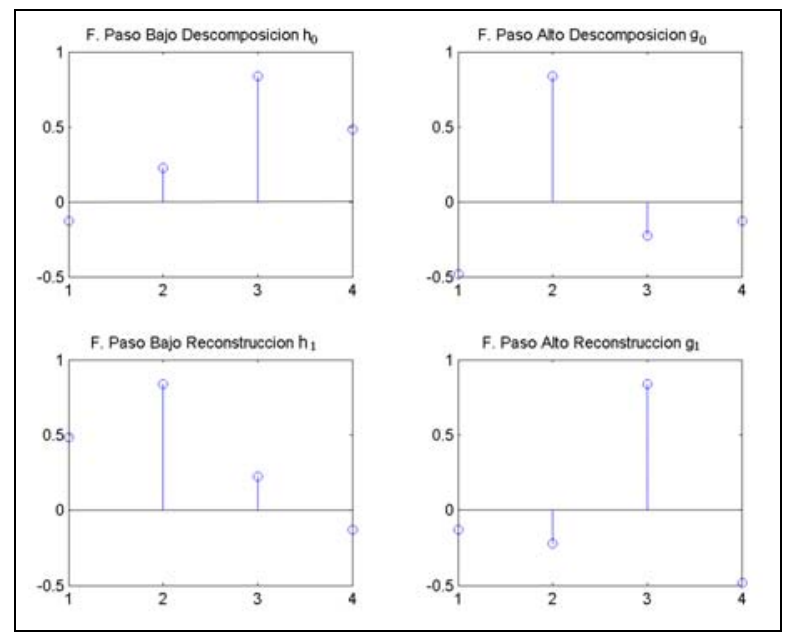

Figura 4-3. Coeficientes de los filtros ortonormales Daubechies 4.

De las expresiones de los tres grupos de filtros se deriva que cada base ortonormal wavelet asociada a un análisis multiresolución da pie a un par de filtros CMF, es decir, a un esquema de filtrado subbanda con perfecta reconstrucción. La relación contraria no se cumple.

Las funciones wavelet más importantes son ortonormales ya que permiten asegurar que cualquier señal $x(t)$ tiene una única transformada $X_{T W}$ lo que asegura que se puede invertir la transformación de forma inequívoca y precisa.

Una transformación como la discreta wavelet corresponde a un banco de filtros críticamente muestreados, es decir, aquel en el que el factor de muestreo coincide con el número de filtros del banco (generalmente se emplean 2 filtros, uno de paso bajo y otro de paso alto).

Para concluir este apartado, decir que la relación entre los coeficientes de los filtros y las funciones wavelet viene definida y controlada por dos ecuaciones, la de dilatación y la ecuación wavelet, que son explicadas en el apartado 4.7.2. 


\subsection{Transformada de Haar}

La transformada de Haar se considera la precursora de la transformada wavelet y el primer paso en la construcción de sus algoritmos de aplicación, al tratarse de una primera base de funciones muy sencillas y con importantes propiedades como la ortonormalidad, que permite una descomposición y reconstrucción perfecta de señales.

Se trata de una de las transformaciones más sencillas que se puede aplicar a una señal y cuyo objetivo es descomponer la citada señal en dos subseñales de dimensión mitad que la inicial y llamadas subseñal aproximación (obtenida calculando promedios o tendencias) y subseñal detalle (obtenida calculando diferencias o fluctuaciones).

Si se parte de una señal discreta $f \in \mathrm{R}^{N}$ tal que:

$$
f=\left(f_{1}, f_{2}, f_{3}, \ldots, f_{N}\right)
$$

los componentes de la subseñal aproximación vienen dados por la expresión:

$$
a_{m}=\frac{f_{2 m-1}+f_{2 m}}{\sqrt{2}}
$$

mientras que los componentes de la subseñal detalle (o fluctuación) son:

$$
d_{m}=\frac{f_{2 m-1}-f_{2 m}}{\sqrt{2}}
$$

para $m=1,2,3, \ldots, N / 2$,

Se puede entender que la señal de entrada es dividida en dos subseñales: una de promedios $(a)$ y otra de detalles $(d)$ y que a partir de ellas se puede restaurar la señal original. Se interpreta que la señal de tendencia o promedios $a$ es una representación de resolución menor de la señal inicial y que las diferencias o detalles $d$ es la información necesaria para pasar de esa representación grosera o aproximada a la señal inicial original (Tsolmon, 2003).

\subsubsection{Transformada de Haar de nivel 1}

Con los anteriores coeficientes (4-10 y 4-11) se obtiene la transformada de Haar de nivel $1\left(H_{1}\right)$ sobre la señal $f$ mediante la concatenación de los coeficientes de 
tendencias (o aproximaciones) y los de las fluctuaciones (o detalles) según el ejemplo siguiente:

$$
\text { Sea } f \in \mathrm{R}^{N}: f=(7,9,10,14,11,7,5,4)
$$

De ella se tiene que:

$$
a^{1}=(8 \sqrt{ } 2,12 \sqrt{ } 2,9 \sqrt{ } 2,4.5 \sqrt{ } 2) \quad d^{1}=(\sqrt{ } 2,2 \sqrt{ } 2,2 \sqrt{ } 2,1 / \sqrt{ } 2)
$$

por lo que $f \rightarrow H_{1} \rightarrow\left(a^{1} \mid d^{1}\right)$ y resulta

$$
(7,9,10,14,11,7,5,4) \rightarrow H_{1} \rightarrow(8 \sqrt{ } 2,12 \sqrt{ } 2,9 \sqrt{ } 2,4.5 \sqrt{ } 2 \mid \sqrt{ } 2,2 \sqrt{ } 2,2 \sqrt{ } 2,1 / \sqrt{ } 2)
$$

Nótese que no se ha producido pérdida ninguna de información, ya que tanto la señal inicial como la descomposición presentan el mismo número de coeficientes. Además de esto, si se define la energía de una señal $f$ como:

$$
E(f)=\|f\|^{2}=\sum_{i=1}^{n} f_{i}^{2}
$$

al ser aplicada sobre el ejemplo anterior se tiene:

$$
E(f)=637 \quad E\left(a^{1}\right)=618.49 \quad E\left(d^{1}\right)=18.51
$$

cuya interpretación demuestra dos importantes propiedades:

$1^{a}$ : Compactación de la energía. La mayor parte de la energía total de una señal se acumula en la subseñal promedio o tendencia, de menor dimensión y con muy poca pérdida de información. Por el contrario, en la subseñal fluctuación o diferencia resta muy poca de la energía inicial. Se puede reducir la dimensión de las señales (de cualquier tipo) sin una pérdida notable de información.

2a: Conservación de la energía. La suma de las energías de tendencias y fluctuaciones es igual a la energía de la señal de partida, por lo cual se puede afirmar que la transformación de Haar de nivel 1 conserva la energía, ya que es una transformación ortogonal y todas ellas preservan las normas.

\subsubsection{Transformada de Haar de niveles sucesivos}

Una vez realizada la transformada de nivel 1 es sencillo repetir el proceso y realizar transformadas de varios niveles. Tras aplicar la transformada de nivel 1 sobre una señal $f$, se ha obtenido una primera tendencia $a^{1}$ y una primera fluctuación $d^{1}$. El segundo nivel de la transformada de Haar determina la segunda tendencia $a^{2}$ y la segunda 
fluctuación $d^{2}$ para la primera tendencia $a^{1}$ tan solo. La transformada de niveles sucesivos calcula la tendencia y la fluctuación de un nivel $s$ pero solamente sobre la tendencia del nivel anterior $s-1$. La transformada de un determinado nivel será por tanto la subseñal tendencia de ese nivel y las subseñales fluctuaciones de niveles anteriores. Por ejemplo, la transformada de nivel 3 de una señal $f$ vendrá dada por:

$$
f \rightarrow H_{3} \rightarrow\left(a^{3}\left|d^{3}\right| d^{2} \mid d^{1}\right)
$$

\subsubsection{Transformada Wavelet de Haar}

La transformada wavelet de Haar (1910) emplea una base de funciones que es la más antigua y simple base ortonormal conocida y que presenta una serie de ventajas como su simplicidad, sus soportes muy pequeños y el hecho de usar funciones scaling y wavelet que no se superponen para un determinado nivel, aunque presenten poca utilidad en aplicaciones como edición de curvados y animación por su falta de continuidad (Stollnitz, 1995). La transformada wavelet de Haar se puede expresar en forma matricial como el producto $T=H \cdot F \cdot H \cdot T$, siendo $F$ la imagen de entrada de tamaño $N \times N, H$ la matriz de transformación de $N \times N$ y $T$ el resultado de la transformación. La matriz de transformación $H$ de $2 \times 2$ es:

$$
H_{2}=\frac{1}{\sqrt{2}}\left[\begin{array}{rr}
1 & 1 \\
1 & -1
\end{array}\right]
$$

Esta base de funciones define el banco de 2 filtros FIR (Finite Impulse Response) que satisface las condiciones de los QMF (Quadrature Mirror Filters). Los coeficientes de los filtros QMF de análisis $h_{0}(n)$ y $g_{0}(n)$ son los elementos de la primera y segunda fila de la matriz $\mathrm{H}_{2}$ respectivamente.

Conocida la matriz de transformación $H$, la transformada wavelet de Haar dice que existen unas funciones llamadas wavelets de Haar de nivel 1 cuyos coeficientes son:

$$
\begin{gathered}
w_{1}^{1}=\left(\frac{1}{\sqrt{2}}, \frac{-1}{\sqrt{2}}, 0,0, \ldots, 0,0\right) \\
w_{2}^{1}=\left(0,0, \frac{1}{\sqrt{2}}, \frac{-1}{\sqrt{2}}, 0, \ldots, 0\right) \\
\vdots \\
w_{N / 2}^{1}=\left(0,0, \ldots, 0, \frac{1}{\sqrt{2}}, \frac{-1}{\sqrt{2}}\right)
\end{gathered}
$$


donde el subíndice expresa el orden de la wavelet o desplazamiento de los coeficientes de la función que posteriormente será aplicada sobre la señal inicial.

De igual manera se definen las funciones scaling de Haar de nivel 1 cuyos coeficientes son los de la primera fila de la matriz $\mathrm{Hy}$ donde el orden o desplazamiento de los coeficientes en la wavelet varía entre 1 y la mitad de la dimensión $N$ o dimensión de la señal de partida:

$$
\begin{gathered}
v_{1}^{1}=\left(\frac{1}{\sqrt{2}}, \frac{1}{\sqrt{2}}, 0,0, \ldots, 0,0\right) \\
v_{2}^{1}=\left(0,0, \frac{1}{\sqrt{2}}, \frac{1}{\sqrt{2}}, 0, \ldots, 0\right) \\
\vdots \\
v_{N / 2}^{1}=\left(0,0, \ldots, 0, \frac{1}{\sqrt{2}}, \frac{1}{\sqrt{2}}\right)
\end{gathered}
$$

Tanto las funciones wavelet como scaling de Haar a nivel 1 cumplen cinco propiedades básicas:

a) Tienen energía igual a 1, es decir, tienen norma unitaria.

b) El soporte de todas las funciones, scaling o wavelet de orden $m$ es el mismo.

c) Las funciones wavelet tienen una media igual a 0 y las scaling igual a $1 / \sqrt{ } 2$.

d) Cada scaling se obtiene a partir de la primera scaling desplazando los coeficientes no nulos a la derecha $2 m$ posiciones, siendo $m$ el orden de la función (o traslación).

e) La familia de funciones wavelet y scaling forman una base ortonormal de $\mathrm{R}^{N}$, ya que todas tienen norma unitaria y el producto interno entre ellas dos a dos es igual a 0.

Retomando la idea básica de la descomposición de Haar, se puede decir que una señal de entrada $f$ lleva asociada la subseñal $d^{1}$ llamada primera fluctuación de Haar y es expresada como:

$$
d^{1}=\left(d_{1}, d_{2}, \ldots, d_{N / 2}\right)=\left(f \cdot w_{1}{ }^{1}, f \cdot w_{2}{ }^{1}, \ldots, f \cdot w_{N / 2}{ }^{1}\right)
$$

La segunda subseñal es la llamada primera tendencia de Haar de la señal $f$ y se define de forma análoga con las funciones scaling: 


$$
a^{1}=\left(a_{1}, a_{2}, \ldots, a_{N / 2}\right)=\left(f \cdot v_{1}{ }^{1}, f \cdot v_{2}{ }^{1}, \ldots, f \cdot v_{N / 2}{ }^{1}\right)
$$

Este tipo de transformada permite un proceso repetitivo de tal forma que se pueden definir las funciones wavelet y scaling de Haar a niveles sucesivos $(2,3, \ldots)$. En cada nivel se modifica el número de coeficientes no nulos así como el soporte de las funciones. Las propiedades a nivel 2 se mantienen iguales a las de nivel 1 si bien tanto las funciones wavelet como las scaling a nivel 2 se obtienen a partir de las scaling de nivel 1 con las siguientes expresiones, muy parecidas a las de la transformada de Haar:

$$
\begin{aligned}
& v_{m}^{2}=\frac{v_{2 m-1}^{1}+v_{2 m}^{1}}{\sqrt{2}} \\
& w_{m}^{2}=\frac{v_{2 m-1}^{1}-v_{2 m}^{1}}{\sqrt{2}}
\end{aligned}
$$

para $m=1,2,3, \ldots, N / 2$. Se puede decir que las wavelet y scaling a nivel 2 se derivan de las de nivel 1 dilatando el soporte (que será el doble) y contrayendo sus valores al multiplicar por el factor $1 / \sqrt{ } 2$, que conserva la energía unitaria. El conjunto de las funciones de nivel 2 también forman una base ortonormal. La posibilidad de trabajar a diferentes niveles (o escalas) permite hablar del análisis multiresolución (apartado 4.7.2.) como eje principal del tratamiento de imágenes mediante wavelets.

Concluyendo este apartado y a modo de resumen se puede decir que la transformada wavelet de Haar es pionera por cuanto define la idea de análisis multiresolución, de descomposición de señales, de fluctuaciones y tendencias, de propiedades que cumple, etc. Cualquier otra familia de funciones base de la transformada wavelet se aplica de forma análoga y se ajusta a las mismas propiedades, si bien cambia la definición de los coeficientes de las funciones wavelt y scaling.

\subsection{La Transformada Wavelet Continua Unidimensional (CWT)}

Como se detalla en el primer apartado del presente capítulo, una wavelet $\psi(x)$ es una función en forma de onda que está limitada en un cierto intervalo (o que tiene una extensión limitada). La función wavelet puede ser definida por cualquier función $\psi(x)$ que satisfaga tres condiciones: (1) que sea normalizada $(\|\psi\|=1)$; (2) que la integral de su 
cuadrado sea finita (la función debe tener una energía finita o expresado de otra manera, debe pertenecer al espacio $L^{2}(R)$, espacio de funciones con integral cuadrada finita):

$$
\int_{-\infty}^{+\infty}|\psi(x)|^{2} d x<\infty
$$

y (3) la integral de la función $\psi(x)$ debe ser igual a cero y por tanto debe ser oscilatoria, es decir, debe ser una onda con:

$$
\int_{-\infty}^{+\infty} \psi(x) d x=0
$$

Esta última condición viene justificada por el rápido decaimiento a cero de la transformada de Fourier de la función en la frecuencia $\omega=0$.

Es conocida la utilidad de las funciones wavelet para localizar una función dada en el espacio y a diferentes escalas. Aprovechando esta cualidad, la Transformada Continua Wavelet (CWT) convierte una función continua en otra función altamente redundante de dos variables continuas, traslación y escala. Si se desea analizar esa señal de diferentes frecuencias y por tanto no armónica es necesario emplear funciones de diferentes frecuencias para diferentes soportes espaciales o temporales.

Así se construye una familia de funciones wavelets linealmente independientes, a partir de una función $\psi(x)$ llamada "wavelet madre", la cual está confinada en un intervalo finito. Las "wavelets hijas" o simplemente "wavelets" $\psi_{a, b}(x)$ se forman por traslación y escalado de la función madre, siendo $a$ la dilatación (la cual es inversamente proporcional a la frecuencia y debe cumplir que $a \neq 0$ ) y $b$ la traslación o desplazamiento (localización en el tiempo o en el espacio), obteniendo así la expresión de todas las versiones trasladadas y escaladas de ella, conocida como familia wavelet, considerando que se trata de funciones continuas y que tanto $a$ como $b$ se definen en el espacio de los reales $\mathrm{R}$ :

$$
\psi_{a, b}(x)=\frac{1}{\sqrt{a}} \psi\left(\frac{x-b}{a}\right)
$$

Todas las funciones de la familia wavelet también son normalizadas $\left(\left\|\psi_{a, b}\right\|=1\right)$.

Si el factor de escala a se expresa como potencias de 2, la transformación pasa a denominarse diádica:

$$
\psi_{a, b}(x)=\frac{1}{\sqrt{2^{a}}} \psi\left(\frac{x-b}{2^{a}}\right)
$$


La transformada wavelet diádica mantiene la invariancia a la traslación muestreando o discretizando sólo el parámetro de escala de una transformada wavelet continua. La escala es muestreada generando una secuencia diádica $\left\{2^{a}\right\}, a \in Z$ para simplificar los cálculos.

El término $a^{-1 / 2}$ normaliza la energía para diferentes escalas mientras el segundo término define el ancho y la traslación de la función. Conforme el parámetro a varía, las wavelets $\psi_{a, b}$ cubren diferentes rangos de frecuencias, de tal manera que valores altos de $a$ se corresponden a pequeñas frecuencias (o escala grande), mientras que valores bajos de $a$ corresponden a altas frecuencias o pequeñas escalas. Variar el valor del parámetro de traslación $b$ implica desplazar el centro de localización en el tiempo a lo largo de la señal. Las funciones $\psi_{a, b}$ tienen anchos adaptados a su frecuencia, funciones de altas frecuencias serán estrechas, mientras que las de bajas frecuencias serán más anchas, tal y como se aprecia en la figura 4-4.

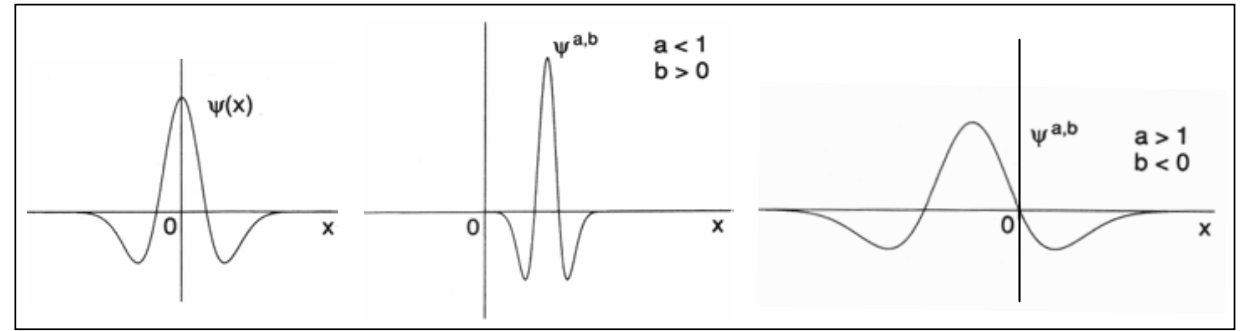

Figura 4-4. Diferentes funciones wavelet con variaciones en la traslación y escala.

La función $\psi(x)$ es usualmente asociada a los coeficientes de un filtro de paso banda. Así, valores altos de la variable dilatación $a(a>>1)$ corresponde a funciones de bases largas e identificarán tendencias de largo término en la señal analizada. Por el contrario, pequeños valores de esa misma variable $(0<a<1)$ nos indica que las funciones tienen bases cortas y nos llevará al comportamiento de corto término de la señal. Se puede decir de todo ello que la escala es proporcional a la duración de las funciones bases empleadas en la dilatación de la señal.

Similar a la construcción de la familia de funciones wavelet se puede obtener una familia de scaling, que conformen bases ortonormales mediante traslación y dilatación de la función $\varphi(x)$ :

$$
\varphi_{a, b}(x)=a^{-1 / 2} \varphi\left(a^{-1} x-b\right)=\frac{1}{\sqrt{a}} \varphi\left(\frac{x-b}{a}\right)
$$

Para funciones definidas en todo el espacio $\mathrm{R}$, se define el producto interno entre dos de ellas fy $g$ como: 


$$
\langle f, g\rangle=\int_{-\infty}^{\infty} f(x) g(x) d x
$$

Con ello se expresa la descomposición o transformada wavelet de una función de partida $f(x) \in \mathrm{L}^{2}(\mathrm{R})$, continua, de diferentes frecuencias y por tanto no armónica, como una combinación lineal de una familia de funciones base ortonormales $\psi_{a, b}(x)$, es decir, como el resultado del producto interno entre la propia señal y la familia wavelet:

$$
W(a, b)=\left\langle f, \psi_{a, b}\right\rangle=\int f(x) \psi_{a, b}^{*}(x) d x
$$

o lo que es lo mismo

$$
W(a, b)=\frac{1}{\sqrt{a}} \int f(x) \psi^{*}\left(\frac{x-b}{a}\right) d x
$$

donde * denota el complejo conjugado de la función $\psi$. Expresado de otra manera, se puede decir que la transformada wavelet $W(a, b)$ de una señal $f(x)$ es el conjunto de coeficientes $C_{i, j}$ que dependen de la dilatación (o escalado) y de la traslación de la señal (Materka y Strzelecki, 1998), (Chien-Chang y Chaur-Chin, 1999):

$$
C_{i, j}=\int_{-\infty}^{+\infty} f(x) \psi_{a, b}(x) d x
$$

$Y$ de ella se tiene que la transformada wavelet se define como la suma sobre todo el intervalo de la señal multiplicada por la familia de wavelets hijas, versiones escaladas y desplazadas de la función wavelet madre $\psi(x)$ (Pajares y de la Cruz, 2001).

La expresión anterior de la transformada wavelet puede reformularse como un producto de convolución (denotada por $\otimes$ ):

$$
W(a, b)=\int f(x) \frac{1}{\sqrt{a}} \psi^{*}\left(\frac{x-b}{a}\right) d x=f \otimes \bar{\psi}_{a}(b)
$$

siendo

$$
\bar{\psi}_{a}(x)=\frac{1}{\sqrt{a}} \psi^{*}\left(\frac{-x}{a}\right)
$$

la expresión general de un filtro paso banda y por ello se puede decir que la transformada wavelet es calculada mediante el empleo de filtros paso banda (bien sean paso alto o bien paso bajo). 
Desde un punto de vista intuitivo, esta transformada calcula un índice de semejanza o correlación entre la señal de partida y la wavelet de análisis en la posición $b$ y a la escala $a$. Si la señal tiene componentes espectrales (o de frecuencia) que se corresponden a la escala actual en determinados lugares, el producto de ambas en esos lugares dará valores relativamente altos. Si por contra esos componentes espectrales no se encuentran en la señal, el resultado será relativamente pequeño o incluso nulo.

Dados los parámetros de una transformada wavelet, $W(a, b)$, la señal inicial $f(x)$ puede ser reconstruida empleando la Transformada Wavelet Continua Inversa:

$$
\begin{gathered}
f(x)=\frac{1}{C_{\psi}} \int_{0}^{\infty} \int_{-\infty}^{\infty} W(a, b) \frac{\psi_{a, b}(x)}{a^{2}} d a d b \\
C_{\psi}=\int_{-\infty}^{\infty} \frac{|\hat{\psi}(\omega)|^{2}}{|\omega|} d \omega
\end{gathered}
$$

donde $\hat{\psi}(\omega)$ es la transformada de Fourier de $\psi(x)$.

Una importante propiedad de la transformada continua es su invarianza respecto a las traslaciones o cambios de escala de la señal, es decir, porciones similares (texturas en el caso de imágenes) serán detectadas de la misma forma, independientemente de su localización o escala.

\subsection{Propiedades de la Transformada Wavelet}

El empleo de una determinada transformada wavelet en una tarea de extracción de características, detección de objetos o reconocimiento de formas viene condicionado en gran medida por el comportamiento de la transformada frente a la traslación y la rotación. La invarianza a la traslación expresa que la transformada de una señal y la de esa señal trasladada en el tiempo (o en el espacio) son simplemente versiones trasladadas una de otra. La falta de invarianza a la traslación junto a la invarianza a la rotación en la clave para su empleo o no. En cuanto a la invarianza a la rotación (Tsolmon, 2003), se conseguiría si los resultados del análisis no estuviesen influenciados por la orientación de la imagen de entrada. Una solución para resolver este problema es emplear una wavelet isotrópica (que tiene el mismo comportamiento para cualquier dirección) como la Mexican Hat, que es la segunda derivada de la función gaussiana. Esta wavelet no puede ser 
implementada en la transformada discreta (DWT), no es ortogonal y sólo puede ser empleada en la continua (CWT). En general, la anisotropía es un importante aspecto de la mayoría de las texturas y aunque al clasificar buscamos resultados independientes de la orientación de la textura, para lograrlo tendríamos que obtener parámetros de textura que reflejasen la anisotropía de las mismas (Livens et al., 1997).

La función wavelet base ha de cumplir dos condiciones para poder ser empleada (Sepala, 2001):

- Condición de admisibilidad: se define por la expresión 4-32 cuyas consecuencias son: (1) que la función está bien localizada en el tiempo o en el espacio; (2) que la transformación con esa función es invertible, es decir, se puede conseguir la reconstrucción perfecta; (3) que su transformada de Fourier es un filtro continuo paso banda, con rápido decaimiento hacia el infinito y hacia $\omega=0 ;$ y (4) que la función debe tener un valor cero en la frecuencia cero, lo cual se cumplirá si la wavelet tiene una media de cero y se trata de una función oscilatoria donde los valores negativos anulan a los positivos.

$$
\int_{-\infty}^{+\infty} \frac{|\hat{\psi}(\omega)|^{2}}{\omega} d \omega<\infty
$$

- Condición de regularidad: Las dos propiedades básicas de las funciones wavelet, soporte compacto y correcta localización en frecuencia y tiempo, no son las únicas. La llamada condición de regularidad expresa que la wavelet madre ha de ser localmente suave y concentrada en los dominios del tiempo y la frecuencia. Como resultado de esta condición aparece el concepto de vanishing moment o momento nulo o momento de desaparición. Si se definen los $p$ momentos de la wavelet $\psi$ como:

$$
M_{p}=\int t^{p} \psi(t) d t
$$

entonces se dice que esa función tendrá $p$ momentos nulos si la expresión anterior es igual a cero:

$$
\int_{-\infty}^{+\infty} t^{k} \psi(t) d t=0 \quad \text { para } 0 \leq k<p
$$

significando ello que $\psi$ es ortogonal a cualquier polinomio de grado $p$ - 1 . Por la condición de admisibilidad tenemos que el momento cero es nulo. Si los demás momentos se anulan, entonces los coeficientes de la transformada wavelet tendrán un decaimiento exponencial $\left(a^{n+2}\right)$ para una señal suave $f(t)$. Esto es conocido como momentos nulos u orden de aproximación. Si una wavelet tiene $N$ momentos nulos, 
entonces el orden de aproximación de la transformada wavelet también será $N$. Los momentos no tienen que ser exactamente igual a cero, ya que pequeños valores son suficientes a menudo.

Para medir la regularidad de una señal, además de usar una función wavelet con un soporte de frecuencias estrecho, es muy importante el número de momentos nulos. Si la wavelet tiene $p$ vanishing moments entonces podemos interpretar la transformada wavelet como un operador diferencial multiescala de orden $p$ (si una función wavelet $\psi(t)$ es $\mathrm{p}$ veces diferenciable y decrece bastante rápido, entonces los primeros $p-1$ momentos desaparecen). Esto proporciona una primera relación entre la diferenciabilidad de la señal de partida $f$ y el decaimiento o suavidad de la transformada wavelet en pequeñas o finas escalas: se cumple que si una función $f$ es regular y $\psi$ tiene suficientes momentos nulos, entonces los coeficientes wavelet $\left\langle f, \psi_{j, n}\right\rangle$ son pequeños en escalas finas $2^{j}$. La ventaja de tener un número alto de momentos nulos para una función $\psi$ es que se deriva de ello una alta compresibilidad porque los coeficientes wavelet a escala pequeña de una función pueden ser esencialmente cero donde la función sea suave.

Por lo que respecta a la transformada de Fourier, si dicha transformada para la función wavelet es $p$ veces diferenciable, entonces se dice que dicha función tiene $p$ momentos nulos.

Asociado a la definición anterior de momento de desaparición o momento nulo se encuentra el concepto de soporte de una función, de tal manera que si $\psi$ es una función wavelet que presenta un total de $p$ momentos nulos y genera una base ortonormal en $\mathrm{L}^{2}(\mathrm{R})$, entonces tiene un soporte de tamaño mayor o igual que $2 p-1$. Una wavelet de la familia Daubechies, por ejemplo, tiene un soporte de tamaño mínimo igual a $[-p+1, p]$. El soporte de la correspondiente función scaling es [0, $2 p-1]$. La tabla 10-1 del apartado 10.2 muestra los distintos coeficientes de los filtros Daubechies para $2 \leq p \leq 10$.

Si la función wavelet que se utilice tiene soporte compacto, es decir, es distinta de cero para un número finito de valores, entonces se necesitarán un número finito de coeficientes wavelet en la descomposición de una señal. Unser (1995) expresa que el incremento del soporte de la función (número de vanishing moments) no parece tener una ventaja evidente para el análisis de texturas y su discriminación. Parecen más importantes las propiedades de los filtros aplicados que las propiedades de las funciones en sí.

Resumiendo, las diferentes familias wavelet buscan el equilibrio entre un soporte compacto en su localización espacial y su suavidad o regularidad. En esa armonía tienen importancia aspectos como la estructura fractal y el número de momentos nulos, que está directamente relacionado con el número de coeficientes de la función (Graps, 1995). 


\subsection{Transformada Wavelet frente a Transformada de Fourier}

La transformada de Fourier es una de las transformadas más empleadas para el análisis de señales unidimensionales e imágenes. Si bien en este trabajo no se ha aplicado como tal, se considera importante citar sus ideas clave para poder ver cómo la transformada wavelet (TW) puede sustituirla en determinados casos y analizar sus diferencias.

Una señal digital de frecuencia variable se puede descomponer como la suma de dos términos a diferentes escalas espaciales: la parte de las bajas frecuencias y la parte de las altas frecuencias (Schowengerdt, 1997). La transformada de Fourier permite extender esta idea a multitud de escalas, es decir, una señal unidimensional puede descomponerse en un conjunto infinito de señales periódicas seno y coseno de diferentes frecuencias y amplitudes. El primer término de esa descomposición representa la amplitud media de la señal y su frecuencia es nula, es decir, es una simplificación. El siguiente componente tiene la misma frecuencia que la señal inicial y los sucesivos términos van teniendo frecuencia mayores de tal manera que añadidos a los términos anteriores se va consiguiendo una aproximación a la señal inicial hasta que con infinitos términos se conseguiría la señal tal y como lo era la original. Al conjunto de todos esos términos se le denomina descomposición o serie de Fourier de la función original:

$$
f(t)=a_{0}+\sum_{k=1}^{\infty} a_{k} \cos k \omega_{0} t+b_{k} \operatorname{sen} k \omega_{0} t
$$

donde la frecuencia se define como:

$$
\omega_{0}=\frac{2 \pi}{T_{0}}
$$

Al añadir más elementos al anterior sumatorio, la señal se aproxima más a la original y el nivel de detalle mejora al ser la variable en el espacio de la frecuencia $\omega$ mayor.

Centrándonos en las señales bidimensionales, la frecuencia espacial de una imagen expresa la distribución espacial de las intensidades o niveles de gris y puede seguir una ley sinusoidal, con su amplitud, fase, frecuencia y orientación. Las altas frecuencias corresponden a bordes abruptos y las bajas frecuencias a la ausencia de bordes y por tanto a regiones de intensidades aproximadamente uniformes. La unidad de frecuencia es siempre la inversa de la unidad de distancia utilizada en el plano de la imagen, es decir, el píxel y por tanto la unidad de frecuencia es el píxel ${ }^{-1}$, mas comúnmente denominada ciclos 
por píxel. Como en el caso unidimensional, la reconstrucción perfecta de la imagen se conseguiría sumando todos los términos de la serie de Fourier. La suma parcial de los primeros, de bajas frecuencias, produciría una versión de la imagen de bajas frecuencias similar a la obtenida tras un proceso de filtrado tipo paso-bajo. Igualmente, la suma de los últimos términos, de frecuencias mayores, produciría una versión de la imagen de altas frecuencias como si se aplicase un filtro de paso alto.

Aunque la transformada de Fourier y la transformada wavelet pueden ser consideradas como una rotación del espacio de funciones a un dominio diferente, éstos son distintos. La primera diferencia que se aprecia es que el análisis de Fourier está asociado al concepto de espectro o contenido de frecuencia de una señal, mientras que el análisis wavelet se asocia al concepto intuitivo de resolución o escala de la señal (Xiong y Ramchandran, 2000). Otra diferencia radica en que la transformada de Fourier descompone una señal mediante funciones base en una suma ponderada de senos y cosenos, mientras que la transformada wavelet emplea como funciones base a las wavelets, de frecuencia variable y duración limitada. La transformada wavelet de una señal que cambia con el tiempo depende de dos variables, a saber, la frecuencia y el tiempo y por ello es una herramienta para el análisis tiempo-frecuencia que presenta ventajas frente al método tradicional de Fourier, más evidentes cuando se analizan señales con discontinuidades y formas "afiladas" o "en pico". Pero la principal diferencia, quizás radique en que las funciones seno y coseno de la TF no están localizadas en el espacio, mientras que las funciones wavelet de la TW sí. Ese comportamiento de localización de frecuencias en el espacio hace que operadores y funciones reducidas se comporten bien en el dominio wavelet, de tal manera que se puedan aplicar en compresión de datos, detección de características y eliminación de ruido (Graps, 1995).

Por ello, el análisis wavelet puede ser una alternativa al clásico análisis de Fourier, cuyo objetivo es medir el contenido de frecuencia local de una señal, mientras que la transformada wavelet analiza la frecuencia de la señal en cada escala (Meyer, 1993).

También es característico el hecho de que la transformada de Fourier asume que las señales a analizar son de duración infinita o al menos periódicas. Esta condición no siempre es así, ya que un sonido inconstante, como unas notas musicales, puede tener partes de diferentes amplitudes y frecuencias. En esos casos se requiere un estudio ajustado a la posición (o tiempo) y a la frecuencia, como lo hace la transformada wavelet. En la figura 4-5 se aprecia la diferencia entre dos señales unidimensionales, una periódica y otra no. 


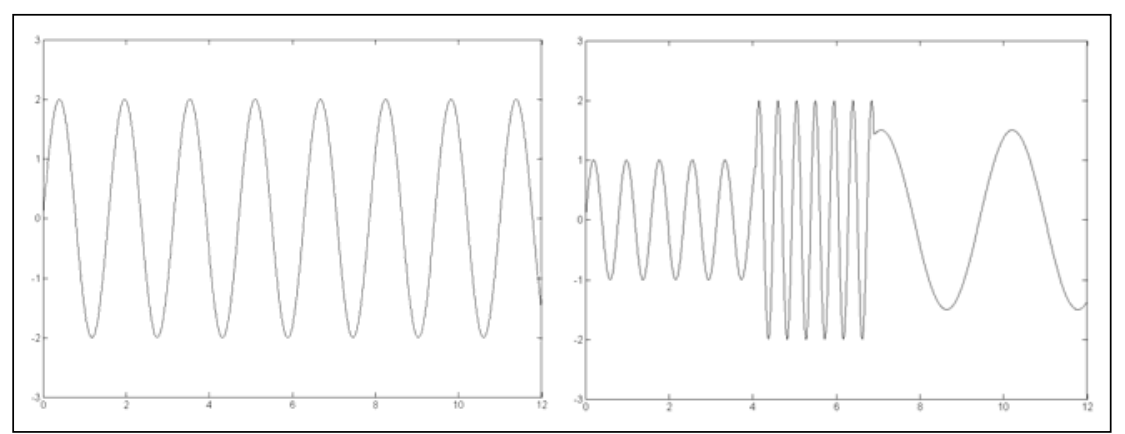

Figura 4-5. Dos señales unidimensionales, periódica (izquierda) y no periódica (derecha).

Respecto a la diferente localización de frecuencias en el espacio, se observa en la figura 4-6 la desigual división (o tiling) del plano tiempo-frecuencia para la transformada de Fourier Ventana (Windowed Fourier Transform) y la TW. Cada una de las celdas es denominada por determinados autores (Gonzalez y Woods, 2002) como celda o caja de Heisenberg (principio de incertidumbre de Heisenberg), mostrando el conjunto de ellas dónde está concentrada la energía de la función base. En la parte superior se puede ver la relación tiempo - frecuencia para la transformada de Fourier, en la que bases de diferentes

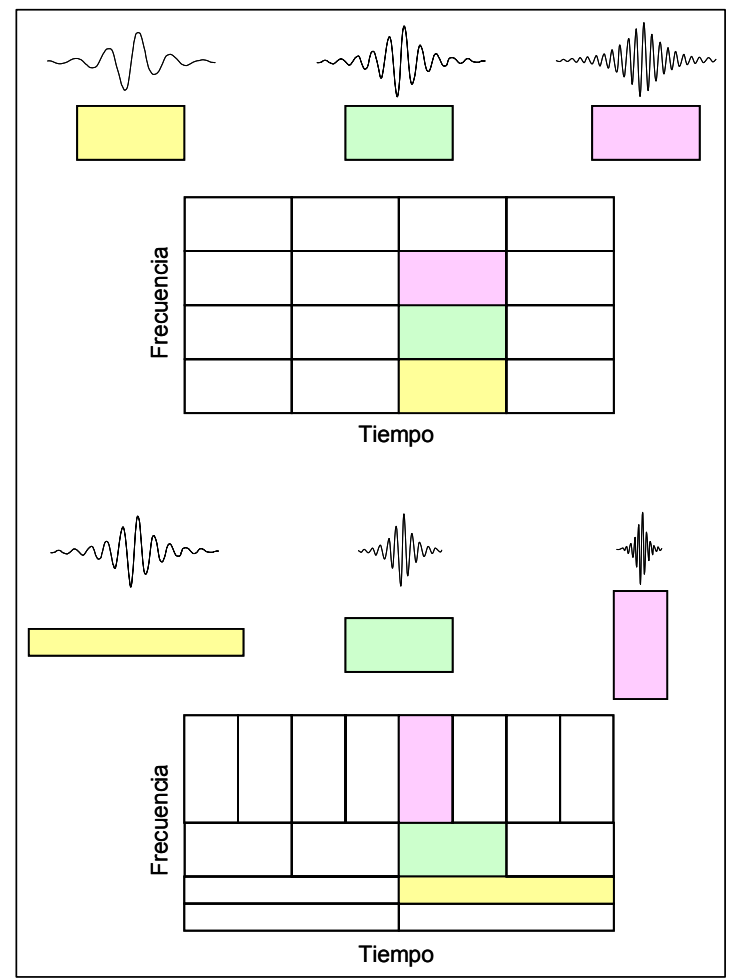

Figura 4-6. Plano tiempo-frecuencia para WFT y TW. 
frecuencias tienen la misma resolución o longitud; y en la parte inferior para la transformada wavelet, donde el tamaño del soporte de las funciones base se ajusta a la frecuencia de tal manera que entre ellos existe una relación inversa. El área de cada uno de los polígonos es constante y distinta de cero. De esta manera, el análisis wavelet proporciona acceso a información que podría ser ocultada por el análisis de Fourier.

De todas maneras existen similitudes entre ambas transformadas, tal y como se puede apreciar en la figura 4-7, donde se representa la división espacio frecuencia para Fourier y wavelet. Las frecuencias horizontales vienen expresadas como $f_{1}$ y las frecuencias verticales como $f_{2}$. Esta gráfica indica el dominio donde la energía de las diferentes funciones wavelet y scaling está concentrada y la información de bajas frecuencias (LL), bajas frecuencias horizontales y altas verticales (LH), altas frecuencias horizontales y bajas verticales $(\mathrm{HL})$ y altas frecuencias en ambas direcciones (HH) (Vetterli, 1995).

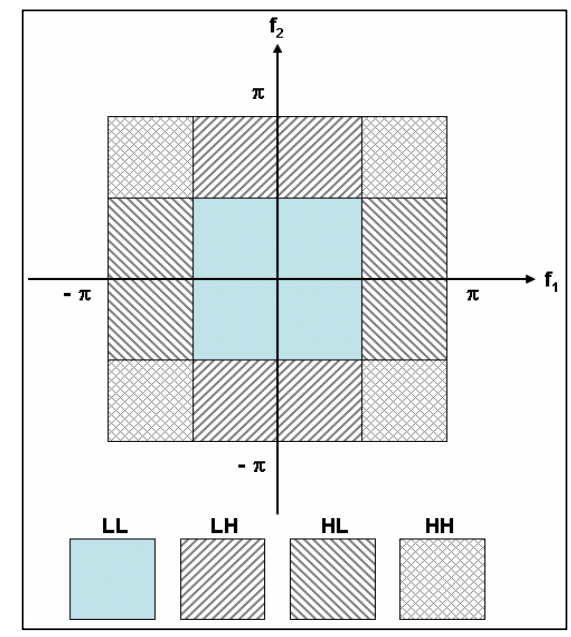

Figura 4-7. Tiling espacio frecuencia para Fourier y Wavelet (adaptada de Vetterli, 1995).

\subsection{Modelos de aplicación de la Transformada Wavelet}

A partir de las ideas generales de las funciones wavelet, su definición y el significado de la transformada wavelet continua, vistos en apartados anteriores, existen varios modelos mediante los cuales han sido puestos en práctica por la comunidad de usuarios, pero casi todos ellos centrados en su aplicación en forma discreta. Algunos de los más importantes (principalmente por su recurrencia de empleo) son los siguientes:

- Transformada Wavelet Discreta (DWT), siendo el remuestreo diádico el más empleado.

- $\quad$ Análisis Multiresolución (MRA). 
- Wavelet Frames Discreta (DWF).

- Otras transformadas redundantes:

- Undecimated Wavelet Transform.

- Algoritmo "à trous".

- Wavelet Packets.

- $\quad$ Transformada Wavelet Rápida (FWT).

- Bases ortonormales Wavelet bidimensionales.

- Transformada Wavelet Rápida bidimensional.

\subsubsection{La Transformada Wavelet Discreta}

Discretizar una variable consiste en reemplazar el muestreo continuo de información por un espectro, es decir, un conjunto finito o numerable de valores. La dificultad de esta tarea reside en conseguir el justo equilibrio entre densidad del muestreo y redundancia de la información, ya que un muestreo muy fino aproxima mejor a la señal pero implica alta redundancia.

Otro hecho evidente es que ni la transformada de Fourier ni la transformada wavelet continua pueden ser calculadas con facilidad para obtener todos los coeficientes para todas las escalas y todas las traslaciones sobre una señal, que es lo que se realiza en una transformada wavelet continua.

Para hacerlo posible se recurre a la transformada discreta (DWT) en la que se elige un conjunto de escalas y posiciones y las señales son muestreadas y convertidas en función de una variable discretizada, como puede ser el tiempo o la posición. Posteriormente se hacen los sucesivos cálculos de forma discreta (Walker, 1999). Por ello, hablar de la DWT es hablar de la CWT discretizada. A efectos computacionales, tampoco se va a realizar el cálculo de coeficientes a todas las escalas, sino que el análisis es mucho más eficiente y preciso cuando el subconjunto de escalas y posiciones son potencias enteras negativas de 2, lo cual se conoce como escalado diádico.

Las wavelets discretas no son continuamente escalables y trasladables ya que sólo pueden serlo en pasos discretos. Por ello la expresión de la wavelet continua (4-21) puede ser reformulada como: 


$$
\psi_{j, k}(x)=\frac{1}{\sqrt{s_{0}^{j}}} \psi\left(\frac{x-k \tau_{0} s_{0}^{j}}{s_{k}^{j}}\right)
$$

siendo $j$ y $k$ factores enteros de escalado (también denominado nivel de la transformada) y traslación y $s_{0}>1$ un paso fijo de dilatación, del cual depende a su vez un factor de traslación $\tau_{0}$. Con dicha expresión se ha conseguido muestrear el espacio tiempo-escala en intervalos discretos. Si se elige $s_{0}=2$ y $\tau_{0}=1$, entonces se habla de un muestreo diádico y los parámetros de traslación y escala se relacionan con sus homólogos continuos de la forma:

$$
a=2^{j}, b=2^{j} k,(j, z) \in Z
$$

Aplicándolos a la expresión básica (4-37) se obtiene la familia wavelet discreta diádica:

$$
\psi_{j, k}(x)=2^{-j / 2} \psi\left(2^{-j} x-k\right), \quad(j, k) \in Z
$$

Para una señal continua dependiente del espacio $f(x)$ que es uniformemente muestreada (o discretizada) en $N$ partes en el intervalo $[0,1]$ su transformada wavelet podrá ser calculada solamente en las escalas $N>s>1$, es decir, el parámetro de escala será $s_{0}=a^{j}$ (con $a=2$ para escalas diádicas, factor de escalado doble o mitad), siendo $j$ el nivel de la transformación. Una wavelet discreta escalada por $a^{j}$ y en una posición en concreto es definida por:

$$
\psi_{j}(n)=\frac{1}{\sqrt{a^{j}}} \psi\left(\frac{n}{a^{j}}\right)
$$

De forma genérica, se puede decir que la transformada wavelet de una señal discretizada $f(n)$ viene dada por la relación siguiente:

$$
W(j, k)=C_{j, k}=\frac{1}{\sqrt{j}} \sum_{x=-\infty}^{+\infty} f(n) \psi_{j, k}(n)
$$

donde $j$ es la dilatación y $k$ la traslación, valores enteros y los valores de $W(j, k)$ también son llamados coeficientes wavelet.

Al generar de la función wavelet madre $\psi$ una base ortonormal de wavelets se cumple que los coeficientes de la descomposición directa son los mismos que se necesita para reconstruir la señal de forma perfecta, consistiendo esta reconstrucción en la suma de las funciones base wavelet ortogonales $\psi_{j, k}(n)$ ponderadas por los coeficientes wavelet $C_{j, k}:$ 


$$
f(n)=\sum_{j} \sum_{k} C_{j, k} \psi_{j, k}(n)
$$

La función $f(n)$ se expresa como una combinación lineal de funciones $\psi_{j, k}(n)$ y los $C_{j, k}$ son los coeficientes wavelet de la señal $f(n)$ en la base formada por la familia wavelet, que indican la contribución relativa de cada función wavelet $\psi_{j, k}(n)$ en la descomposición.

En el caso de imágenes discretas de tamaño $N \times M$, la variable $n$ en la ecuación anterior es el par de coordenadas $\left(n_{1}, n_{2}\right)$ que definen la posición de un píxel y el dominio de la función son las dimensiones de la imagen $\{0,1,2, \ldots, N-1\} \times\{0,1,2, \ldots, M-1\}$. Las funciones base en este caso serán discretas y la descomposición de una imagen consistirá en una transformación lineal de los valores originales de los píxeles en un conjunto de coeficientes wavelet $C_{j, k}$. El subíndice $j$ indica el nivel de la descomposición y $k$ indica una posición concreta del coeficiente wavelet dentro de cada subbanda de la descomposición. Por ello y para analizar toda la imagen, las funciones bases $\psi_{j, k}(n)$ han de ser trasladadas por todos los píxeles. La forma de $\psi_{j, k}(n)$ dependerá de la escala y orientación de cada subbanda y por ello la función base en la subimagen obtenida por filtro paso bajo - paso bajo presenta un máximo centrado, mientras que las correspondientes a las subimágenes de detalles tienen media cero y presentan orientaciones verticales, diagonales y horizontales. Esta orientación cambiante permite emplear esas funciones para caracterizar patrones en las imágenes.

La aplicación práctica de la DWT se realiza implementando bancos de filtros. Por ello es importante profundizar un poco más en el significado de la descomposición discreta tanto en las altas como en las bajas frecuencias y en su relación con las convoluciones. Considerando el planteamiento de Mallat (1989), si se entienden la señal de entrada $f(n)$ (discretización de una señal continua en el espacio $f(x)$ en $N$ partes) y la función wavelet $\psi_{j},(n)$ como periódicas de periodo $N^{-1}$, los coeficientes de detalle de la transformada discreta pueden ser escritas como una convolución circular:

$$
W f\left(n, a^{j}\right)=\sum_{m=0}^{N-1} f(m) \psi_{j}^{*}(m-n)=f \otimes \bar{\psi}_{j}(n)
$$

$\mathrm{y} \bar{\psi}_{j}(n)=\psi_{j}^{*}(-n)$ (importante propiedad para definir algunos bancos de filtros).

Pero hasta ahora no se puede decir que se tenga una completa representación de la señal de entrada ya que las funciones wavelet proporcionan información de las altas frecuencias y se hace necesario añadir las bajas frecuencias. Un función periódica de filtrado scaling es calculada muestreando la función scaling $\varphi(x)$ continua: 


$$
\varphi_{j}(n)=\frac{1}{\sqrt{a^{j}}} \varphi\left(\frac{n}{a^{j}}\right)
$$

Siendo de forma análoga a las funciones wavelet una convolución circular donde $\bar{\varphi}_{j}(n)=\varphi_{j}^{*}(-n)$, y los coeficientes de aproximación (o contribución de las bajas frecuencias) son obtenidos según:

$$
L f\left(n, a^{j}\right)=\sum_{m=0}^{N-1} f(m) \varphi_{j}^{*}(m-n)=f \otimes \bar{\varphi}_{j}(n)
$$

Las propiedades principales de la DWT se centran en su nivel de redundancia y en su comportamiento ortonormal. Una DWT se le denomina redundante si una señal de $\mathrm{N}$ muestras es transformada por la DWT en $M>N$ muestras. Se le llama no redundante si la base wavelet es ortogonal. Las wavelets discretas pueden ser construidas ortogonales a sus propias dilataciones y traslaciones si se cumple que

$$
\int \psi_{j, k}(t) \psi_{m, n}^{*}(t) d t= \begin{cases}1 & \text { si } j=m \text { y } k=n \\ 0 & \text { otro caso }\end{cases}
$$

Las wavelets ortogonales pueden ser llamadas ortonormales si son normalizadas para tener la norma en $\mathrm{L}^{2}$ :

$$
\forall i \quad\left\|\psi_{i}\right\|=\int\left|\psi_{i}\right|^{2} d t=1
$$

La ortonormalidad de las funciones tiene una gran importancia ya que cualquier función continua puede ser únicamente proyectada en la base de funciones wavelet y expresada como una combinación lineal de las funciones que definen esa base. Además, dos funciones son ortonormales cuando su producto interno es dado por:

$$
\left\langle\psi_{j, k}, \psi_{j^{\prime} k^{\prime}}\right\rangle=\delta_{j j^{\prime}} \delta_{k^{\prime} k}
$$

donde $\delta_{\mathrm{jk}}$ es la delta de Kronecker. Esto significa que para una base ortonormal, el producto interno de cualquier función base consigo misma es la unidad. El producto interno de una función consigo misma es la conocida "norma".

Las dos ecuaciones 4-45 y 4-46 anteriores implican que el conjunto de funciones que definen una familia wavelet son ortonormales, lo que significa que es posible la reconstrucción perfecta aplicando la transformada inversa. 
Para terminar, decir que la discretización de la CWT hace perder la propiedad de invarianza a la traslación que presenta ésta, por lo que una imagen con pequeños desplazamientos generará diferentes coeficientes en la transformación.

Comparada con la transformada continua, la DWT es más útil en compresión y eliminación del ruido mientras que la CWT se emplea más en reconocimiento de formas y detección y extracción de características de imágenes (Tsolmon, 2003).

\subsubsection{Análisis Multiresolución}

Al observar una imagen, nuestro sistema perceptivo visual conecta regiones de similares textura y nivel de gris para combinarlos y formar los diferentes objetos que conforman la imagen. Si esos objetos son pequeños o entre ellos hay pocas variaciones en el nivel de gris, la imagen tendrá que ser observada a una alta resolución espacial para poder ser percibidos. Si por contra los objetos son grandes o de importante contraste, se pueden analizar a una resolución menor. $\mathrm{Si}$ ambos tipos de objetos se presentan simultáneamente en la imagen puede ser útil analizar ésta a varias resoluciones, ya que la estructura de los detalles es la misma en cada escala y es tan solo la granulometría o la rugosidad lo que cambia (Topiwala, 1998). Esta es la justificación del análisis multiresolución, ya que las imágenes naturales generalmente tienen esa variabilidad de patrones espaciales.

El análisis multiresolución (MRA) se basa en la descomposición wavelet y permite descomponer una señal de entrada (bien unidimensional, bien bidimensional en forma de imagen) en sus componentes de distintas frecuencias y estudiar cada componente a una resolución distinta (González-Audicana et al., 2003). Los detalles de una imagen se corresponden con los componentes de altas frecuencias y a diferentes resoluciones se produce la caracterización de diversos elementos o estructuras presentes en la imagen. Con resoluciones bajas (píxel de gran tamaño), los detalles se corresponden con las estructuras de mayores dimensiones mientras que a resoluciones altas (píxeles de tamaños pequeños), los detalles se relacionan con los objetos de menor tamaño. Al aplicar la transformada wavelet al análisis multiresolución y realizar comparaciones entre niveles diferentes se está extrayendo el detalle espacial que se pierde al pasar de una resolución espacial a otra menor.

Se puede decir por tanto, que el análisis multiresolución consiste en la representación y análisis de señales unidimensionales e imágenes en más de una resolución espacial o nivel de trabajo, ya que ciertas características de esas señales pueden no ser detectadas a una resolución pero pueden ser fácilmente identificadas a otra diferente. Se trata de un proceso completo de estudio y aplicación de la DWT en señales, 
uni o bidimensionales en sentido directo (fase de análisis o descomposición) e inverso (fase de síntesis o reconstrucción) a lo largo de diversas escalas o niveles y por tanto a distintas resoluciones. Son varias las formas de llevar a cabo este análisis, descomposición subbanda, bancos de filtros ortonormales y análisis piramidal de imágenes (González y Woods, 2002).

Empleando un factor de escalado diádico, la aproximación de una función $f$ a una resolución $2^{-j}$ es especificada por una malla discreta de muestras que proporcionan promedios locales de $f$ sobre vecindarios de tamaño proporcional a $2^{j}$. La variable $j$ indica la escala a la que se encuentra una señal y no ha de ser confundida con el factor de escala $a$ definido para las familias de funciones wavelet continuas. Por tanto, el parámetro $j$ se refiere al nivel o escala de trabajo.

La expresión matemática del MRA fue formulada por primera vez por Mallat y Meyer en 1986. Consiste en una secuencia de sucesivos espacios aproximación $V_{j}$ tal que la unión de todos ellos define el espacio $L^{2}(R)$, las intersecciones entre los sucesivos espacios es nula y todos los espacios son versiones escaladas del espacio central $V_{0}$. Una aproximación multiresolución es una composición de las diferentes aproximaciones a otras escalas o niveles. La aproximación de una función a la resolución $2^{-j}$, nivel $j$, es definida como una proyección ortogonal en un espacio $V_{j} \subset \mathrm{L}^{2}(\mathrm{R})$, donde este espacio $V_{j}$ agrupa a todas las posibles aproximaciones en la resolución $2^{-j}$. La proyección ortogonal de $f$ es la función $f_{j} \in V_{j}$ que minimiza $\left\|f-f_{j}\right\|$. La aproximación multiresolución es plenamente caracterizada por la función scaling $\varphi$ que genera una base ortogonal de cada espacio $V_{j}$. Las propiedades de la función scaling $\varphi$ garantizan que los espacios $V_{j}$ satisfacen todas las condiciones de una aproximación multiresolución.

Se ha demostrado que existe una función scaling $\varphi$ perteneciente a $V_{0}$, tal que su familia de funciones $\varphi_{0, n}(x)$ es una base ortonormal de $V_{0}$, es decir, que para cualquier nivel $j$ y traslación $n$ se define que la función siguiente es una base ortonormal de $V_{j}$ :

$$
\varphi_{j, n}(x)=2^{-j / 2} \varphi\left(2^{-j} x-n\right)
$$

Como complemento a los espacios de aproximación, existe una base wavelet ortonormal de $L^{2}(R)$,

$$
\psi_{j, n}(x)=2^{-j / 2} \psi\left(2^{-j} x-n\right)
$$

tal que para cualquier función $f$ en $L^{2}(R)$,

$$
P_{j-1} f=P_{j} f+\sum_{n \in Z}\left\langle f, \psi_{j, n}\right\rangle \psi_{j, n}
$$


indicando $P_{j}$ la proyección ortogonal en $V_{j}$ y $P_{j} f$ es la aproximación de $f$ en la resolución $j$. Se comprueba que si $\psi_{0, n}(x)$ es una base ortonormal de $W_{0}$, para el nivel $j=0$ y una traslación $n$ se cumple que la función (4-49) es base ortonormal de $W_{\mathrm{j}}$ y que $\left\|\psi_{j, n}\right\|=1$.

Al ser $P_{j}$ una proyección ortogonal, se tiene que $P_{j} f$ es un elemento del espacio de vectores $V_{j}$ definido por:

$$
V_{j}=\left\{P_{j} f \mid f \in \mathrm{L}^{2}(R)\right\}
$$

Un análisis multiresolución es entonces construido proyectando $f$ en sucesivas aproximaciones de menor resolución. Una aproximación multiresolución de $L^{2}(R)$ consiste en una serie de subespacios anidados $V_{j} \subset \mathrm{L}^{2}(\mathrm{R})$ para los cuales

$$
\ldots V_{2} \subset V_{1} \subset V_{0} \subset V_{-1} \subset V_{-2} \subset \ldots
$$

con dos propiedades básicas:

$$
\overline{\mathrm{j} \in \mathrm{Z}} V_{j}=\mathrm{L}^{2}(\mathrm{R}) \quad y \quad \bigcap_{\mathrm{j} \in \mathrm{Z}} V_{j}=\{0\}
$$

Para construir esta escalera de subespacios como una representación multiescala se debe cumplir:

$$
f(x) \in V_{j} \Rightarrow f(2 x) \in V_{j-1} \quad \forall j \in Z
$$

es decir, que una señal reescalada pertenezca a subespacios diferentes. También se requiere invarianza de $V_{0}$ bajo traslación:

$$
f(x) \in V_{0} \Rightarrow f(x-n) \in V_{0} \quad \forall n \in Z
$$

Para completar este modelo se requiere que exista una función $\varphi(x) \in V_{0}$, tal que

$$
\left\{\varphi_{0, n}\right\}_{n \in Z} \text { sea una base ortonormal de } V_{0}
$$

Con los anteriores requerimientos se llega a concluir que la familia de funciones scaling

$$
\varphi_{j, n}(x)=2^{-j / 2} \varphi\left(2^{-j} x-n\right)
$$

es una base ortonormal para $V_{j}$.

Proyectar $f$ desde $V_{j-1}$ hasta $V_{j}$ genera una pérdida de información de la señal. Por este motivo se define el espacio $W_{j}$ como complemento ortogonal de $V_{j}$ en $V_{j-1}$, es decir:

$$
v_{j-1}=v_{j} \oplus W_{j}
$$


y a $W_{j}$, que contendrá la diferencia de información entre $P_{j} f$ y $P_{j-1} f$, se le llama espacio de detalles en el nivel o escala $j$.

La ecuación anterior expresa la idea básica de que un análisis o espacio multiresolución es una serie de subespacios $V_{j}$ anidados y expandidos por la base ortonormal $\varphi_{j, n}(x), n \in Z$. El subespacio $W_{j}$ es extendido por la base ortonormal $\psi_{j, n}(x)$, $n \in Z$ y es el espacio complementario de $V_{j}$ en el subespacio $V_{j-1}$. Los subespacios $V_{j}$ y $W_{j}$ son llamados espacio de aproximación y de detalle al nivel $j$.

De forma análoga, para cada aproximación multiresolución existe una base ortonormal de funciones wavelet $\left\{\psi_{j, n}\right\}_{j \in Z}$ para cada subespacio $W_{j}$ que calcula la proyección de $f$ en $W_{j}$.

Este modelo aplicado a un número $d$ de niveles, permite entender cómo una señal de partida es descompuesta en los sucesivos subespacios de cada nivel $j$. Si se parte de un nivel genérico $j=0$, se puede obtener:

$$
V_{0}=V_{d} \oplus \underset{j=1}{\stackrel{d}{\oplus}} W_{j}
$$

y una señal $f(x) \in V_{0}$ puede ser descompuesta como:

$$
f(x)=\sum_{n} l_{d, n} \varphi_{d, n}(x)+\sum_{j=1}^{d} \sum_{n} d_{j, n} \psi_{j, n}(x)
$$

donde el primer término es la señal de baja resolución o aproximación $L_{d}=\left\{I_{d, n}\right\}_{n \in z}$; los coeficientes $D_{j}=\left\{d_{j, n}\right\}_{n \in Z}$ forman la señal de detalle en la escala $j$. Al conjunto completo de coeficientes $\left\{L_{d},\left\{D_{j}\right\}_{1 \leq j \leq d}\right\}$ se le llama representación wavelet a nivel $d$ de la señal $f(x)$.

Recordando que una función de partida $f(x)$ puede ser reconstruida sumando las funciones de la base wavelet ortogonal ponderadas por los coeficientes de la transformada wavelet:

$$
f(x)=\sum_{j} \sum_{n} C_{j, n} \psi_{j, n}(x)
$$

entonces en un nivel $j$ y para toda traslación $n$, el detalle $D_{j}$ es el sumatorio:

$$
D_{j}(x)=\sum_{n \in Z} C_{j, n} \psi_{j, n}(x)
$$

Sumando los detalles a todos los niveles, la señal inicial es reconstruida: 


$$
f(x)=\sum_{j \in Z} D_{j}
$$

Para un determinado nivel de trabajo $J$, existen dos tipos de detalles. Aquellos de niveles o escalas $j \leq J$, llamados detalles finos, o simplemente detalles; y otros correspondientes a $j>J$ que son los más groseros y a los cuales se les denomina aproximaciones de la señal a ese nivel $J$ :

$$
A_{J}=\sum_{j>J} D_{j}
$$

Por tanto, la señal original es obtenida por la suma de los detalles finos y la aproximación en la escala $J$.

$$
f(x)=A_{J}+\sum_{j \leq J} D_{j}
$$

Alguna de las propiedades de las funciones detalladas en este estudio multiresolución permiten relacionar funciones con los coeficientes de los filtros asociados. Dado que la función $\varphi \in V_{0} \subset V_{-1}$ y la familia $\varphi_{-1, n}$ es una base ortonormal de $V_{-1}$, tenemos que

$$
\varphi=\sum_{n} h_{n} \varphi_{-1, n}
$$

siendo

$$
\begin{gathered}
h_{n}=\left\langle\varphi, \varphi_{-1, n}\right\rangle=\int_{-\infty}^{+\infty} \varphi(n) \varphi(-1, n) \\
\sum_{n \in Z}\left|h_{n}\right|^{2}=1
\end{gathered}
$$

que para una señal que sea función de $x$

$$
\varphi(x)=\sqrt{2} \sum_{n} h_{n} \varphi(2 x-n)
$$

Esta función es conocida por algunos autores como ecuación de dilatación (Strang, 1996, Ward, 2000) y es una relación clara entre los coeficientes del filtro paso bajo $h_{n}$ (o filtro $H$ genéricamente) y la función scaling $\varphi$ implicando dos tamaños consecutivos, $x$ y $2 x$. 
Siguiendo el desarrollo de Daubechies (1992) y al igual que para la función scaling, se puede definir $\psi$ en función de la scaling $\varphi$ y se llega a que la función wavelet $\psi$ es dependiente de la scaling $\varphi$ de la manera siguiente:

$$
\begin{gathered}
\psi=\sum_{n} g_{n} \varphi_{-1, n} \\
\psi(x)=\sqrt{2} \sum_{n} g_{n} \varphi(2 x-n)
\end{gathered}
$$

Usando la condición de que las funciones wavelet amplían ortogonalmente a las funciones scaling se puede explicar la relación entre los coeficientes de los filtros paso bajo $h_{n}$ y paso alto $g_{n}$ :

$$
g_{n}=(-1)^{n} h_{-n+1}
$$

es decir, esta relación controla los valores de los filtros asociados tal y como se produce en los bancos de filtros ortonormales, de tal forma que se presentan modulaciones inversas y signos contrarios, es decir, los coeficientes del filtro paso alto $g_{n}$ son los de $h_{n}$ invertidos y de signo cambiado o no según su posición en el vector de coeficientes (el parámetro de traslación $n$ ha de ser entendido como posición en el filtro) y sustituyendo obtenemos la también conocida como ecuación wavelet (Strang, 1996, Ward, 2000):

$$
\psi(x)=\sqrt{2} \sum_{n}(-1)^{n-1} h_{-n-1} \varphi(2 x-n)
$$

que claramente muestra la dependencia de los coeficientes del filtro paso alto $g_{n}$ (o filtro $G$ genéricamente) respecto de los del filtro paso bajo $h_{n}$.

En los trabajos de algunos autores, Unser (1995), se demuestra que la transformada wavelet aplicada como análisis multiresolución en varios niveles es útil para la discriminación de texturas. Las características obtenidas de una descomposición MRA de nivel dos o tres generan mejores resultados que un análisis con una resolución tan solo.

\subsubsection{Wavelet Frames Discreta (DWF)}

El término FRAME (traducido por "marco") ha sido introducido en la transformada wavelet para expresar una variedad de ella que se centra básicamente en ser redundante. No debe ser confundido por tanto con el método-modelo FRAME (Filters, Random fields and Maximum Entropy) de síntesis imitativa de texturas, propuesto en 1996 por Chun Zhu 
et al., y basado en la generación de una textura con las mismas funciones de densidad de probabilidad marginales en un conjunto de filtros (Chun Zhu et al., 1998).

El término frame hace referencia a un conjunto de vectores no independientes, $\mathrm{N}$ dimensionales definidos en el espacio $\mathrm{R}^{\mathrm{N}},\left\{f_{k}\right\}$, con $1 \leq k \leq K$ y $K \geq N$. Expresado en forma de matriz, un frame viene dado por una matriz $F$ de tamaño $N \times N, K \geq N$, donde las columnas son los vectores del frame $f_{k}$ (Skretting y Husoy, 2002). En dimensiones finitas, cualquier grupo de vectores que abarque el espacio $\mathrm{R}^{N}$ es un frame. Esa familia de vectores caracteriza cualquier señal a partir de sus productos internos. Al ser un conjunto de vectores no independientes pueden ser redundantes, por lo que están asociados con sobremuestreo o redundancia.

El punto de partida de este modelo se puede localizar en la discretización de la CWT, donde la reconstrucción perfecta de la señal inicial mediante la transformada inversa discreta no es fácilmente obtenible. Para lograr esa reconstrucción perfecta, la familia wavelet $\left\{\psi_{m, n}\right\}, m, n \in Z$ debe constituir un frame, lo que significa que deben existir dos variables $A$ y $B$ tal que $0<A \leq B<\infty$ y para $\forall f \in \mathrm{L}^{2}(\mathrm{R})$ se cumpla:

$$
A\|f\|^{2} \leq \sum_{m, n}\left|\left\langle f, \psi_{m, n}\right\rangle\right|^{2} \leq B\|f\|^{2}
$$

donde $A$ y $B$ son los límites del frame, que es esencialmente una generalización de una base (una base ortonormal es un frame ajustado para el que $A=B=1$ )

También es llamada Overcomplete Wavelet Decomposition y tiene buenas aplicaciones en caracterización de texturas, clasificaciones y segmentaciones. Su puesta en práctica se realiza como una descomposición wavelet sin remuestreos, mediante el empleo de bancos de filtros, de tal manera que las imágenes resultantes de aplicar esos bancos de filtros no son submuestreadas. Esto provoca que se presente una alta redundancia en los resultados. Empleada para crear representaciones de señales que no son invariantes a la traslación, aunque esto incremente su dificultad para su empleo en alguna aplicación como reconocimiento de patrones, genera descriptores de textura invariantes con respecto a la traslación de la imagen de entrada. Esta propiedad, que parece ser bastante deseable en el contexto de imágenes, puede proporcionar una mejor estimación de las estadísticas de textura y caracterización de texturas más detallada en las zonas próximas a los bordes. Los resultados de algunas comparaciones (Unser, 1995) entre la DWT y DWF apuntan a que la DWF es ligeramente mejor que DWT y que las características multiresolución con nivel 2 o 3 contribuyen en mejor medida que las de nivel 1 a la clasificación y discriminación de las texturas. Además, para la extracción de características, la DWF tiende a disminuir la variabilidad de las características de textura estimadas lo cual mejora la realización de la clasificación. Los algoritmos que aplican la transformación DWF se 
prestan bastante bien a la segmentación de texturas, como ocurre con la wavelet discreta frame DWF (aplicada como la wavelet discreta ordinaria) o bien la wavelet packet discreta frame DWPF (variedad de la wavelet packet discreta), por citar algunos.

Los bancos de filtros críticamente muestreados (sin redundancias en los coeficientes obtenidos) implican imprecisiones en la identificación de bordes. El uso de representaciones sobremuestreadas, es decir, de wavelet frames, es una solución para minimizar ese problema. Algunos ejemplos los encontramos en las wavelets Mexican Hat (segunda derivada de una gaussiana) y Morlet (gaussiana modulada).

Un inconveniente de esta variedad de la transformada wavelet es que al ser redundante conlleva una cierta ineficiencia computacional y la definición de los coeficientes de los filtros requiere aplicar transformadas de Fourier, tanto directas como inversas.

\subsubsection{Otras transformadas redundantes}

Uno de los inconvenientes de la Transformada Wavelet Discreta radica en que no es invariante a las traslaciones, es decir, una imagen inicial y otra en la que se haya realizado una pequeña traslación, presentarán diferentes coeficientes wavelet en la transformación (Moulin, 2000, Gyaourova, 2002). Este contratiempo es importante en aplicaciones como detección de bordes, determinación de patrones espaciales y reconocimiento de imágenes en general.

Se puede evitar este efecto aplicando una transformada wavelet redundante o no dividida (Undecimated Wavelet Transform), de dos formas posibles: (1) no dividiendo la imagen de entrada, es decir no submuestreándola sino tan solo operando sobre ella mediante los correspondientes bancos de filtros, de tal forma que las subbandas resultantes de la transformada wavelet tengan las mismas dimensiones que la imagen inicial; o bien (2) aplicando sobre ella y sobre sus versiones desplazadas la DWT ordinaria (que implica submuestreo), consiguiendo una redundancia de información que es equivalente a no dividirla.

Al hablar de versiones desplazadas de una señal bidimensional o imagen, se entiende que se ha realizado un desplazamiento de la imagen un número determinado de filas (desplazamiento vertical), columnas (desplazamiento horizontal) o de ambas (desplazamiento diagonal). En la figura 4-8 se puede apreciar un detalle de la imagen original y de la modificada diagonalmente mediante el desplazamiento de la $1^{\text {a }}$ fila hacia abajo y la inserción de la última en su lugar y de la $1^{\text {a }}$ columna hacia la derecha y la inserción de la última en su lugar. 


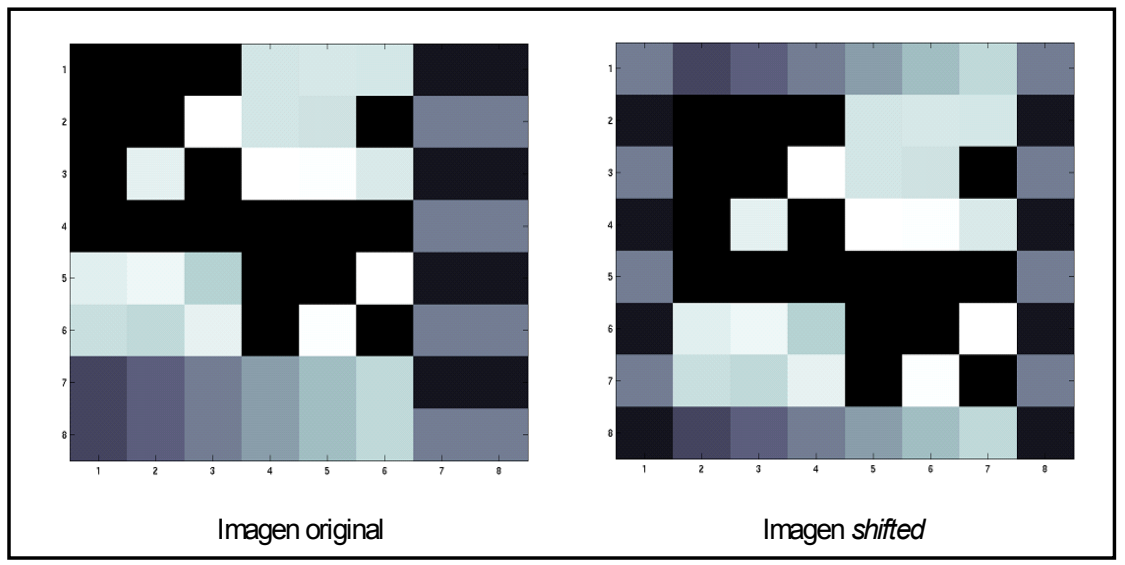

Figura 4-8. Ejemplo de la modificación de una imagen por desplazamiento.

Son varias las aproximaciones al estudio de la transformada wavelet redundante, a saber, wavelet packet, algoritmo "à trous", algoritmo de Beylkin, algoritmo undecimated, algoritmo "shift4"... (Gyaourova, 2002). Algunos de estos modelos de transformada son empleados en diferentes campos científicos, pudiendo destacar los tres siguientes:

- Algoritmo "à trous"

- Algoritmo "shift4"

- Wavelet Packet

\subsubsection{Algoritmo "à trous"}

Fue desarrollado por Holschneider, Kronland-Martinet, Morlet y Tchamitchian, en 1989. Consiste en una descomposición basada en la transformación wavelet discreta en la que no se produce submuestreo de las imágenes, sino que éstas presentan siempre la misma resolución. Se realiza una convolución con los filtros básicos paso bajo $\mathrm{H}$ y paso alto $\mathrm{G}$ que son expandidos insertando un número apropiado de ceros entre los coeficientes (Unser, 1995, González-Audicana et al., 2003). De forma práctica se descompone la imagen convolucionándola mediante un filtro paso bajo bidimensional, obteniendo de esta manera una imagen de aproximaciones, mientras que los coeficientes de detalles resultan de la diferencia entre dos imágenes consecutivas filtradas con el citado filtro paso bajo (Núñez et al., 1999). De forma inversa se procedería para la reconstrucción.

El filtro bidimensional de paso bajo generalmente consiste en un filtro spline bicúbico, asociado a la función scaling, si bien se pueden aplicar otros filtros cuyos coeficientes sean los correspondientes a los aplicados en la descomposición wavelet discreta. En la figura 4-9 se muestra la rutina de cálculos para obtener las imágenes de aproximaciones y detalles a diferentes niveles, con un filtro genérico de paso bajo de $5 \times 5$. 


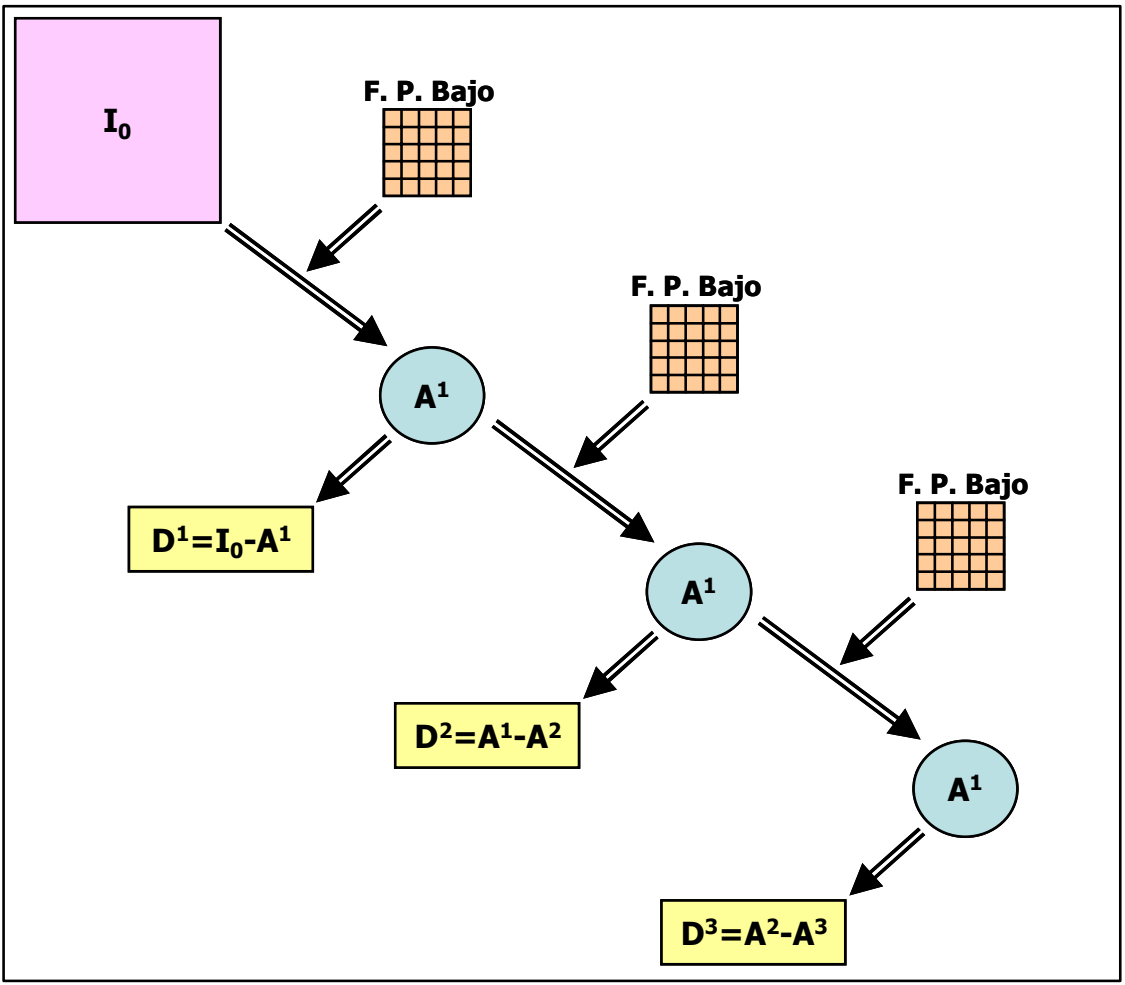

Figura 4-9. Algoritmo "à trous" aplicado sobre una imagen de partida $\mathrm{I}_{0}$ e imágenes resultantes.

Dado que es uno de los algoritmos con los cuales se ha experimentado en el presente trabajo, los detalles de su aplicación práctica se detallan en el apartado 6.3.4.1. del capítulo "Metodología".

\subsubsection{Algoritmo "shift4"}

Se trata de un algoritmo que presenta un buen comportamiento estadístico y visual en diferentes aplicaciones (Gyaourova, 2002). Consiste en la descomposición DWT a nivel 1 y posterior reconstrucción en aproximación y detalles, aplicado tanto sobre la imagen inicial como sobre otras imágenes ligeramente modificadas por desplazamientos de filas y columnas de píxel en píxel. Para la obtención de la imagen reconstruida se deberían promediar los resultados de la reconstrucción de cada una de las 4 imágenes de partida (la original, la desplazada en 1 fila, la desplazada en 1 columna y la desplazada en diagonal 1 fila y 1 columna), tal y como detalla el gráfico de la figura 4-10.

Ha sido aplicado en el presente estudio y los detalles sobre la metodología de trabajo se detallan en el apartado 6.3.4.1. 


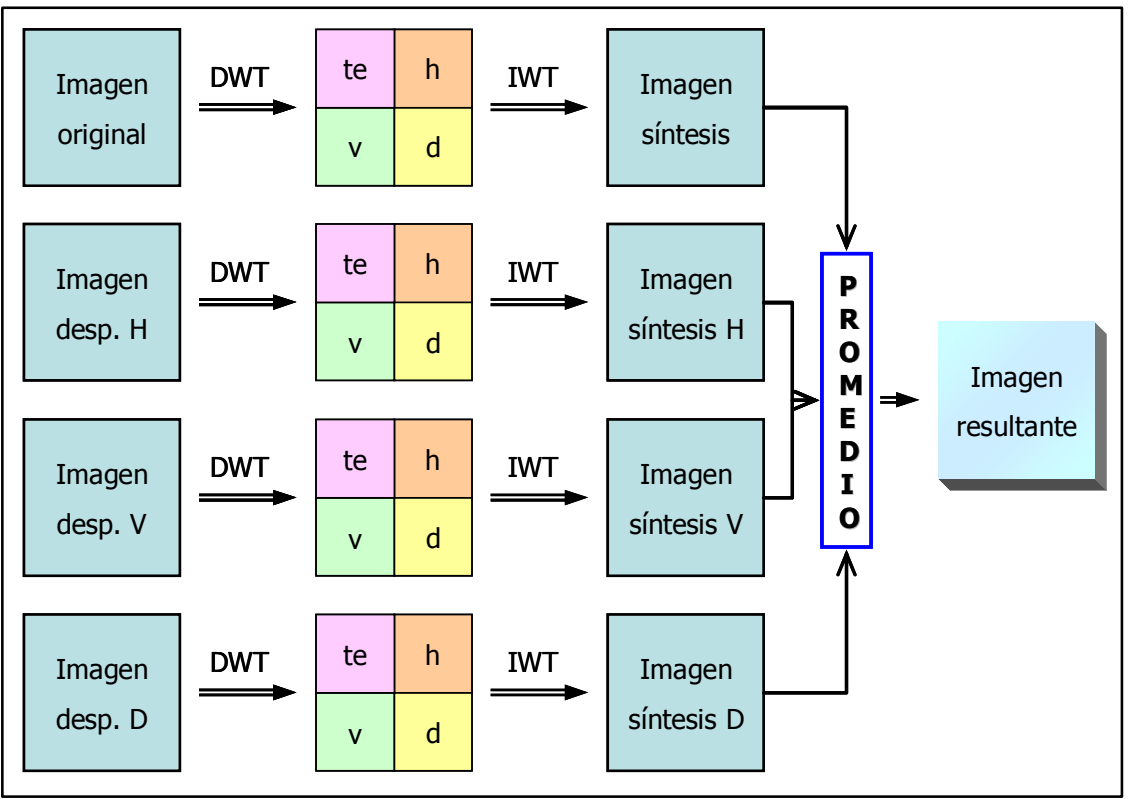

Figura 4-10. Esquema de procedimiento del algoritmo shift4.

\subsubsection{Transformada Wavelet Packet}

Consiste en otra forma de aplicar la transformada wavelet que genera resultados redundantes por lo que a veces se le incluye dentro de la wavelet frame discreta (DWF). Corresponde a un esquema de descomposición en árbol sin submuestreo, en el que el resultado de cada proceso de filtrado sirve como entrada al siguiente, por lo que se genera una estructura arborescente desde una imagen inicial $s$ que es descompuesta en aproximación $\left(a_{1}\right)$ y detalles $\left(d_{1}\right)$ y estos a su vez en aproximación y detalles y así sucesivamente (figura 4-11). Son varios los autores que la han aplicado con diferentes finalidades (Lain y Fan, 1993, Rajpoot, 2002, Randen, 1997, Chang y Kuo, 1993,...) tal y como se detalla en el análisis de antecedentes del capítulo II.

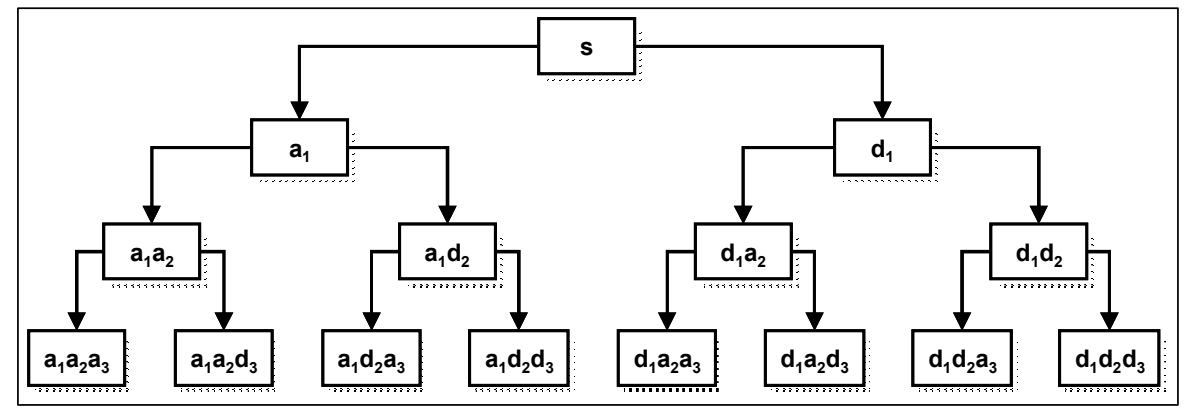

Figura 4-11. Esquema de descomposición de la transformada wavelet packet. 


\subsubsection{La Transformada Wavelet Rápida (FWT)}

También denominada algoritmo piramidal o algoritmo de Mallat (Mallat, 1989, Strang, 1996), se basa en una descomposición siguiendo un modelo piramidal, en el que en cada nivel de la descomposición se produce una disminución del tamaño de la imagen. La implementación de este algoritmo se realiza mediante filtros unidimensionales asociados a las funciones wavelet y scaling, cuyos coeficientes satisfacen los parámetros de dichas funciones. El filtro de paso bajo $(h)$ se asocia a la función de escala y permite analizar los componentes de bajas frecuencias, mientras que el filtro de paso alto $(g)$ se asocia a la función wavelet y extrae la información referente a las altas frecuencias, es decir, los detalles. Los parámetros de cada filtro dependen de la familia de funciones wavelet y scaling empleadas pero siempre son filtros de paso bajo y paso alto que se aplican mediante la convolución con la señal.

En este algoritmo de descomposición y para señales unidimensionales se cumple que $M=L+1$, donde $M$ es el número de canales o de salidas, resultados del algoritmo y $L$ es el número de niveles del árbol. A cada salida se le suele denominar octava, porque realmente corresponde a una banda frecuencial de anchura una octava y la primera salida (la del primer filtro paso bajo) se corresponde a la octava de frecuencia más alta y la última salida (de todos los filtrados y submuestreos) a la octava de frecuencia mas baja. El comportamiento con imágenes será diferente al realizarse un proceso por filas y por columnas conjuntamente.

La transformada wavelet rápida (FWT) es una implementación bastante eficiente desde el punto de vista computacional de la transformada wavelet discreta (DWT) que se aprovecha de una relación entre los coeficientes de la DWT en escalas adyacentes. La FWT se asemeja mucho al esquema de codificación o descomposición subbanda de la figura 4-2.

Considerando de nuevo las ecuaciones que relacionan las funciones scaling y wavelet con los coeficientes de los filtros de paso bajo y paso alto, expresadas en el apartado del MRA:

$$
\begin{aligned}
& \varphi(x)=\sum_{n} h(n) \sqrt{2} \varphi(2 x-n) \\
& \psi(x)=\sum_{n} g(n) \sqrt{2} \varphi(2 x-n)
\end{aligned}
$$

Escalando por $2^{j}$, trasladándola por $k$ y siendo $m=2 k+n$, tenemos 


$$
\begin{aligned}
\varphi\left(2^{j} x-k\right) & =\sum_{n} h(m-2 k) \sqrt{2} \varphi\left(2^{j+1} x-m\right) \\
\psi\left(2^{j} x-k\right) & =\sum_{n} g(m-2 k) \sqrt{2} \varphi\left(2^{j+1} x-m\right)
\end{aligned}
$$

formulación que expresa la relación entre los coeficientes de dos niveles o escalas consecutivos $j$ y $j+1$.

Partiendo de las ecuaciones de los coeficientes de detalle y de aproximaciones a un nivel $j$

$$
\begin{aligned}
& W \varphi(j, k)=\frac{1}{2^{j}} \sum_{x} f(x) \varphi_{j, k}(x) \\
& W \psi(j, k)=\frac{1}{2^{j}} \sum_{x} f(x) \psi_{j, k}(x)
\end{aligned}
$$

y entendiendo esa dependencia de los coeficientes de un nivel respecto de los anteriores, se tiene que esos coeficientes para un nivel $j$ y un desplazamiento $k$ son:

$$
\begin{aligned}
& W_{\varphi}(j, k)=\sum_{m} h(m-2 k) W_{\varphi}(j+1, m) \\
& W_{\psi}(j, k)=\sum_{m} g(m-2 k) W_{\varphi}(j+1, m)
\end{aligned}
$$

que indica que tanto los coeficientes de detalle como los de aproximación de la DWT al ser aplicada sobre una señal de entrada y en la escala o nivel $j$ serán función de los coeficientes de aproximación de DWT en el nivel $j+1$. Dada la ortonormalidad de la transformada wavelet, el número de coeficientes resultantes de la descomposición a un nivel es igual al número de coeficientes del nivel anterior. Estas dos últimas ecuaciones revelan una marcada relación entre coeficientes de escalas contiguas. Los coeficientes de aproximaciones y detalles a nivel $j, W \varphi(j, k)$ y $W \psi(j, k)$ pueden ser calculados convolucionando los coeficientes scaling a escala $j+1, W \varphi(j+1, k)$ con los filtros paso bajo y paso alto invertidos $h(-n)$ y $g(-n)$ y submuestreando los resultados. Este esquema de trabajo es el detallado en la figura 4-12, muy similar al de codificación subbanda, donde $h_{0}(-n)$ y $g_{0}(-n)$ son los filtros paso bajo y paso alto de descomposición respectivamente y $h_{1}(n)$ y $g_{1}(n)$ son los filtros paso bajo y paso alto de síntesis o reconstrucción.

El banco de filtros de la figura 4-12 puede ser iterado tantas veces como niveles de la descomposición (escalas) se deseen de tal forma que para $2^{p}$ muestras de la señal y empleando $p$ bancos de filtros se genera la transforma rápida wavelet a las escalas $j-1, j$ 
- 2,..., $j$ - $p$. La figura 4-13 muestra una descomposición en dos niveles. En ella, se divide la señal original en un componente de aproximación o de tendencia $W \varphi(j-1, n)$ y un componente de detalle o de fluctuación $W \psi(j-1, n)$. El segundo lote de filtros, similar al primero, se aplica sobre los coeficientes de aproximación de la primera descomposición dividiéndola en otras dos componentes de coeficientes de aproximación y de detalle a la escala segunda (cada uno de ellos de tamaño un cuarto de la señal inicial) $W \varphi(j-2, n)$ y $W \psi(j-2, n)$.

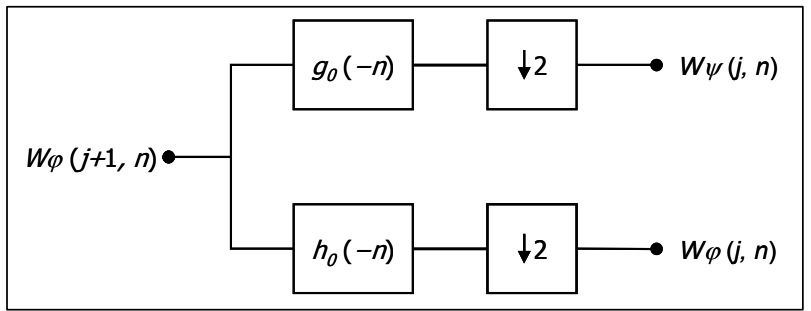

Figura 4-12. Descomposición de los coeficientes de aproximación en el nivel $j+1$.

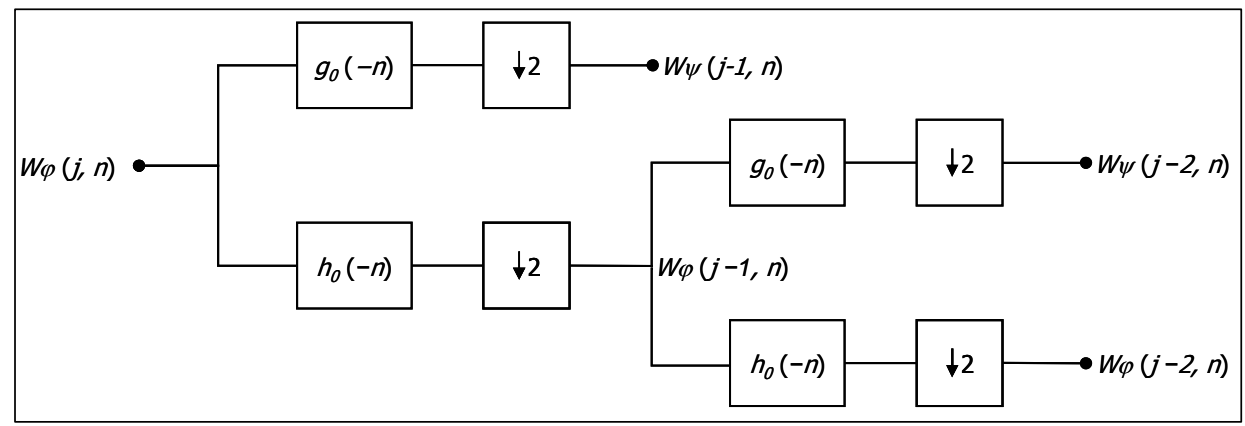

Figura 4-13. Descomposición en dos niveles.

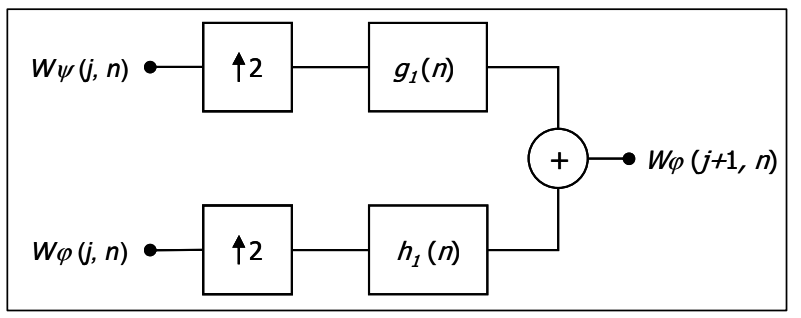

Figura 4-14. Reconstrucción en un solo nivel.

La transformada inversa presenta la ventaja de que al seguir un modelo inverso al anterior se puede conseguir la reconstrucción perfecta de la señal de partida sin pérdida de información y evitando el efecto aliasing, ya que esta transformada se basa en bancos de filtros ortonormales. Denominada transformada wavelet rápida inversa (IFWT), se parte de los filtros paso bajo y paso alto (a veces llamados vectores scaling y wavelet) usados en 
la transformación directa, junto a los coeficientes de detalle y de aproximación de un determinado nivel $j$ para generar los coeficientes de aproximación del nivel $j+1$ (figura 4-14).

Cumpliendo la condición de la ecuación (4-8) para una perfecta reconstrucción mediante filtros ortonormales, se ha de verificar que $g_{i}(n)=h_{i}(-n)$ para $i=\{0,1\}$, es decir, los filtros de análisis y de síntesis han de ser versiones invertidas o traspuestas los unos de los otros. Si los filtros de análisis son $h_{0}(-n)$ y $g_{0}(-n)$, los filtros inversos de síntesis son $h_{1}(n)$ y $g_{1}(n)$.

Como la FWT directa, la FWT inversa puede ser iterada tantas veces como escalas de estudio se consideren de tal manera que siempre se consiga la reconstrucción perfecta de la señal. En la figura 4-15 se adjunta el esquema de reconstrucción desde el nivel $j$ - 2 para obtener los coeficientes de la transformada sobre una determinada señal $f(x)$ unidimensional en el nivel $j$ :

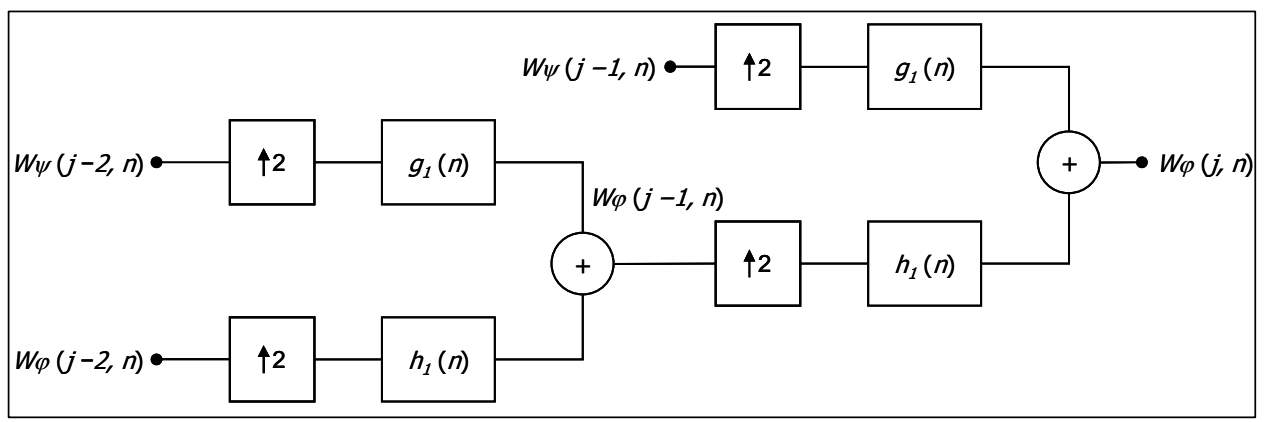

Figura 4-15. Reconstrucción en dos niveles.

\subsubsection{Bases Ortonormales Wavelet Bidimensionales}

Para entender el comportamiento de la transformada wavelet sobre señales bidimensionales (imágenes) hemos de considerar los fundamentos teóricos reseñados para funciones unidimensionales como son las bases de la DWT, el análisis multiresolución, etc.

Una base wavelet separable y ortonormal en $\mathrm{L}^{2}\left(\mathrm{R}^{2}\right)$ es construida con productos separables de funciones scaling $\varphi$ y wavelet $\psi$. La función scaling $\varphi$ es asociada a un filtro paso bajo y a una aproximación en el esquema multiresolución unidimensional $\left\{V_{j}\right\}_{j \in Z}$. La aproximación en la multiresolución bidimensional será $\left\{V^{2}{ }_{j}\right\}_{j \in Z}$ Y vendrá definida por el producto tensorial de los espacios $V_{j}: V^{2}{ }_{j}=V_{j} \otimes V_{j}$. Llamando $W^{2}{ }_{j}$ al espacio de detalles que es complemento ortogonal del espacio de la aproximación de menor resolución $V^{2}{ }_{j}$ en $V^{2}{ }_{j-1}$ : 


$$
V_{j-1}^{2}=V_{j}^{2} \oplus W_{j}^{2}
$$

Para construir una base wavelet ortonormal de $L^{2}\left(R^{2}\right)$ se ha de partir de cada espacio de detalles $W^{2}{ }_{j}$. Sea $\varphi$ una función scaling y $\psi$ una función wavelet que generan una base wavelet ortonormal de $L^{2}(R)$. A partir de ellas se pueden definir tres wavelets separables mediante los correspondientes productos:

$$
\psi^{1}(x)=\varphi\left(x_{1}\right) \psi\left(x_{2}\right), \quad \psi^{2}(x)=\psi\left(x_{1}\right) \varphi\left(x_{2}\right), \quad \psi^{3}(x)=\psi\left(x_{1}\right) \psi\left(x_{2}\right)
$$

que en conjunto forman una base ortonormal de $W^{2}{ }_{j}$ y por extensión de $\mathrm{L}^{2}\left(\mathrm{R}^{2}\right)$. La ecuación (4-81) se puede reescribir como:

$$
V_{j-1} \otimes V_{j-1}=\left(V_{j} \otimes V_{j}\right) \oplus W_{j}^{2}
$$

y como el espacio $V_{j-1}$ también se puede descomponer, reagrupando términos:

$$
W_{j}^{2}=\left(v_{j} \otimes W_{j}\right) \oplus\left(W_{j} \otimes V_{j}\right) \oplus\left(W_{j} \otimes W_{j}\right)
$$

El espacio completo $\mathrm{L}^{2}\left(\mathrm{R}^{2}\right)$ puede ser descompuesto como la suma ortogonal de los espacios de detalles a todas las resoluciones:

$$
\mathrm{L}^{2}\left(\mathrm{R}^{2}\right)=\oplus_{j=-\infty}^{j=+\infty} W_{j}^{2}
$$

Y por tanto el conjunto de las tres wavelets bidimensionales definidas en la ecuación (4-82) forman una base ortonormal de $L^{2}\left(R^{2}\right)$ y extraen de la imagen los detalles a diferentes escalas y orientaciones.

\subsubsection{Transformada Wavelet Rápida en dos dimensiones}

La implementación de la transformada wavelet en imágenes se puede llevar a cabo mediante el uso de filtros (Mallat, 1989). Para muchas señales, sean imágenes o no, el contenido de bajas frecuencias es la parte más importante ya que proporciona su "identidad", mientras el contenido de altas frecuencias matiza esa identidad. Para una imagen, el filtrado de bajas frecuencias suaviza la imagen mientras que el de altas frecuencias extrae los bordes. Se dice entonces que se puede descomponer la imagen en dos componentes, (1) tendencia, aproximación o imagen de baja resolución y (2) detalle de la imagen. Cada una de ellas también es denominada subbanda y por eso se dice que con la transformada wavelet se descompone una imagen en subbandas de diferentes frecuencias. La transformada wavelet en 2 dimensiones también produce la compactación 
de la energía de tal manera que la subimagen de las tendencias acumula la mayor parte de la energía de la imagen. Esta propiedad es el fundamento de los métodos de compresión de imágenes y de eliminación de ruido.

En el caso bidimensional se parte de que la familia de wavelets o wavelets hijas viene definida por:

$$
\psi_{a, b}(x, y)=\frac{1}{\sqrt{a_{1} a_{2}}} \psi\left(\frac{x-b_{1}}{a_{1}}, \frac{y-b_{2}}{a_{2}}\right)
$$

con $(x, y) \in \mathrm{R}^{2}$ y se puede decir que la transformada bidimensional consiste en la extensión del algoritmo unidimensional a dos dimensiones.

Empleando la misma nomenclatura que en apartados anteriores, para aplicar la transformada wavelet sobre una imagen se necesita una función scaling bidimensional $\varphi(x, y)$ y tres funciones wavelet bidimensionales $\psi^{H}(x, y), \psi^{V}(x, y)$ y $\psi^{P}(x, y)$, obtenidas del producto de las funciones unidimensionales scaling $\varphi$ y wavelet $\psi$ :

$$
\begin{gathered}
\varphi(x, y)=\varphi(x) \varphi(y) \\
\psi^{H}(x, y)=\psi(x) \varphi(y) \\
\psi^{V}(x, y)=\varphi(x) \psi(y) \\
\psi^{D}(x, y)=\psi(x) \psi(y)
\end{gathered}
$$

Estas funciones bidimensionales son separables, al poder ser aplicadas de forma individual cada una de las funciones que las generan y las diferencias entre las 3 funciones wavelet radica en que cada una de ellas mide variaciones de intensidades o de niveles de gris en la imagen en 3 direcciones: $\psi^{H}$ mide variaciones a lo largo de columnas (capta los bordes horizontales), $\psi^{V}$ mide variaciones en filas captando así los bordes verticales y $\psi^{P}$ refleja las variaciones en la diagonal de la imagen. Este comportamiento frente a la direccionalidad es consecuencia de la separabilidad de esas funciones al poder ser aplicadas sobre filas o columnas indistintamente.

Al tratar las imágenes como señales discretas estructuradas en filas y columnas, aplicar la transformada wavelet requiere de la definición de las bases de funciones escaladas y trasladadas siguientes: 


$$
\begin{aligned}
& \varphi_{j, m, n}(x, y)=2^{j / 2} \varphi\left(2^{j} x-m, 2^{j} y-n\right) \\
& \psi^{H}{ }_{j, m, n}(x, y)=2^{j / 2} \psi^{H}\left(2^{j} x-m, 2^{j} y-n\right) \\
& \psi^{V}{ }_{j, m, n}(x, y)=2^{j / 2} \psi^{V}\left(2^{j} x-m, 2^{j} y-n\right) \\
& \psi^{D}{ }_{j, m, n}(x, y)=2^{j / 2} \psi^{D}\left(2^{j} x-m, 2^{j} y-n\right)
\end{aligned}
$$

siendo $j$ el nivel de la transformada y $m$ y $n$ traslaciones tal que $m, n=0,1,2, \ldots 2^{j}-1$. La transformada wavelet discreta de una función o imagen $f(x, y)$ de tamaño $M x N$ es:

$$
\begin{gathered}
W_{\varphi}\left(j_{0}, m, n\right)=\frac{1}{\sqrt{M N}} \sum_{x=0}^{M-1} \sum_{y=0}^{N-1} f(x, y) \varphi_{j_{0}, m, n}(x, y) \\
W^{i}{ }_{\psi}(j, m, n)=\frac{1}{\sqrt{M N}} \sum_{x=0}^{M-1} \sum_{y=0}^{N-1} f(x, y) \psi^{i}{ }_{j, m, n}(x, y), \quad i=\{H, V, D\}
\end{gathered}
$$

donde $j_{0}$ es la escala de inicio de la transformación y los coeficientes $W_{\varphi}(j, m, n)$ definen una aproximación a $f(x, y)$ en la escala $j_{0}$. Los coeficientes $W_{\psi}^{i}(j, m, n)$ aportan detalles horizontales, verticales y diagonales para las escalas $j \geq j_{0}$. La escala de partida es generalmente $j_{0}=0$ y si $M=N=2^{j}$ se tendrán como niveles de transformación $j=0,1$, $2, \ldots, J-1$ y $m, n=0,1,2, \ldots, 2^{j}-1$, traslaciones o desplazamientos.

La implementación de la transformada wavelet discreta bidimensional puede ser llevada a cabo, tal y como en el caso unidimensional, mediante bancos de filtros y submuestreos y sobremuestreos. Al ser las funciones scaling y wavelet separables, se pueden aplicar como filtros separables de dos maneras, bien de forma separada por filas o columnas y posteriormente por columnas o filas; o bien de forma conjunta aplicando los filtros bidimensionales sobre toda la imagen.

En la figura 4-16 se puede observar el esquema operativo de la transformada wavelet discreta sobre una señal bidimensional en un solo nivel de escalado. Se parte de los coeficientes de aproximación de nivel $j+1$ para obtener los coeficientes de aproximación y de detalles verticales, horizontales y diagonales del nivel siguiente $j$. En primer lugar se aplican los filtros paso bajo y paso alto unidimensionales sobre las filas, se realiza un submuestreo sobre columnas con factor diádico y el resultado se filtra de nuevo en columnas y tras submuestrear las filas con el mismo factor se obtienen las imágenes de detalles diagonales, verticales y horizontales así como la de aproximación. Estas imágenes tienen una resolución menor, ya que son reducidas por un factor 2 . Este modelo se puede ejecutar en varios niveles de tal forma que los coeficientes de aproximación de un nivel sirvan como entrada en la descomposición del nivel siguiente. Al tratarse de filtros separables, el modelo anterior es plenamente válido, así como el propuesto en la figura 
4-17, en el que se aplican filtros bidimensionales directamente sobre la imagen y tras ellos un submuestreo diádico en filas y columnas para obtener los mismos resultados que al hacerlo mediante filtros unidimensionales. Los coeficientes de los filtros bidimensionales pueden obtenerse bien multiplicando entre sí los vectores de los coeficientes de los filtros unidimensionales o bien directamente como coeficientes de filtros bidimensionales no separables. En ambos casos el resultado será la misma matriz de coeficientes.

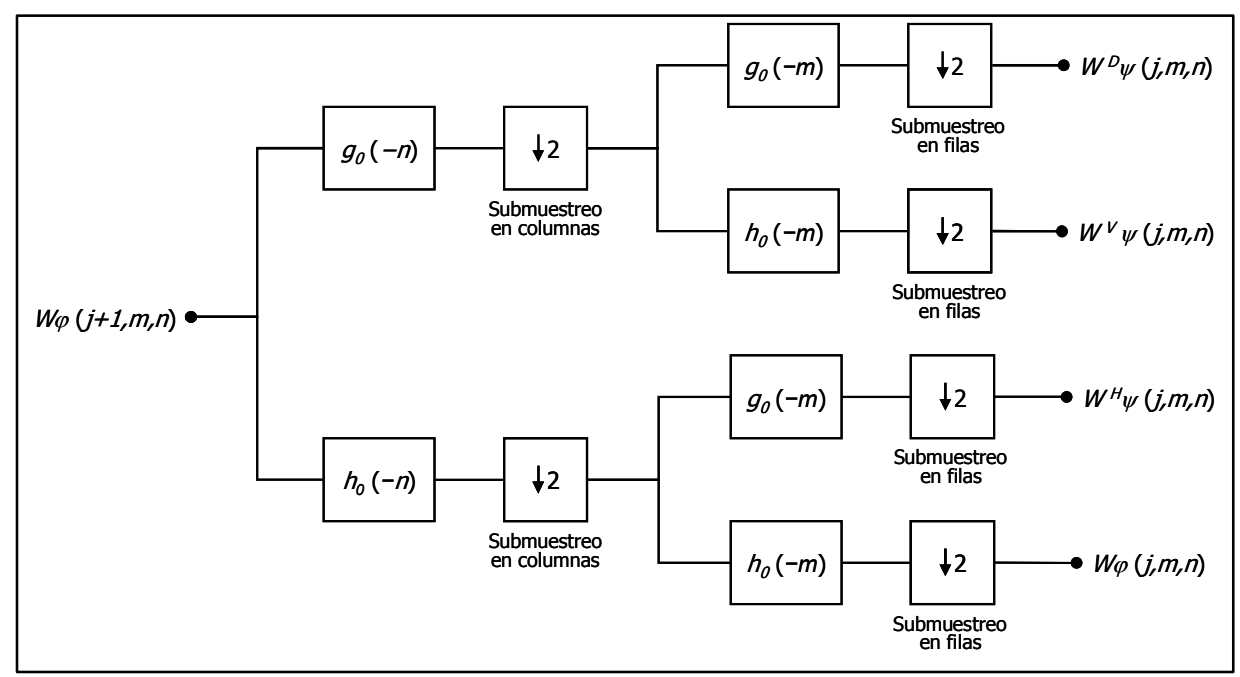

Figura 4-16. Banco de filtros de descomposición en dos niveles y dos dimensiones.

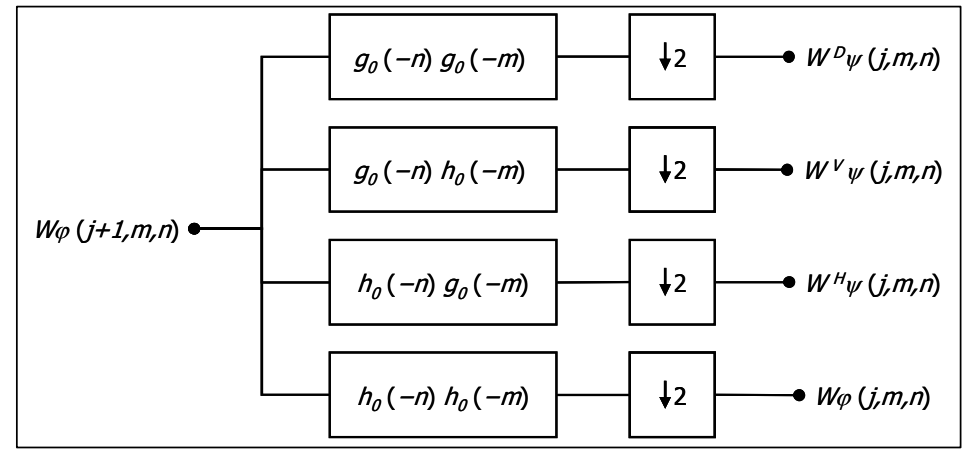

Figura 4-17: Banco de filtros de descomposición bidimensional.

Al aplicar los modelos anteriores de transformación directa se puede decir que la información de tendencias (bajas frecuencias) y de fluctuaciones (altas frecuencias) es obtenida por el producto interno de la señal de partida $f$ con las funciones scaling y wavelet correspondiente. En todas las escalas $2^{j}$ y para toda traslación $(m, n)$ se tiene: 


$$
\begin{aligned}
& a_{j, m, n}=\left\langle f, \varphi_{j, m, n}\right\rangle \\
& d_{j, m, n}^{H}=\left\langle f, \psi_{j, m, n}^{H}\right\rangle \\
& d_{j, m, n}^{V}=\left\langle f, \psi_{j, m, n}^{V}\right\rangle \\
& d_{j, m, n}^{D}=\left\langle f, \psi_{j, m, n}^{D}\right\rangle
\end{aligned}
$$

Dado que este producto interior se aplica en forma de filtros sobre la señal inicial, los coeficientes de las imágenes de aproximación y de detalle a una escala genérica $j$ son obtenidos desde la aproximación a la escala $j+1$ con convoluciones y submuestreos:

$$
\begin{aligned}
& a_{j, m, n}=a_{j+1} \otimes h_{0} h_{0} \\
& d_{j, m, n}^{H}=a_{j+1} \otimes h_{0} g_{0} \\
& d_{j, m, n}^{V}=a_{j+1} \otimes g_{0} h_{0} \\
& d_{j, m, n}^{D}=a_{j+1} \otimes g_{0} g_{0}
\end{aligned}
$$

Partiendo de un nivel 0 (imagen inicial), la descomposición a nivel 1 generaría coeficientes como los de la figura 4-18.

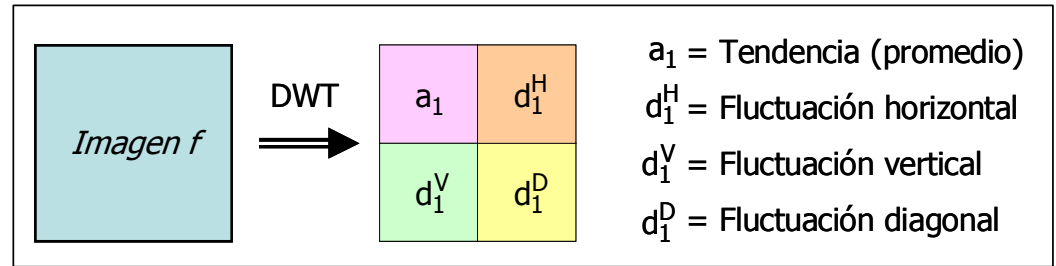

Figura 4-18: Descomposición de una imagen en 4 subimágenes de tendencia y fluctuaciones.

La subimagen tendencia de primer nivel, se ha construido calculando las tendencias a lo largo de las filas en primer lugar y a lo largo de las columnas a continuación. Es una versión de menor resolución, de menos detalle, y de menor tamaño (la cuarta parte) de la imagen original.

La subimagen primera fluctuación horizontal se ha creado calculando tendencias a lo largo de filas y fluctuaciones sobre columnas. Se suavizan los detalles al desplazarnos en sentido horizontal sobre la imagen mientras que se resaltan las variaciones en sentido vertical, por lo que esta imagen resalta los bordes y líneas horizontales en la imagen.

La subimagen primera fluctuación vertical se ha creado calculando fluctuaciones a lo largo de filas y tendencias sobre columnas. Se suavizan los detalles al desplazarnos en sentido vertical mientras que se resaltan las variaciones en sentido horizontal, por lo que esta imagen resalta los bordes y líneas verticales en la imagen. 
Por último, la subimagen primera fluctuación diagonal es el resultado de calcular fluctuaciones tanto en filas como en columnas. Tiende a borrar los bordes horizontales y verticales y a resaltar los diagonales.

La obtención de la imagen inicial $f(x, y)$ desde los coeficientes de fluctuaciones y tendencia es posible mediante la transformada inversa. La figura 4-19 muestra el banco de filtros que invierte el proceso anterior mediante filtros unidimensionales dando lugar a la transformada inversa. Se puede observar como se parte de la información de tendencia y fluctuaciones de un nivel $j$ para, tras ser sobremuestreada insertando filas de ceros, ser filtrada en columnas, sumada, sobremuestreada en columnas, filtrada en filas y sumada, obtener la imagen de aproximación del nivel anterior $j+1$.

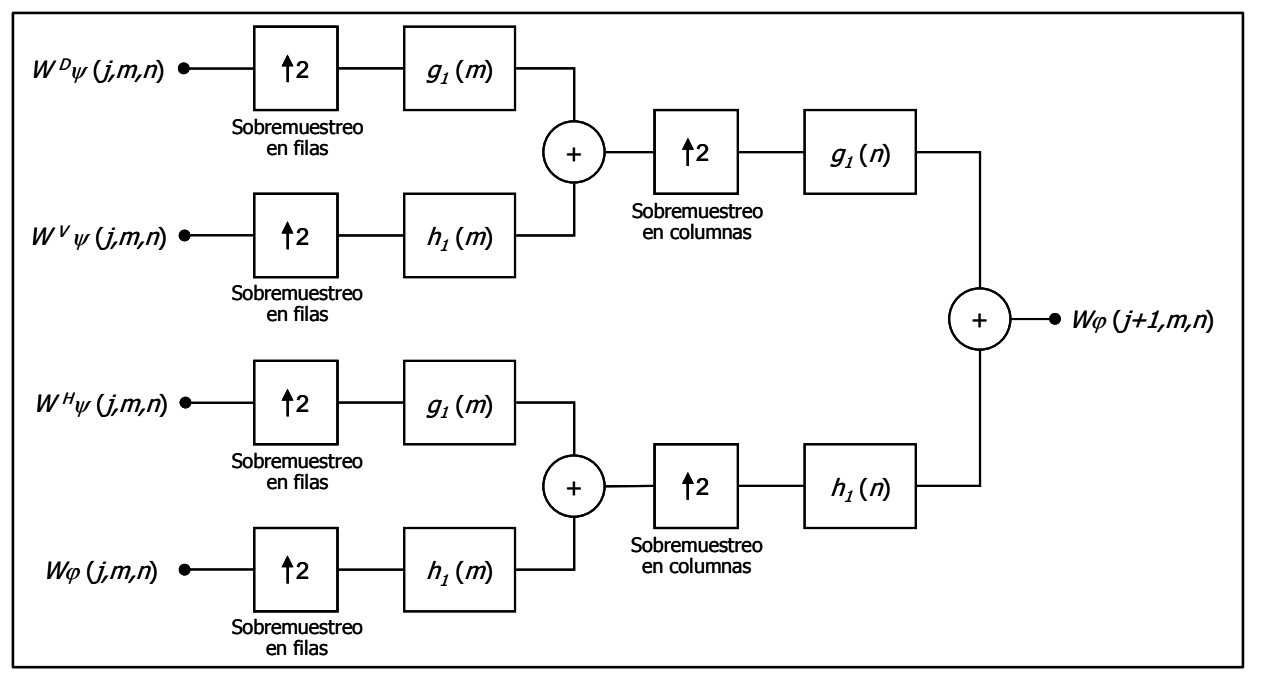

Figura 4-19. Banco de filtros de reconstrucción en dos dimensiones.

El esquema de procedimiento reseñado al hablar de análisis multiresolución nos permite obtener las imágenes de aproximación o promedio y las de detalles mediante la aplicación de la transformada inversa, como muestra la figura 4-20. Estas imágenes tienen la misma resolución espacial y dimensiones que la original. Si se suman las cuatro, se está reconstruyendo la imagen inicial sin pérdida de información, si bien el interés práctico radica en la posibilidad de emplearlas por separado, es decir, emplear la información de detalles verticales, horizontales o diagonales para, entre otros objetivos, caracterizar las texturas presentes en las imágenes y extraer sus variables texturales.

Tras la presente introducción a las bases de la teoría wavelet y los procedimientos posibles de aplicación, se procede en los siguientes capítulos a detallar los datos de partida 
y la metodología desarrollada en el presente trabajo, con el objetivo general de aplicar la transformada wavelet al estudio de texturas en imágenes de la superficie terrestre.

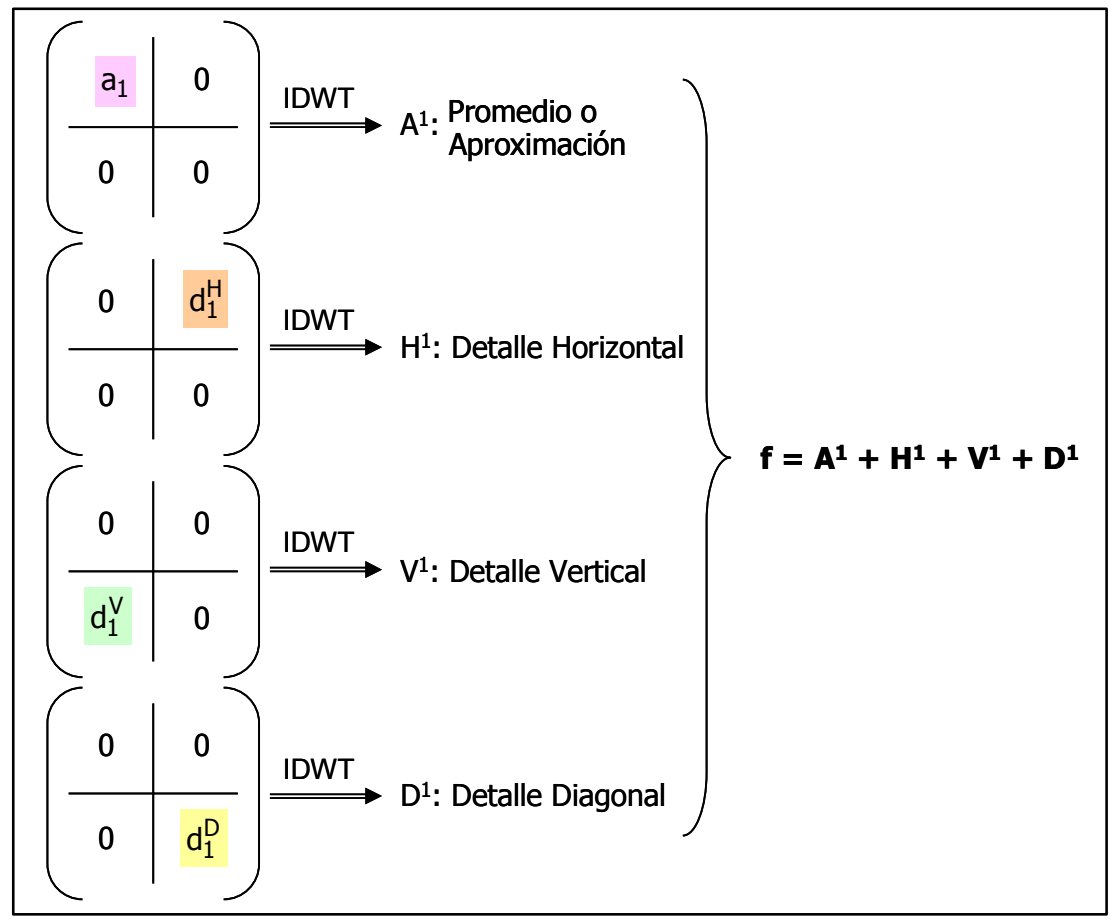

Figura 4-20. Esquema del análisis multiresolución para la obtención de aproximaciones y detalles. 


\section{Capítulo V}

\section{Datos de trabajo}

\subsection{Tipología de las superficies}

Son varias las tipologías de superficies consideradas en el trabajo de cara a analizar una alta representatividad de la realidad de las cubiertas naturales o antrópicas presentes en las imágenes aéreas del territorio. Son 4 las áreas analizadas:

- Zonas urbanas y peri-urbanas (Valencia).

- Zonas rurales mediterráneas (Menorca).

- Zonas agrícolas (Daimiel).

- Zonas de montaña con vegetación natural (Espadán).

- $\quad$ Zonas de montaña mixtas (Ayora).

Respecto al origen de los datos, básicamente se han empleado para los diversos análisis imágenes de dos tipos: unas de alta resolución espacial provenientes del satélite QuickBird y fotogramas aéreos georreferenciados y digitalizados. Las características de la plataforma espacial QuickBird se detallan en la tabla 5-1.

Otras imágenes provienen del SIG Oleícola (elaborado por la Subsecretaría de Agricultura, Pesca y Alimentación del Ministerio del mismo nombre), tratándose de ortofotogramas en blanco y negro, tomados en junio de 2001, con una resolución espacial nominal de 1 metro por píxel. Además se han escaneado fotogramas en blanco y negro de otros vuelos, como es el caso de la imagen de Daimiel y Espadán. 


\begin{tabular}{|l|l|}
\hline - Fecha de lanzamiento & 18 de octubre de 2001 \\
- Altitud orbital & $450 \mathrm{~km}$ \\
- Tipo de órbita & Heliosíncrona, con $98^{\circ}$ de inclinación \\
- Velocidad & $7.1 \mathrm{~km} / \mathrm{s}$ \\
- Hora de cruce con el Ecuador & $10: 30 \mathrm{a} . \mathrm{m}$. (descendente) \\
- Duración de la órbita & 93.4 minutos \\
- Ancho de escena & $16.5 \mathrm{~km}$ x $16.5 \mathrm{~km}$ \\
- Resolución temporal & $1-3.5$ días, según la latitud \\
- Precisión planimétrica & $23 \mathrm{~m}$ en el nadir (CE90\%) \\
- Resolución radiométrica & 11 bits \\
- Resolución espectral & PAN $\quad 450$ - $900 \mathrm{~nm}$. \\
& Azul $\quad 450$ - $520 \mathrm{~nm}$. \\
& Verde $520-600 \mathrm{~nm}$. \\
& Rojo $630-690 \mathrm{~nm}$. \\
- Resolución espacial & Infrarrojo 760 - $900 \mathrm{~nm}$. \\
& PAN: de $61 \mathrm{~cm}$ en el nadir a $72 \mathrm{~cm}$ \\
& MS: de $2.44 \mathrm{~m}$ en el nadir a $2.88 \mathrm{~m}$ \\
\hline
\end{tabular}

Tabla 5-1. Características técnicas de la plataforma comercial QuickBird.

\subsubsection{Zonas urbanas y peri-urbanas}

\section{Imagen QuickBird de Valencia}

Esta imagen corresponde al área metropolitana norte de la ciudad de Valencia y parte de la comarca de L'Horta Nord, las cuales han experimentado un importante crecimiento urbano en las últimas décadas, por lo que se ha producido una notable mezcla entre parcelas de cultivos y áreas urbanas e industriales.

En la tabla 5-2 se recogen las características técnicas de la imagen pancromática, ya que la multiespectral se ha empleado a modo de referencia o para ciertas tareas fotointerpretativas. Algunos parámetros de las imágenes tienen el siguiente significado:

- GSD: Ground Sample Distance, indica el tamaño de un píxel como una medida en el terreno.

- PNIIRS: Calidad prevista de la imagen en el National Imagery Interpretability Rating Scale (NIIRS) calculada por la General Image Quality Equation (GICE). Puede oscilar entre 0.0 y 9.0 .

Ha sido necesario aplicar a la imagen original un proceso de rectificación para corregir posibles errores geométricos, bien sean sistemáticos (efecto de rotación terrestre, 
distorsión panorámica, curvatura de la Tierra u oblicuidad), o bien sean no sistemáticos (cabeceo, alabeo y guiñada), y serles asignada unas coordenadas en el sistema de referencia cartográfico oficial, proyección UTM, datum ED50.

\begin{tabular}{|c|c|c|}
\hline Fecha y hora de adquisición & $17 / 02 / 2004$ & $10: 37: 21$ \\
\hline Descriptor de la imagen & Standard2A & \\
\hline Número de filas y de columnas & 31152 & 20000 \\
\hline Nivel del producto & LV2A & \\
\hline Nivel radiométrico & Corregido & \\
\hline Formato de la imagen & GeoTIFF & \\
\hline GSD (Ground Sample Distance) medio & $0.646 \mathrm{~m}$ & \\
\hline $\begin{array}{l}\text { Incertidumbre posicional de las } \\
\text { coordenadas de la esquina (m) }\end{array}$ & $\begin{array}{lr}\text { Filas: } \quad 37.50 \\
\text { Columnas: } 87.08\end{array}$ & \\
\hline Azimut y elevación solar & $150.8^{\circ}$ & $33.7^{0}$ \\
\hline Azimut y elevación del satélite & $101.0^{\circ}$ & $74.5^{\circ}$ \\
\hline$\%$ de cubierta nubosa & 0.0 & \\
\hline PNIIRS (Calidad prevista de imagen) & 4.5 & \\
\hline Datum, Proyección, Huso, Hemisferio & WE (WGS84) & UTM, 30, Norte \\
\hline Tamaño del píxel & $0.60 \mathrm{~m}$ & \\
\hline Coordenada superior izquierda & $\mathrm{X}: 719897.100$ & Y: 4384792.499 \\
\hline Coordenada inferior derecha & $X: 731896.500$ & Y: 4378797.899 \\
\hline
\end{tabular}

Tabla 5-2. Especificaciones técnicas de la imagen QuickBird pancromática de Valencia.

Tanto en la figura 5-1 como en la figura 5-2 se muestran algunos fragmentos de la imagen multiespectral, así como la equivalencia entre ésta y la pancromática en una porción de la primera, para poder comparar las diferencias en la definición de los elementos a dos resoluciones distintas.

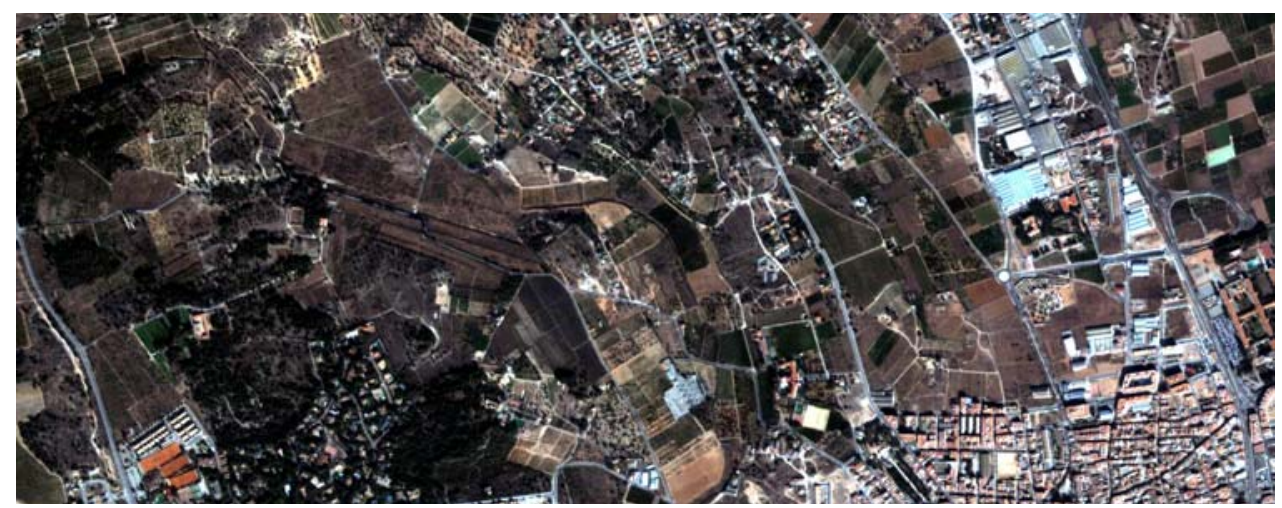

Figura 5-1. Fragmento de la imagen multiespectral QuickBird de Valencia. 

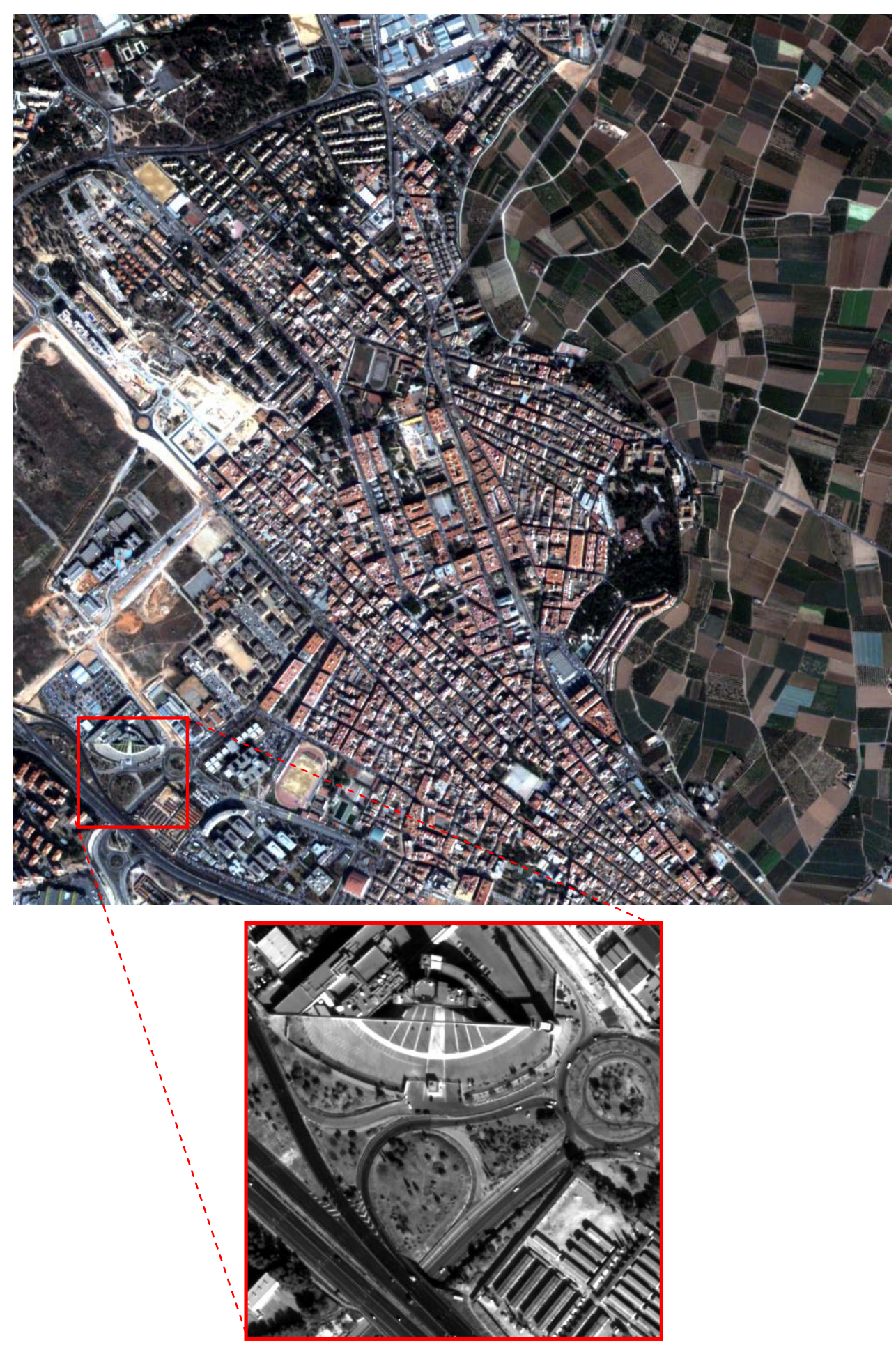

Figura 5-2. Fragmento de la imagen multiespectral y detalle equivalente en la imagen pancromática. 
Partiendo de la imagen pancromática se han elaborado mosaicos homogéneos con porciones de la imagen de una misma clase, para aplicar algunas rutinas como la de determinación de la mejor resolución espacial, pero también para sintetizar en una imagen de menores dimensiones toda la variabilidad de cubiertas y superficies presentes en el área completa. Se han construido otros mosaicos con la heterogeneidad propia de todas las cubiertas presentes en la imagen inicial, como el de la figura 5-3.

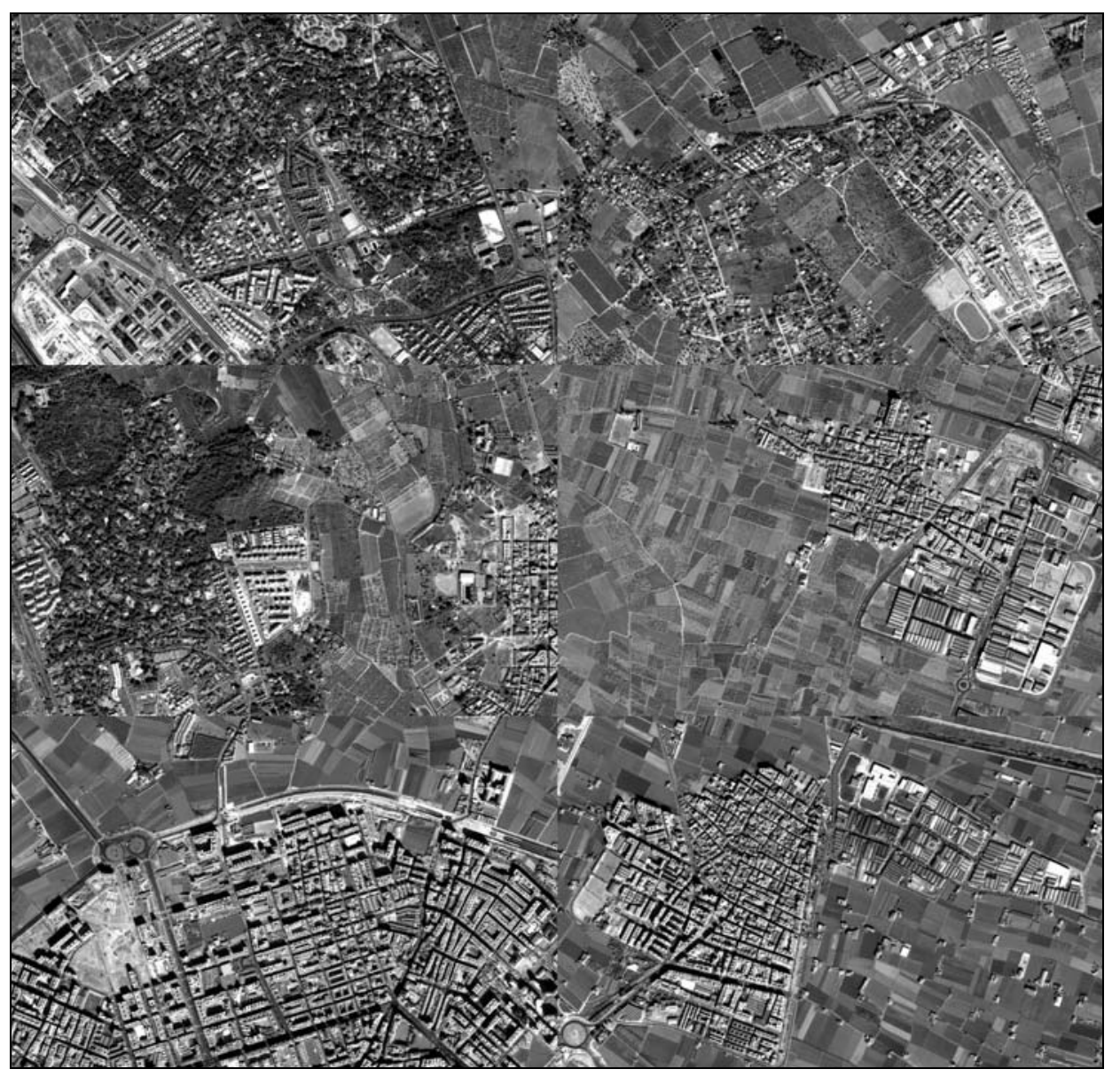

Figura 5-3. Mosaico de la imagen pancromática remuestreada a $1.7 \mathrm{~m}$ por píxel.

En la zona cubierta por esta imagen existen unas tipologías de superficies bastante definidas (figura 5-4): núcleo antiguo (áreas urbanas de edificación irregular y sin planeamiento urbanístico), ensanche (áreas urbanas de expansión urbanística planificada), urbanización con arbolado (áreas residenciales próximas a la ciudad con muchas zonas arboladas), polígono industrial (las construcciones se corresponden a naves industriales que en la mayor parte de los casos tienen formas rectangulares y una marcada regularidad en su distribución espacial), cítricos (cultivos básicamente de naranjos con marcos de 
plantación cuadrados, en diamante o en línea y tamaños variables) y huerta (cultivos hortícolas sin arbolado y con edificaciones dispersas).

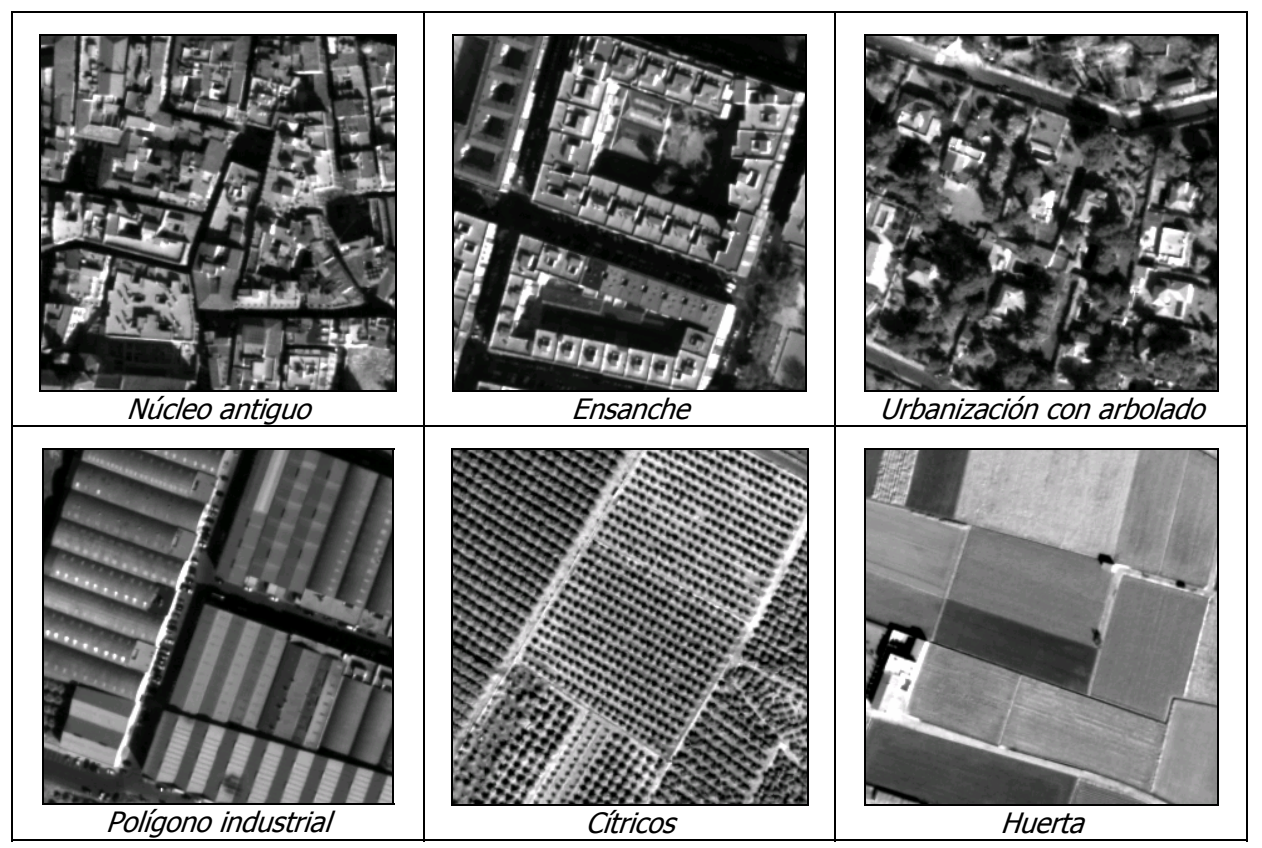

Figura 5-4. Muestras de las clases analizadas en la zona metropolitana de Valencia.

\subsubsection{Zonas rurales mediterráneas}

\section{Imagen QuickBird de Menorca}

Los datos técnicos de esta imagen se detallan en la tabla 5-3. Capta una porción de la isla de Menorca, en concreto de la vertiente sur, organizada hidrológicamente por un conjunto de barrancos vertientes al mar generando calas. Esta parte de la isla ha sido analizada en campo mediante un trabajo in situ realizado en octubre de 2004, fecha en la que la vegetación está menos influenciada por factores estacionales como el estío o la pérdida de masa foliar propia del invierno. Los datos que permiten caracterizar litología, tipo y características de suelo y vegetación han sido tomados según el modelo de ficha de campo adjuntada en el apartado 10.1 de los anejos.

La topografía de ese entorno se caracteriza por una pendiente media baja, entre 3 y $5 \%$. Los barrancos se han formado por procesos de disolución cárstica subsuperficial y posterior colapso de los materiales carbonatados que forman la plataforma sur de la isla 
por lo que son bastante encajados, de paredes verticalizadas y cabeceras en fondo de saco. Al no presentar cursos fluviales continuos existe poco material aluvial en su fondo, siendo el existente de tipo coluvial principalmente. La litología dominante es calcárea y más concretamente se mezclan calcarenitas y materiales calcáreos de origen arrecifal coralino. El afloramiento directo de la base rocosa es bastante frecuente en forma de roca poco fisurada o poco alterada en un alto porcentaje (figuras 5-5 a, b y c), lo que conlleva que el nivel de pedregosidad llegue en algunos puntos de muestreo hasta el $80 \%$. Dada esta meteorización de las calizas poco desarrollada pero evidente, en aquellos espacios que permitan la acumulación es fácil encontrar depósitos arcillosos de descalcificación, que suelen generar espesores de sedimentos a veces considerables (figura 5-5 d), si bien la profundidad media del suelo suele ser relativamente pequeña $(20-30 \mathrm{~cm})$, mientras que su textura predominante es franco arcillosa. El desarrollo del horizonte humífero no es muy alto y se podría calificar como medio $(3-5 \mathrm{~cm}$ ). En aquellos espacios donde se aprecia una mayor meteorización del roquedo y una acumulación de sedimentos es donde se han implantado cultivos (figuras 5-5 e, $f$ y $g$ ) en parcelas de pequeñas dimensiones $y$ generalmente delimitadas por muros de "piedra seca", sin ningún tipo de material cementante.

\begin{tabular}{|lll|}
\hline Fecha y hora de adquisición & 25/12/02 & $10: 32: 12$ \\
\hline Descriptor de la imagen & Standard2A & \\
\hline Número de filas y de columnas & 17500 & 13232 \\
\hline Nivel del producto & LV2A & \\
\hline Nivel radiométrico & Corregido \\
\hline Formato de la imagen & GeoTIFF & \\
\hline GSD (Ground Sample Distance) medio & 0.614 m & \\
\hline $\begin{array}{l}\text { Incertidumbre posicional de las } \\
\text { coordenadas de la esquina (m) }\end{array}$ & Filas: & \\
\hline Azimut y elevación solar & $162.0^{\circ}$ & $24.8^{\circ}$ \\
\hline Azimut y elevación del satélite & 206.50 \\
\hline \% de cubierta nubosa & 0.0 & 84.70 \\
\hline PNIIRS (Calidad prevista de imagen) & 4.5 \\
\hline Datum, Proyección, Huso, Hemisferio & WE (WGS84) & UTM, 31, Norte \\
\hline Tamaño del píxel & 0.60 & \\
\hline Coordenada superior izquierda & X: 596107.500 & Y: 4418999.699 \\
\hline Coordenada inferior derecha & X: 604046.100 & Y: 4408500.299 \\
\hline
\end{tabular}

Tabla 5-3. Especificaciones técnicas de la imagen QuickBird pancromática de Menorca. 


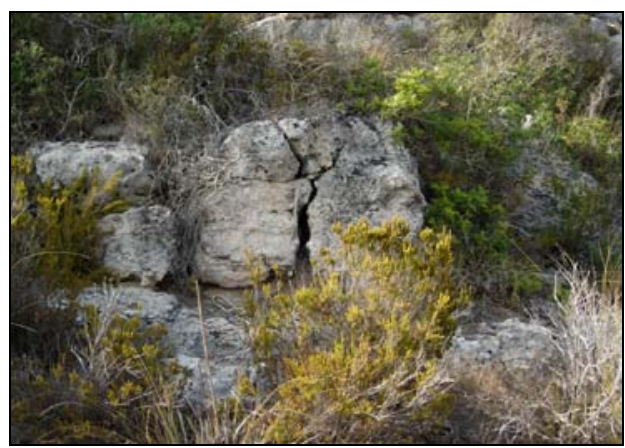

a)

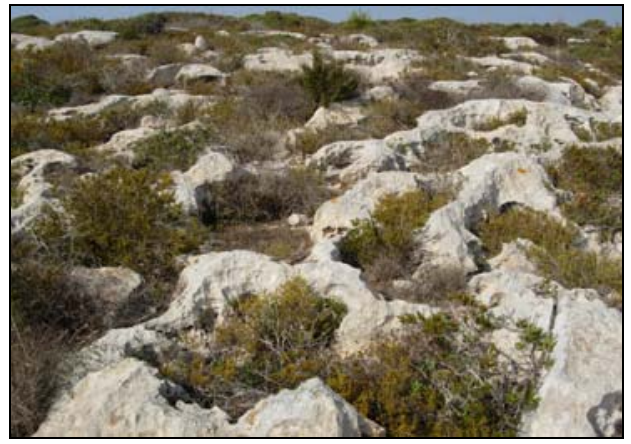

c)

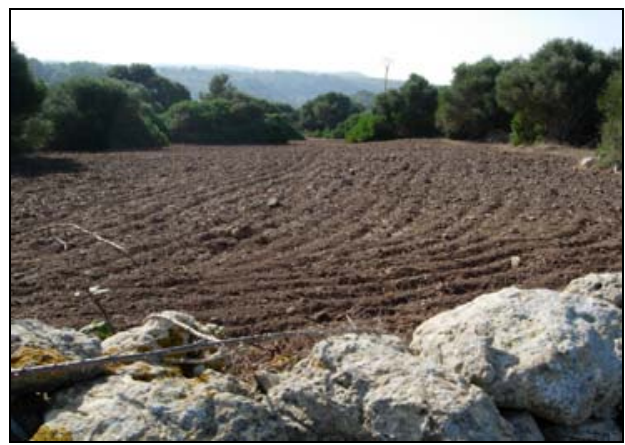

e)

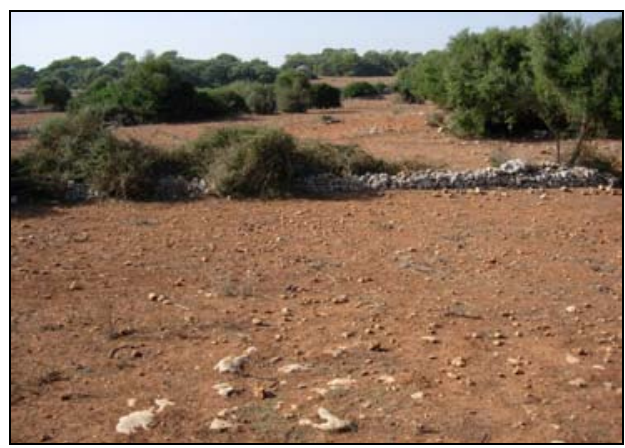

g)

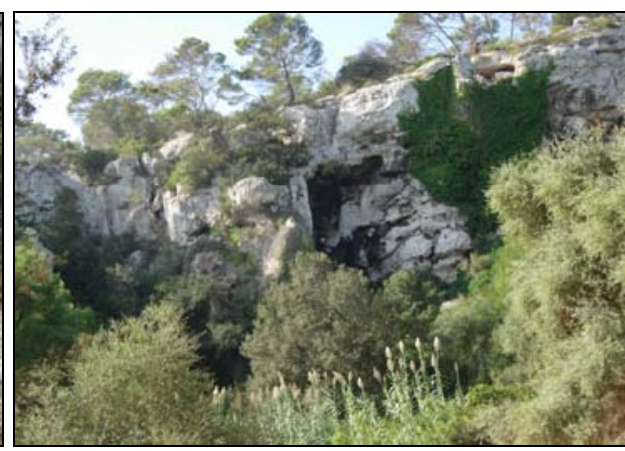

b)

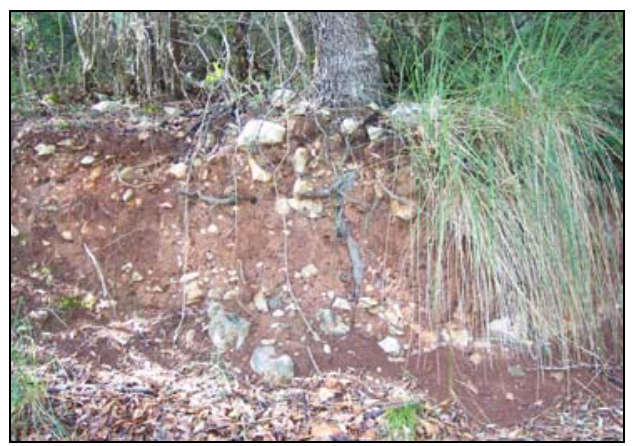

d)

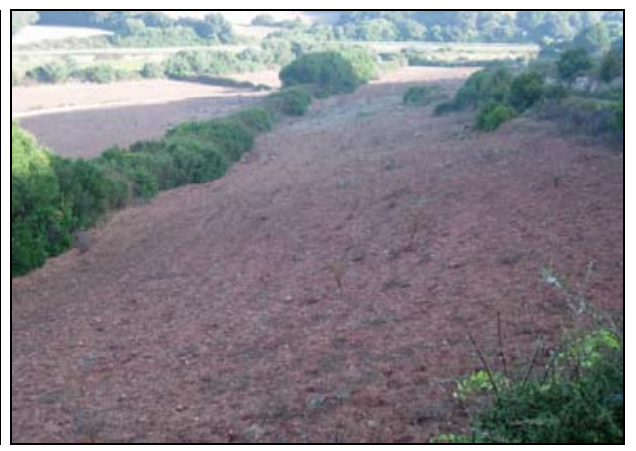

f)

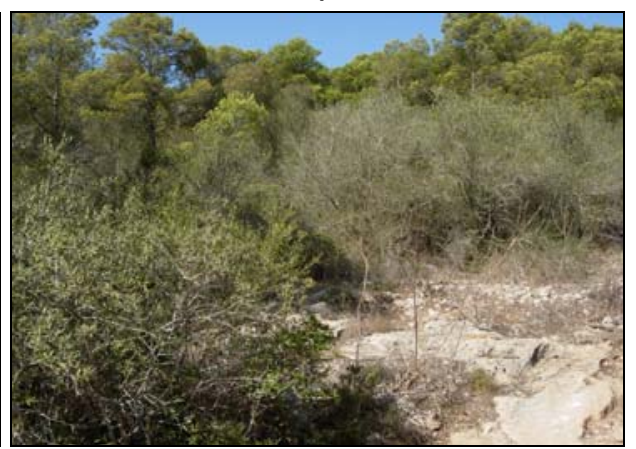

h) 


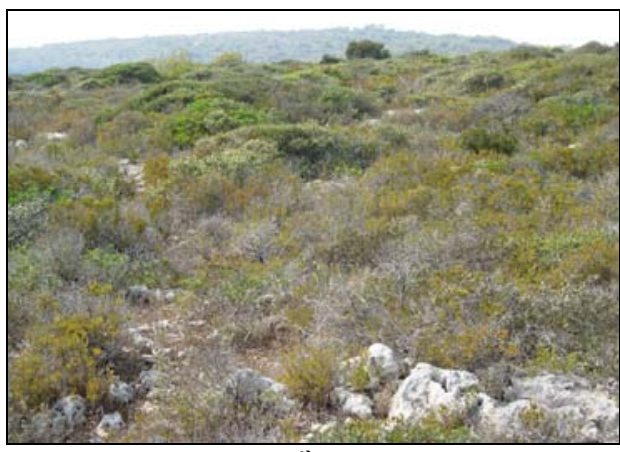

i)

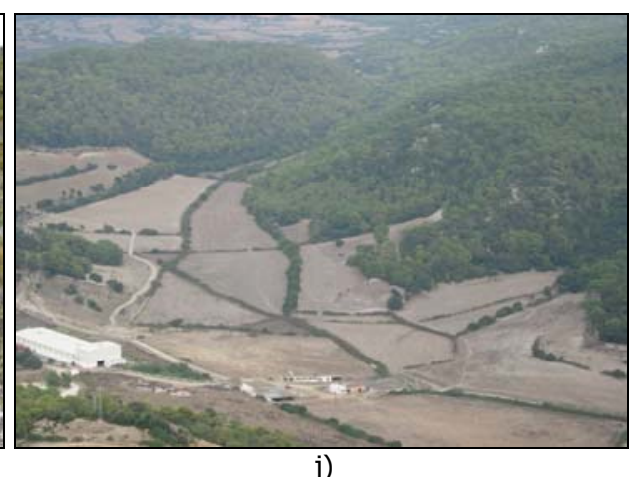

j)

Figura 5-5. Diversos ejemplos de las cubiertas presentes en la isla de Menorca, área del Mitjorn.

Por lo que respecta a la vegetación, se podría hablar de 3 estratos claramente diferenciados, con especies como Pinus halepensis, Quercus ilex y Olea europaea var. sy/vestris en mayor proporción y otras como Ceratonia siliqua, Savina turífera y Cupressus sempervirens para el estrato arbóreo (figura 5-5 h). Forman un paisaje con pequeñas áreas de bosque entremezclado con el estrato arbustivo, de tipo matorral mediterráneo (Pistacia lentiscus, Quercus coccifera y Rhamnus alaternus principalmente con otras especies como Ulex parviflorus, Arbutus unedo, Rubus ulmifolius, Smilax aspera, Erica multiflora, Phragmites communis y bastantes ejemplares de Olea europaea var. sy/vestris de porte arbustivo) tal y como se aprecia en las figuras 5-5 h, i. En cuanto al estrato herbáceo, es de destacar la alta variedad de especies sin un predominio evidente de algunas de ellas, siendo las monocotiledóneas (como las gramíneas) y líquenes las que más abundan con presencia de otras como Rosmarinus officinalis, Thymus vulgaris, Stipa tenacissima, diversas variedades de cardos, Foeniculum vulgare, Asparagus officinalis, Ammophila arenaria, Hedera helix y Pteridium aquilinum en los lugares más húmedos.

Por lo que respecta a la influencia humana, se puede hablar de zonas de pasto extensivo y cereales que en su conjunto y combinado con los ámbitos de vegetación natural generan un paisaje fragmentado como se puede apreciar en la figura 5-5 j. Junto a ellas se deben citar las áreas residenciales tradicionales (pueblos y aldeas) y turísticas (urbanizaciones de chalets con trazados geométricos).

Tras el conocimiento detallado de la realidad de la superficie plasmada en la imagen de satélite se definieron las siguientes clases temáticas para su clasificación final: Bosque denso (áreas con vegetación arbórea de alta densidad espacial y alta ocupación de la superficie), bosque-matorral (lugares donde se produce alternancia de vegetación arbórea y matorrales sin olvidar las herbáceas), matorral denso (sólo hay matorrales y hierbas sin árboles y con una alta ocupación del suelo), árboles dispersos y herbáceas 
(mezcla a partes iguales de estos dos tipos de plantas), herbáceas (donde hay un predominio claro de este grupo de vegetación), cereales y prados (destinados a la ganadería), agrícola sin cultivo (aquellas parcelas de cultivo que en el momento de captar la imagen se encontraban en reposo o barbecho, por lo que tienen muy poca vegetación herbácea), zonas residenciales (viviendas unifamiliares bajas con áreas verdes y viales de trazados geométricos) y mar (donde distintas profundidades generan reflectancias diferentes). Los patrones espaciales de estas clases en la imagen pancromática se corresponden a los de la figura 5-6.

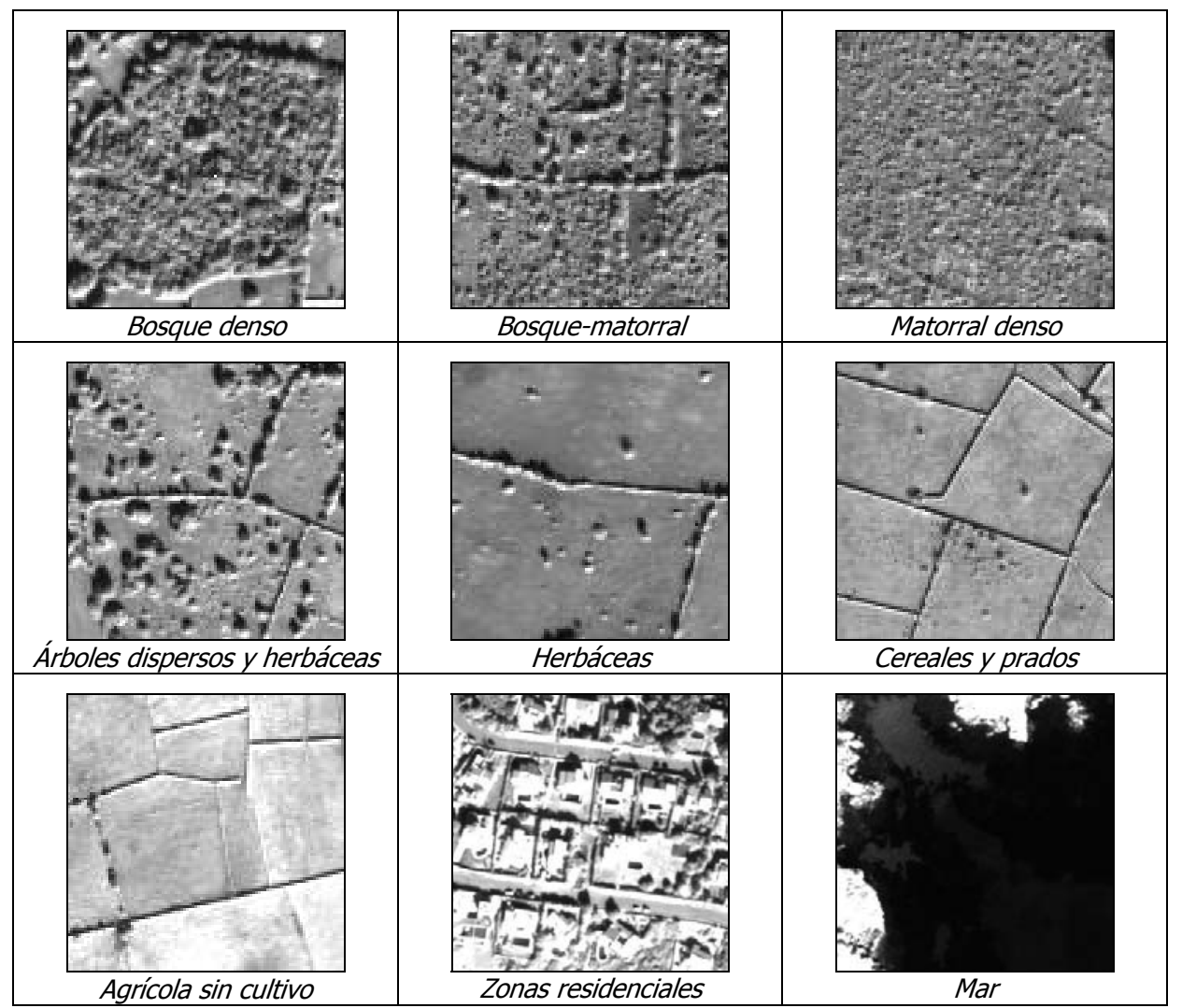

Figura 5-6. Ejemplos de las clases definidas en la imagen de Menorca.

En la figura 5-7 se detalla un fragmento de la imagen multiespectral de Menorca a $2.4 \mathrm{~m}$ por píxel. Además, en la parte inferior se muestra un fragmento de la pancromática de $60 \mathrm{~cm}$ por píxel, así como una porción de la imagen multiespectral con una combinación de bandas en falso color infrarrojo. 

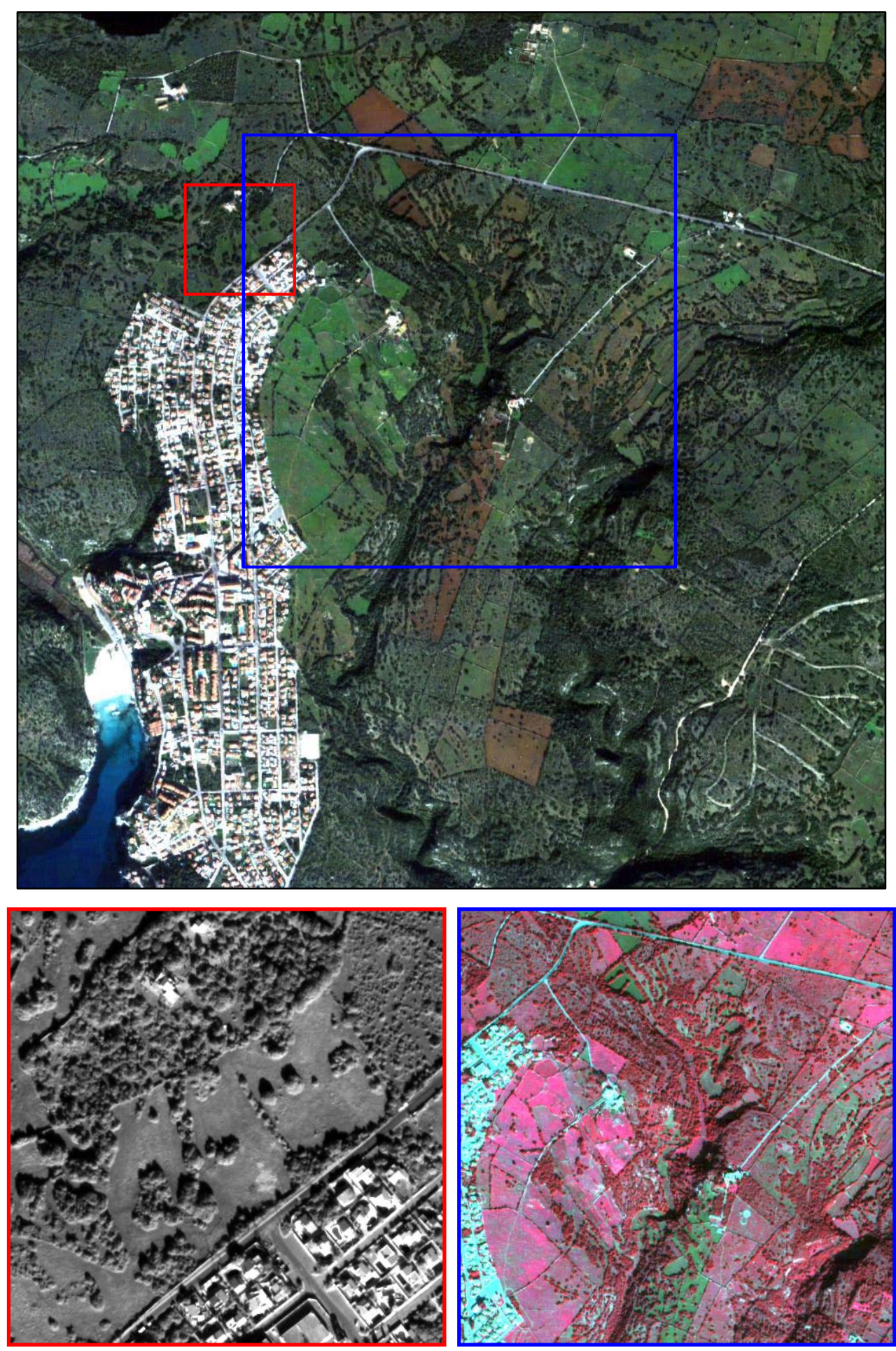

Figura 5-7. Diversos detalles de la imagen de Menorca, color natural, pancromática y falso color IR. 
Debido a la fecha y hora de toma de esta imagen, se genera un efecto importante de sombras por el bajo ángulo de elevación solar en el momento de captación de la radiancia por el sensor. Se probaron diferentes métodos de corrección del efecto topográfico como los de Minnaert y Lambert para reducir las sombras en los barrancos pero los resultados no fueron todo lo positivos que se deseó debido básicamente a la inexistencia de un modelo digital de elevaciones ajustado a la alta resolución espacial de la imagen.

\subsubsection{Zonas agrícolas}

\section{Imagen mosaico de Daimiel}

Se trata de un área de estudio que proporciona variabilidad suficiente en la distribución de la información como para caracterizar diferentes tipos de texturas de cultivos. Los datos de partida son imágenes aéreas pancromáticas de la zona de Daimiel, en Ciudad Real. Dicha geografía se considera adecuada ya que se encuentra en ella vegetación natural de diferentes densidades, así como distintos tipos de agricultura, incluyendo cultivos intensivos y extensivos. Algunas áreas urbanas han sido incluidas para incrementar la diversidad a la hora de clasificar. La vegetación natural existente se corresponde principalmente a áreas de dehesa con ejemplares dispersos de encinas (Quercus ilex), algunas de ellas con cultivos de cereales, otras con un sustrato herbáceo formado principalmente por gramíneas de bajo porte. Por lo que respecta a cultivos, se han identificado cultivos de vid, de olivos, de vid con olivos (estos tres con un claro patrón geométrico), de cereal sin cosechar, de cereal cosechado, de maíz, de alfalfa y de alfalfa cosechada. Algunos de estos cultivos son de regadío por lo que las tonalidades que presentan son sensiblemente más intensas que los de secano. Se ha observado también la existencia de gran cantidad de flujos subsuperficiales de humedad, lo que genera distintas tonalidades en zonas de vegetación homogénea, sobre todo en las parcelas de secano.

Los datos de partida son fotogramas aéreos, tomados en agosto de 1984, en un vuelo del Instituto Geográfico Nacional a unos $5000 \mathrm{~m}$ de altura y a una escala media de $1 / 30.000$, posteriormente digitalizados a dos resoluciones, 0.60 y $2 \mathrm{~m}$ por píxel, de tal manera que se pudiese trabajar sobre la influencia de la resolución de las imágenes.

De esos fotogramas se han seleccionado 6 porciones con el criterio de preservar una alta variedad de clases de texturas y reducir la cantidad de datos a la hora de realizar las pruebas, sintetizando en una sola imagen todas las tipologías de texturas a emplear. Ésta consiste en el mosaico de esos 6 recortes y es la que se adjunta en la figura 5-8. 


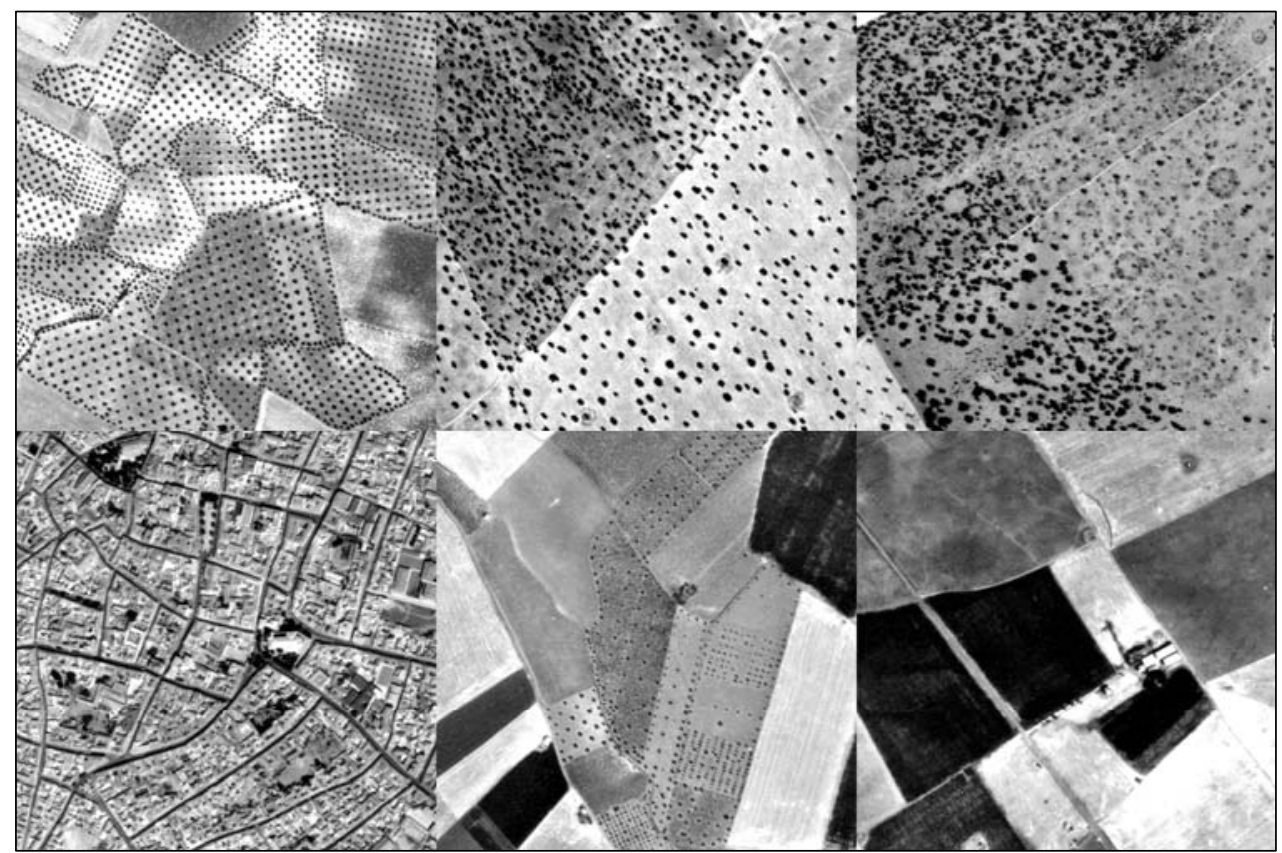

Figura 5-8. Mosaico de partida a resolución espacial de 2 metros por píxel.

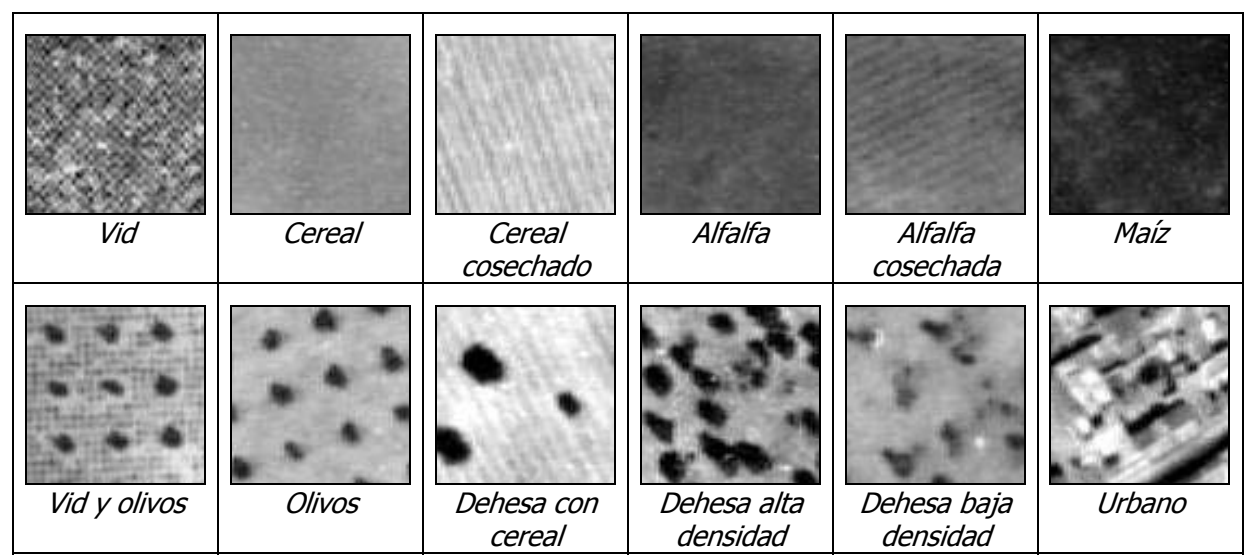

Figura 5-9. Texturas finas (las 6 primeras) y gruesas (el resto) a una resolución de $60 \mathrm{~cm}$.

De la imagen mosaico se han extraído a su vez muestras de cada una de las clases a analizar. En primer lugar es importante destacar una primera diferenciación entre todas las clases adoptadas en función de su variabilidad textural (figura 5-9). De esta manera, se puede hablar de texturas finas, como vid (plantas pequeñas con distribución cuadrada), cereal (plantas herbáceas donde no se aprecia ninguna geometría), cereal cosechado (la maquinaria de recolección deja alineaciones de la paja de la planta), alfalfa (cultivo herbáceo de alto requerimiento hidrológico y que por ello presentan tonalidades 
más oscuras y homogéneas), alfalfa cosechada (al igual que con el cereal se aprecian marcas de la maquinaria tras la recolección) y maíz (cultivo homogéneo y de baja reflectividad); y texturas gruesas, como vid y olivo (plantas entremezcladas en la misma parcela y con marco cuadrado), olivo (árboles de grandes dimensiones y marco de plantación cuadrado), dehesa con cereal (áreas de encinas dispersas con suelo cultivado de cereal ya recolectado), dehesa de alta densidad (zonas con gran cantidad de encinas irregulares en su tamaño y distribución), dehesa de baja densidad (pocas encinas con plantas herbáceas en el suelo) y urbano (núcleos urbanos irregulares al no presentar ningún tipo de planeamiento urbanístico).

Al disminuir la resolución espacial a $2 \mathrm{~m}$ se comienza a perder capacidad de discriminación visual en algunas texturas, sobre todo de las más finas y en todas ellas su aspecto es ligeramente diferente (figura 5-10), por lo que la resolución se considera una importante variable del estudio.

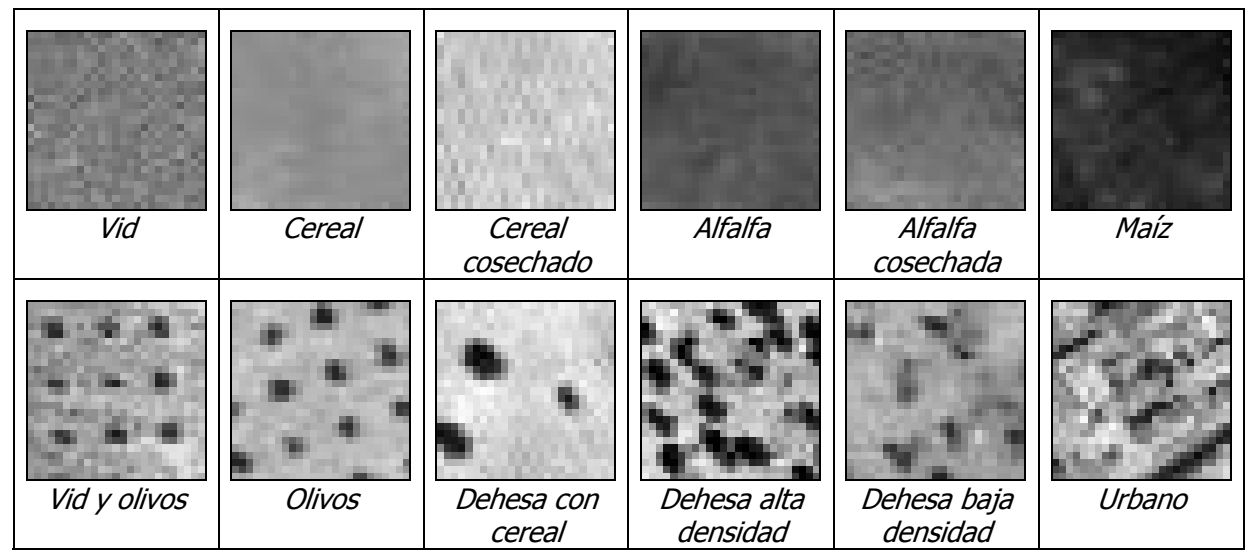

Figura 5-10. Texturas finas (las 6 primeras) y gruesas (el resto) a una resolución de 2 m.

\subsubsection{Zonas de montaña con vegetación natural}

\section{Imagen aérea de Espadán}

Los entornos montañosos presentan diferencias evidentes a los espacios considerados hasta ahora por su topografía, geología, vegetación asociada, posibles aprovechamientos, usos del suelo, etc. Por ello se considera importante su inclusión en el conjunto del proyecto de trabajo. 
En estas áreas la influencia humana sobre la distribución de la vegetación es menor de tal manera que no se habla tanto de tipos de texturas como de densidades de vegetación natural. Para ello se eligió una zona montañosa al sur de la provincia de Castellón, correspondiente a una porción de la Sierra de Espadán. Al tratarse de un área con desniveles considerables es muy importante el efecto topográfico conocido sobre la distribución de la vegetación, sobre todo el efecto de orientación de las laderas y su influencia sobre la insolación potencial y el crecimiento de la vegetación (Pardo Pascual, 1999). Se partió de un fotograma aéreo a escala $1 / 25.000$ de marzo de 1991 , el cual se digitalizó a una resolución de 2 metros por píxel (figura 5-11).

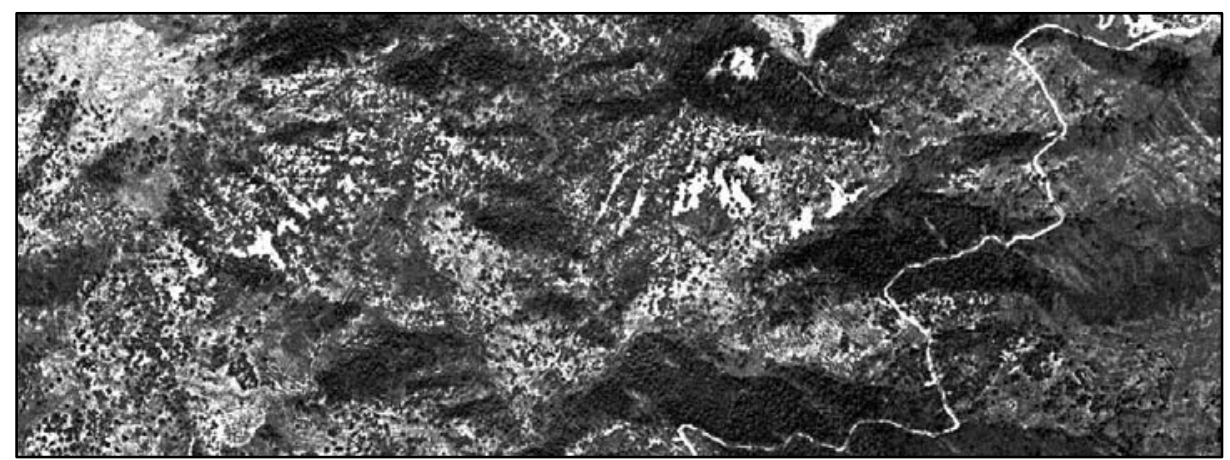

Figura 5-11. Muestra del área de estudio de texturas en zona montañosa (Espadán).

Desde el punto de vista geológico, la Sierra de Espadán se corresponde a un conjunto de pliegues con direccionalidad propia del Sistema Ibérico sobre materiales del Triásico y más concretamente sobre areniscas y argilitas de la facies Buntsandstein, con pequeños afloramientos de margas, dolomías y calizas propias de la facies Muschelkak. Al tratarse de una zona de sierra, las pendientes medias son elevadas, en torno a $30^{\circ}-40^{\circ}$ y la cota media ronda los $600 \mathrm{~m}$. En cuanto al análisis de las características de los depósitos superficiales y los suelos, se ha observado en los ensayos de campo que los afloramientos litológicos son en forma de roca medianamente alterada o fisurada y en un porcentaje del $50 \%$ aproximadamente. El nivel de pedregosidad de los suelos es variable dependiendo del lugar concreto, variando desde un $80 \%$ hasta no tener prácticamente ninguno. Tanto el espesor medio del suelo como su textura son muy variables, si bien predominan las texturas francas o medias con un horizonte humífero de entre 1 y $3 \mathrm{~cm}$ (figura 5-12 a). La erosión se produce de forma laminar en la mayoría de los punto de muestreo considerados.

Por lo que respecta a la vegetación, los tres estratos que se pueden definir, arbóreo, arbustivo y herbáceo, se presentan con desigual ocupación de la cubierta. Así el estrato arbóreo ocupa entre el 50 y el $75 \%$ de la total posible. El arbustivo ocupa algo menos del $50 \%$ y el herbáceo varía desde una ocupación muy baja hasta un $50 \%$. 
Las especies dominantes en cada estrato son las siguientes (figuras 5-12 b, c y d). En cuanto a árboles, predominan el Pinus pinaster, Quercus suber y el Pinus halepensis, con algunos ejemplares menos frecuentes de Quercus faginea y Quercus rotundifolia. Son los arbustos los que presentan una mayor variedad de especies. Predominan la Erica multiflora, Ulex parviflorus, Rosmarinus officinalis, Cistus albidus y Juniperus oxycedrus y se encuentran ejemplares de otras especies como Pistacia lentiscus, Lonicera implexa, Hedera helix, Rubus ulmifolius, Rhamnus alaternus, Crataegus monogyna, Quercus coccifera, así como ejemplares de porte arbustivo de Quercus suber. En cuanto a herbáceas, la variedad también es importante destacando las gramíneas, Thymus vulgaris, Asparagus officinalis, Lavandula stoechas, Rubia peregrina, Pteridium aquilinum, Smilax aspera, así como algunos musgos y labiadas.

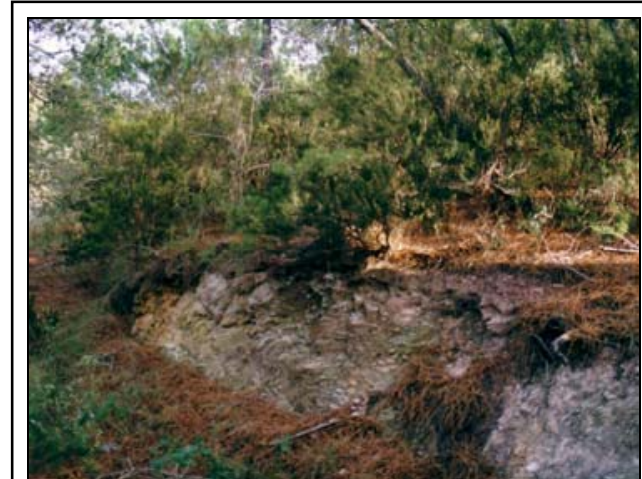

a)

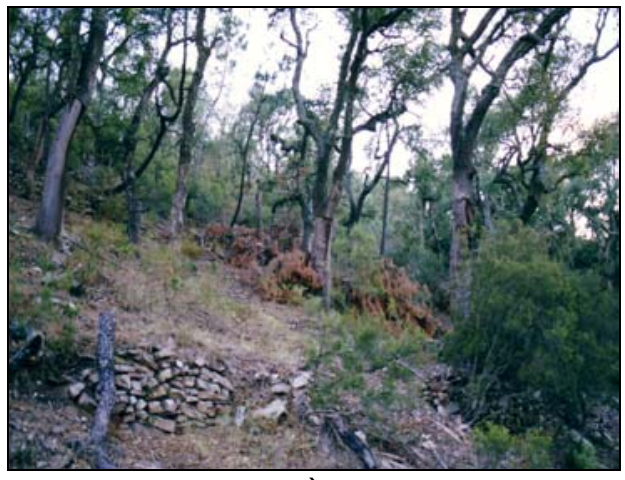

c)

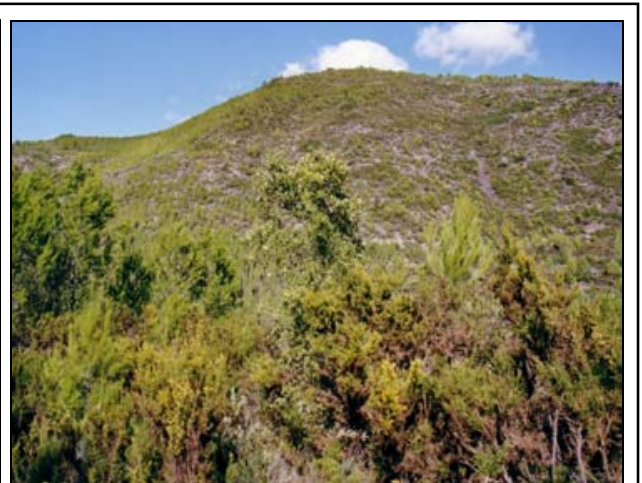

b)

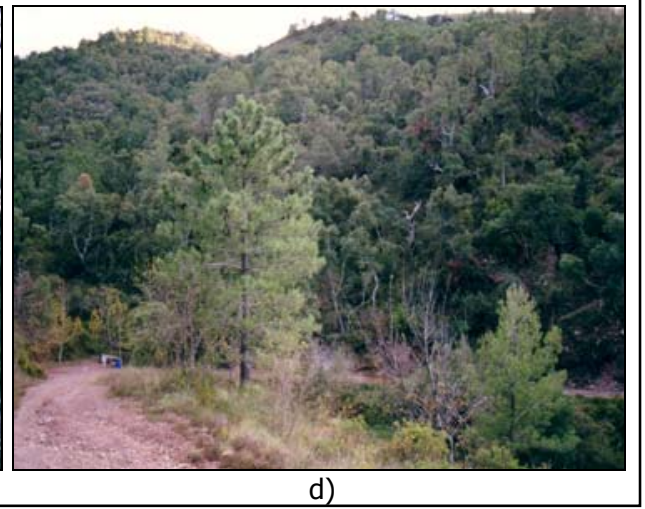

d)

Figura 5-12. 4 ejemplos de las cubiertas presentes en la Sierra Espadán, Castellón.

Además de los entornos de vegetación natural se localizan en un porcentaje pequeño cultivos de olivos, pequeños núcleos de población así como áreas de suelo desnudo, donde se producen acumulaciones de fragmentos rocosos resultantes de la meteorización física del roquedo, en forma de canchales o pedreras. 
Tras el riguroso estudio de la información anterior y el análisis de las imágenes disponibles de este entorno se ha decidido establecer las siguientes clases temáticas para la posterior clasificación (figura 5-13): suelo desnudo (áreas de canchales o pedreras con fuertes pendientes y fruto de la acumulación de fragmentos rocosos desprendidos de los escarpes rocosos, básicamente por procesos de termoclastia y crioclastia), matorral de baja densidad (el porcentaje de ocupación del suelo por las diversas especies arbustivas es muy bajo, apreciándose el suelo desnudo en un alto porcentaje), matorral de media densidad (el porcentaje de ocultación del suelo por las plantas arbustivas o herbáceas es medio), matorral de alta densidad (donde se cubre prácticamente todo el suelo sin la presencia de árboles), arbolado de baja densidad (se aprecia el suelo desnudo, algo de arbustos y algunos árboles), arbolado de media densidad (donde también se pueden encontrar arbustos y herbáceas) y arbolado de alta densidad (aquellos que cubren prácticamente todo el suelo).

Además de las diferencias ya comentadas en la densidad y distribución de las texturas, también es evidente que en entornos montañosos la definición de los bordes es más complicada, ya que la vegetación natural no presenta límites geométricos y la interacción entre tipos y densidades de vegetación es muy importante.

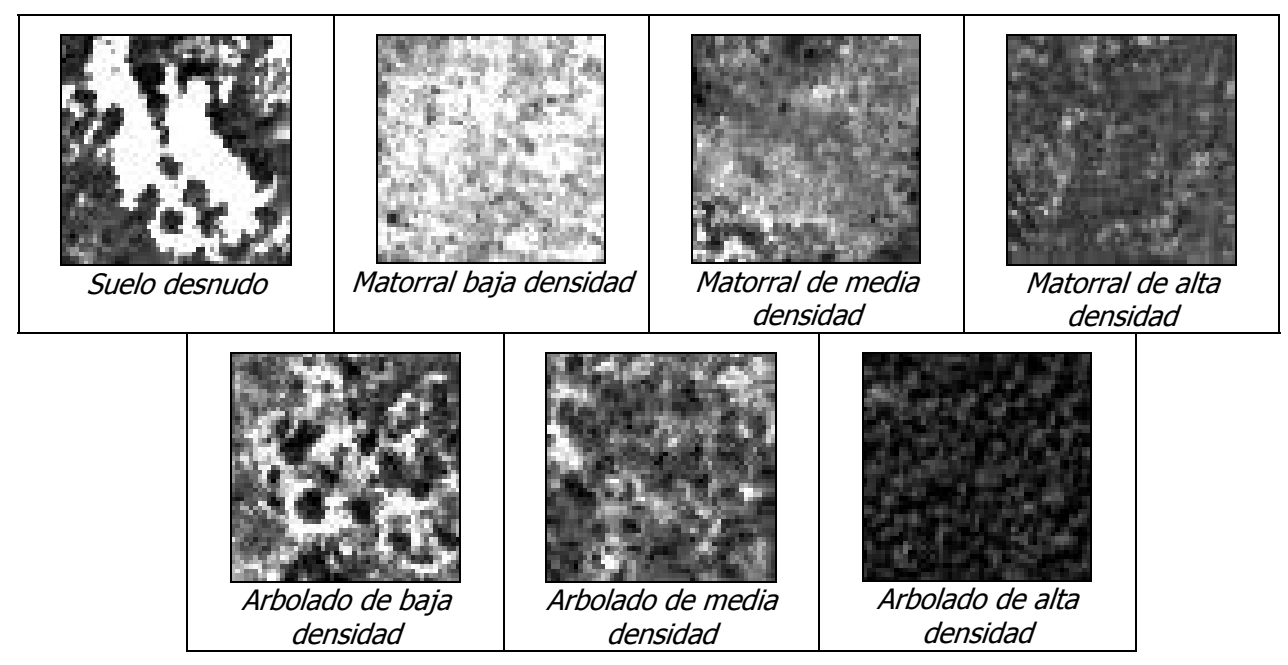

Figura 5-13. Áreas típicas de texturas de montaña.

\section{Imagen mosaico de fotogramas aéreos de Espadán}

Dado que los fotogramas anteriormente reseñados y empleados no permitían analizar toda la variabilidad de cubiertas presentes en la Sierra de Espadán y de posible interés de cara a la gestión forestal y de aprovechamientos agrícolas, se planteó la 
posibilidad de crear un mosaico compuesto de porciones de varios ortofotogramas aéreos de $1 \mathrm{~m}$ de resolución del SIG Oleícola de junio de 2001. Se construyó una imagen pancromática con 9 subescenas combinadas para reflejar las cubiertas vegetales tipo identificadas (figura 5-14).

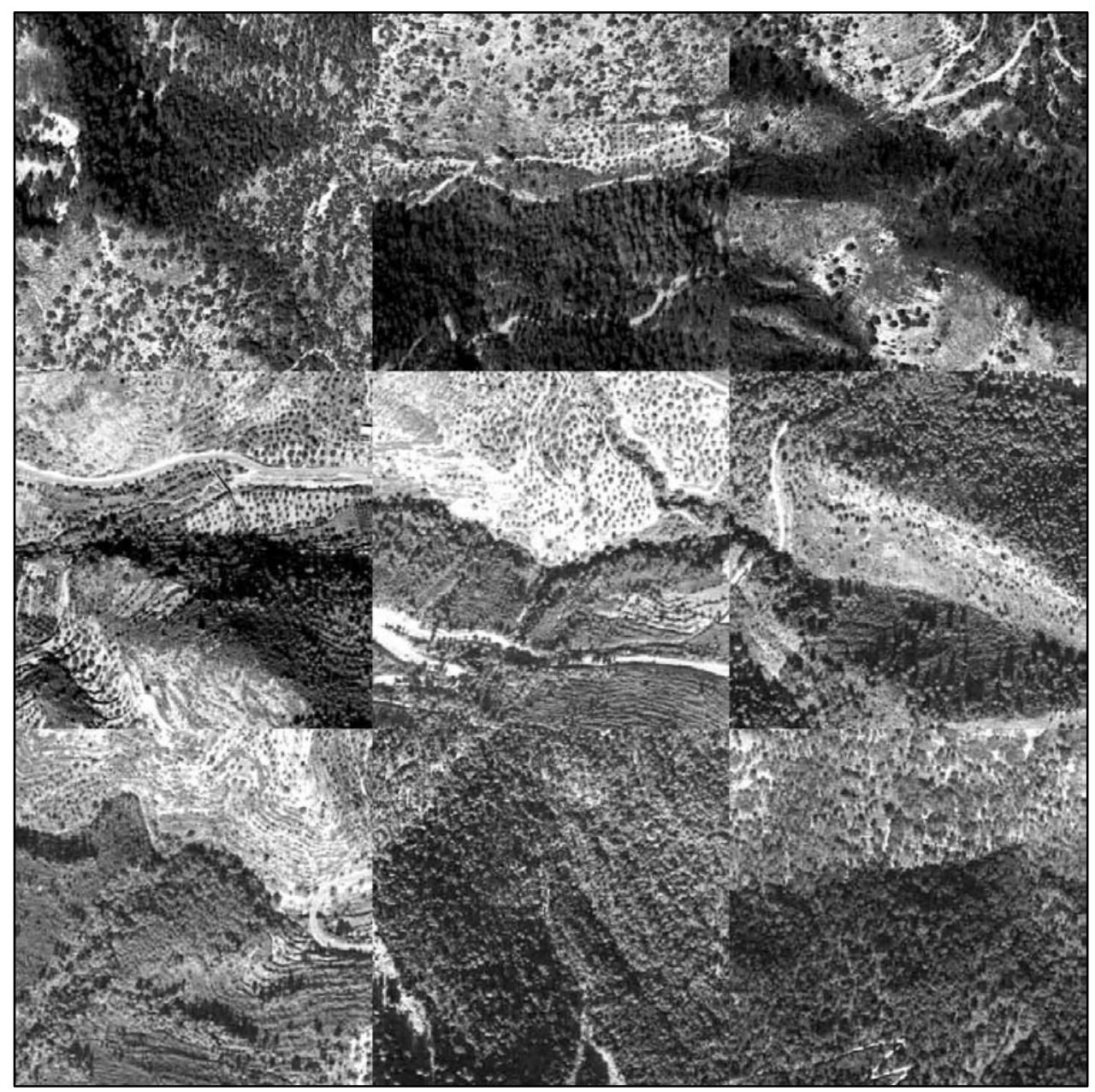

Figura 5-14. Mosaico de fotogramas aéreos del área montañosa de Espadán.

Se han considerado un total de 6 clases, ligeramente diferentes a las reseñadas anteriormente, que se muestran en la figura 5-15 y que son: bosque denso (zonas arboladas con una alta densidad de ocupación del suelo), bosque de baja densidad (arbolados con huecos ocupados por especies arbustivas o herbáceas), arbolado sobre suelo desnudo (donde la baja densidad arbórea y arbustiva permite la visión directa del suelo), matorral sobre suelo desnudo (existe una baja densidad de matorrales y mucho 
suelo desnudo o limpio de vegetación), matorral(de media o alta proporción de ocupación del suelo) y olivos (cultivos sin un claro marco de plantación y de tamaños variables e implantados en parcelas de escasas dimensiones, formas irregulares y con fuertes pendientes o en abancalamientos a mitad de ladera).

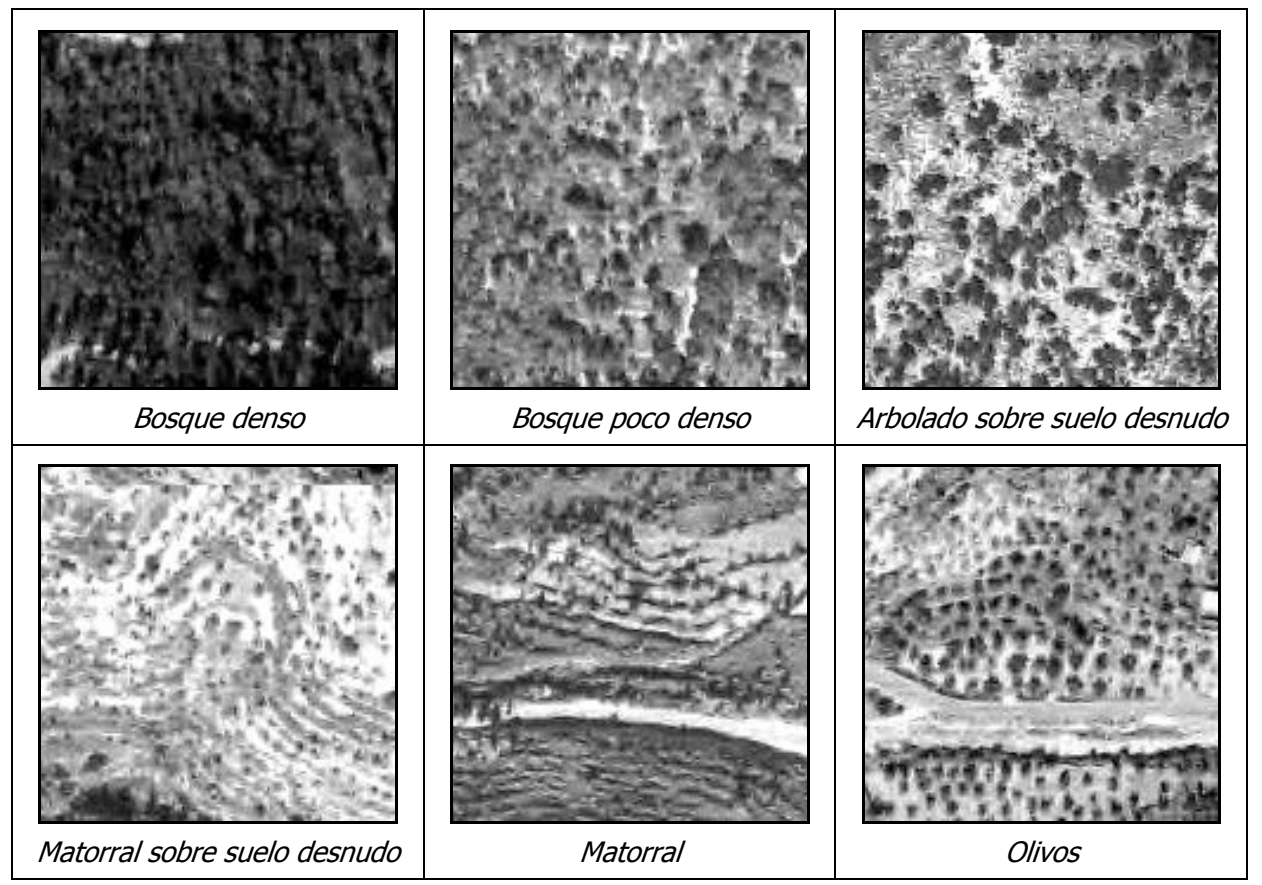

Figura 5-15. Clases definidas sobre el mosaico de la zona montañosa de Espadán.

\subsubsection{Zonas de montaña mixtas}

\section{Imagen mosaico de fotogramas aéreos de Ayora}

Este entorno de trabajo se corresponde con la zona de confluencia de la Muela de Cortes y los valles de los ríos Cabriel, Júcar y Cantabán, situada en la parte más occidental de la provincia de Valencia. Geográficamente se correspondería con la hoja 745 del MTN a escala 1/50000, denominada Jalance y delimitan la zona las coordenadas UTM (657000, 4338000) y $(685000,4356000)$ del huso 30. Presenta un relieve importante, con gradientes altitudinales de hasta 800 metros y un sistema tectónico complejo, dominado por la existencia de 3 valles fluviales que vertebran la zona y generan sobre ellos relieves elevados en forma de muelas (figura 5-16 a). 
Litológicamente y muy esquematizado, se pueden encontrar por orden de antigüedad los materiales triásicos en los valles (Keuper principalmente) y sobre ellos calizas y dolomías básicamente del Cretácico y Terciario formando los relieves tabulares superiores. En cuanto a litologías, se presentan diferentes rocas, como arcillas, yesos, margas, areniscas y dolomías, si bien son las calizas las que predominan (figura 5-16 b, c y d). Por lo que respecta a las pendientes, son muy variables desde casi nulas en las partes altas de las muelas o los fondos de los valles hasta muy altas en la zonas de transición. En cuanto a los depósitos superficiales y los suelos, los ensayos de campo han permitido detectar los rasgos que siguen. La roca madre aflora medianamente alterada o fisurada entre un 20 y un $30 \%$ del total de las superficies muestreadas y el nivel de pedregosidad es muy variable dependiendo de que se analice un ámbito deposicional de materiales finos o un ámbito denudativo. La capa edáfica por norma general es escasa y de textura arcillosa, si bien en sectores de umbría se aprecia un mayor contenido de humus y un desarrollo más vigoroso de los diferentes estratos vegetativos, destacando la variación del suelo en función del sustrato rocoso en el que se ha originado y de la erosión, la cual se ha producido principalmente de forma laminar.

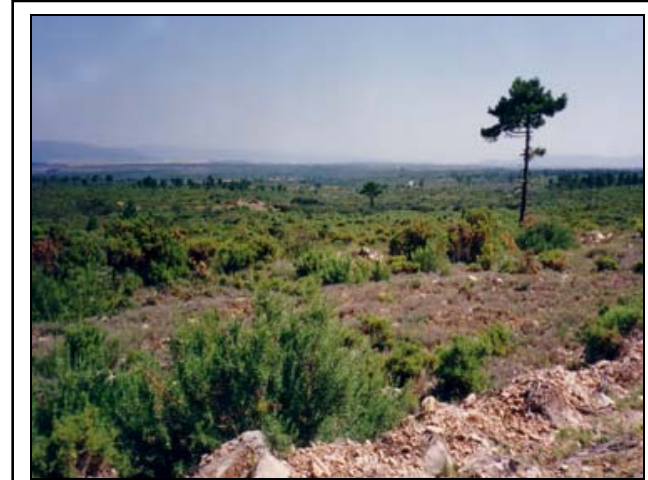

a)

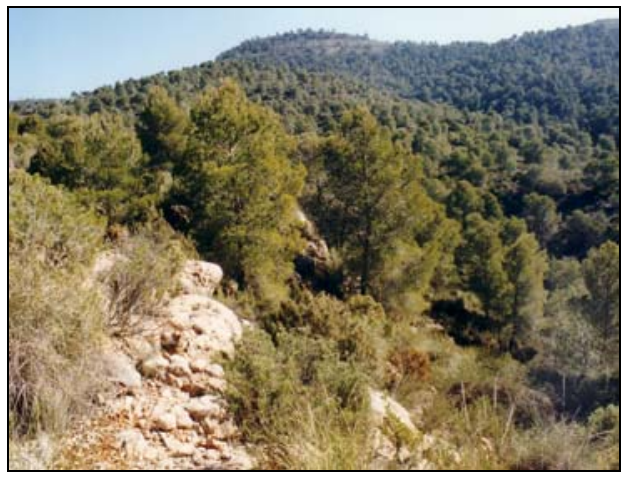

c)

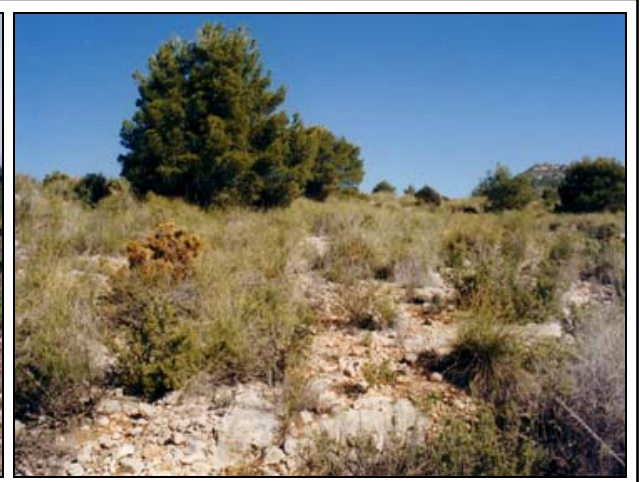

b)

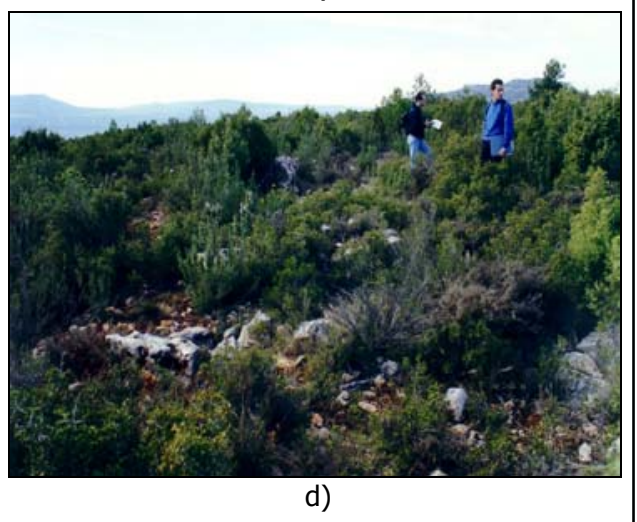

d)

Figura 5-16. 4 ejemplos de las cubiertas presentes en el área montañosa de Ayora, Valencia. 
De los registros meteorológicos de los observatorios situados en este área se han deducido sus principales características climáticas (Pardo et al., 1999). Se trata de una región dominada por un clima semiárido y seco, mesotérmico, con un superávit de agua escaso o nulo y con una elevada concentración estival de la eficacia térmica, es decir, una elevada influencia del verano en las temperaturas medias anuales. Estos rasgos condicionan la tipología de la cubierta vegetal.

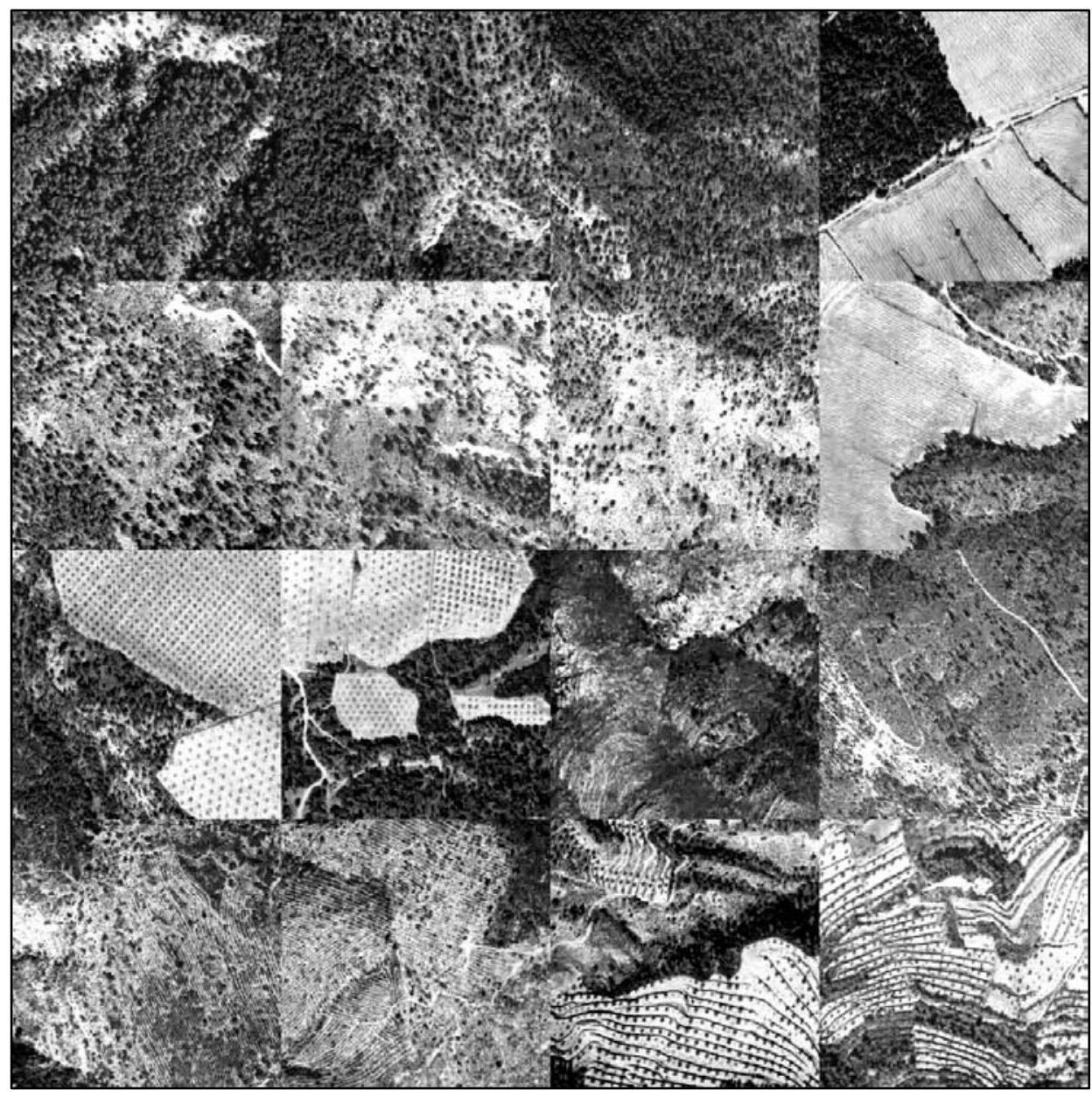

Figura 5-17. Mosaico de fotogramas aéreos de la zona montañosa mixta de Ayora.

La vegetación potencial de la zona está dominada por carrascales (Quercus rotundifolia), pero la degradación fruto de incendios sucesivos ha provocado que ésta quede reducida a pequeños bosquetes, siendo escasas las superficies que no se han visto afectadas de alguna manera por alguno de ellos. Tras el análisis del II Inventario Forestal Nacional (1995) y las salidas a campo se ha comprobado que la vegetación predominante en este momento son arbustos xerófitos (Ulex parviflorus, Rosmarinus officinalis, Juniperux 
oxycedrus, Erica multiflora, Quercus coccifera, Pistacia lentiscus, Arbutus unedo en zonas de umbría, Cistus albidus, etc.) como se aprecia en la figura 5-16 a, b y d. El estrato arbóreo está dominado por Pinus halepensis junto a Pinus pinaster en algunos sectores y ejemplares de Quercus rotundifolia (figura 5-16 c). Por lo que respecta a plantas herbáceas, son las gramíneas las dominantes, si bien se localizan bastantes Thymus vulgaris, Stipa tenacissima y algunos ejemplares de musgos.

La vegetación, y más concretamente, el arbolado de esta zona presenta una importante tasa de dispersión debido en parte a la recurrencia de incendios forestales en los últimos años. Además de la vegetación natural es importante la presencia de áreas de cultivos de montaña (Amigdalus communis, Olea europaea, Ceratonia siliqua) que en ocasiones se disponen en terrazas sobre las laderas.

Para obtener una representación suficiente y manejable de las distintas clases, se creó una imagen mosaico, a partir de los ortofotogramas aéreos de $1 \mathrm{~m}$ de resolución del SIG Oleícola, compuesta por 16 sub-zonas (figura 5-17).

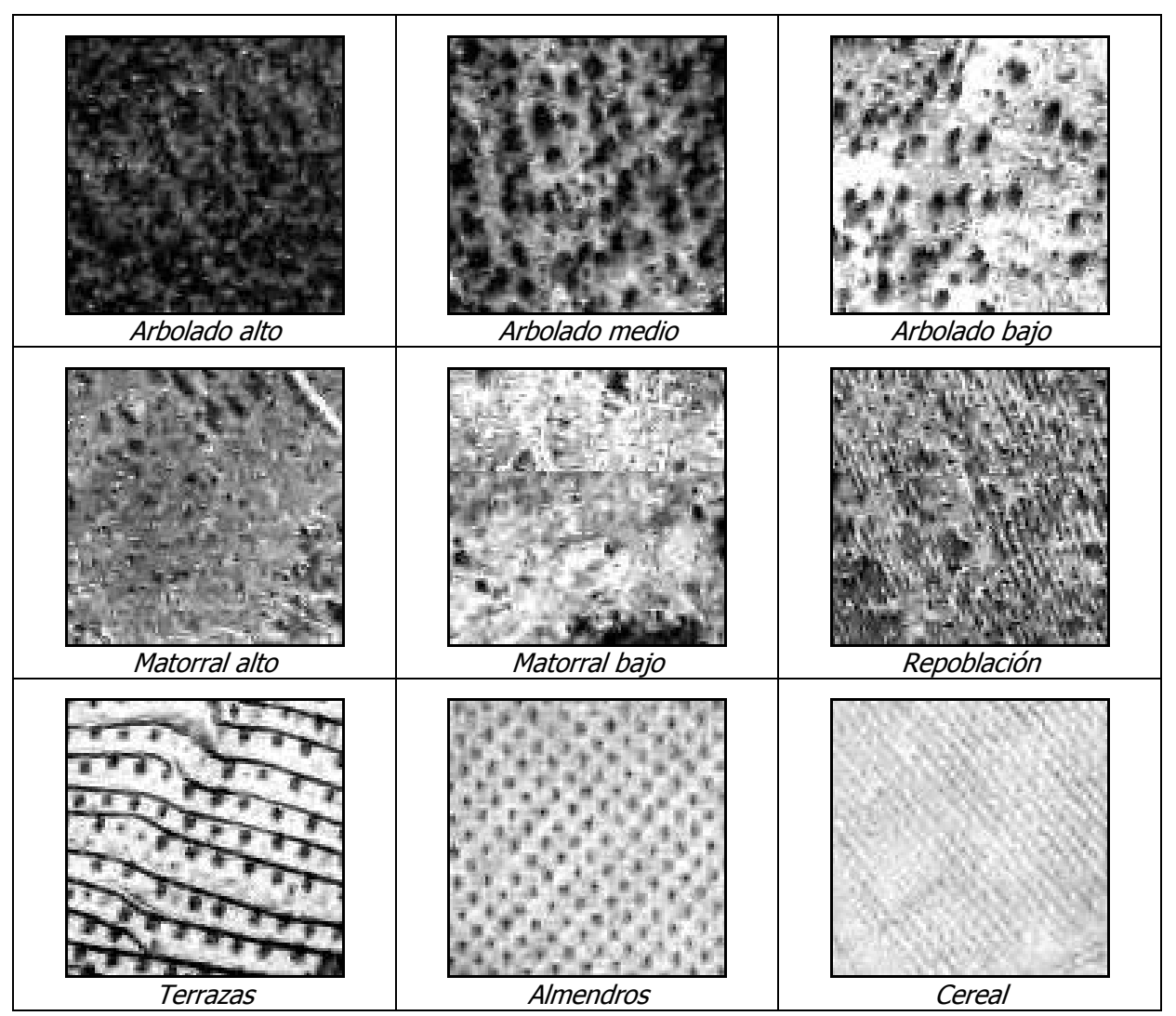

Figura 5-18: Clases definidas en la imagen Ayora. 
Las clases definidas inicialmente fueron las siguientes (figura 5-18): Arbolado alta densidad (zonas de alta densidad de árboles y con predominio de coníferas), arbolado media densidad (las coníferas tienen una densidad media y se aprecia cierta vegetación herbácea en el suelo), arbolado baja densidad (la vegetación arbórea es escasa y dispersa y las plantas herbáceas también son poco abundantes), matorral alta densidad (sin apenas presencia de árboles, la vegetación cubre casi por completo el suelo), matorral baja densidad (las plantas arbustivas y las hierbas suponen un porcentaje bajo), cereales (áreas cultivadas de cereal y que ya han sido recolectadas, apreciándose el bandeado propio de la siega mediante máquinas cosechadoras), almendros (parcelas en las que los árboles presentan un claro patrón geométrico, generalmente cuadrado y a veces en diamante, en su disposición), zonas de repoblación forestal (donde el suelo presenta alineaciones al ser roturado para la repoblación mediante coníferas) y cultivos en terrazas (pequeñas parcelas de uso agrícola implantadas a mitad de las laderas mediante abancalamientos para plantas poco exigentes como olivos o algarrobos).

Tras la descripción de las superficies reflejadas en las diversas imágenes, se procede a detallar la metodología específica a aplicar en el capítulo siguiente. 


\section{Metodología}

En este capítulo de la tesis se justifican y describen los diversos procesos de cálculo aplicados, las técnicas empleadas y las ideas que las han motivado. Todo ello se ha organizado para tener una secuencia lógica y estructurada. El esquema general de este capítulo se puede observar en la figura 6-1.

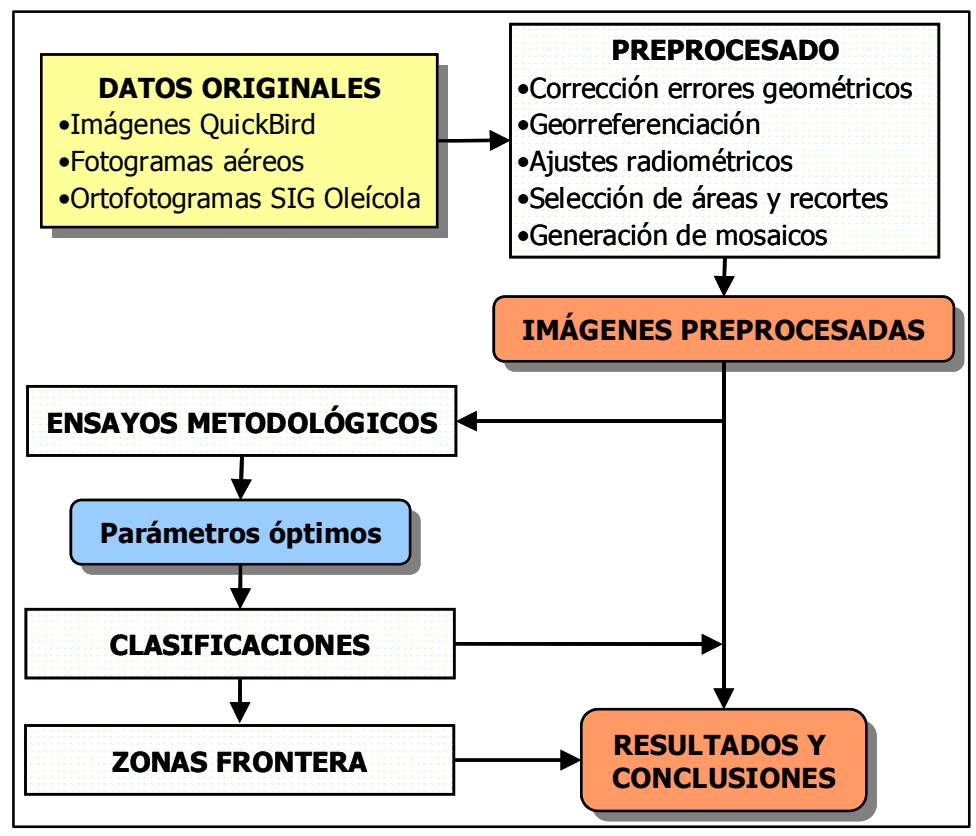

Figura 6-1. Esquema general del capítulo.

Analizando dicho esquema se puede apreciar cómo existen unas fases claramente definidas y que articulan este capítulo. Son las siguientes: 
10- Preprocesado de la información: para eliminar errores en los datos de partida (capítulo V), unificarlos radiométricamente, dotarlos de coordenadas en el sistema UTM, ED50, elaborar los mosaicos, correcciones topográficas, etc.

20- Determinación de las variables de textura y los parámetros metodológicos: En esta fase se ha procedido a la elaboración de unos ensayos previos para la determinación de los parámetros metodológicos óptimos de cara a la clasificación final. El esquema general de los ensayos sobre diferentes parámetros es el siguiente:

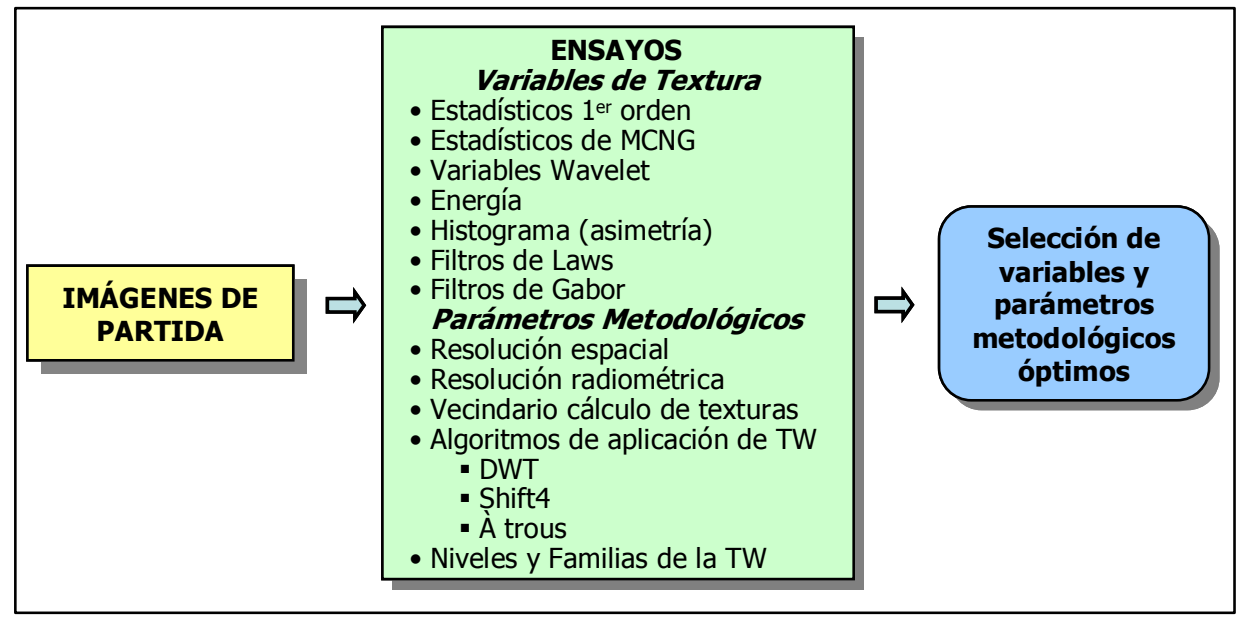

Figura 6-2. Esquema general de los ensayos metodológicos.

30- Validaciones globales sobre los ámbitos de estudio: La tercera fase ha consistido en la verificación de los parámetros anteriores mediante el estudio de su influencia en los diversos grupos de variables de textura y en diversas familias de funciones wavelet. Se han aplicado sobre 4 tipologías de superficies y cubiertas, tal y como muestra la figura 6-3.

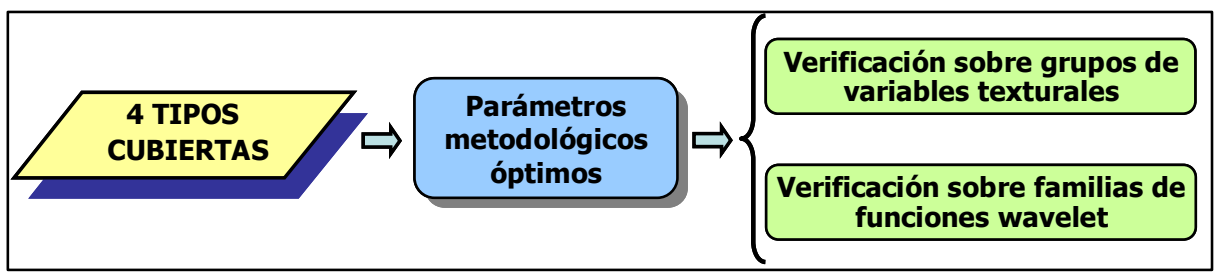

Figura 6-3. Esquema de las verificaciones globales.

40- Estudio de modelos post-clasificación: Con el fin de minimizar el efecto frontera se analizan hasta 4 procesos de extracción de bordes para su procesado mediante un algoritmo diferente al de las áreas internas a las imágenes. 


\subsection{Preprocesado de las imágenes de partida}

\subsubsection{Correcciones geométricas}

Permiten eliminar los errores de carácter geométrico que acompañan al proceso de adquisición, así como dotar a la imagen de coordenadas, de tal forma que sea posible compararla con otra imagen o con información extraída de un mapa, intentando que la imagen resultante de estos procesos conserve, en la medida de lo posible, los valores radiométricos de la imagen inicial. Los errores geométricos que se presentan con más frecuencia en las imágenes son agrupados en dos tipos:

- Sistemáticos: distorsión panorámica, distorsión por la curvatura terrestre, distorsión por movimiento de rotación terrestre y distorsión de oblicuidad debida al tiempo de barrido.

- No sistemáticos: distorsión provocada por los movimientos de la plataforma y deformación debida al relieve.

Las correcciones geométricas hacen referencia a cualquier cambio en la posición que ocupan los píxeles en una imagen. Los cambios pueden explicarse a través de una transformación numérica, cuya expresión puede ser:

$$
\mathrm{F}(x, y)=\mathrm{G}(f, c)
$$

donde $(x, y)$ hacen referencia a las coordenadas de la imagen corregida y $(f, c)$ son las coordenadas de la imagen de entrada. Estas correcciones se pueden realizar:

a) Por una modelización escena-sensor: a partir de la información orbital disponible.

b) De forma empírica, mediante un ajuste directo a partir de puntos de control cuyas coordenadas son conocidas tanto en la imagen de partida como en la imagen corregida. Este ha sido el modelo aplicado en la práctica totalidad de imágenes empleadas, transformando mediante un polinomio de grado 2 y con errores medios cuadráticos menores a 1 píxel.

\subsubsection{Correcciones radiométricas}

La teledetección se fundamenta en la recepción de la energía electromagnética que, proveniente del sol, es reflejada o absorbida para después ser emitida por los objetos de la superficie terrestre. Entran en juego en este proceso una serie de elementos que 
condicionan las características de los datos captados como son la energía solar, las particularidades de los elementos de la superficie, los componentes de la atmósfera atravesada por la energía (que provocan absorción y dispersión atmosférica) y las cualidades de los sensores (ganancias y desfases). La influencia de cada uno de ellos en la imagen resultante es evidente. Son los efectos atmosféricos y los posibles desajustes técnicos en el sensor los que pueden provocar anomalías o errores radiométricos, lo que implica que los valores codificados por el sensor no se corresponderán con los valores reales de reflectancia, es decir, existirán discrepancias entre los valores digitales de intensidad de la imagen y los que debería presentar. Por lo tanto, los datos obtenidos sólo en pocas ocasiones pueden utilizarse en estado original y deberán someterse a un conjunto de tratamientos previos.

Las correcciones radiométricas son esas operaciones previas que modifican los datos de origen, generando alteraciones en las medias, desviaciones típicas, varianzas o en los histogramas, por ejemplo. Esto puede provocar cambios en los resultados de los análisis por lo que estas correcciones, al igual que las geométricas, se deben aplicar en la fase previa al procesamiento de los datos.

El modelo de corrección empleado principalmente ha sido el consistente en establecer relaciones entre los valores de reflectancia de las diferentes bandas espectrales y definir rectas de regresión entre bandas.

\subsubsection{Elaboración de mosaicos}

Los mosaicos consisten en combinaciones de varias imágenes, aéreas o de satélite, en una única composición, para generar publicaciones o composiciones de mapa, o como un medio de combinar imágenes georreferenciadas en una sola que cubra una gran extensión. Generalmente las imágenes a componer presentan zonas comunes que permiten el enlace de unas con otras y que facilitan las correcciones radiométricas de forma adecuada.

Con las imágenes empleadas en el presente trabajo se han elaborado algunos mosaicos para representar en imágenes más manejables toda la variedad de tipologías presentes en una superficie. 


\subsection{Análisis de las diferentes variables de textura}

\subsection{1. Índices estadísticos de primer orden}

Una imagen es una función bidimensional $f(x, y)$ de dos variables espaciales $x \mathrm{e}$ $y$, donde $x=0,1,2, \ldots, N-1$ e $y=0,1,2,3, \ldots, M-1$. La función puede tomar valores discretos (valor digital de cada píxel) $i=0,1,2, \ldots, G-1$, donde $G$ es el número de niveles de gris 0 niveles de intensidad en la imagen. El histograma de la imagen o función bidimensional $f(x, y)$ es una función que determina para cada nivel digital i su frecuencia de repetición $h(i)$ dentro de la imagen:

$$
h(i)=\sum_{x=0}^{N-1} \sum_{y=0}^{M-1} \delta(f(x, y), i)
$$

siendo la función delta de Kronecker:

$$
\delta(i, j)= \begin{cases}1, & i=j \\ 0, & i \neq j\end{cases}
$$

El histograma de frecuencias de los niveles de gris acumula toda la información estadística de primer orden sobre una imagen o cualquier fragmento de ella. De cada nivel de gris se puede determinar cuál es la probabilidad de que aparezca en la imagen (o de ocurrencia):

$$
p(i)=\frac{h(j)}{N M}, \quad i=0,1,2, \ldots, G-1
$$

A partir de ella se pueden determinar algunas variables de textura de la imagen relacionadas directamente con la forma del histograma, con su anchura, con la forma de su distribución, etc. Estas variables permiten describir cuantitativamente las propiedades estadísticas de primer orden de la imagen y están basadas en el cálculo de los momentos centrales:

a. Media: determina el nivel de intensidad promedio de la imagen

$$
\mu=\sum_{i=0}^{G-1} i \cdot p(i)
$$


b. Varianza: describe la variación de la intensidad alrededor de la media:

$$
\sigma^{2}=\sum_{i=0}^{G-1}(i-\mu)^{2} \cdot p(i)
$$

c. Skewness, tercer momento o coeficiente de asimetría: Determina si una distribución es simétrica alrededor del nivel digital de máxima frecuencia. Valores positivos indican que la distribución está desplazada hacia la derecha con una mayor cola hacia la derecha del máximo. Valores negativos indican que la distribución está desplazada hacia la izquierda, con una forma más prolongada hacia ese lado del máximo.

$$
\mu_{3}=\sum_{i=0}^{G-1}\left(\frac{(i-\mu)}{\sqrt{\sigma^{2}}}\right)^{3} \cdot p(i)
$$

d. Kurtosis o apuntamiento: se define como el grado en el que una distribución estadística de frecuencias es puntiaguda y se determina por la expresión:

$$
\mu_{4}=\sum_{i=0}^{G-1}\left(\frac{(i-\mu)}{\sqrt{\sigma^{2}}}\right)^{4} \cdot p(i)-3
$$

e. Energía: es una medición de la magnitud de los datos.

$$
E=\sum_{i=0}^{G-1}[p(i)]^{2}
$$

f. Entropía: mide la uniformidad del histograma:

$$
H=-\sum_{i=0}^{G-1} p(i) \cdot \log _{2}[p(i)]
$$

g. Intervalo de datos:

$$
R=i_{\text {max }}-i_{\text {min }}
$$

De las variables anteriores, la media y la varianza son las que peor información aportan sobre la textura, ya que representan en mayor medida las condiciones del proceso de adquisición de la imagen, como iluminación o brillo general de la escena o la ganancia o desfase del sistema de adquisición. 


\subsection{2. Índices estadísticos de segundo orden}

Los estadísticos de primer orden son una aproximación a las texturas bastante sencilla, pero no pueden por sí solos caracterizarlas completamente. El principal método estadístico de análisis de texturas se basa en la definición de las distribuciones de probabilidad de co-ocurrencia entre pares de píxeles vecinos (Haralick et al., 1973), si bien existen otros como la auto-correlación espacial, el covariograma y el semivariograma (Maillard, 2003).

Los estadísticos de segundo orden son los obtenidos de la Matriz de Coocurrencia de Niveles de Gris (MCNG), la cual representa los cambios en la distribución de intensidades o niveles de gris de una imagen y cuyos elementos $P(i, j)$ indican la frecuencia con la que dos niveles de gris $i$ y $j$ se dan en la imagen, tomando los píxeles dos a dos y separados una distancia $D$ según una determinada dirección. Esta matriz de frecuencias (representada por $P$ ) es simétrica y está en función de la relación angular entre píxeles vecinos, así como de la distancia entre ellos. En la figura 6-4 se presenta un ejemplo.

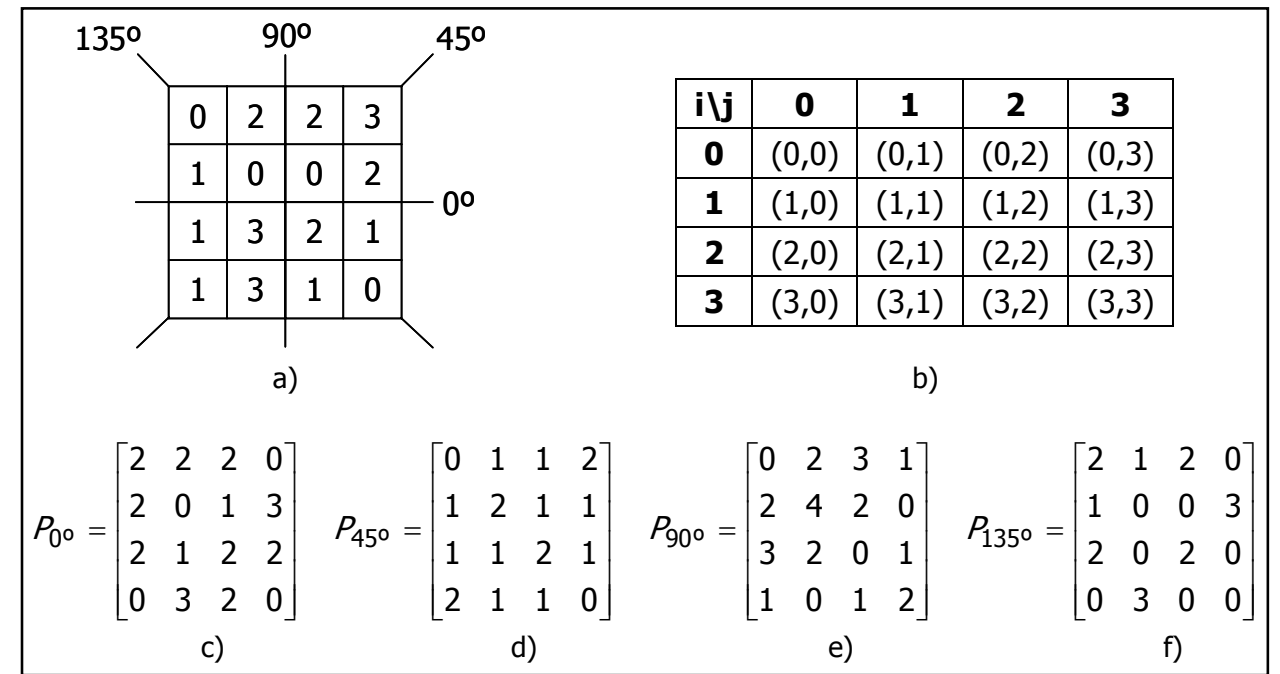

Figura 6-4. a) fragmento $4 x 4$ de una imagen con sus niveles de gris y las 4 direcciones de cálculo. b) construcción de la matriz de co-ocurrencias de los 4 niveles de gris. c), d), e) y f) matrices de coocurrencia para las cuatro direcciones.

La MCNG permite caracterizar la organización espacial de los niveles de gris de un patrón de textura, si bien no puede recoger los aspectos de forma de las primitivas de nivel de gris, por lo que no es adecuada para texturas formadas por patrones de grandes dimensiones o primitivas extensas. Una vez formada la MCNG de una imagen, la caracterización de los niveles de gris y de sus patrones se consigue mediante la extracción 
de sus características o descriptores de textura, propuestos por Haralick et al. (1973 y 1979). Para su cálculo se parte de los conceptos de matriz normalizada $p(i, j)$ y de la matriz de probabilidad marginal $p_{x}(i)$.

Matriz de co-occurencias normalizada $\boldsymbol{p}(\boldsymbol{i}, \boldsymbol{j})$ : Se define como la obtenida al dividir cada elemento de la matriz de co-ocurrencias $P(i, j)$ por el número de transiciones totales que se producen en dicha matriz. Cada elemento $p(i, j)$ representa la probabilidad de co-ocurrencia de los niveles de gris $i, j$ para las condiciones de distancia y dirección consideradas. La matriz normalizada viene dada por la expresión:

$$
p(i, j)=\frac{P(i, j)}{\sum_{i=0}^{N-1} \sum_{j=0}^{N-1} P(i, j)}
$$

siendo $N$ el rango de niveles de gris empleado. Siguiendo el ejemplo anterior, para la dirección $90^{\circ}$ sería:

$$
p_{(i, j)_{900}}=P_{(i, j)_{900}} * \frac{1}{18}=\left[\begin{array}{cccc}
0 & 2 & 3 & 1 \\
2 & 4 & 2 & 0 \\
3 & 2 & 0 & 1 \\
1 & 0 & 1 & 2
\end{array}\right] * \frac{1}{18}
$$

Matriz de probabilidad marginal, $\boldsymbol{p}_{\boldsymbol{x}}(\boldsymbol{i})$ : la definida por los respectivos sumatorios de los elementos de cada fila de la matriz normalizada:

$$
p_{X}(i)=\sum_{j=0}^{N-1} p(i, j)
$$

Las principales características de textura propuestas por Haralick et al. (1973) son las 8 que se describen a continuación y que son obtenidas a partir de la MCNG normalizada:

a. Media: proporciona información sobre el brillo global de la imagen, sensación similar a la obtenida a partir del histograma:

$$
\mu=\sum_{i=0}^{N-1} i \cdot p_{X}(i)
$$

b. Varianza: mide la heterogeneidad, es decir, la variabilidad de las intensidades en la imagen y aumenta su valor cuando los niveles de gris difieren de la media: 


$$
\sum_{i=0}^{N-1} \sum_{j=0}^{N-1}(i-\mu)^{2} \cdot p(i, j)
$$

c. Contraste: También llamado inercia, establece la diferencia de la frecuencia entre valores altos y bajos del nivel de gris. Está directamente relacionado con la frecuencia espacial de la imagen y en imágenes con pocas variaciones locales en los niveles de gris el valor del contraste será bajo:

$$
\sum_{i=0}^{N-1} \sum_{j=0}^{N-1}(i-j)^{2} \cdot p(i, j)
$$

d. Uniformidad, homogeneidad o momento angular de segundo orden: mide la homogeneidad textural de una imagen. Las imágenes homogéneas se caracterizan por tener pocas transiciones de niveles digitales entre píxeles vecinos y la uniformidad será alta en aquellos vecindarios que presenten un pequeño número de valores distintos de cero pero de gran magnitud. Es un parámetro análogo a la energía (de la Escalera, 2001):

$$
\sum_{i=0}^{N-1} \sum_{j=0}^{N-1} p(i, j)^{2}
$$

e. Entropía: indica la aleatoriedad, complejidad o desorden en la distribución de intensidades de una imagen, es decir, la existencia de variaciones de niveles de gris en entornos próximos:

$$
-\sum_{i=0}^{N-1} \sum_{j=0}^{N-1} p(i, j) \cdot \log [p(i, j)]
$$

f. Momento de diferencia inverso: está inversamente relacionado con el contraste y valores altos indican que la frecuencia de ocurrencia en la imagen de niveles de intensidad similares es elevada, discriminando zonas de variación de niveles de gris entre píxeles:

$$
\sum_{i=0}^{N-1} \sum_{j=0}^{N-1} \frac{p(i, j)}{1+(i, j)^{2}}
$$

g. Momento producto o covarianza: valores positivos altos indican una mayor probabilidad de que se den juntos en la imagen valores de intensidad similar. Por el contrario, valores negativos son propios de imágenes donde píxeles vecinos difieren mucho en su nivel de gris: 


$$
\sum_{i=0}^{N-1} \sum_{j=0}^{N-1}(i-\mu) \cdot(j-\mu) \cdot p(i, j)
$$

h. Correlación: equivale al momento producto normalizado respecto a la varianza. Mide la dependencia lineal de las intensidades en la imagen y es el coeficiente de correlación entre dos variables aleatorias $i, j$ donde $i$ representa el posible valor en nivel de gris para el primer elemento y $j$ el nivel de gris para el segundo elemento, separados ambos por la distancia $D$. Será mayor en imágenes que presenten grandes áreas con intensidades similares que en aquéllas que presenten ruido:

$$
\frac{\sum_{i=0}^{N-1} \sum_{j=0}^{N-1}(i-\mu) \cdot(j-\mu) \cdot p(i, j)}{\sum_{i=0}^{N-1} \sum_{j=0}^{N-1}(j-\mu)^{2} \cdot p(i, j)}
$$

La correlación presenta valores bajos alrededor de los bordes de zonas homogéneas por lo que será un buen estadístico para discriminar esas áreas.

De todas ellas, los diversos resultados publicados en la literatura específica resaltan algunas de ellas como más usadas o populares, siendo en orden decreciente las siguientes: Segundo momento angular, entropía, contraste (o inercia) correlación y momento de diferencia inverso (Maillard, 2003).

\subsubsection{Signaturas o variables wavelet}

Existen métodos que relacionan el tiempo y la frecuencia de las señales, sean uni o bidimensionales. Materka y Strzelecki, 1998 plantean la existencia de 3 métodos: distribuciones Wigner, funciones de Gabor y transformadas wavelet y de estos dos últimos analizan ciertas características. Los filtros de Gabor no son ortogonales y ello genera características redundantes en diferentes escalas. Por contra, la transformada wavelet, pese a ser una operación lineal, no produce interferencias entre términos. A diferencia de la transformada de Fourier, la transformada wavelet tiene capacidad de localizar en el tiempo (o espacio) las características espectrales de la señal.

La ventaja anterior, junto a otras detalladas en los correspondientes capítulos de este trabajo, sugieren el empleo de la transformada wavelet. Tras ser aplicada, de los 
resultados obtenidos se pueden extraer ciertas características de textura como las anteriormente indicadas o como las de los bloques siguientes.

Un problema importante en el análisis de texturas mediante wavelets (Livens et al., 1997) es el número de características obtenidas para segmentar o clasificar sobre ellas, sobre todo al emplear la wavelet packet. Son diversos los enfoques propuestos para la reducción de ese volumen de información, si bien el problema radica en establecer un criterio para continuar aplicando la transformada y de esa manera extraer más variables de textura, o bien parar en un determinado nivel y emplear las variables obtenidas hasta dicho nivel. Este proceso es denominado como transformada wavelet adaptativa. Son varios los criterios citados, como el de la varianza, el de la energía, o el de separabilidades entre clases.

La descomposición wavelet de una imagen genera una información referente a las altas frecuencias espaciales en forma de imágenes de detalles horizontales, verticales y diagonales y de bajas frecuencias en forma de aproximaciones. A partir de dicha descomposición se puede calcular una serie de estadísticos de primer y segundo orden, cada uno de ellos obtenidos mediante procedimientos diferentes. Los estadísticos de primer orden se obtienen a partir de los propios valores digitales de la imagen y de la distribución frecuencial de dichos niveles de gris en forma de histograma. Los de segundo orden son obtenidos a partir de la matriz de co-ocurrencias de niveles de gris. Algunos autores (Van de Wouver, 1998) los han aplicado de forma conjunta de cara a clasificar y segmentar imágenes de textura, englobándolos a todos ellos bajo la denominación "Wavelet Signatures". Bajo esta expresión podremos analizar por tanto las signaturas de energía ("Energy Signatures"), las signaturas extraídas de los histogramas ("Histogram Signatures") y las obtenidas de la MCNG ("Coocurrence Signatures").

\subsubsection{Signaturas de energía}

La energía calculada sobre un vecindario de cada píxel de la imagen es una característica de textura importante, de tal manera que el conjunto de energías a diferentes escalas es considerado un buen rasgo a analizar (Livens et al., 1997). Según estos autores, no existen claras conclusiones sobre las mejores características a emplear siendo algunas de las más usadas la energía y la entropía, segunda varianza y algunas de las derivadas de la MCNG.

La energía es una de las características de textura más empleadas en la literatura (Laine y Fan, 1993, Van de Wouwer, 1998, Van de Wouwer et al., 1999, Porter, 1996, Materka, 1998). La energía normalizada de una imagen $f(x, y)$ es definida como: 


$$
E=\frac{1}{N} \sum_{x, y}(f(x, y))^{2}
$$

siendo $x$ e $y$ los índices de columna y fila de la imagen y $N$ el número total de píxeles de la imagen. Otra medida que a veces es usada es la desviación media de la imagen:

$$
M D=\frac{1}{N} \sum_{x, y}|f(x, y)|
$$

Ambas son medidas de la dispersión de los valores de la imagen y están altamente correlacionadas.

La aplicación práctica de estas dos medidas para la discriminación de texturas se realiza sobre las imágenes de detalle obtenidas al aplicar la transformada wavelet a diferentes niveles, de tal manera que se genere un vector de características, en el que cada miembro sea la energía o desviación media de cada una de las imágenes de detalles (verticales, horizontales o diagonales) en cada escala.

Una variante a esos vectores de rasgos texturales consiste en la construcción de una imagen de energía o desviación media de cada imagen de detalle, calculando la medida correspondiente sobre un determinado vecindario de cada uno de los píxeles iniciales. Esta rutina operativa generará tantas imágenes de energía o de desviación media como imágenes de detalle se tengan y de las mismas dimensiones. Es la variante empleada en los ensayos prácticos sobre imágenes.

\subsubsection{Signaturas del histograma}

El empleo de variables derivadas de los histogramas es aplicado por diversos autores en diferentes vías. Así, además de los estadísticos de primer orden anteriormente reseñados, Fatemi-Ghomi (1997) define el histograma de distancia, básicamente una medida de la separabilidad de las características de textura para un conjunto de clases definidas, por lo que sirve para evaluar la validez del modelo de variables de textura a emplear. El histograma de distancia es un gráfico en el que en abscisas se representa el número de características de textura y en ordenadas las distancias tanto dentro de las clases de una clasificación, como entre ellas.

Existen otros modelos basados en histogramas. En concreto, Van de Wouwer (1998), Van de Wouwer et al. (1999), parten de las imágenes de detalle resultantes de aplicar la transformada wavelet y extraen información estadística de sus respectivos 
histogramas o diagramas de frecuencias de sus coeficientes. La justificación del empleo del histograma se basa en que las imágenes de detalles provienen de sucesivas convoluciones con dos filtros paso bajo y paso alto, genéricamente denominados $\mathrm{H}$ y $\mathrm{G}$ respectivamente. El filtro $\mathrm{G}$ es un filtro paso alto puro y ello implica que la media de las imágenes de detalle que surgen de su aplicación será igual a cero. Por tanto, su energía será exactamente su varianza y emplear dicha energía como variable de textura (tal y como se indica en el apartado anterior) equivale a caracterizar el histograma de cada imagen de detalles por una función gaussiana. Emplear el histograma como fuente de rasgos de textura tiene la ventaja de aprovechar la invarianza a la traslación de las características derivadas. Mallat (1989), estableció que los histogramas de las imágenes de detalle pueden ser definidos por una familia de funciones exponenciales:

$$
h(u)=K e^{-\left(\frac{|u|}{\alpha}\right)^{\beta}}
$$

siendo $h(u)$ la frecuencia de un nivel digital $u, \beta$ inversamente proporcional al decaimiento del pico del histograma ( $\beta=2$ equivale a una función gaussiana), $\alpha$ expresa el ancho del pico del histograma (es decir, la varianza) y $K$ es una constante de normalización. Todas las estadísticas de primer orden del histograma vienen proporcionadas por esas dos variables $\alpha$ y $\beta$.

Otra característica de textura extraída del histograma parte de su forma, es decir, de su simetría. Es la que Van de Wouwer (1998) denomina parámetro de asimetría y que se expresa como:

$$
a s m=\frac{1}{N} \sum_{i=1}^{N}\left(h\left(u_{\max }-u_{i}\right)-h\left(u_{\max }+u_{i}\right)\right)^{2}
$$

donde $u_{\max }$ es el nivel digital o coeficiente de frecuencia máxima. La anterior ecuación genera un único valor para toda una imagen, si bien se puede crear una imagen de asimetría calculando dicho parámetro sobre un vecindario de cada uno de los coeficientes de cada imagen de detalle. Este parámetro de asimetría es parecido al coeficiente de asimetría estadístico que la literatura denomina skewness y ambos han sido evaluados en los ensayos realizados.

\subsubsection{Filtros de energía textural o de Laws}

Este método (Laws, 1980, 1985) consiste en la convolución de la imagen con varios filtros, produciendo tantas imágenes como convoluciones realizadas. Si llamamos $I$ a 
la imagen inicial y $g_{1}, \ldots, g_{n}$ a los respectivos filtros, una imagen genérica resultante de la convolución vendrá definida por la expresión: $J_{n}=I^{*} g_{n}$. Cada uno de esos filtros resalta una característica textural distinta (bordes, forma, ondulación, rugosidad, etc.), por lo que las nuevas imágenes tendrán valores relacionados directamente con esas características.

Las ventanas de filtro (kernel) definidas por Laws para vecindarios de 3x3, 5x5 y 7x7 están representadas en su forma unidimensional en la tabla 6-1. Los filtros de energía estudiados han sido: media ponderada $(\mathrm{L})$, que proporciona información del nivel de gris promedio en el vecindario; gradiente (E), que es un filtro de realce de bordes; forma (S), realza ciertas formas en la dimensión de los niveles de gris; ondulación (W); rugosidad (R); y para terminar, oscilación (O). Los tres últimos relazan formas ondulatorias en la imagen. A ellos se les ha añadido el laplaciano de un filtro gaussiano (LoG).

\begin{tabular}{rlr|}
\hline \multicolumn{5}{c|}{$3 \times 3$} \\
\hline $\mathrm{L}$ & $=\left[\begin{array}{rrr}1 & 2 & 1\end{array}\right]$ \\
$\mathrm{E}$ & $=\left[\begin{array}{lrr}-1 & 0 & 1\end{array}\right]$ \\
$\mathrm{S}$ & $=\left[\begin{array}{llr}-1 & 2 & -1\end{array}\right]$
\end{tabular}

\begin{tabular}{|c|c|c|c|c|c|}
\hline \multicolumn{6}{|c|}{$5 \times 5$} \\
\hline$L=$ & 1 & 4 & 6 & 4 & 1 \\
\hline$E=$ & -1 & -2 & 0 & 2 & 1 \\
\hline$S=$ & -1 & 0 & 2 & 0 & -1 \\
\hline$W=$ & -1 & 2 & 0 & -2 & 1 \\
\hline $\mathrm{R}=$ & 1 & -4 & 6 & -4 & 1 \\
\hline
\end{tabular}

\begin{tabular}{|c|c|c|c|c|c|c|c|c|}
\hline \multicolumn{9}{|c|}{$7 \times 7$} \\
\hline $\mathrm{L}=$ & 1 & 6 & 15 & 20 & 15 & 6 & 1 & \\
\hline$E=$ & -1 & -4 & -5 & 0 & 5 & 4 & 1 & \\
\hline$S=$ & -1 & -2 & 1 & 4 & 1 & -2 & -1 & \\
\hline$W=$ & -1 & 0 & 3 & 0 & -3 & 0 & 1 & \\
\hline $\mathrm{R}=$ & 1 & -2 & -1 & 4 & -1 & -2 & 1 & \\
\hline $\mathrm{O}=$ & -1 & 6 & -15 & 20 & -15 & 6 & -1 & \\
\hline
\end{tabular}

Tabla 6-1. Ventanas de filtros de tres vecindarios.

Para el estudio de la influencia del tamaño del filtro se realiza el filtrado con los vecindarios de $5 \times 5$ y de $7 \times 7$, ya que son los más adecuados a las dimensiones de los elementos texturales presentes en las imágenes. El principal problema de este método es la posibilidad de introducir errores significativos en las zonas de transición entre diferentes texturas (efecto de bordes), ya que en estas zonas se tienen en cuenta vecindarios con mezcla de clases texturales, pudiendo estimarse valores para las características texturales correspondientes a patrones intermedios no existentes en la imagen real. A fin de minimizar este efecto se ha utilizado el método propuesto por Hsaio y Sawchuk (1989), que consiste en un nivel más de procesado: Para cada píxel de la imagen $J_{n}$ se calcula la media y la varianza de los cuatro cuadrantes para los que el píxel $(r, c)$ es un vértice, consiguiendo una imagen de energía, en la que a cada elemento $\mathrm{E}(r, c)$ se le asigna el valor de la media del cuadrante que posee menor varianza (figura 6-5). De esta forma se 
asegura que la clase asignada a cada píxel es aquélla en la cual está mayoritariamente incluido.

En la realización de este segundo nivel de procesado se utilizan distintos tamaños de vecindario, en función del tamaño de los filtros de textura utilizados. Así pues, para las imágenes de características texturales obtenidas con filtros de tamaño $5 \times 5$ se ha realizado el post- procesado con vecindarios de $5 \times 5,7 \times 7$ y $11 \times 11$, mientras que para las imágenes obtenidas con filtros de $7 x 7$, el post-procesado se ha hecho con vecindarios de $7 x 7,11 \times 11$ y $15 \times 15$.

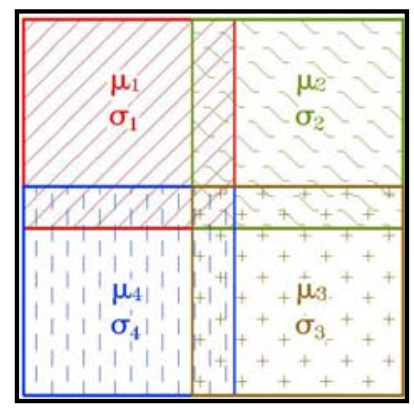

Figura 6-5. Método de post-procesado.

La evaluación del poder discriminatorio de los distintos filtros de energía así como de los distintos tamaños de los vecindarios del post-procesado se hace mediante análisis de separabilidad (distancias de Jeffries-Matusita y Divergencia Transformada) de las muestras de aprendizaje representativas de las texturas a caracterizar. De las separabilidades obtenidas para cada una de las clases, con las combinaciones expuestas de tamaño de filtros y de post-procesado, se ha comprobado que la separabilidad mayor para el conjunto de las clases, se corresponde con la imagen obtenida con los filtros de $7 \times 7$ y el post-procesado para un vecindario también de $7 \times 7$.

\subsubsection{Densidad de bordes}

La textura puede caracterizarse en términos de la cuantía e intensidad de bordes por unidad de área. Una transición brusca en los niveles de gris de una imagen alrededor de un píxel dado puede detectarse comparando por pares los valores de los vecindarios del píxel. Para obtener la densidad de bordes para un vecindario de la imagen se ha utilizado la expresión propuesta por Sutton y Hall (1972), en la que para cada distancia $d$ en la imagen $I$, con un vecindario $N$, se calcula para cada píxel $(i, j)$ el gradiente (suma de los valores absolutos de las diferencias entre píxeles vecinos): 


$$
\begin{array}{r}
g(d)=\sum_{(i, j) \in N}\{|I(i, j)-I(i+d, j)|+|I(i, j)-I(i-d, j)|+ \\
+|I(i, j)-I(i, j+d)|+|I(i, j)-I(i, j-d)|\}
\end{array}
$$

Variando la distancia $d$ con la que se calcula la densidad de bordes, pueden detectarse bordes de diferentes tamaños. En este caso, se han obtenido tres imágenes de densidad de bordes con tres valores de distancia entre píxeles: $d=1, d=2$ y $d=3$.

De nuevo se ha realizado el cálculo de separabilidades de las muestras de aprendizaje, para las imágenes resultantes de los filtros de energía, con un tamaño de filtro de $7 \times 7$ y post-procesado de $7 \times 7$, añadiendo el filtro del laplaciano del gaussiano y cada una de las tres imágenes de densidad de bordes obtenidas. Se comprueba que la imagen de densidad de bordes que más información aporta para las clasificaciones posteriores es la correspondiente a una distancia de 3 píxeles para el conjunto de las imágenes a analizar, si bien, de forma desglosada se obtiene una distancia de 2 píxeles para algunas imágenes de muy alta resolución espacial $(60 \mathrm{~cm})$, mientras que para otras de resolución menor $(2 \mathrm{~m})$, es mejor una distancia de 1 píxel. En la figura 6-6 se detallan algunos fragmentos de los diversos filtros de energía y densidad de bordes para la imagen de Daimiel.

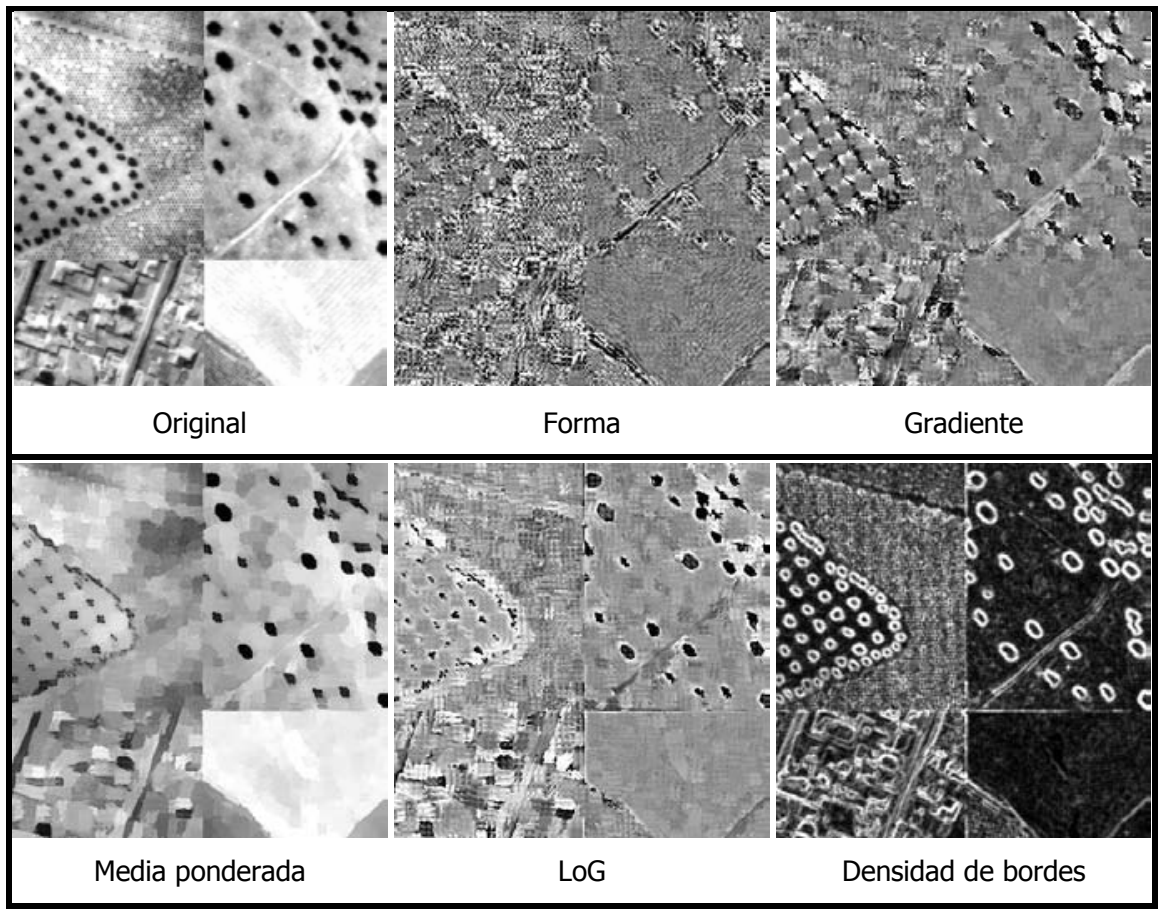

Figura 6-6. Fragmento de la imagen original y de cinco de las características texturales obtenidas. 


\subsubsection{Filtros de Gabor}

El origen de las funciones de Gabor y por extensión de la Transformada de Gabor se remonta a 1946, cuando Dennis Gabor dedujo la formulación de la Short Time Fourier Transform (STFT), la cual permitía analizar:

- Componentes de altas frecuencias usando pequeñas ventanas, o bien

- Componentes de bajas frecuencias usando ventanas mas anchas.

Gabor introdujo en la STFT una familia de wavelets no ortogonales con soporte infinito basadas en las traslaciones sobre una función gaussiana (Seppälä, 2001), por lo que se puede considerar a la transformada de Gabor como una STFT en la que se emplea una ventana gaussiana.

La aplicación de las funciones de Gabor se puede realizar como filtros en el dominio de la frecuencia para extraer características de textura específicas de cada frecuencia y orientación (Maillard, 2003), o lo que es lo mismo, se puede aplicar la transformada de Gabor mediante bancos de filtros discretos. Un banco de filtros Gabor es un banco de filtros paso banda con forma gaussiana, con cobertura diádica del rango de frecuencias espaciales radiales y múltiples orientaciones, es decir, es un conjunto de filtros gaussianos que cubren el dominio frecuencial con distintas frecuencias radiales y orientaciones (figura 6-7).

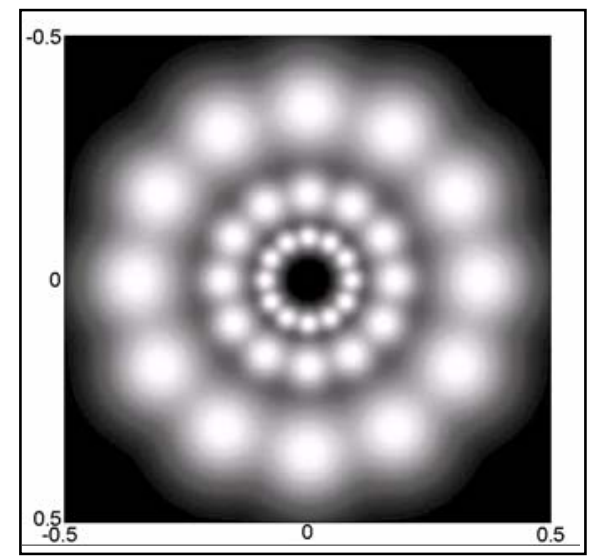

Figura 6-7. Orientaciones y frecuencias radiales de un banco de filtros de Gabor.

En el dominio espacial, un filtro de Gabor consiste en una función gaussiana modulada por una curva sinusoidal (figura 6-8): 


$$
h(x, y)=\frac{1}{2 \pi \sigma_{g}^{2}} \cdot \exp \left[-\frac{\left(x^{2}+y^{2}\right)}{2 \sigma_{g}^{2}}\right] \cdot \exp (j 2 \pi F(x \cos \theta+y \operatorname{sen} \theta))
$$

donde $\sigma_{g}$ determina la extensión espacial del filtro.

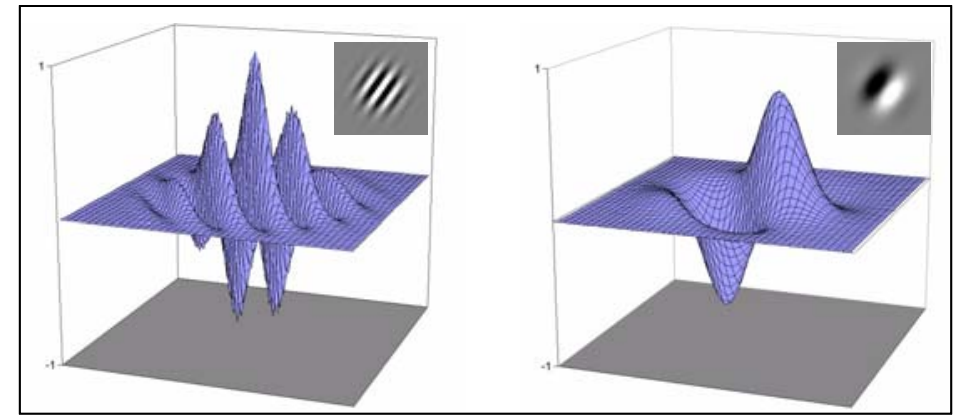

Figura 6-8. Parte real (izquierda) e imaginaria (derecha) de un filtro de Gabor.

En el dominio frecuencial, la función Gabor es una curva gaussiana:

$$
g(x, y)=\frac{1}{2 \pi \sigma_{x} \sigma_{y}} \exp \left(-\frac{1}{2}\left(\frac{x^{\prime 2}}{\sigma_{x}^{2}}+\frac{y^{\prime 2}}{\sigma_{y}^{2}}\right)\right) \exp \left(2 \pi j f_{c}\left(x^{\prime} \cos \beta+y^{\prime} \sin \beta\right)\right)
$$

donde $(x, y)$ son las coordenadas rotadas de $(x, y)$, es decir:

$$
\begin{aligned}
& x^{\prime}=x \cos \alpha+y \sin \alpha \\
& y^{\prime}=-x \sin \alpha+y \cos \alpha
\end{aligned}
$$

los parámetros $\sigma_{x} \sigma_{y}$ controlan el ancho espacial y espectral de la función, los parámetros $f_{c}$ y $\beta$ controlan el desplazamiento en frecuencia en el dominio espectral y $\alpha$ controla la rotación de las coordenadas.

La función de Gabor tiene la propiedad de tener un ancho efectivo finito tanto en el dominio espacial como en el espectral. Esto es importante en el análisis de texturas, especialmente en la segmentación, ya que diferentes texturas tienden a concentrar, en muchos casos, sus energías en rangos estrechos de frecuencias. La transformada de Fourier de la función de Gabor viene dada por la expresión:

$$
H(u, v)=\exp \left[-2 \pi^{2} \sigma_{g}^{2}\left((u-F \cos \theta)^{2}+(v-F \operatorname{sen} \theta)^{2}\right)\right]
$$

Los parámetros que definen cada uno de los filtros de Gabor son: la frecuencia radial $F$ donde está centrado el filtro en el dominio frecuencial, la desviación típica $\sigma$ de la 
curva gaussiana y la orientación $\theta$ respecto al eje de abscisas. Por simplicidad, se supone que la curva gaussiana es simétrica.

El banco de filtros aplicado sobre las diversas imágenes se ha construido con 6 orientaciones $\left(0^{\circ}, 30^{\circ}, 60^{\circ}, 90^{\circ}, 120^{\circ}\right.$ y $\left.150^{\circ}\right)$ y tres combinaciones de frecuencia y desviación típica: $F=0.3536$ y $\sigma=2.865, F=0.1768$ y $\sigma=5.73, F=0.0884$ y $\sigma=11.444$, dando lugar a un total de 18 filtros que cubren el dominio frecuencial. Una vez aplicado el banco de filtros sobre la imagen, se ha obtenido su magnitud, para a continuación aplicarle un filtro gaussiano $(\sigma=5)$ paso-bajo que reduce la varianza y, consecuentemente, el error de clasificación.

Dado que tanto la descomposición wavelet como la transformada de Gabor se aplican mediante bancos de filtros, puede analizarse la relación existente entre ellos. Algunas ventajas de los filtros de Gabor radican en su fácil diseño, la posibilidad de seleccionar la orientación y frecuencia y la definición de filtros con un determinado ancho de banda (Laine y Fan, 1993). Por contra, presentan desventajas frente a la transformada wavelet como son ineficiencia computacional y el requerimiento de un gran número de canales para cubrir de forma aproximada el plano de frecuencias en su totalidad. En cambio, los filtros usados en la transformada wavelet (o filtros wavelet) cubren exactamente todo el dominio de la frecuencia, permiten diseñar algoritmos de cálculo sencillos y se pueden incorporar mejor a un sistema integrado de tratamiento de imágenes que busque la compresión, detección de bordes, clasificación, segmentación, etc. Además y teniendo en cuenta el coste computacional, la transformada wavelet es recomendada por su mayor rapidez de cálculo frente a la descomposición de Gabor (Livens et al., 1997).

Desde el punto de vista de la ortogonalidad de las funciones de una transformación, la principal desventaja de emplear Gabor es que la salida del banco de filtros de Gabor no es mutuamente ortogonal, lo que puede implicar una significante correlación entre características de textura. Esto puede ser evitado usando la transformada wavelet, la cual analiza una señal a diferentes escalas. Otra ventaja de wavelet frente a Gabor es que los filtros paso bajo y paso alto de la transformación wavelet permanecen constantes entre dos escalas consecutivas, mientras que el modelo de Gabor requiere filtros de diferentes parámetros en cada escala, lo que conlleva un análisis previo de dichos parámetros (Arivazhagan, 2002). 


\subsubsection{Selección de variables de textura}

De los estudios previos se ha determinado emplear tan sólo algunas de todas las variables propuestas en el apartado anterior, ya que no todas ellas contribuyen de la misma manera a la fiabilidad de las clasificaciones (ver capítulo VII). Para ello se han aplicado cálculos de separabilidades estadísticas entre las diferentes variables, se han determinado las correlaciones estadísticas entre las bandas y se han evaluado los resultados de las clasificaciones con diversas agrupaciones.

Las medidas de separabilidad se pueden emplear para 3 fines: (1) Analizar si la elección de las clases temáticas a obtener es adecuada, es decir, si son suficientemente diferenciables. (2) Determinar si las muestras tomadas para todas las clases son lo suficientemente representativas de ellas o si por contra son muy heterogéneas. $Y$ (3) conocer la mejor combinación de variables texturales que optimicen la clasificación, es decir, para seleccionar las mejores bandas o para saber el número de bandas necesario para una buena clasificación.

Se han calculado las separabilidades entre áreas de entrenamiento del clasificador en cada clase mediante las distancias de Jeffries Matusita y la de divergencia transformada (Richards, 1999). Estas distancias presentan valores comprendidos entre 0 y 2 y a mayor valor, mejor separabilidad estadística entre las áreas de aprendizaje de dos clases y para dos bandas. Tendrán un valor bajo para clases próximas (poco separables) y alto para las clases que estén más aisladas (muy separables).

La distancia de Jeffries-Matusita entre dos clases iy $j$ se define como:

$$
J_{i j}=\left[\int_{x}\left(\sqrt{p\left(x / \omega_{i}\right)}-\sqrt{p\left(x / \omega_{j}\right.}\right)^{2} d x\right]^{\frac{1}{2}}
$$

Conceptualmente, esta distancia está directamente relacionada con el área no común de las curvas de distribución de probabilidad $p(x / \omega)$ para cada clase. Cuanto mayor sea el área, mayor separabilidad existirá entre las clases.

La distancia de divergencia transformada se basa en la relación entre las probabilidades de dos clases $i$ y $j$, según la expresión:

$$
D^{T}=2\left[1-e^{-D / 8}\right]
$$

donde se define la divergencia como: 


$$
D=\frac{1}{2}\left[\left(C_{i}-C_{j}\right)\left(C_{j}^{-1}-C_{i}^{-1}\right)\right]+\frac{1}{2}\left[\left(C_{i}^{-1}+C_{j}^{-1}\right)\left(\mu_{i}-\mu_{j}\right)\left(\mu_{i}-\mu_{j}\right)^{T}\right]
$$

siendo $C_{i}$ y $C_{j}$ las matrices de covarianzas para las clases $i, j$.

La información estadística básica obtenida de las imágenes compuestas de todas las variables de textura derivadas (imágenes multibanda) en forma de matriz de covarianzas permite conocer los vectores y valores propios, así como la matriz de correlación entre bandas en su totalidad. Esta matriz permite resaltar aquellas variables que están fuertemente correlacionadas y que al aportar información redundante al modelo de datos podrían ser simplificadas.

El último modelo de selección de variables ha sido un modelo a posteriori, es decir, tras generar un conjunto de clasificaciones con diferentes agrupaciones de todas las variables se han evaluado mediante el cálculo de estadísticas entre clases, matrices de confusión e índice kappa y se ha determinado cuáles de ellas son más discriminantes. Se ha dado más peso a este modelo dado que las diferentes variables texturales presentan valores digitales muy heterogéneos entre ellas (al proceder de diversas ecuaciones de cálculo) y por ello las separabilidades y las correlaciones no generan buenos resultados e incluso llegan a provocar errores matemáticos en determinados casos.

\subsection{Determinación de los parámetros metodológicos globales}

El tratamiento digital de señales se puede realizar desde diversos enfoques y mediante un amplio abanico de técnicas y algoritmos de procesado. Todos ellos generan resultados en función de las propias rutinas de trabajo en sí pero también dependiendo de las características intrínsecas de los datos de partida, bien sean señales unidimensionales o bien sean imágenes. Por ello se considera de gran importancia una correcta selección de aquellas características de partida que nos optimizarán los resultados esperados y considerar también que las diversas rutinas divergirán más o menos en los resultados finales. 


\subsubsection{Determinación de la resolución espacial óptima}

La disponibilidad de información geoespacial de cualquier parte del territorio puede en determinados casos llegar a ser importante: cartografía analógica, digital, ortofotografías, ortoimágenes, modelos digitales del terreno, etc. y además pueden provenir de diversas fuentes, como distintas plataformas espaciales y sensores o bien de diferentes organismos. A su vez, el abanico de posibles aplicaciones con objetivos variados experimenta cada vez un incremento considerable. Por todo ello, el responsable de un determinado proyecto que requiera el empleo de imágenes raster, bien aéreas o de satélite, puede encontrarse en las primeras fases del organigrama de trabajo con la disyuntiva de qué fuentes de datos seleccionar en función, evidentemente de los objetivos buscados, pero también de las diversas resoluciones posibles así como del presupuesto asignado para la adquisición de esos datos.

La escala de trabajo, entendida como 4 tipos posibles de escala (Cao y Lam, 1997) determina en gran medida el diseño de las rutinas de trabajo. Esas 4 escalas son (a) la escala cartográfica en sí; (b) la escala geográfica u observacional que se refiere a la dimensión del área de trabajo; (c) la escala operacional, entendida como la escala a la que cierta rutina opera en el terreno; y (d) la escala de medida o resolución espacial. La selección de estas escalas y resolución depende de la realidad de la escena, es decir, de la naturaleza de los objetos, sus formas, dimensiones, agrupaciones que pueden formar, etc. y de cómo varíen con el cambio de resolución. Cada porción de la superficie terrestre presenta unos patrones distintos dependiendo de los objetos, sus tamaños, sus formas, etc. y para cada escala de trabajo esos patrones pueden cambiar. Esto implica que sea importante seleccionar el mejor tamaño de píxel para conseguir un cierto equilibrio entre definición espacial de los objetos y variabilidad espectral de los tipos de coberturas, ya que una resolución espacial alta hace disminuir la separabilidad espectral de las clases y genera peores fiabilidades en una clasificación.

Un trabajo previo de análisis del entorno de trabajo, de los datos disponibles y de los objetivos buscados puede evitar tareas innecesarias, poco relevantes o incluso que generen resultados erróneos. Uno de esos análisis previos es el que sigue a continuación.

\section{Método de la varianza local}

La varianza local es definida como el valor medio de las varianzas en un vecindario determinado desplazado sobre la totalidad de la imagen.

En una imagen cuya resolución espacial sea alta, es decir, tamaño de los píxeles menor a las dimensiones de los objetos de la escena, la mayor parte de las medidas realizadas estarán claramente influenciadas y correlacionadas con sus vecinos y la varianza 
local será baja. Si aumentamos el tamaño del píxel hasta que se aproxime al de los objetos de la imagen, los valores tenderán a ser independientes de sus vecinos y la varianza local se incrementará. Si el tamaño del píxel se aumenta hasta superar las dimensiones de los elementos de la escena, varios de esos elementos conformarán cada píxel y la varianza local comenzará a decrecer. Por tanto, para determinar el mejor tamaño del píxel de la imagen debemos encontrar la resolución a la cuál la imagen presenta una mayor varianza local, cuantificada como la media de la imagen de varianza.

La varianza de una imagen en un determinado vecindario se determina según la expresión

$$
\sigma^{2}=\frac{1}{n} \sum_{i=1}^{n}\left(x_{i}-\bar{x}\right)^{2}
$$

donde $\mathrm{n}$ es el número de elementos del vecindario.

El método propuesto por Cao y Lam (1997) establece el cálculo de la varianza local en un vecindario de $3 \times 3$ píxeles. Este vecindario se muestra claramente pequeño para caracterizar la mayoría de las texturas, ya que empíricamente se ha demostrado que con ese vecindario las mejores varianzas locales se obtienen para píxeles de un tamaño superior a la media. Se han analizado vecindarios de cálculo de 3x3, 5x5, 7x7, 9x9, 11x11, $15 \times 15$ y $25 \times 25$. Todos los cálculos para las distintas resoluciones y vecindarios han sido implementados en una rutina propia en lenguaje IDL $^{1}$.

La aplicación de este cálculo tiene su justificación en el hecho de que en las aplicaciones sobre el territorio a partir de información remota se suele plantear, entre otras, una cuestión importante en el esquema organizativo del trabajo: ¿cuál es la mejor resolución espacial para una aplicación y unos objetivos específicos? Pues bien, mediante la determinación de la varianza local para cada imagen se puede determinar a qué resolución se consigue maximizar dicha varianza para obtener los mejores resultados en cualquier tarea posterior de cálculo de variables de textura, clasificación, etc.

Para contrastar si la mejor resolución espacial obtenida por el método de la varianza local es efectivamente la mejor a la hora de obtener los resultados finales, también se han realizado clasificaciones supervisadas mediante el método de máxima probabilidad basado en la regla de decisión de Bayes, aplicado sobre la imagen original y las 8 variables de textura obtenidas de la matriz de co-ocurrencias de niveles de gris (véase el capítulo de resultados). Los elementos de esta matriz $P(i, j)$ representan las

${ }^{1}$ IDL (Interactive Data Language) es el lenguaje fuente de la aplicación ENVI (Environment for Visualizing Images), que permite tanto programar en el entorno propio del código fuente como sobre ENVI. Ambos han sido desarrollados por Research Systems Inc. 
frecuencias relativas de los niveles de gris $i$ y $j$, tomando los píxeles dos a dos y separados una determinada distancia $d$ en una dirección dada. Cuanto mayores sean los valores de su diagonal principal más homogénea será la textura, mientras que cuanto más repartidos estén los valores fuera de la diagonal, más heterogénea será. De esta matriz se han obtenido, según el método propuesto por Haralick (1973), 8 variables estadísticas de segundo orden que representan las propiedades texturales de una imagen y son: uniformidad, contraste, media, entropía, varianza, momento producto, correlación y momento diferencia inverso. El cálculo de estas variables se ha realizado con un vecindario de $25 \times 25$, ya que en la zona de trabajo ha demostrado ser el vecindario óptimo para clasificar (Ruiz et al., 2004).

Para la clasificación mediante el método señalado se han tomado una serie de nuestras de aprendizaje para cada clase, lo suficientemente representativas pero lo más homogéneas posible, con las que se han obtenido las funciones de densidad de probabilidad y las funciones de decisión del método probabilístico. Se han considerado otras porciones de la imagen empleadas en el análisis a posteriori de la clasificación, generando la matriz de confusión o matriz de errores.

Otros autores como Maillard (2003) también han aplicado la rutina de Cao y Lam (1997) para conseguir la resolución espacial óptima en un problema de clasificación de un mosaico de fragmentos de fotogramas aéreos (escala 1/25.000) escaneados, obteniendo un tamaño óptimo de píxel de 1.4 metros que preserva casi toda la variabilidad espacial sin aumentar excesivamente el tamaño de la imagen a procesar. Fdez.-Sarría et al. (2005) también aplican esta rutina sobre varias imágenes y constatan, mediante clasificaciones a las diferentes resoluciones, que la que maximiza la varianza media de la imagen es la que proporciona una mayor fiabilidad global. Estos resultados son bastante coherentes con los obtenidos en nuestros ensayos y parecen demostrar la validez de este planteamiento.

\subsubsection{Determinación de la resolución radiométrica óptima}

La resolución radiométrica de una imagen de satélite nos indica el intervalo de niveles digitales o niveles de gris que pueden tener todos los píxeles de dicha imagen. Las imágenes en formato binario representarán dichos valores como combinaciones de 0 y 1 . En función de la dimensión de esas combinaciones se hablará de mayor o menor radiometría, de tal manera que una imagen con 2 bits por píxel podrá presentar en cada uno de ellos valores comprendidos en el rango de $2^{2}=4$, es decir, en el rango $[0,3]$. Otra que codifique los niveles digitales con 8 bits por píxel presentará un rango de valores de $2^{8}=256$, lo que es lo mismo, [0, 255]. La primera de ellas tendrá una pobre definición de las diferencias entre respuestas espectrales de los elementos de la superficie, mientras que 
la segunda permitirá discriminar bastante mejor los diversos elementos de la realidad. En la figura 6-9 se puede apreciar la diferencia evidente para una misma escena codificada con $8,5,2$ y 1 bits por píxel.

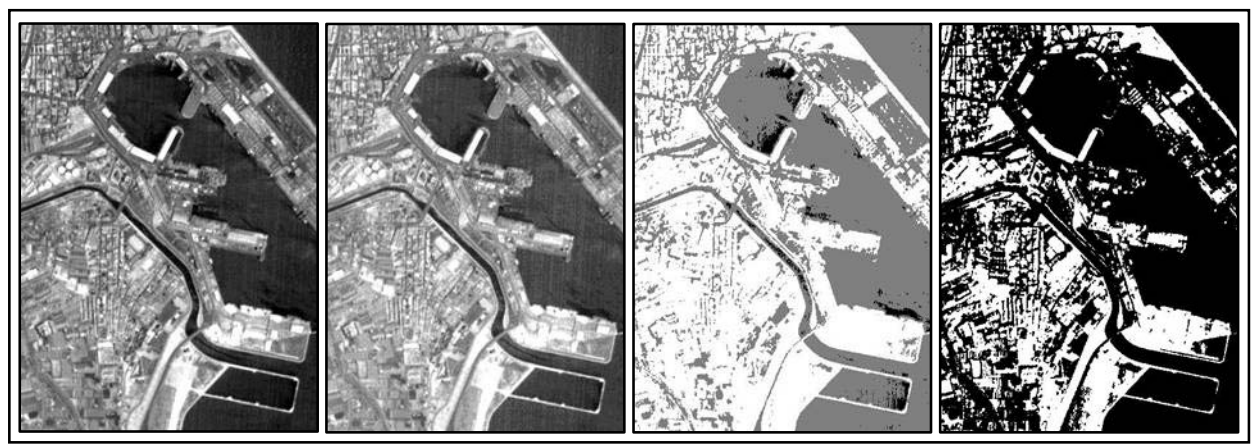

Figura 6-9. Porción de una imagen Landsat TM en la que se aprecia parte del puerto de Valencia con distintos rangos de grises. De izquierda a derecha: con 256 ND, con 32 ND, con 4 ND y con 2 ND.

Las diferencias en la radiometría de las imágenes influyen mucho en los cálculos posteriores de variables texturales, ya que dichas variables, sean estadísticos de primer orden, segundo, variables de energía, etc. se basan en los valores digitales de la imagen o en vecindarios de ella. En el caso de la MCNG, sobre una imagen con muchos niveles digitales no se encontrarán co-ocurrencias suficientes dentro de la matriz como para caracterizar una textura. Para un mismo conjunto de variables y en una imagen específica, cabe esperar que haya una resolución radiométrica a la cual la clasificación se maximice porque la discriminación entre los elementos del vecindario de análisis sea la óptima.

Los ensayos realizados tendentes a encontrar la mejor resolución radiométrica sobre 4 tipologías de superficies parten de la naturaleza de cada una se esas imágenes. Así algunas de ellas (las provenientes del satélite QuickBird) presentan una resolución nominal de 11 bits por píxel, mientras que las imágenes escaneadas de ortofotogramas parten de 8 bits por píxel. En todas ellas se han realizado las correspondientes operaciones matemáticas para abarcar un abanico de resoluciones que van desde 5 hasta 11 bits en todas. El cálculo aplicado para el remuestreo radiométrico ha sido un ajuste lineal entre los valores mínimo y máximo, sin aplicar ningún otro tipo de realce de la imagen, ya que ello alteraría las comparaciones finales.

Tras el ajuste a los diversos intervalos de niveles digitales se ha procedido a calcular el mismo conjunto de variables de textura en todos los niveles de remuestreo, en concreto las 8 variables de textura derivadas de la MCNG. La clasificación de esos conjuntos y su evaluación mediante las matrices de confusión, expresan, en términos de 
fiabilidad global, que no hay una resolución radiométrica óptima para todas las imágenes, sino que la realidad de cada escena condiciona la mejor radiometría.

\subsubsection{Determinación del mejor vecindario de cálculo de textura}

De los entornos considerados en el presente trabajo se puede extraer una conclusión un tanto simple pero real y que va a condicionar en gran medida los ensayos: la heterogeneidad de las cubiertas reflejadas en todas las imágenes. Ello supone un reto frente a la mayoría de los trabajos que se pueden encontrar en la literatura específica, los cuales se nutren en un alto porcentaje de imágenes homogéneas (no existe mucha variabilidad dentro de un mismo tipo de textura) de la base de Brodazt, o de VisualTex, o de imágenes clásicas como Lena, Barb,..., donde la mayoría de ellas en absoluto presentan la variabilidad de los elementos reales de la superficie terrestre. A modo de ejemplo se pueden comparar las tres subimágenes de la figura 6-10, donde cada una de ellas tiene un patrón espacial de diferente forma, tamaño, homogeneidad, etc.

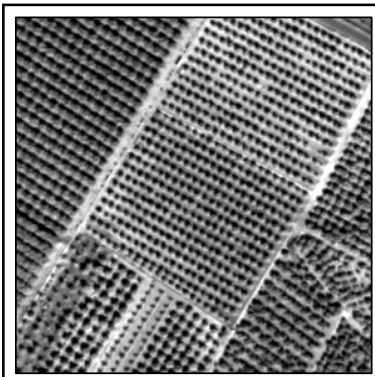

a)

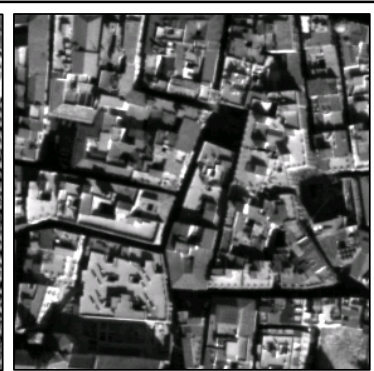

b)

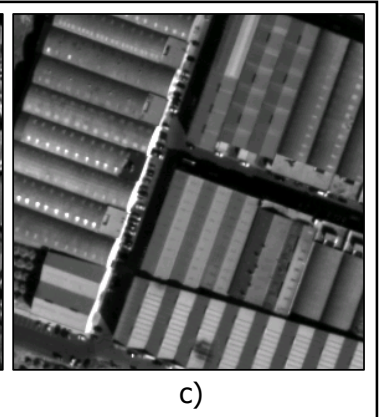

c)

Figura 6-10. 3 tipos de cubiertas reales: cítricos (a), urbano desordenado (b) e industrial (c).

Los cálculos de las variables de textura que se detallan en apartados anteriores se basan en vecindarios, es decir, en calcular dichas variables en el vecindario de un píxel y asignarlas a él. Tal y como se ha referido anteriormente, las imágenes presentan cierta variabilidad y por ello se ha extendido este análisis previo a los 4 entornos analizados en el capítulo "Datos de trabajo". Además se han considerado entre 4 y 5 vecindarios para los ensayos, de dimensiones $9 \times 9,11 \times 11,15 \times 15,17 \times 17,21 \times 21$ y $25 \times 25$. No se han tenido en cuenta vecindarios mayores ya que introducirían en los cálculos importantes influencias de los píxeles pertenecientes en realidad a otros elementos contiguos pero diferentes de la imagen. Tal y como se detalla en los resultados del apartado 7.3.3, el vecindario que mejor se comporta es el de $25 \times 25$. 


\subsubsection{Algoritmos de aplicación de la Transformada Wavelet}

En la literatura específica sobre la transformada wavelet, son varias las formas en que es aplicada, dependiendo del tipo de datos de partida y del objetivo buscado. De todas ellas y tal y como se explica a continuación, se han elegido 3 para realizar unos ensayos comparativos de cara a clasificar imágenes de alta resolución de diversas tipologías de superficies naturales del terreno. El objetivo de esta comparativa ha sido el de contrastar si alguna de las tres modalidades presenta claras ventajas sobre las demás, ya que las diferencias en su aplicación son tangibles, tanto desde el punto de vista matemático como operacional. En los apartados 4.7.4.1, 4.7.4.2 y 4.7.7 del capítulo IV se detallan la base teórica del algoritmo "à trous", del llamado "shift4" (ambos redundantes) y de la "transformada wavelet rápida bidimensional".

El algoritmo "à trous" ha sido aplicado en forma de filtros bidimensionales, en concreto un filtro paso bajo basado en un spline bi-cúbico de $5 \times 5$, cuyos coeficientes se asocian a la función scaling.

De otros ensayos realizados en este trabajo se deduce que el nivel óptimo de aplicación de la transformada wavelet es el nivel 3 (apartado 6.3.5). Dado que de una transformada wavelet nos interesa la información de las altas frecuencias propia de los detalles, se ha aplicado el algoritmo "shift4" ampliado al nivel 3, extrayendo la información de los detalles en cada nivel. Se ha procedido a promediarlos para cada nivel de cada una de las 4 imágenes ( 1 original y 3 desplazadas), obteniendo de esta manera una información relevante de las altas frecuencias para las 4 imágenes y en cada nivel.

La aplicación de la transformada wavelet rápida bidimensional se ha realizado según los modelos del apartado 4.7.7 y mediante un conjunto de bancos de filtros bidimensionales, dependientes de cada una de las familias de funciones empleadas, tal y como se detalla en el apartado 6.3.6.

\subsubsection{Aplicación práctica de los algoritmos}

Trabajando sobre cualquiera de los tres algoritmos anteriormente reseñados, la metodología operativa presenta 3 fases claramente diferenciadas, a saber, una primera fase en la que se aplica el algoritmo específico; una segunda en la que se extraen las variables de textura óptimas; y una tercera donde se clasifican éstas.

\section{$1^{\text {a- }}$ Aplicación de los 3 algoritmos de descomposición wavelet}

Se han realizado dos ensayos aplicando los tres algoritmos sobre 3 tipologías de cubiertas diferentes, como son el ámbito metropolitano del norte de la ciudad de Valencia; entornos 
forestales de áreas montañosas (mosaico de Espadán) y entornos mixtos entre zonas forestales y cultivos (mosaico de Ayora).

En el primer ensayo se han aplicado las tres transformaciones o algoritmos anteriormente citados de la siguiente manera: La DWT aplicada mediante los filtros de Coiflet de soporte 12; el algoritmo shift4 con la misma función Coif12; y el algoritmo "à trous" como una descomposición a nivel tres mediante el empleo de un filtro s-pline discreto de tamaño $5 \times 5$ en el que los coeficientes quedan definidos según el esquema adjunto, con todos sus coeficientes multiplicados por $1 / 256$ :

\begin{tabular}{|c|c|c|c|c|}
\hline 1 & 4 & 6 & 4 & 1 \\
\hline 4 & 16 & 24 & 16 & 4 \\
\hline 6 & 24 & 36 & 24 & 6 \\
\hline 4 & 16 & 24 & 16 & 4 \\
\hline 1 & 4 & 6 & 4 & 1 \\
\hline
\end{tabular}

En el segundo ensayo se ha empleado la familia de funciones wavelet de Meyer y en concreto la Meyer3 con 13 coeficientes (tabla 6-2), tanto para la DWT como para shift4, mientras que en la rutina "à trous" se ha empleado un filtro de $13 \times 13$ cuyos coeficientes se ajustan con bastante precisión a los de la función de Meyer empleada en las otras rutinas.

\begin{tabular}{|r|r|r|r|r|r|r|r|r|r|r|r|r|}
\hline 0.00059 & -0.00155 & -0.00074 & 0.00323 & 0.00085 & -0.01080 & -0.01809 & -0.01080 & 0.00085 & 0.00323 & -0.00074 & -0.00155 & 0.00059 \\
\hline-0.00155 & 0.00405 & 0.00195 & -0.00845 & -0.00223 & 0.02827 & 0.04735 & 0.02827 & -0.00223 & -0.00845 & 0.00195 & 0.00405 & -0.00155 \\
\hline-0.00074 & 0.00195 & 0.00094 & -0.00406 & -0.00107 & 0.01360 & 0.02277 & 0.01360 & -0.00107 & -0.00406 & 0.00094 & 0.00195 & -0.00074 \\
\hline 0.00323 & -0.00845 & -0.00406 & 0.01761 & 0.00465 & -0.05893 & -0.09869 & -0.05893 & 0.00465 & 0.01761 & -0.00406 & -0.00845 & 0.00323 \\
\hline 0.00085 & -0.00223 & -0.00107 & 0.00465 & 0.00123 & -0.01556 & -0.02607 & -0.01556 & 0.00123 & 0.00465 & -0.00107 & -0.00223 & 0.00085 \\
\hline-0.01080 & 0.02827 & 0.01360 & -0.05893 & -0.01556 & 0.19722 & 0.33030 & 0.19722 & -0.01556 & -0.05893 & 0.01360 & 0.02827 & -0.01080 \\
\hline-0.01809 & 0.04735 & 0.02277 & -0.09869 & -0.02607 & 0.33030 & 0.55316 & 0.33030 & -0.02607 & -0.09869 & 0.02277 & 0.04735 & -0.01809 \\
\hline-0.01080 & 0.02827 & 0.01360 & -0.05893 & -0.01556 & 0.19722 & 0.33030 & 0.19722 & -0.01556 & -0.05893 & 0.01360 & 0.02827 & -0.01080 \\
\hline 0.00085 & -0.00223 & -0.00107 & 0.00465 & 0.00123 & -0.01556 & -0.02607 & -0.01556 & 0.00123 & 0.00465 & -0.00107 & -0.00223 & 0.00085 \\
\hline 0.00323 & -0.00845 & -0.00406 & 0.01761 & 0.00465 & -0.05893 & -0.09869 & -0.05893 & 0.00465 & 0.01761 & -0.00406 & -0.00845 & 0.00323 \\
\hline-0.00074 & 0.00195 & 0.00094 & -0.00406 & -0.00107 & 0.01360 & 0.02277 & 0.01360 & -0.00107 & -0.00406 & 0.00094 & 0.00195 & -0.00074 \\
\hline-0.00155 & 0.00405 & 0.00195 & -0.00845 & -0.00223 & 0.02827 & 0.04735 & 0.02827 & -0.00223 & -0.00845 & 0.00195 & 0.00405 & -0.00155 \\
\hline 0.00059 & -0.00155 & -0.00074 & 0.00323 & 0.00085 & -0.01080 & -0.01809 & -0.01080 & 0.00085 & 0.00323 & -0.00074 & -0.00155 & 0.00059 \\
\hline
\end{tabular}

Tabla 6-2. Coeficientes de la función wavelet Meyer3.

\section{$2^{a}$ - Cálculo de las variables de textura derivadas de las imágenes de detalle}

De la fase anterior se ha obtenido una imagen de detalle para cada nivel de la transformada. De ellas se han calculado 4 variables de textura obtenidas de las correspondientes matrices de co-ocurrencias de niveles de gris (MCNG), a saber, varianza, homogeneidad, contraste y correlación, de tal forma que para cada imagen y algoritmo se tienen, entre otras, 12 variables de textura, 4 de cada nivel. 


\section{$3^{\text {a- }}$ Clasificación y comparación de resultados}

Las variables empleadas en las clasificaciones son las siguientes, obtenidas para cada algoritmo y área de estudio:

- 1 imagen original pancromática

- 8 variables de textura obtenidas de la MCNG

- 4 variables de texturas de la MCNG de los detalles de nivel 1

- 4 variables de texturas de la MCNG de los detalles de nivel 2

- 4 variables de texturas de la MCNG de los detalles de nivel 3

Del estudio de los resultados de la página 204 se puede concluir que las similitudes entre los 3 algoritmos son importantes, no destacando ninguno de ellos de forma llamativa. Entrando en detalle se puede apreciar cómo la DWT genera en las 3 áreas analizadas las mejores fiabilidades globales e índice Kappa. Las mejores fiabilidades de usuario para las clases por separado también se repiten con mayor frecuencia en esta variedad de la transformada frente a las otras dos analizadas, por lo que se puede afirmar que la aplicación de la DWT nos proporcionará, a priori, los mejores resultados posibles.

\subsubsection{Niveles de descomposición de la Transformada Wavelet}

La transformada wavelet discreta consiste en un modelo de aplicación de descomposiciones y reconstrucciones de una imagen a diferentes escalas, lo que se denomina multiresolución. Es conocido que de cada una de esas resoluciones o niveles se puede extraer la información de las altas o bajas frecuencias presentes en la imagen. Dado que las imágenes analizadas en este trabajo presentan variabilidad en sus patrones texturales, realizar una descomposición tan solo a nivel 1 no nos proporcionará toda la información deseada ya que quedarán objetos en la imagen que a esa nueva resolución no puedan ser exhaustivamente considerados. Por ello se considera importante determinar a qué nivel o niveles se debe extender el modelo de descomposición (con los correspondientes submuestreos de factor diádico) para sacar la máxima información de la imagen en forma de altas y bajas frecuencias y poder ser analizadas (en la figura 6-11 se puede ver un ejemplo de un fragmento de imagen y su descomposición a nivel 2).

Se ha aplicado la descomposición discreta wavelet mediante bancos de filtros hasta el nivel 3 para, sobre las imágenes de detalles (que reflejan la información de las altas frecuencias) promediadas entre detalles verticales, horizontales y diagonales, calcular variables de textura obtenidas de las MCNG de cada imagen de detalle y proceder a las 
clasificaciones. Los resultados muestran que el nivel óptimo de descomposición es el nivel 3, ya que presenta un cierto equilibrio entre la resolución final y el contenido de frecuencias altas.

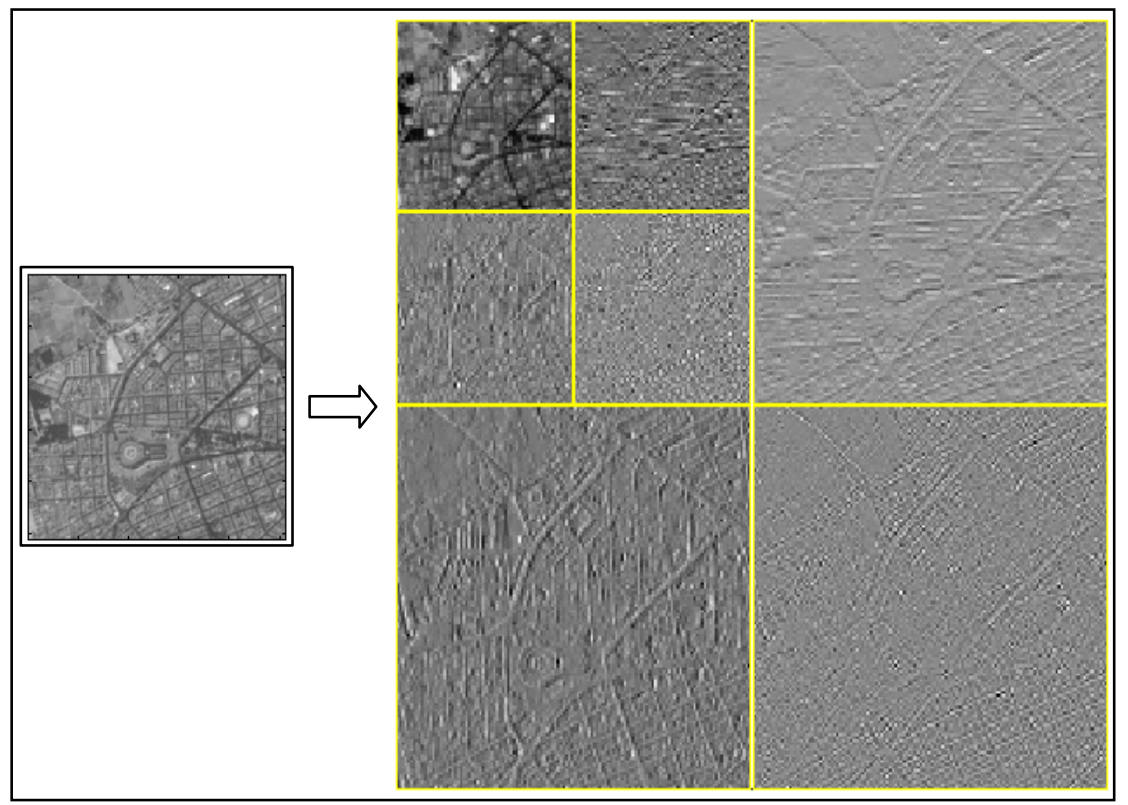

Figura 6-11. Imagen (izquierda) y su descomposición a nivel 2 en detalles y aproximaciones.

\subsubsection{Aplicación de la Transformada Wavelet Rápida: implementación mediante bancos de filtros}

La aplicación práctica de la transformada wavelet rápida se puede orientar hacia el empleo de bancos de filtros unidimensionales, siendo aplicados por filas y por columnas de manera consecutiva; o bien hacia los filtros bidimensionales, resultantes del producto tensorial de los dos filtros unidimensionales expresados como vector fila o vector columna según corresponda. Los filtros paso bajo, como su nombre indica, dejan pasar las bajas frecuencias en la señal y filtran las altas, es decir, suavizan los bordes (altas frecuencias), por lo que su efecto es similar al de un suavizado. Por contra, el filtro paso alto permite pasar las altas frecuencias (bordes) de la señal y filtra las bajas, por lo que este filtro enfatiza los contornos o lugares donde la frecuencia cambie notablemente.

La transformada wavelet más básica y elemental data de principios del siglo XX y es conocida como wavelet de Haar. De ella se derivan los filtros de Haar, cuyos coeficientes, junto a los de los filtros bidimensionales se especifican a continuación. 
El filtro paso bajo de Haar $(1 / \sqrt{ } 2,1 / \sqrt{ } 2)$ aplicado en forma de vector fila sobre las filas de una imagen, suavizaría los cambios en dirección horizontal. Aplicado en forma de vector columna sobre las mismas, conseguiría el mismo efecto en dirección vertical. El efecto conjunto al ser aplicado en filas y columnas es una imagen promediada o suavizada.

El filtro paso alto de Haar $(1 / \sqrt{2},-1 / \sqrt{ } 2)$ aplicado sobre las filas resaltaría los cambios en dirección horizontal (bordes verticales de objetos) y sobre columnas los cambios en dirección vertical (bordes horizontales de los objetos). De forma conjunta, se destacarían bien los contornos o límites de los objetos de una imagen.

Al combinar los dos filtros anteriores, se enfatizan los bordes horizontales o los verticales de la siguiente manera: (1) el filtro paso bajo en filas, seguido del filtro paso alto en columnas resaltarían las altas frecuencias en columnas por lo que marcarían los bordes horizontales; (2) el filtro paso alto en filas, seguido del paso bajo en columnas resaltaría las altas frecuencias en filas por lo que marcarían los bordes verticales.

Para obtener el filtro bidimensional equivalente a los dos unidimensionales (siempre y cuando sean separables) se debe realizar el producto de vectores para obtener la matriz cuadrada:

- $\quad$ Paso Bajo de Haar: $(1 / \sqrt{ } 2,1 / \sqrt{ } 2)$

- $\quad$ Paso Alto de Haar: $(1 / \sqrt{ } 2,-1 / \sqrt{ } 2)$

- Para aplicar el filtro paso bajo en columnas y en filas:

$$
\left(\begin{array}{l}
\frac{1}{\sqrt{2}} \\
\frac{1}{\sqrt{2}}
\end{array}\right) \cdot\left(\frac{1}{\sqrt{2}}, \frac{1}{\sqrt{2}}\right)=\left(\begin{array}{ll}
0.5 & 0.5 \\
0.5 & 0.5
\end{array}\right)
$$

- $\quad$ Para aplicar el filtro paso alto en columnas y el paso bajo en filas:

$$
\left(\begin{array}{c}
\frac{1}{\sqrt{2}} \\
-\frac{1}{\sqrt{2}}
\end{array}\right) \cdot\left(\frac{1}{\sqrt{2}}, \frac{1}{\sqrt{2}}\right)=\left(\begin{array}{rr}
0.5 & 0.5 \\
-0.5 & -0.5
\end{array}\right)
$$

- $\quad$ Para aplicar el filtro paso bajo en columnas y el paso alto en filas: 


$$
\left(\begin{array}{l}
\frac{1}{\sqrt{2}} \\
\frac{1}{\sqrt{2}}
\end{array}\right) \cdot\left(\frac{1}{\sqrt{2}},-\frac{1}{\sqrt{2}}\right)=\left(\begin{array}{ll}
0.5 & -0.5 \\
0.5 & -0.5
\end{array}\right)
$$

- $\quad$ Para aplicar el filtro paso alto en columnas y en filas:

$$
\left(\begin{array}{c}
\frac{1}{\sqrt{2}} \\
-\frac{1}{\sqrt{2}}
\end{array}\right) \cdot\left(\frac{1}{\sqrt{2}},-\frac{1}{\sqrt{2}}\right)=\left(\begin{array}{rr}
0.5 & -0.5 \\
-0.5 & 0.5
\end{array}\right)
$$

De las funciones base scaling y wavelet definidas en la teoría de la transformada wavelet se derivan los coeficientes de los filtros que se pueden emplear en diversas aplicaciones. A su vez, se establecen familias de funciones base obtenidas a partir de la función wavelet madre mediante muestreo al entorno discreto y traslaciones y escalados y con diversos parámetros propios de cada función, como suavidad, momentos nulos, tamaño del soporte de la función,... que a su vez definen subtipos de funciones y coeficientes dentro de cada familia wavelet.

A continuación se detallan tanto las gráficas de algunas de las funciones wavelet y scaling, como los coeficientes de los cuatro filtros derivados y que forman el banco de filtros necesario para aplicar la transformada wavelet en su fase de descomposición y en la de síntesis. La literatura al respecto establece un alto número de familias, si bien son las de Daubechies (1992), las Coiflet, las Symlet, y algunas otras las más empleadas.

\subsubsection{Familias de funciones wavelet empleadas en los cálculos}

Algunas funciones wavelet son simétricas, como la Meyer y la Battle-Lemarié, mientras que otras son casi simétricas y otras, las que tienen soportes compactos, no lo son. En algunas aplicaciones esto no tiene excesiva importancia, como en compresión de imágenes, mientras que en otras, como segmentación o clasificación de imágenes es preferible usar wavelets simétricas para que el resultado de los algoritmos aplicados no cambie para imágenes con cierta simetría (Van de Wouver, 1998). En líneas generales, las funciones wavelet simétricas parecen tener mejor comportamiento al ser aplicadas sobre imágenes que las que no son simétricas, comportamiento desigual atribuido a la propiedad de tener fase lineal de los filtros simétricos (Materka y Strzelecki, 1998). Existen tres niveles de simetría en las funciones wavelet: las funciones no simétricas, como las familias 
Daubechies o Biortogonales; las funciones casi simétricas, como las familias Symlet o Coiflets; y las simétricas, como las de Haar, Meyer y Battle-Lemarié (Tsolmon, 2003).

En la mayoría de aplicaciones, el diseño de la función wavelet $\psi$ debe optimizarse para conseguir los objetivos buscados, de tal manera que dicha función produzca el máximo número posible de coeficientes wavelet (resultado del producto de la señal por la familia de funciones wavelet $\left.\left\langle f, \psi_{j, n}\right\rangle\right)$ que sean cercanos a cero (Mallat, 1999). Una función $f$ tiene pocos coeficientes wavelet significantes si la mayoría de los coeficientes wavelet a pequeña escala (alta resolución) son pequeños. Todo esto depende de varios aspectos: en primer lugar de la regularidad de la función $f$ de partida, sea uni o bidimensional, del número de momentos nulos (vanishing moments) de la función $\psi$ y del tamaño del soporte de la función $\psi$.

Por lo que respecta al número de momentos nulos, se cumple que si una función $f$ es regular y $\psi$ tiene suficientes momentos nulos, entonces los coeficientes wavelet $\left\langle f, \psi_{j, n}\right\rangle$ son pequeños en escalas finas $2^{j}$.

En cuanto al tamaño del soporte, para minimizar el número de coeficientes de gran amplitud podemos reducir el tamaño del soporte de $\psi$, sin olvidar que el soporte de la función scaling $\varphi$ será compacto si y solo si el filtro $h$ tiene un soporte compacto. Si el filtro $h$ es FIR en $\left[N_{1}, N_{2}\right]$, la función $\psi$ tendrá un soporte de tamaño $N_{2}-N_{1}$ centrado en la mitad de esa diferencia. Para minimizar el tamaño del soporte, se deben crear filtros conjugados en espejo (conjugate mirror filters, CMF) con tantos coeficientes distintos de cero como sea posible. Por tanto, al hablar de las diferentes familias se puede diferenciar entre las de soporte compacto y aquellas que no lo tienen.

Se puede establecer una interdependencia entre el número de momentos nulos y el tamaño del soporte, si bien a priori son independientes. En las wavelets ortogonales, si la función $\psi$ tiene un número $p$ de momentos nulos, entonces su soporte es al menos de tamaño $2 p-1$. Al elegir una wavelet se debe conseguir un cierto equilibrio entre el número de momentos nulos y el tamaño del soporte. Por ejemplo, si la función de entrada $f$ tiene pocas singularidades y aisladas y es regular entre ellas, se puede elegir una wavelet que tenga muchos momentos nulos para producir un alto número de pequeños coeficientes wavelet $\left(\left\langle f, \psi_{j, n}\right\rangle\right)$. Si por el contrario aumenta la densidad de singularidades de la señal, puede ser mejor disminuir el tamaño del soporte a cambio de reducir el número de momentos nulos, ya que las wavelets que se superpongan a las singularidades de la señal producirán coeficientes de alto valor o amplitud. Todas estas particularidades se pueden analizar sobre las wavelets que siguen a continuación. 


\subsubsection{Wavelet de HAAR}

La función de Haar es el ejemplo más antiguo de una función $\psi$ que define una familia wavelet $\psi_{m, n}(x)$ y constituye una base ortonormal de $L^{2}(R)$, si bien no tiene una perfecta localización tiempo-frecuencia. Recordando la expresión de una familia de funciones wavelet para una dilatación $m$ y una traslación $n$, y considerando un factor de escala $a=2$ y una traslación $b=1$.

$$
\psi_{m, n}(x)=2^{-m / 2} \psi\left(2^{-m} x-n\right)
$$

La expresión de las funciones scaling y wavelet de Haar es obtenida a partir de la formulación planteada en el análisis multiresolución sobre la función de Haar, que es constante a tramos. La función scaling es $\varphi(x)=1$ para $0 \leq x<1$ y 0 en cualquier otro caso. El filtro de paso bajo $h(n)$ tiene coeficientes no nulos e iguales a $1 / \sqrt{ } 2$ para $n=0$ y $n=1$. Por tanto:

$$
h_{n}=\sqrt{2} \int d x \varphi(x) \varphi(2 x-n)= \begin{cases}1 / \sqrt{2} & \text { si } n=0,1 \\ 0 & \text { otro caso }\end{cases}
$$

y aplicando expresiones propias del MRA, como son la ecuación de dilatación y la ecuación wavelet,

$$
\psi=\sum_{n} g_{n} \varphi_{-1, n} \quad \text { con } \quad g_{n}=(-1)^{n} h_{-n+1}
$$

se tiene que

$$
g_{n}=\left((-1)^{0} h_{1},(-1)^{1} h_{0}\right)=\left(h_{1},-h_{0}\right)
$$

y por extensión

$$
\psi=g_{0} \varphi_{-1,0}+g_{1} \varphi_{-1,1}=\left(1 / \sqrt{ } 2 \varphi_{-1,0},-1 / \sqrt{ } 2 \varphi_{-1,1}\right)
$$

o expresado de otra forma, la función wavelet es definida:

$$
\psi(x)=\left\{\begin{aligned}
-1 & \text { si } 0 \leq x<0.5 \\
1 & \text { si } 0.5 \leq x<1 \\
0 & \text { cualquier otro } x
\end{aligned}\right.
$$

La wavelet de Haar tiene el menor soporte de todas las wavelets ortogonales y no se adapta bien a funciones suaves porque solamente tiene un momento nulo (figura 6-12). 


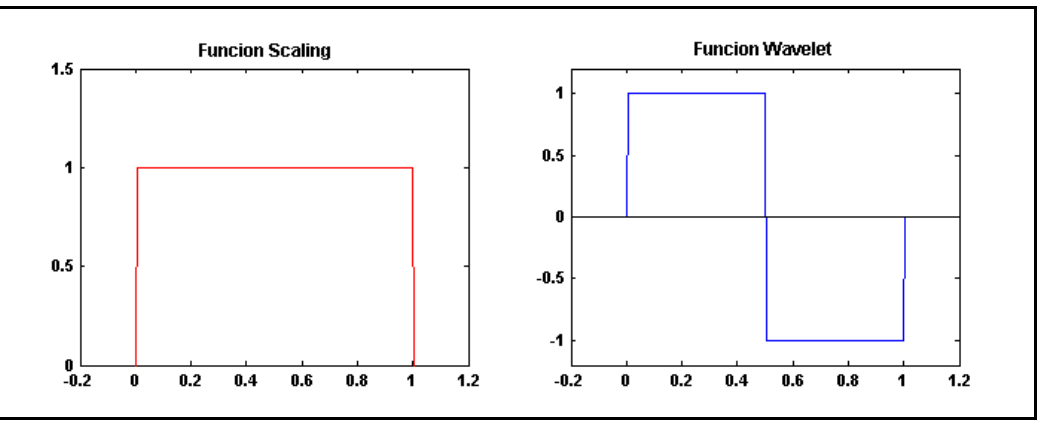

Figura 6-12. Funciones scaling y wavelet de Haar.

\subsubsection{Wavelet DAUBECHIES}

Son una amplia familia de funciones ortogonales diseñadas por Ingrid Daubechies. Se adaptan bien a señales o imágenes que posean cierta "suavidad" y esa es una de sus principales ventajas, que mejoran sustancialmente el tratamiento de señales que posean esa cualidad. Las scaling y las wavelet pueden llegar a tener soportes grandes y ello produce promedios y diferencias empleando pocos valores de la señal. La normalización de estas funciones viene expresada como (Strang, 1996):

$$
\sum h(n)=\sqrt{2}
$$

Las wavelet de Daubechies son óptimas en el sentido de que tienen un tamaño de soporte mínimo para un número dado $p$ de momentos nulos. Las wavelets de soporte compacto son calculadas con filtros de impulso finito en forma de filtros conjugados de espejo CMF (Conjugate Mirror Filters). Estos filtros tienen $2 p=n$ coeficientes no nulos, siendo $p$ el número de momentos nulos, estando esto justificado por el hecho de que un filtro $h$ de este tipo, tal que su transformada de Fourier para una frecuencia $\omega$ tenga $p$ valores nulos en $\omega=\pi$, tendrá al menos $2 p=n$ coeficientes no nulos.

Como demuestra Daubechies (Mallat, 1999), si una wavelet $\psi$ tiene $p$ momentos nulos y genera una base ortonormal de $L^{2}(R)$, entonces tiene un soporte de tamaño mayor o igual a $2 p-1$. Una wavelet Daubechies tiene un soporte de tamaño mínimo definido en el intervalo $[-p+1, p]$ y el soporte de la función scaling $\varphi$ está definido en $[0,2 p-1]$.

En la tabla 10-1 se detallan los coeficientes de algunos filtros de paso bajo derivados y aplicados. Estos coeficientes son los correspondientes a los filtros de paso bajo de reconstrucción $h_{1}(n)$ ya que al tratarse de filtros ortonormales (en los que se basa la FWT), el resto de filtros del esquema de descomposición-reconstrucción de obtienen de él según las relaciones expresadas en la tabla 4-1. 
a)
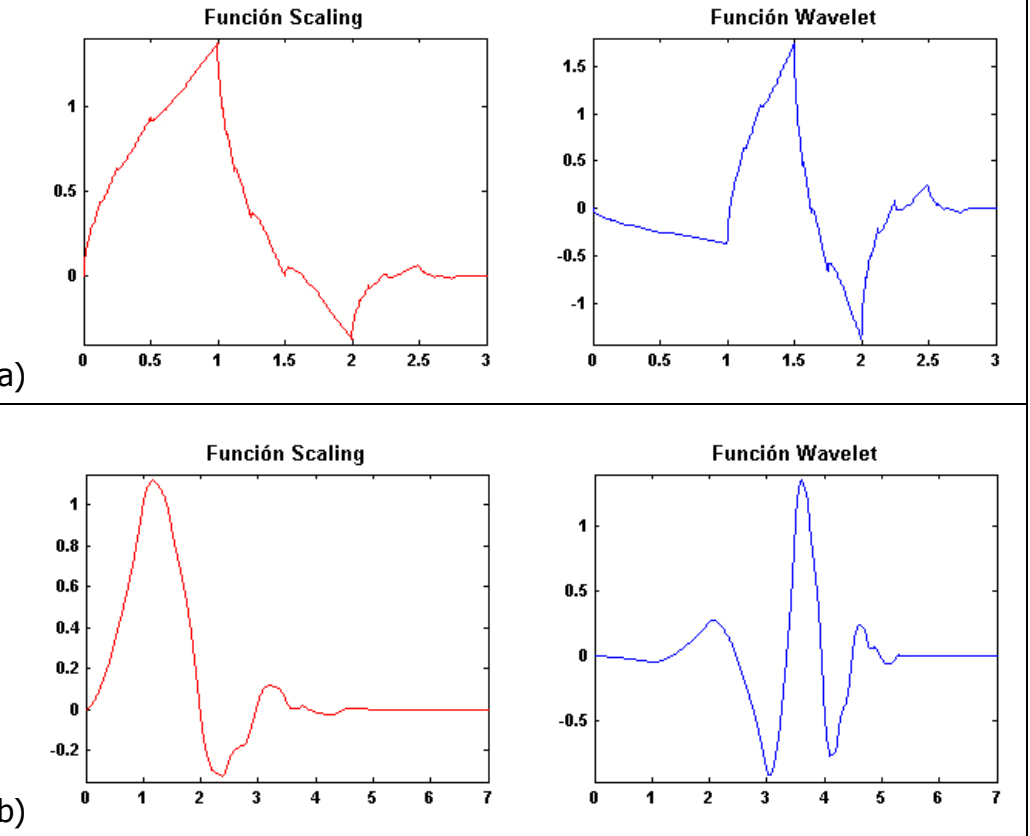

Figura 6-13. Funciones scaling y wavelet Daubechies 4 (a) y Daubechies 8 (b).

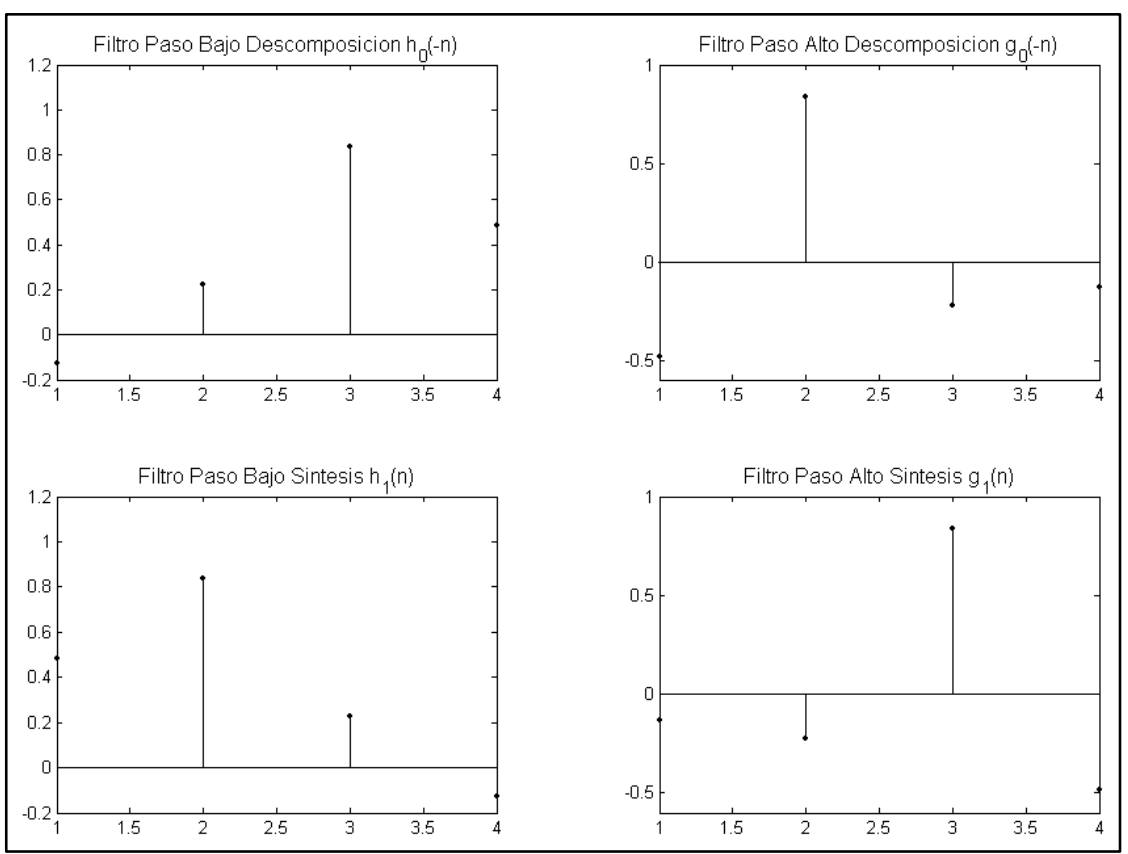

Figura 6-14. Relación gráfica entre los coeficientes de los 4 filtros de un banco de filtros ortonormales, concretamente los de la función Daubechies 4. 
En los ensayos se han aplicado dos de las funciones Daubechies, en concreto las de soporte igual a 4 y 8 y con 2 y 4 momentos nulos respectivamente, representadas en las figuras $6-13$ y 6-14, en las que se aprecia la forma de las funciones scaling y wavelet y las relaciones entre los coeficientes de los filtros derivados. Ese comportamiento de los filtros ortonormales se repite para todas las familias de funciones empleadas por lo que se omite su representación gráfica, bastando las tablas del apartado 10.2 para tener una clara interpretación de su realidad y posibles efectos sobre las imágenes.

\subsubsection{Wavelet COIFLET}

Este tipo de wavelets ortogonales pretenden mejorar las Daubechies consiguiendo una aproximación mejorada entre los valores de las tendencias y los de la señal original y siendo funciones casi simétricas. Son una familia de wavelets $\psi$ que tienen $p$ momentos nulos y un tamaño de soporte mínimo, pero cuyas funciones scaling $\varphi$ además cumplen:

$$
\int_{-\infty}^{+\infty} \varphi(t) d t=1 \quad \text { y } \quad \int_{-\infty}^{+\infty} t^{k} \varphi(t) d t=0 \quad \text { para } 1 \leq k<p
$$

Esta condición complementaria requiere incrementar el soporte de $\psi$ y por ello las wavelets Coiflet tienen un soporte de tamaño $3 p-1$ en vez de $2 p-1$ de las Daubechies.

Algunos ensayos previos (Abrishami et al., 2004) han mostrado que filtros como el laplaciano del gaussiano (LoG) no permite una reconstrucción completa de la imagen, justificando esto el empleo de una wavelet Coiflet de soporte 6, cuya forma es similar al LoG. En los ensayos realizados se han empleado las Coiflet de 6, 12, 18 y 24 coeficientes, ya que su soporte más amplio que el de otras funciones hace pensar que se puede adaptar mejor a las texturas de las imágenes. En las figuras 6-15 y las tablas $10-2,10-3,10-4$ y 10-5 se detallan las funciones wavelet, scaling y los coeficientes de los filtros asociados para las funciones Coiflet de soporte $6,12,18$ y 24 coeficientes.

\subsubsection{Wavelet SYMLET}

La familia de funciones wavelet denominadas symlets, nombre derivado de "symmetrical wavelets", fueron diseñadas con el objetivo fundamental de conseguir la mayor simetría posible en las funciones a aplicar. Si bien no son perfectamente simétricas, fueron diseñadas para tener la menor asimetría posible y el mayor número de momentos nulos en un soporte relativamente compacto. 
a)
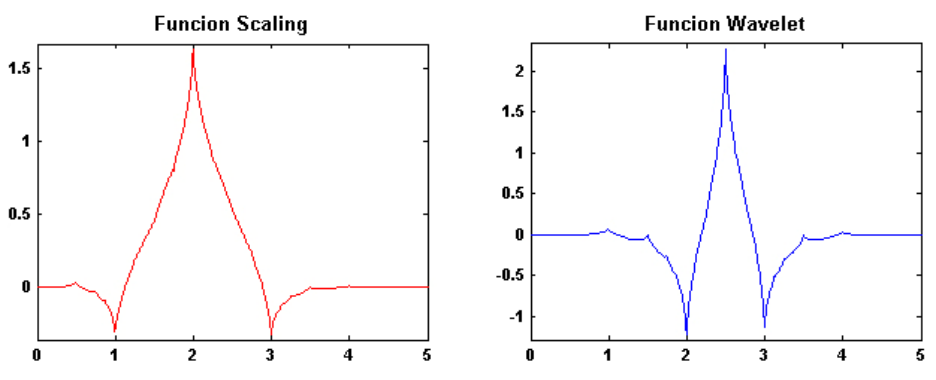

b)
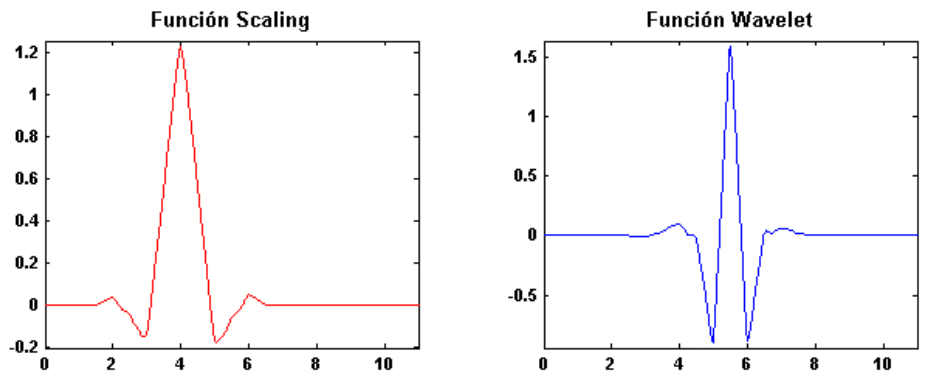

c)
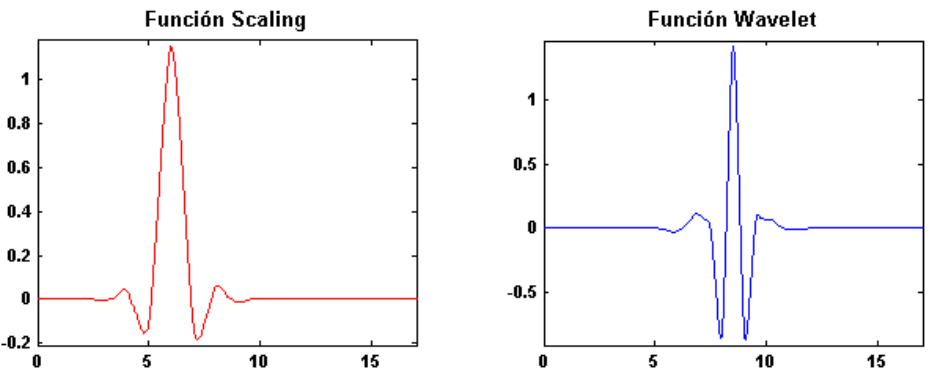

d)
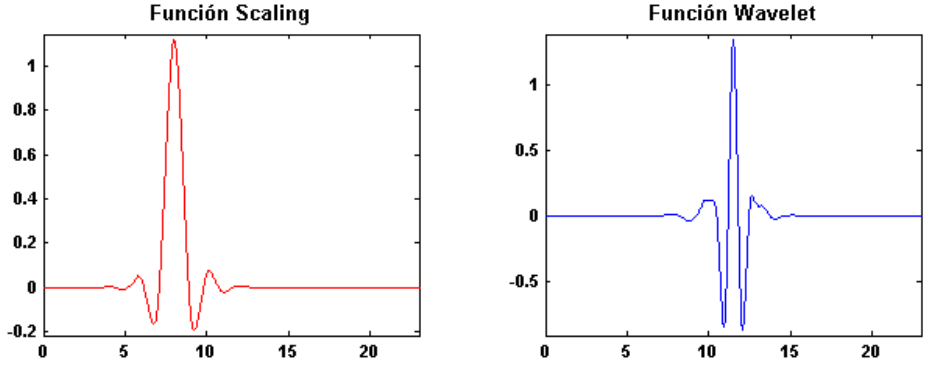

Figura 6-15. Funciones scaling y wavelet Coiflet 6 (a), Coiflet 12 (b), Coiflet 18 (c) y Coiflet 24 (d).

Las wavelets de Daubechies anteriormente analizadas son bastante asimétricas y los filtros correspondientes tienen su energía concentrada cerca del inicio de su soporte. Las funciones wavelet casi simétricas, como las Coiflet o las Symlet, siguen teniendo un 
soporte mínimo en el intervalo $[-p+1, p]$ con $p$ momentos nulos, pero tienen filtros asociados más simétricos respecto del centro de su soporte y por ello no se concentra la energía de la imagen en uno u otro extremo sino que se concentra en la parte central, tal y como puede observarse en la figura 6-16 y tablas $10-6$ y $10-7$, donde se aprecian las funciones Symlet de soporte 8 y 16.

Para las funciones Symlet de soporte 8 y 16 y partiendo de los coeficientes del filtro paso bajo de reconstrucción $h_{1}(n)$ con 4 y 8 momentos nulos respectivamente se obtienen el resto de coeficientes de los filtros ortonormales restantes del proceso completo de descomposición - reconstrucción de la señal o imagen de entrada según las relaciones:

$$
\begin{aligned}
& g_{1}(n)=(-1)^{n} \cdot h_{1}(2 K-1-n) \\
& h_{0}(n)=h_{1}(2 K-1-n) \\
& g_{0}(n)=g_{1}(2 K-1-n), \quad n=\{0, \ldots, K-1\}
\end{aligned}
$$

siendo $n$ la posición de cada coeficiente en el filtro $(n=0,1,2, \ldots)$ y $2 K$ el tamaño o soporte del filtro (es este caso, $2 K=8,2 K=16$ ). La tabla $6-5$ detalla esos coeficientes.

a)
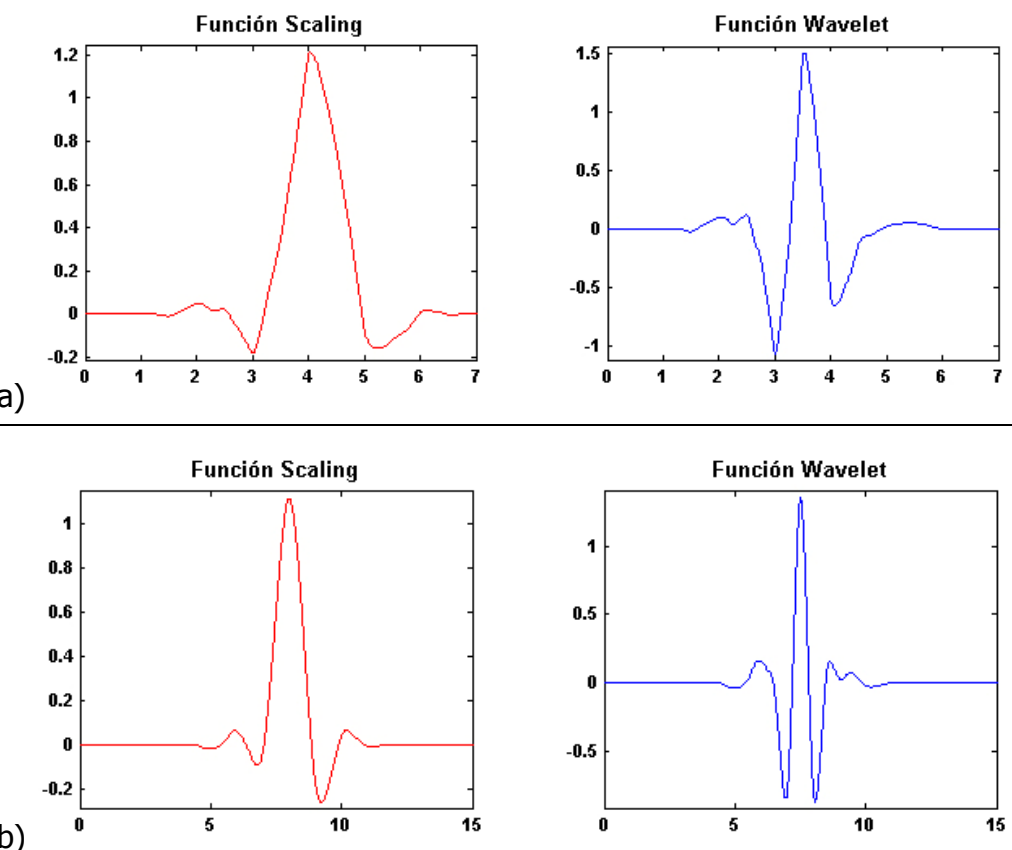

Figura 6-16. Funciones scaling y wavelet Symlet 8 (a) y Symlet 16 (b). 


\subsubsection{Wavelet de BATTLE-LEMARIÉ}

Battle (1987) y Lemarié (1988) construyeron unas wavelets ortonormales usando funciones base simétricas con un decaimiento exponencial. Para ello, partieron de un Bspline con valores enteros para la función scaling. Al provenir del proceso de ortogonalización de los B-splines se les llama también "wavelets splines".

Al tratarse de funciones spline, y mas precisamente polinomios a tramos de grado $k$, tienen $k-1$ derivadas continuas en los nodos del polinomio. Son funciones asociadas a un análisis multiresolución consistente en espacios de funciones splines. En cada caso se toma un B-spline como la función scaling original.

Todas las wavelets Battle-Lemarié y sus correspondientes funciones scaling ortonormales tienen un decaimiento exponencial y el ratio de decaimiento disminuye al incrementar el orden $k$ del espacio $C^{k}$ donde se define. Ya que se trata de un spline polinomial de grado $m$, es $m-1$ veces continuamente diferenciable. Las wavelets spline polinomial son menos regulares que las wavelets de Meyer pero tienen un decaimiento asintótico más rápido en el tiempo. Si el grado del polinomio $m$ es impar, $\psi$ es simétrica sobre $1 / 2$. Si $m$ es par, es antisimétrica sobre $1 / 2$.

La única función empleada de esta familia es la Battle-Lemarié de orden 6, cuyos coeficientes se adjuntan en la tabla 10-8.

Las funciones madre de las wavelets Daubechies, Coiflet, Symlet y Battle-Lemarié tienen soporte compacto (la función toma valores en un intervalo acotado) y por lo tanto el número de coeficientes a manejar es finito, evitando la pérdida de información al ser aplicada. Por el contrario, existen otras funciones wavelet madre, como las dos siguientes, que no tienen soporte compacto o finito y eso conlleva que a partir de un determinado momento se desprecian coeficientes considerándolos no significativos, y se produce un error de aproximación. El decaimiento de las wavelets no finitas debe ser por tanto lo más rápido posible en el tiempo para que el error cometido sea a su vez el menor posible. Pese a tener soporte infinito, su transformada de Fourier sí tiene soporte compacto, llamándoseles por ello de banda limitada y considerando que físicamente tienen energía finita.

\subsubsection{Wavelet de SHANNON}

Se define en el espacio de los números complejos $\mathrm{C}^{\infty}$, siendo equivalente a la de Haar pero en el espacio de frecuencias, ya que aproxima la función restringiéndose a los intervalos de bajas frecuencias. Los coeficientes del filtro asociado a la función scaling, definida como $\varphi(t)=\operatorname{sinc}(t)$ y con un decaimiento exponencial son (ver tabla 10-9): 


$$
h_{k}=\left\{-\frac{\sqrt{2}}{3 \pi}, 0, \frac{\sqrt{2}}{\pi}, \frac{1}{\sqrt{2}}, \frac{\sqrt{2}}{\pi}, 0,-\frac{\sqrt{2}}{3 \pi}\right\}
$$

Esta wavelet es obtenida a partir de la aproximación multiresolución de Shannon, la cual aproxima la función por su restricción a intervalos de bajas frecuencias. Esta función pertenece al espacio $C^{\infty}$ y tiene un lento y asintótico decaimiento en el tiempo, además de que la función $\psi$ tiene un número infinito de momentos nulos.

\subsubsection{Wavelet de MEYER}

Una wavelet de Meyer es una función de frecuencia limitada a una banda cuya transformada de Fourier es suave, al contrario que la de Shannon, por lo que tiene un mas rápido y asintótico decaimiento en el tiempo. Suaviza mediante interpolación el problema de discontinuidad que presentaba la wavelet de Shannon y al igual que ésta, las bases de Meyer tienen soporte infinito (Daubechies, 1992) y su función $\psi$ tiene un número infinito de momentos nulos.

Si la función de suavizado empleada es una función simple se obtiene la wavelet de Meyer de orden 0 . Al emplear una función de suavizado polinómica de grado 5 se obtiene la wavelet de Meyer de orden 3, de la que tomando 13 de los coeficientes de la función scaling se define el filtro de paso bajo empleado (figura 6-17 y tabla 10-10).

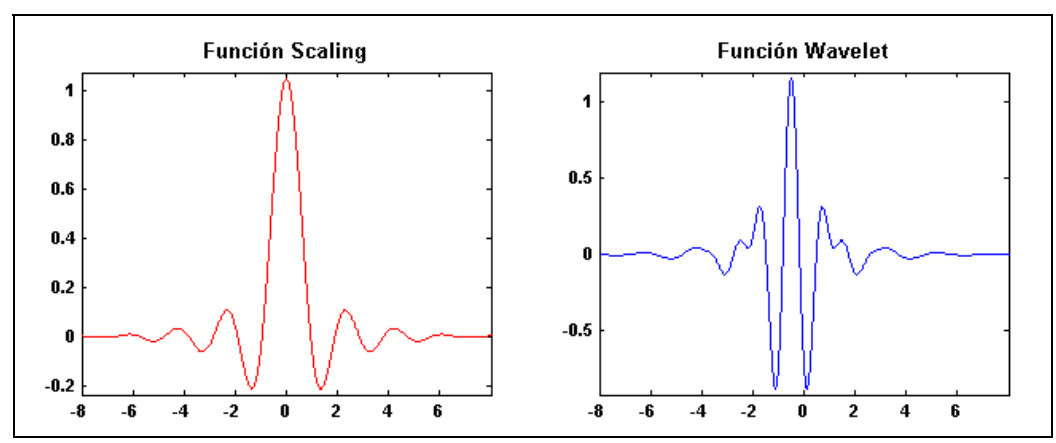

Figura 6-17. Funciones scaling y wavelet Meyer 3.

\subsubsection{Esquema de trabajo aplicado mediante bancos de filtros}

La aplicación de la Transformada Wavelet Discreta Rápida mediante bancos de filtros bidimensionales se realiza según los modelos de descomposición y reconstrucción formulados por Mallat, 1989. En ellos, ver apartado 4.7.7 del capítulo 4, se aplican filtrados 


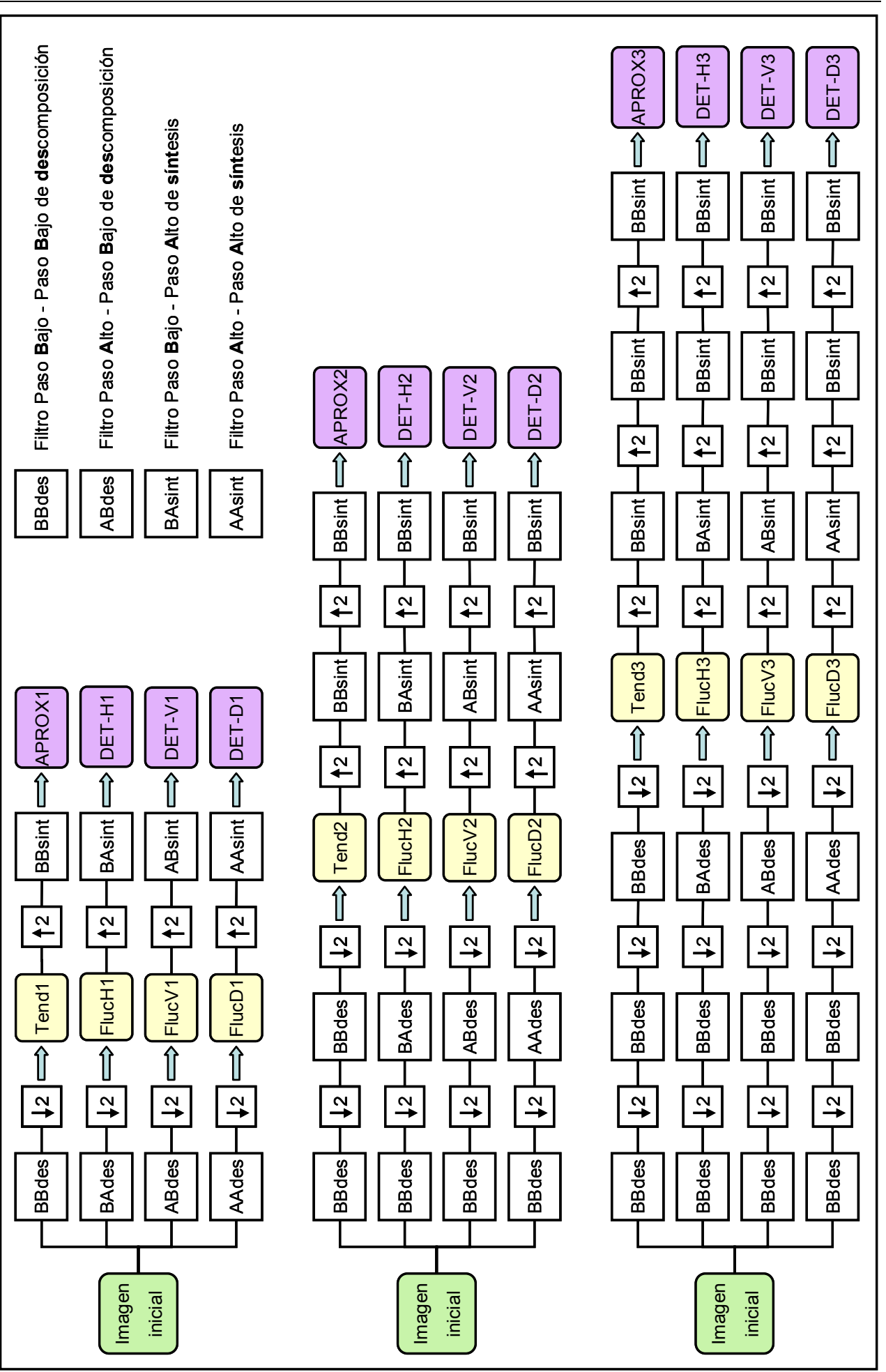

Figura 6-18. Flujo de tareas para aplicar la transformada wavelet discreta en 3 niveles. 
por filas, submuestreos, filtrados por columnas y submuestreos para terminar el esquema a nivel 1. Su extensión a más niveles es análoga. Para la reconstrucción de la imagen inicial se aplican sobremuestreos y filtrados con los filtros de reconstrucción o síntesis para, en una última fase, sumar los resultados parciales y lograr la imagen inicial. El objetivo de nuestros ensayos no es reconstruir la imagen, sino extraer la información de altas frecuencias en forma de imágenes de detalles, por lo que el esquema de Mallat es adaptado a nuestros requerimientos de la forma que muestra el esquema de la figura 6-18 donde se especifica el procedimiento de trabajo aplicado con los coeficientes de los filtros anteriormente reseñados. En amarillo se muestran los resultados parciales de la transformada directa como tendencias (Tend) y fluctuaciones horizontales, verticales y diagonales (FlucH, FlucV y FlucD). En morado los resultados finales, obtenidos al aplicar sobre los anteriores la transformada inversa, en forma de imágenes de aproximación (APROX) y detalles verticales, horizontales y diagonales (DET-H, DET-V y DET-D).

\subsubsection{Selección de parámetros asociados a las funciones wavelet}

Para aplicar la transformada wavelet en los términos detallados en apartados anteriores es muy importante analizar el comportamiento de cada uno de los parámetros considerados frente a cada imagen o tipo de textura concreta. No todos ellos tienen la misma influencia en los resultados finales y por ello se han determinado, a partir de los resultados de una batería de clasificaciones, aquellos que más peso presentan para conseguir buenas fiabilidades. Si bien es importante destacar que no hay una preponderancia de unos parámetros frente a otros, sí es evidente que la mayor parte de las texturas son analizadas mejor con un tipo de función wavelets, o un soporte concreto o un nivel de descomposición determinado, etc. Se perfilan algunas ideas similares a las obtenidas por otros autores. Son las que siguen.

Se han realizado ensayos sobre todas las áreas de trabajo para comprobar si de todas las familias de funciones detalladas en el apartado anterior, con sus filtros asociados, hay alguna que conlleve a una mejor clasificación. Se han empleado las funciones Daubechies de soporte 4 y 8 , las Symmlet 8 y 16, la Battle-Lemarié 6, la Shannon 7, la Meyer 3 y las Coiflet de tamaño 6, 12, 18 y 24. Los resultados muestran que no hay una función que claramente destaque sobre el resto moviéndose casi todas ellas en unas fiabilidades que divergen entre sí un porcentaje bajo (entre un 8-10\% de promedio). Parece apuntarse no obstante, que la familia Coiflet y su función de soporte 24 se comporta algo mejor que el resto. Se puede decir, por tanto, que la elección de la función wavelet tiene sólo pequeños efectos en los resultados, como previamente apuntaban otros 
trabajos (Chang y Kuo, 1993, Fatemi-Ghomi et al., 1996, Simard, 1999), si bien es frecuente el empleo de funciones de la familia Coiflet, de forma similar al LoG pero que permiten una reconstrucción completa de la imagen (Abrishami et al. 2004). Este buen comportamiento en el estudio de las texturas de las funciones Coiflet se justifica por su simetría casi total.

Por lo que respecta al tamaño de la función, parece que los soportes de mayor dimensión generan mejores resultados, sobre todo al analizar texturas rugosas o de patrones espaciales mayores. En el trabajo de Laine y Fan (1993) se experimenta con dos funciones de tamaños diferentes ( 20 y 6 coeficientes) encontrando resultados levemente mejores para la más grande. Se puede afirmar que para un conjunto de funciones de una misma familia, aquellas de mayor soporte generan fiabilidades mayores.

En cuanto al mejor nivel de descomposición, en los resultados obtenidos de los ensayos previos se apunta a que una descomposición multiescala de nivel 3 es la óptima, tal y como otros autores proponen (Unser, 1995).

\subsubsection{Método de clasificación empleado}

Para la realización de las diversas clasificaciones se ha empleado un clasificador supervisado paramétrico y en concreto el de máxima probabilidad. Se ha elegido este método porque a diferencia de otros, tiene en cuenta la distribución de frecuencias de los niveles digitales y determina funciones de densidad de probabilidad que otorgan mayor consistencia a las asignaciones que si tan solo se consideran medias y desviaciones típicas. De hecho, es el más empleado en los diversos trabajos realizados. Este método se fundamenta en la Teoría de la decisión de Bayes, la cual define:

- $\quad \bar{x}_{i}$ : vector de características del píxel $i ; \quad i=1, \ldots, n$

- $\quad \omega_{i}$ : clases de asignación; $\quad i=1, \ldots, m$

- $\quad p: n^{0}$ de variables de entrada (bandas espectrales,...).

- $\quad n: n^{0}$ de píxeles en al imagen.

- $\quad m: \mathrm{n}^{\circ}$ de clases (vegetación, urbano, agua,...).

- $\quad \mathrm{P}\left(\omega_{i}\right)$ : Probabilidad "a priori" de que un píxel tomado al azar pertenezca a la clase $\omega_{i}$

- $\quad \mathrm{p}\left(\bar{x} / \omega_{i}\right)$ : Función de densidad de probabilidad condicional del vector $\bar{x}$ para la clase $\omega_{i}$. Es la probabilidad de que un píxel de la clase $\omega_{i}$ tenga un vector de características $\bar{x}$. 
- $\quad \mathrm{p}\left(\omega_{i} / \bar{x}\right)$ : Probabilidad " a posteriori ". Es la probabilidad de que, dado un vector de características $\bar{X}$, el píxel en cuestión pertenezca a la clase $\omega_{i}$.

Según la regla de decisión de Bayes:

$$
\begin{gathered}
p\left(\omega_{i} / \bar{x}\right)=\frac{p\left(\bar{x} / \omega_{i}\right) \cdot P\left(\omega_{i}\right)}{p(\bar{x})} \\
p(\bar{x})=\sum_{i=1}^{m} p\left(\bar{x} / \omega_{i}\right) \cdot P\left(\omega_{i}\right)
\end{gathered}
$$

Dados los valores espectrales de un píxel $\left(\bar{x}_{i}\right)$, diremos que pertenece a la clase $\omega_{i}$ si su probabilidad a posteriori es máxima, esto es, si cumple la condición:

$$
\forall j \neq i \quad p\left(\omega_{i} / \bar{x}\right)>p\left(\omega_{j} / \bar{x}\right)
$$

o lo que es lo mismo, si:

$$
\forall j \neq i \quad \underbrace{p\left(\bar{x} / \omega_{i}\right) \cdot P\left(\omega_{i}\right)}_{g_{i}(\bar{x})}>\underbrace{p\left(\bar{x} / \omega_{j}\right) \cdot P\left(\omega_{j}\right)}_{g_{j}(\bar{x})}
$$

Es decir, la regla de decisión de Bayes se reduce a maximizar la probabilidad a posteriori de $\bar{x}$.

Así pues, las funciones de decisión $g_{i}(\bar{x})$ y $g_{j}(\bar{x})$ se obtienen a partir de las probabilidades a priori de cada clase y de las funciones de densidad de probabilidad condicional de un vector de características dado, $\bar{x}$ para cada clase $\omega_{i}$. Comparando las funciones de decisión, la de mayor valor corresponderá a la clase que maximiza la probabilidad de que el vector $\bar{x}$ pertenezca a ella, por lo que se le asignará al píxel en cuestión por minimizar el riesgo de error.

La probabilidad a priori puede estimarse a partir de los datos iniciales o de información auxiliar. Su efecto es el de ponderar más unas clases que otras.

La densidad de probabilidad condicional de un vector $\bar{X}$ para una clase $\omega_{i}$ puede estimarse a partir de una muestra de aprendizaje. El proceso de estimación de las funciones de densidad de probabilidad condicional o de sus parámetros, a partir de medidas u observaciones relativas a los píxeles, se conoce como aprendizaje o entrenamiento. 
En términos de cálculo, en el proceso de clasificación supervisada por el método de máxima probabilidad bayesiana se seguirán los siguientes pasos:

1. Selección de muestras de aprendizaje: selección de píxeles cuya clase es conocida, ya que la clasificación supervisada requiere el "entrenamiento" del clasificador mediante la extracción de una serie de muestras de aprendizaje. Tal conocimiento se adquiere a partir de datos auxiliares recogidos en campo, a partir de mapas, tras una fotointerpretación de las fotografías aéreas existentes de la zona, 0 bien a partir de la visualización de la propia imagen (suponiendo un conocimiento previo de la misma) con las diferentes composiciones de las bandas de la imagen (la composición en falso color infrarroja resalta la vegetación, etc.). Las muestras deben ser lo más representativas posible de cada clase. En general, cuantos mejores píxeles seleccionemos más representativa será la muestra para esa clase.

2. Cálculo de la función de distribución de probabilidad p-dimensional para cada clase, $\mathrm{p}\left(\bar{x} / \omega_{i}\right)$, (equivalente al histograma normalizado en las $\mathrm{p}$ dimensiones).

3. Estimación de las probabilidades a priori, $\mathrm{P}\left(\omega_{i}\right)$, de cada clase, que se utilizarán para ponderar las $\mathrm{p}\left(\bar{x} / \omega_{i}\right)$. Se pueden obtener a partir de datos de la zona, o bien a partir de una observación de la imagen. La consideración de probabilidades a priori, estimadas a partir de información existente de anteriores trabajos sobre la zona (Pardo et al., 1999), permite una mejor determinación de la frontera de decisión entre clases, tal y como se muestra en la figura 6-19, donde las densidades de probabilidad de las clases $1\left(p\left(x / \omega_{1}\right)\right)$ y $2\left(p\left(x / \omega_{2}\right)\right)$ se ven afectadas por la estimación de probabilidades a priori de tal manera que la frontera de decisión entre esas dos clases se ve modificada de $\mathrm{F}$ a $\mathrm{F}^{\prime}$, mejorando el resultado de la clasificación.

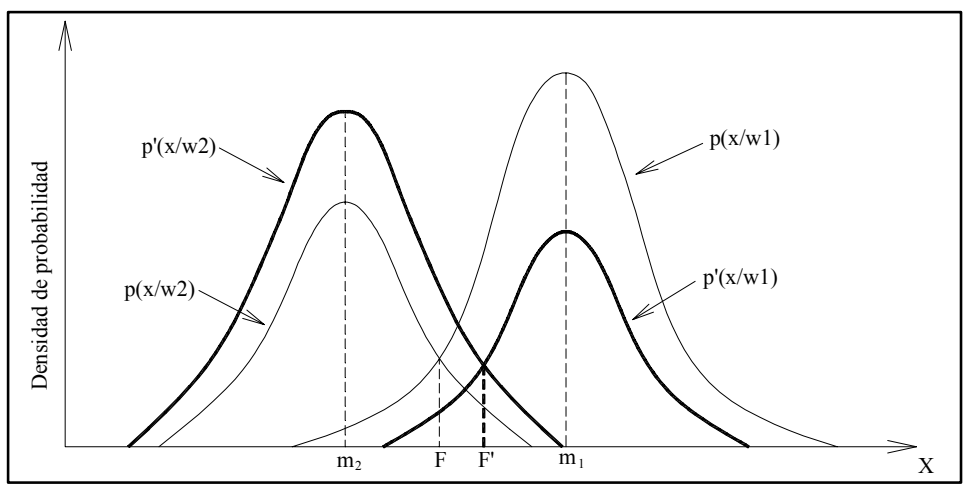

Figura 6-19. Distribución de las funciones de densidad de probabilidad con 2 clases y 1 variable. 
4. Asignación de una clase a cada píxel en la imagen a partir del cálculo de las funciones de decisión, $g_{i}(\bar{x})$.

A la hora de estimar las funciones de densidad de probabilidad, $\mathrm{p}\left(\bar{x} / \omega_{i}\right)$, si el vector de características, $\bar{x}$ es p-dimensional, entonces $\mathrm{p}\left(\bar{x} / \omega_{i}\right)$ será una función de $p$ variables. Si su forma es desconocida se requieren métodos de teoría de probabilidad multivariante para su estimación, los cuales suelen ser difíciles de aplicar en la práctica, especialmente si las muestras de aprendizaje son pequeñas o si las funciones de densidad de probabilidad no siguen una forma estándar.

Por ello, una de las simplificaciones más comunes es considerar que las funciones de densidad de probabilidad condicional para cada clase siguen distribuciones normales. Cuanto más se aproxime esta suposición a la realidad, mayor será la probabilidad de acierto en la clasificación. En el caso unidimensional, los parámetros que deben estimarse son la media $(\mu$ ) y la desviación típica $(\sigma)$ de la distribución para esa dimensión. La forma general de una distribución normal unidimensional para una clase genérica sería:

$$
p\left(\bar{x} / \omega_{i}\right)=\frac{1}{\sqrt{2 \pi} \cdot \sigma_{i}} \cdot e^{-\frac{1}{2} \frac{\left(x-\mu_{i}\right)^{2}}{\sigma_{i}^{2}}}
$$

donde $\mu_{i}$ y $\sigma_{i}$ se estiman a partir de las muestras de aprendizaje, independientemente para cada clase.

En el caso genérico de $p$ bandas o variables de partida, $\mu_{i}$ se convierte en un vector $\mathrm{p}$-dimensional de medias $\left(\bar{\mu}_{i}\right)$, y $\sigma_{i}$ en una matriz de covarianzas $C_{i(p \times p)}$. La función de densidad normal multivariada se expresa entonces:

$$
p\left(\bar{x} / \omega_{i}\right)=\frac{1}{(2 \pi)^{2} \cdot\left|C_{i}\right|^{\frac{1}{2}} \cdot e^{-\frac{1}{2} \underbrace{\left(\bar{x}-\bar{\mu}_{i}\right)^{\prime} C_{i}^{-1}\left(\bar{x}-\bar{\mu}_{i}\right)}}}
$$

siendo $\left|C_{i}\right|$ el determinante de la matriz $C_{i r}$ y donde la función de densidad para cada clase quedaría completamente definida por su vector de medias $\bar{\mu}_{i}$ y su matriz de covarianzas $C_{i}$ estimados ambos a partir de las muestras de aprendizaje. Así, si para la clase $\omega_{i}$ disponemos de $n_{i}$ elementos de aprendizaje, tendremos:

$$
\bar{\mu}_{i}=\frac{1}{n_{i}} \sum_{i=1}^{n_{i}} \bar{x}_{i}
$$




$$
C_{i}=\frac{1}{n_{i}} \sum_{i=1}^{n_{i}}\left(\bar{x}-\mu_{i}\right) \cdot\left(\bar{x}-\mu_{i}\right)^{\prime}
$$

En el caso bidimensional, resulta una superficie gaussiana en forma de campana. Proyectando sobre el plano $\mathrm{x}_{1} \mathrm{x}_{2}$ los puntos de corte de la función de densidad con planos horizontales a distintas alturas, se obtienen las curvas de isodensidad en forma de elipses concéntricas. La orientación y el tamaño relativo de los ejes de dichas elipses dependen de las varianzas y covarianzas entre $\mathrm{x}_{1}$ y $\mathrm{x}_{2}$.

Las funciones de decisión derivadas de este método son hipercuadráticas (funciones cuadráticas en el espacio $p$-dimensional). Por ello, un clasificador bayesiano basado en la máxima probabilidad y suponiendo funciones de distribución gaussianas, producirá superficies de decisión de segundo orden entre cada par de clases. Si las variables se distribuyen realmente según una función normal, este tipo de superficies producirá los mejores resultados.

\subsubsection{Evaluación de las clasificaciones}

Entre los métodos comunes para evaluar la precisión de una clasificación, el más extendido en teledetección es el de la matriz de errores o matriz de confusión, que consiste en la representación numérica bidimensional de las muestras utilizadas como evaluación, en la que las filas (o columnas) representan las clases asignadas en el proceso de clasificación y las columnas (o filas) las clases reales obtenidas a partir del muestreo de campo o de los datos de referencia.

A partir de esta matriz pueden deducirse varios índices. En primer lugar la fiabilidad global, que se obtiene dividiendo el total de píxeles correctamente clasificados (suma de la diagonal principal) entre el número total de píxeles en la muestra de evaluación.

Además, pueden estudiarse las precisiones individuales de cada clase mediante dos índices complementarios. El primero de ellos se calcula dividiendo el número de píxeles correctos de una clase entre el número total de píxeles de esa clase obtenido a partir de los datos de referencia (el total de la columna correspondiente). Este valor expresa la proporción de píxeles pertenecientes a una clase que han sido correctamente clasificados, dando una idea de los errores por defecto. A este índice se le conoce como fiabilidad del productor, ya que a éste le interesará saber los aciertos en la clasificación de una determinada zona en el terreno. 
Por otra parte, dividiendo el número total de píxeles de una clase correctamente clasificados entre el total de píxeles que fueron clasificados dentro de esa clase (la suma de la fila correspondiente) se obtiene información sobre los errores por exceso. A este índice se le denomina fiabilidad del usuario, y expresa la probabilidad de que un píxel clasificado dentro de una clase pertenezca realmente a dicha clase. En última instancia, al usuario de los datos le interesará conocer acerca de la veracidad de la información contenida en la imagen clasificada.

Otro índice para calcular la fiabilidad de una clasificación es el coeficiente kappa, que se define a partir de la matriz de errores:

$$
\hat{\kappa}=\frac{N \cdot \sum_{i=1}^{f} x_{i i}-\sum_{i=1}^{f}\left(x_{i+} \cdot x_{+i}\right)}{N^{2}-\sum_{i=1}^{f}\left(x_{i+} \cdot x_{+i}\right)}
$$

donde $f$ representa el número de filas de la matriz, $x_{i j}$ el número de observaciones en la fila $i$ y la columna $i, x_{i+}$ y $x_{+i}$ los valores totales marginales de la fila $i$ y de la columna $i$, respectivamente y $N$ es el número total de observaciones.

El coeficiente kappa expresa la proporción en la reducción del error al aplicar la clasificación respecto al error que se hubiera producido realizando una asignación de clases completamente aleatoria. A diferencia de la fiabilidad global, este coeficiente lleva implícita información sobre los elementos marginales (fuera de la diagonal principal) de la matriz. Además, recoge en un solo valor información sobre el proceso y permite la comparación directa de varias matrices.

\subsection{Tratamientos post-clasificación de las zonas de bordes}

El incorrecto tratamiento de bordes que se genera en imágenes donde la variabilidad entre y dentro de cubiertas es importante es un error común a la mayor parte de los algoritmos de tratamiento y clasificación de imágenes digitales mediante análisis de texturas. La literatura así lo refleja en numerosos trabajos (Jones, 1994; Ferro, 1998; Lin y Huang, 2004; Clausi y Yue, 2005). 
Algunas aproximaciones a este problema apuntan al empleo de modelos específicos basados en operadores que asignan valores altos de ciertas variables en áreas internas y bajos en las externas (Jones, 1994) o incluso el empleo de redes neuronales implementadas mediante bancos de filtros de Gabor (Lin y Huang, 2004).

En el presente trabajo se han aplicado varios métodos para minimizar en la medida de lo posible el efecto frontera que genera importantes confusiones en la asignación de cada píxel a las correspondientes clases cualitativas, sobre todo cuando las cubiertas no son muy diferentes y existe variabilidad interna (como puede ser el desigual nivel de área foliar, LAI, en una zona boscosa).

Los ensayos diseñados se basan en los siguientes preceptos y antecedentes. Hasta ahora se ha estimado como mejor vecindario de cálculo de variables de textura el de $25 \times 25$ al ser el que mejor puede describirlas sobre la mayor parte de las superficies analizadas. Pero en los píxeles periféricos de un área homogénea, el cálculo con ese vecindario se verá fuertemente influenciado por la naturaleza de la clase adyacente, tal y como se puede apreciar en la figura 6-20 donde un fragmento de imagen pancromática inicial (izquierda) se ha clasificado en varias clases (centro) y tal y como se puede ver en la superposición de las anteriores existe un claro error de asignación en la zona frontera entre el área urbana (magenta) y el área de huerta (verde) habiéndose creado una franja de píxeles asignados a la clase industrial (cian) claramente inexistente.

Este se considera el origen de la baja fiabilidad en la clasificación de los bordes. Por ello, cualquier propuesta de mejora debe ir encaminada a evitar dicha interferencia de cálculo de texturas, empleando vecindarios menores en las áreas periféricas de las cubiertas. Con ello se realizaría un cálculo con un vecindario ajustado en las áreas internas, homogéneas y sin bordes, y un cálculo con un vecindario sensiblemente menor que recoja la variabilidad espacial de cada cubierta pero minimice la influencia de otras coberturas.

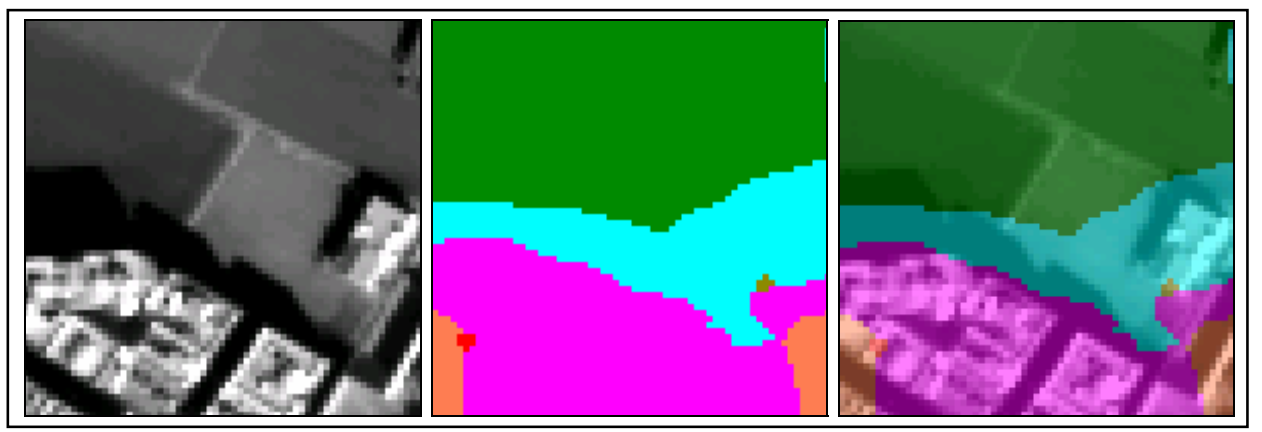

Figura 6-20. Ejemplo de la incorrecta asignación de clases en una zona frontera entre dos clases (verde: huerta, cian: industrial, magenta: urbano). 
En el presente trabajo se han intentado discriminar las áreas de bordes de las internas para aplicar sobre cada una de ellas un procedimiento de trabajo particular (figura 6-21). En las áreas internas se han tomado las variables de textura derivadas de las transformadas wavelet reseñadas en apartados anteriores. Las variables de la MCNG para toda la imagen y calculadas con un vecindario menor, han sido enmascaradas según el modelo de bordes, para evitar la influencia de los píxeles nulos en el cálculo de variables de textura si se hubiese realizado a la inversa. Posteriormente, se han clasificado por separado con muestras de aprendizaje definidas a tal efecto y distintas de las usadas en las evaluaciones.

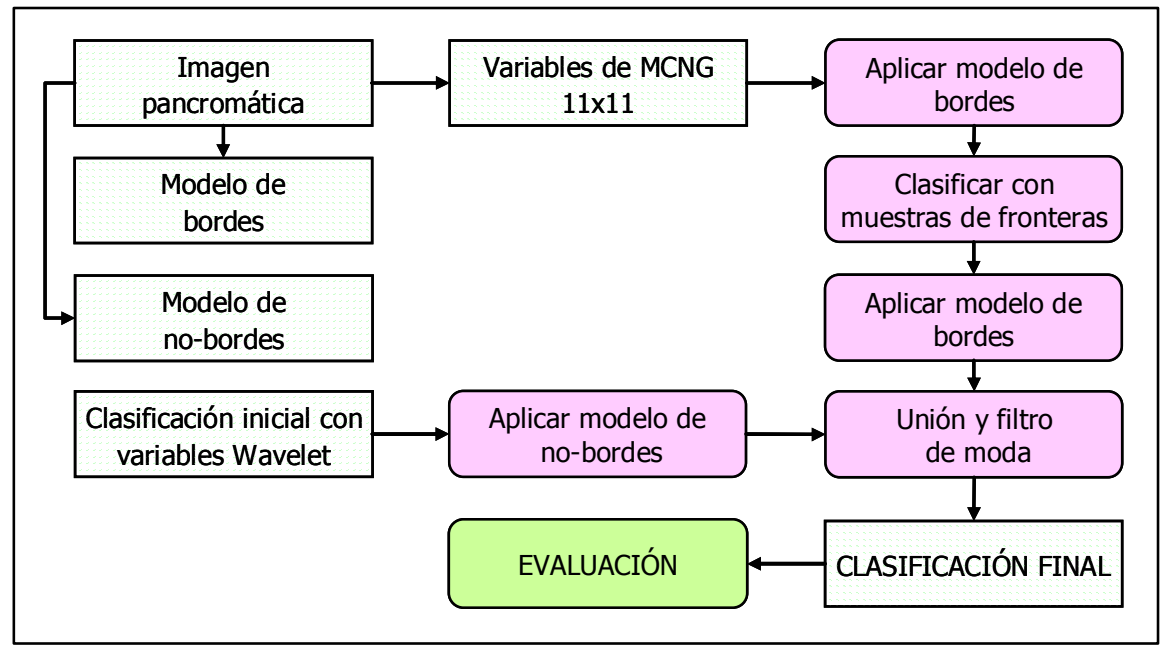

Figura 6-21. Algoritmo de trabajo.

Pero el principal reto del algoritmo de trabajo anteriormente citado consiste en la definición de las áreas frontera (o modelos de bordes). Para lograrlo se han establecido hasta 4 modelos, segundas varianzas, bordes de la media, filtros de Canny y bordes de la clasificación inicial, con resultados diferentes pero siempre mejores a los obtenidos sin su puesta en práctica. Son los que siguen a continuación.

\subsubsection{Segundas varianzas}

Partiendo de una imagen pancromática, la variable varianza de la MCNG (ecuación 6-14) refleja la heterogeneidad, es decir, la variabilidad de las intensidades en la imagen y aumenta su valor cuando los niveles de gris difieren de la media. El cálculo de una segunda varianza sobre la primera y con un vecindario menor resalta los píxeles situados en zonas de transición entre texturas, es decir, donde la heterogeneidad es 
mayor, dejando prácticamente nulos aquellos otros interiores a las texturas. El esquema operativo consta de varias fases y los modelos parciales se detallan en la figura 6-22:

10- Detalle de una de las imágenes pancromáticas empleadas en los ensayos (a).

20- Cálculo de la varianza de la MCNG con un vecindario de $25 \times 25$ y que comienza a destacar las zonas frontera, como se aprecia en (b).

30- Sobre la anterior se obtiene la varianza de MCNG con vecindario de $11 \times 11$, la cual asigna valores altos a los bordes y prácticamente nulos al resto (c).

40- Por último se realizaría una umbralización para definir el modelo de bordes, sobre el cual se aplicaría el patrón de análisis de la figura 6-21.

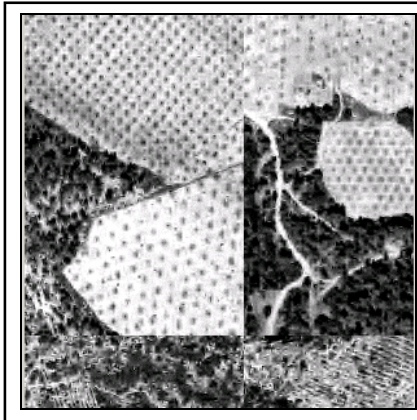

a)

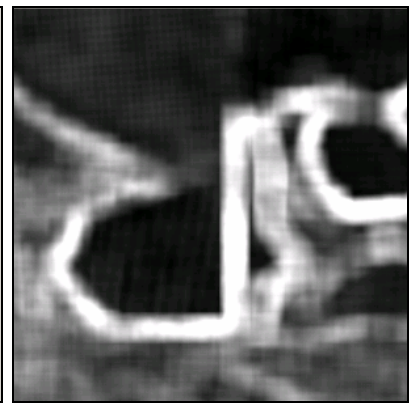

b)

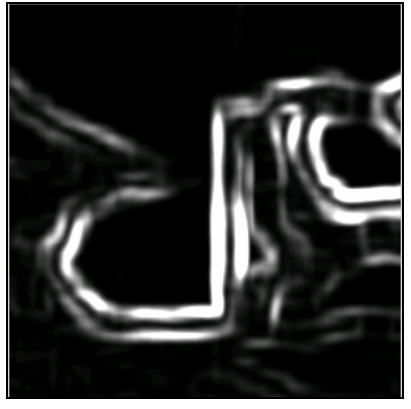

c)

Figura 6-22. Modelo de definición de bordes basado en segundas varianzas.

\subsubsection{Bordes de la media}

La media de la MCNG (ecuación 6-13) proporciona información sobre el brillo global de la imagen, generando una sensación similar a la obtenida a partir del histograma. Permite intuir los límites de zonas homogéneas al tener valores similares en el interior de dichas zonas y variables en los contornos. Por otro lado, son conocidas las capacidades de los filtros de gradiente para determinar bordes, pudiendo destacar como más usuales los de Sobel, Roberts y Prewitt. De la unión de estas dos premisas surge este segundo modelo de definición de bordes al ser aplicados dichos filtros sobre la variable de media. En la figura 6-23 se presentan detalles de los modelos derivados, que siguen las siguientes fases:

10- Detalle de una de las imágenes pancromáticas empleadas en los ensayos (a).

20- Se calcula la media de MCNG con un vecindario de $25 \times 25$ (b). 
30- Sobre la media se aplica un filtro de Sobel de $3 \times 3$ (c).

40- Sobre la media se aplica otro filtro de bordes, en concreto el de Roberts (d).

50- Sobre la media se aplica un filtro de Prewitt de $3 \times 3$ (e).

60- Se procede a la intersección de los 3 filtros anteriores umbralizados para asegurar que los píxeles asignados a la zona de bordes sean resultados de los 3 filtros (f).

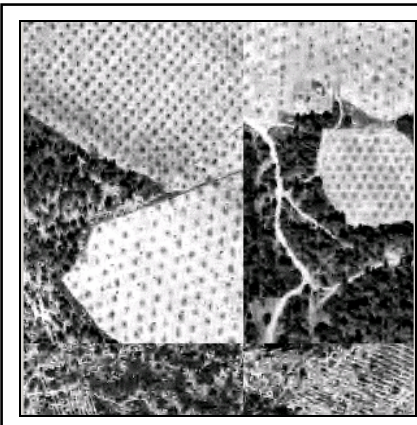

a)

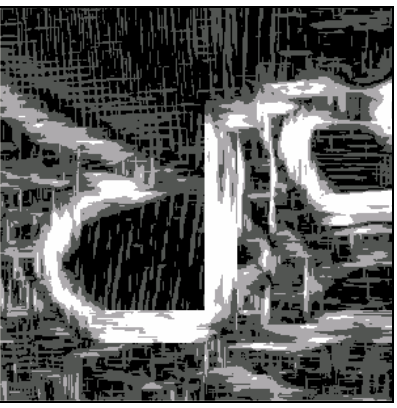

d)

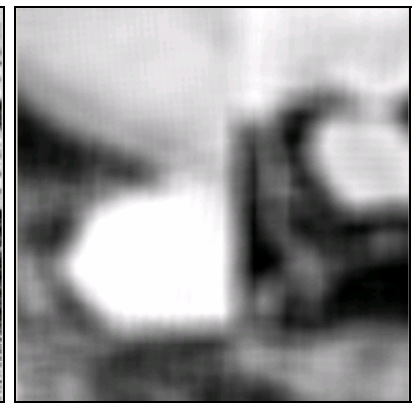

b)

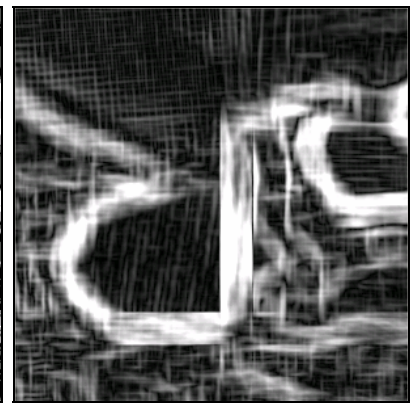

e)

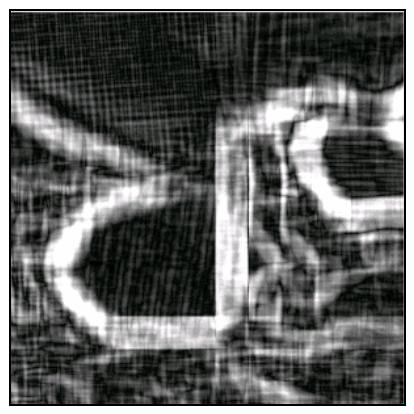

c)

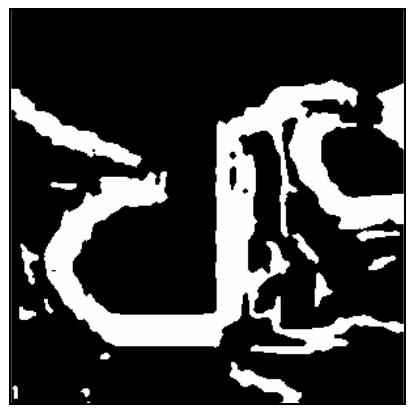

f)

Figura 6-23. Modelo de definición de bordes basado en filtros de gradiente sobre la media.

\subsubsection{Filtros de Canny}

El operador de Canny (Canny, 1986) es considerado como uno de los mejores detectores de bordes. Se trata de un operador que trabaja en varios niveles o fases. La primera de ellas consiste en aplicar un suavizado a la imagen de entrada para eliminar el ruido presente mediante una convolución de tipo gaussiano. El siguiente paso determina la magnitud del borde calculando el gradiente de la imagen en las dos direcciones principales $\mathrm{X}$ e $\mathrm{Y}$. Con esto se resaltan las regiones de la imagen con altas variaciones espaciales y los bordes quedan identificados como crestas en la imagen de gradiente. A partir de los 
gradientes en $\mathrm{X}$ e $\mathrm{Y}$ se puede conocer la magnitud del borde, como magnitud absoluta del gradiente, además de su dirección. Dado que desde el punto de vista computacional, las direcciones en una imagen se cuantifican como múltiplos de $45^{\circ}$, la dirección real del borde se ha de reasignar a alguna de ellas. Se identifican entonces los puntos que sean máximos locales en la dirección del gradiente y a partir de ellos se eliminan aquellos otros que no sean máximos para de esta manera definir el borde como una delgada línea en la imagen de salida. Finalmente se aplica un proceso de histéresis controlada por dos umbrales, uno inferior y otro superior para eliminar líneas que no se correspondan realmente con bordes. Estas líneas o rayas incorrectas pueden aparecer al romperse un borde porque la salida del operador esté fluctuando por encima y por debajo de los umbrales. Se parte de los puntos cuyo gradiente están por encima del límite superior y buscando en las dos direcciones, se agregan aquellos puntos conexos y cuyo gradiente sea superior al límite inferior.

Para aplicar esta rutina se debe especificar la desviación típica que define los coeficientes del filtro de gaussiano de eliminación de ruido y los umbrales superior e inferior para la histéresis. De estos 3 parámetros, es el límite superior el que más influye en que el resultado final presente más o menos bordes interiores a las texturas, los cuales no son deseables.

De esta manera se obtiene una imagen binaria de bordes, bastante precisa para el caso de imágenes con texturas muy homogéneas y diferentes entre sí pero un poco menos fiable sobre imágenes de cubiertas del terreno, tal y como se puede apreciar en la figura 6-24. En ésta se observa como de la imagen original (a) se genera un modelo de bordes (b) que no es del todo correcto al no detectar todo el borde exterior al cultivo de almendros y sí hacerlo con otros dentro de la zona forestal. De los elementos lineales obtenidos se ha definido un modelo o franjas de bordes (c).

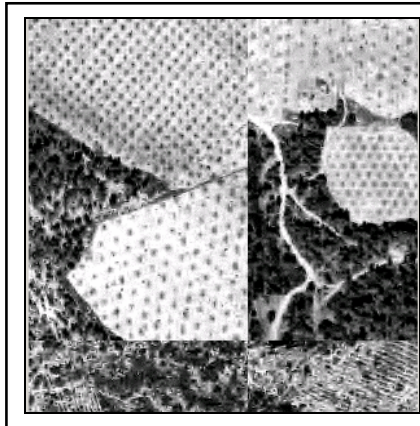

a)

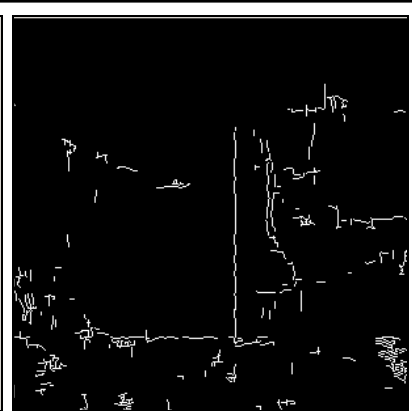

b)

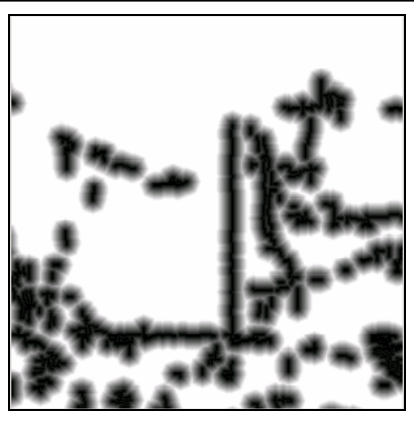

c)

Figura 6-24. Modelo de definición de bordes basado en filtros de Canny. 


\subsubsection{Bordes de la clasificación inicial}

La clasificación obtenida a partir de las variables wavelet se ha mostrado bastante precisa en la asignación temática a los píxeles interiores a las superficies. Por ello se puede plantear conservar esas áreas internas y reasignar las clases en las zonas exteriores, creando un modelo de ellas que se aplicará según el algoritmo de la figura 6-21. Para conseguir ese modelo se han de seguir unas fases, cuyos resultados parciales se aprecian en la figura 6-25:

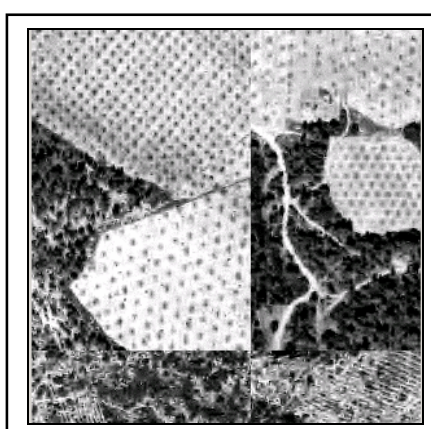

a)

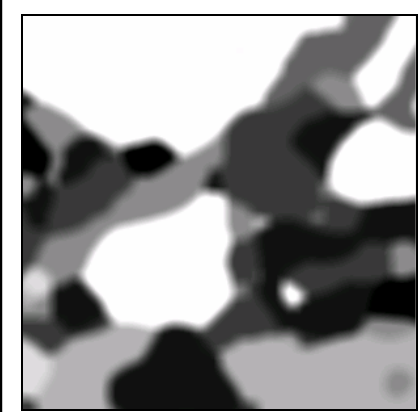

d)

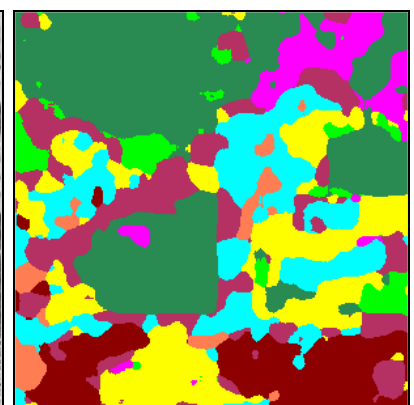

b)

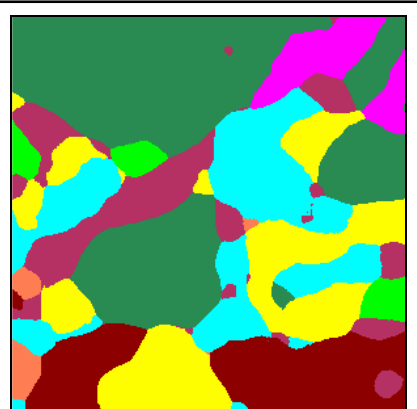

c)

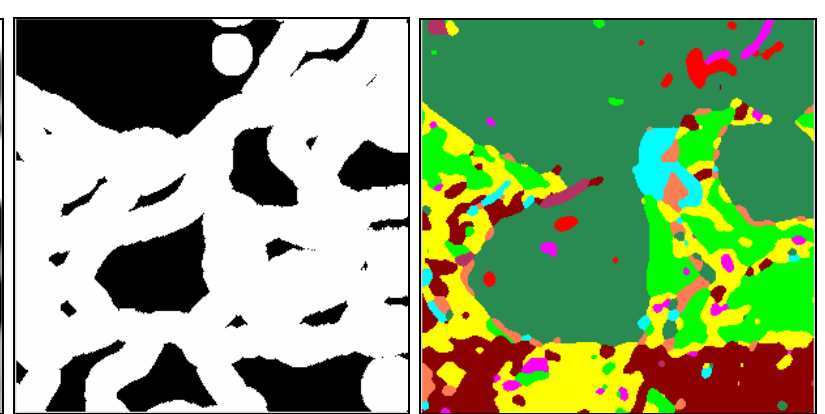

e)

Almendros

Olivos

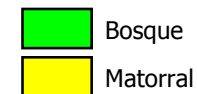

(1)
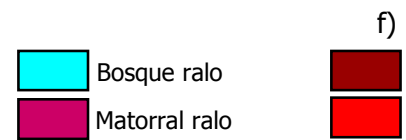

Repob. forestal

Cereal

Figura 6-25. Modelo de definición de bordes basado en la clasificación de las variables wavelet.

10- Detalle de una de las imágenes pancromáticas empleadas en los ensayos (a).

20- Con las variables de textura analizadas en apartados anteriores se obtiene una clasificación (b) que se comporta bastante bien en las áreas internas a las texturas.

30- Se simplifica la clasificación anterior eliminando clusters de pequeñas dimensiones mediante filtros de moda (c). 
40- De este modelo simplificado se ha calculado la media de la MCNG con un vecindario de $11 \times 11$ (d) de tal manera que los píxeles de contornos presentan valores cambiantes y los interiores son constantes.

50- De la selección de los píxeles con valores variables y dentro de un determinado rango se obtiene el modelo de bordes (e) que tras introducirse en el algoritmo de trabajo de la figura 6-24 genera una clasificación final ( $\mathrm{f}$ ) bastante más fiable que la inicial (b), y si bien siguen existiendo incorrectas asignaciones en algunos píxeles, los bordes se definen casi completos y en su verdadera posición. 


\section{Resultados experimentales y discusión}

\subsection{Introducción y justificación}

El principal objetivo de este capítulo es determinar aquellos parámetros y variables de textura que se pueden derivar de una imagen y que pueden influir en los resultados finales de una clasificación temática de cubiertas naturales. En el presente capítulo se detallan los resultados obtenidos de todos los ensayos realizados, tanto en la fase previa de análisis de los parámetros metodológicos y variables (figura 7-1) como en la de su verificación global sobre diferentes tipologías de cubiertas naturales, constituyendo los dos grandes bloques que articulan este capítulo. Por apartados, en primer lugar se analizan las variables de textura, luego los parámetros de metodología a aplicar, luego se verifican todos de forma global y por último se plantean soluciones al problema de bordes.

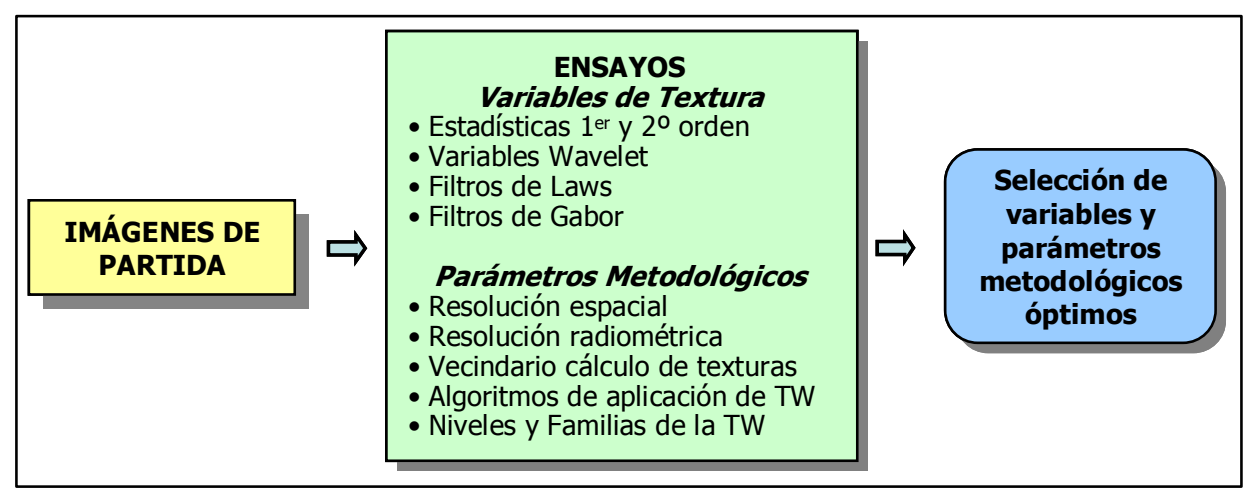

Figura 7-1. Esquema de procedimientos a realizar. 


\subsection{Análisis de variables de textura}

El esquema que resume el contenido de este apartado es el de la figura 7-1. Sobre un amplio abanico de imágenes de diversos entornos geográficos y climáticos se han realizado ensayos sobre aspectos tanto inherentes a la naturaleza de las propias imágenes (resoluciones espacial y radiométrica) como a la forma en que éstas son tratadas (variables de textura, transformada wavelet, ...), para poder obtener, a partir del análisis de los resultados, conclusiones sobre su influencia en la clasificación por texturas.

Los datos de partida considerados son los detallados en el capítulo V "Datos de trabajo", cuyas características están en él referidas. Además, se han analizado variaciones de algunos de ellos, como por ejemplo subimágenes parciales centradas en una determinada característica, remuestreos, mosaicos con fragmentos, etc.

En los diferentes ensayos se ha trabajado con paquetes de software como Matlab 7.1, ENVI 3.6, Erdas 8.6, ArcMap V.9.1. y diferentes rutinas propias implementadas en IDL (lenguaje fuente de ENVI). Por lo que respecta a los resultados, en las tablas están remarcados de color amarillo algunos de ellos por su significación.

\subsubsection{Eficiencia de las variables estadísticas de $1^{\mathrm{er}}$ y $\mathbf{2}^{\circ}$ orden y derivadas del histograma: energía y asimetría}

En el apartado 6.2 del capítulo de metodología se detallan una serie de variables de textura a calcular sobre las imágenes, tanto las pancromáticas originales como las de detalle resultantes de los algoritmos de la transformada wavelet. Todas esas variables pueden ser empleadas en bloque, generando cantidades importantes de información y mayor tiempo de procesado, o bien se puede plantear cuáles de ellas son las que mejor discriminan los diversos tipos de cubiertas de las imágenes. Con este análisis, se intenta descartar aquellas que no contribuyen de forma considerable a mejorar el resultado de una clasificación de entre el conjunto de posibles y que pueden requerir tiempo de procesado y recursos importantes de hardware. Estas discriminaciones se han realizado a priori, mediante el análisis de separabilidad entre clases para todas las variables según las distancias de Jeffries-Matusita y divergencia transformada, y a posteriori, tras realizar las clasificaciones y expresarla en términos de fiabilidades globales. Se han analizado los resultados de este segundo proceso dado que las medidas de separabilidad requieren disponer de variables cuyas estadísticas sean lo más homogéneas posible y ello generalmente no es así dada la diferente naturaleza y método de cálculo de cada una de ellas. 
Para las diferentes tipologías de superficies presentes en las imágenes se ha planteado el cálculo de la misma cantidad de variables y con parámetros similares. Además de ello y dado que la influencia de la resolución radiométrica es evidente, como se demostrará en apartados posteriores, se ha experimentado con dos resoluciones radiométricas para cada imagen en función de la naturaleza propia de cada una de ellas. Las resoluciones espaciales son de $1 \mathrm{~m}$ para los mosaicos de Ayora y Espadán y de $1.7 \mathrm{~m}$ para el de Valencia y la imagen de Menorca.

Los resultados mostrados en la tabla 7-1 y figura 7-2 consisten en las fiabilidades globales de las clasificaciones realizadas con cada uno de los grupos de variables (numerados del 1 al 13), siendo las variables consideradas las siguientes:

- $\quad$ MCNG: las 8 variables de textura calculadas con un vecindario de $25 \times 25$ de la MCNG y planteadas por Haralick et al. (1973).

- $\quad$ PAN: imagen pancromática de partida.

- $\quad$ Asimetría: imagen de asimetría calculada con un vecindario de 25×25.

- $\quad$ Energía: imagen de energía calculada con vecindario de 25×25.

- $\quad$ Kurtosis: imagen del coeficiente de apuntamiento del histograma (25×25).

- $\quad$ Skewness: imagen del coeficiente de forma del pico del histograma (25x25).

Para el entorno mixto entre áreas de cultivos y forestales, propio de la imagen de Ayora, los resultados muestran que existen una serie de máximos y mínimos relativos con el siguiente significado: (1) el parámetro de asimetría se comporta mejor que la energía o la kurtosis; (2) la variable skewness no genera buenos resultados, sobre todo con 10 bits; (3) la suma de la energía y la kurtosis hacen incrementar sensiblemente la fiabilidad global; (4) las mejores fiabilidades se consiguen con casi todas las variables y se aprecia que el no tener en cuenta la imagen pancromática original no conlleva pérdida de acierto.

En el entorno peri-urbano de Valencia, en el que la mejor resolución radiométrica, según ensayos previos, es la de 9 bits por píxel, se ha extendido el ensayo a 10 bits para constatar el desigual comportamiento de las variables en función del nivel radiométrico del que hayan sido obtenidas. Se pueden apreciar las siguientes conclusiones: (1) La imagen pancromática original no aporta mejora de fiabilidad; (2) usar la variable kurtosis genera un máximo relativo; (3) la variable skewness empeora el porcentaje de acierto; (4) utilizar la energía y la kurtosis supone una mejoría hasta tal punto que casi se obtiene el máximo absoluto con un grupo menor de variables. 


\begin{tabular}{|l|c|c|c|c|c|c|c|c|c|}
\cline { 3 - 10 } \multicolumn{2}{c|}{} & \multicolumn{2}{c|}{ Ayora } & \multicolumn{2}{c|}{ Valencia } & \multicolumn{2}{c|}{ Espadán } & \multicolumn{2}{c|}{ Menorca } \\
\hline \multicolumn{1}{c|}{ VARIABLES DE TEXTURA } & & $\begin{array}{c}\mathbf{1 0} \\
\text { bits }\end{array}$ & $\begin{array}{c}\mathbf{8} \\
\text { bits }\end{array}$ & $\begin{array}{c}\mathbf{1 0} \\
\text { bits }\end{array}$ & $\begin{array}{c}\mathbf{9} \\
\text { bits }\end{array}$ & $\begin{array}{c}\mathbf{1 0} \\
\text { bits }\end{array}$ & $\begin{array}{c}\mathbf{6} \\
\text { bits }\end{array}$ & $\begin{array}{c}\mathbf{1 0} \\
\text { bits }\end{array}$ & $\begin{array}{c}11 \\
\text { bits }\end{array}$ \\
\hline MCNG & 1 & 78.37 & 77.60 & 78.85 & 80.71 & 67.61 & 70.18 & 76.84 & 77.61 \\
\hline MCNG+PAN & 2 & 78.55 & 77.57 & 78.43 & 80.60 & 67.66 & 70.13 & 76.91 & 77.53 \\
\hline MCNG+Asimetría & 3 & 81.48 & 78.10 & 78.01 & 80.70 & 67.47 & 69.63 & 76.16 & 77.13 \\
\hline MCNG+Energía & 4 & 80.56 & 76.79 & 74.72 & 80.57 & 68.73 & 71.91 & 77.39 & 78.68 \\
\hline MCNG+Kurtosis & 5 & 80.18 & 77.93 & 79.53 & 81.24 & 68.34 & 71.12 & 77.43 & 77.76 \\
\hline MCNG+Skewness & 6 & 78.18 & 77.39 & 77.71 & 79.54 & 65.59 & 69.43 & 76.61 & 76.93 \\
\hline MCNG+Energía+Kurtosis & 7 & 82.61 & 77.75 & 76.02 & 81.25 & 70.01 & 72.87 & 78.34 & 79.14 \\
\hline MCNG+Energía+Skewness & 8 & 80.73 & 77.72 & 74.81 & 79.93 & 67.82 & 73.34 & 77.00 & 78.46 \\
\hline MCNG+Energía+Asimetría & 9 & 82.14 & 77.68 & 75.62 & 80.83 & 68.59 & 72.52 & 77.22 & 78.85 \\
\hline MCNG+Energía+Kurtosis+Skewness & 10 & 83.00 & 78.91 & 75.49 & 80.75 & 71.14 & 73.75 & 78.06 & 79.07 \\
\hline MCNG+Energía+Kurtosis+Asimetría & 11 & 84.00 & 78.76 & 76.12 & 81.39 & 69.89 & 72.39 & 78.01 & 79.79 \\
\hline MCNG+Energía+Kurtosis+Asimetría+Skewn. & 12 & 83.98 & 79.60 & 75.47 & 80.89 & 71.30 & 73.60 & 77.61 & 79.65 \\
\hline Todas (13 bandas) & 13 & 84.18 & 79.77 & 75.57 & 80.97 & 71.31 & 73.68 & 77.61 & 79.64 \\
\hline
\end{tabular}

Tabla 7-1. Fiabilidades del productor para cada grupo de variables sobre las dos imágenes.

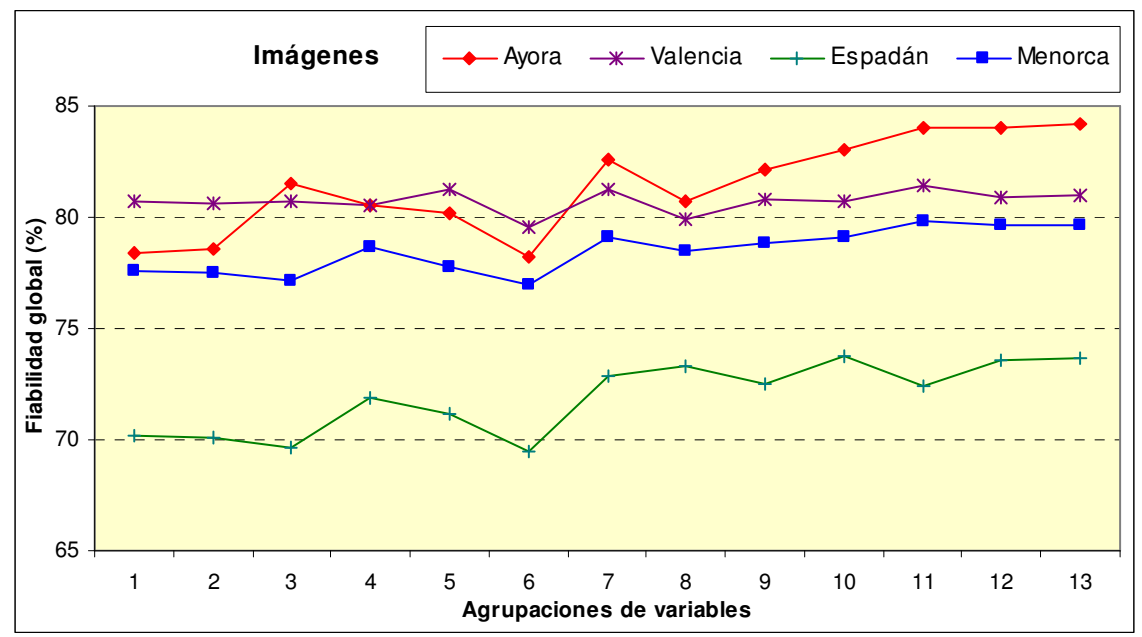

Figura 7-2. Fiabilidades globales para cada grupo de variables sobre todas las imágenes.

Para las superficies de montaña con vegetación natural, las propias de la imagen Espadán, se han considerado las resoluciones radiométricas de 10 y 6 bits. Para las zonas rurales mediterráneas como las de la imagen de Menorca se han analizado las variables de textura comentadas a dos resoluciones radiométricas, 10 y 11 bits por píxel. Tal y como se aprecia en la tabla y figura anteriores, los resultados son bastante similares para las dos áreas y todas las radiometrías: (1) puede evitarse emplear la imagen pancromática ya que 
no mejora la clasificación; (2) la variable energía genera un máximo relativo frente a otras variables como asimetría o skewness; (3) el parámetro de forma del histograma llamado skewness es menos robusto que el parámetro de asimetría propuesto e implementado en IDL; (4) la suma de energía y kurtosis consigue llegar hasta casi los máximos absolutos; (5) al sumar a la energía y la kurtosis uno de los dos parámetros de forma del histograma (skewness o asimetría) se consiguen prácticamente los máximos de las clasificaciones.

De los resultados conjuntos anteriores se pueden extraer las siguientes conclusiones: (1) la imagen pancromática no aporta información adicional decisiva en la clasificación, probablemente porque se incluye la media de la MCNG, la cual contiene información similar; (2) las variables energía y kurtosis sí aportan información sobre las texturas y por ello deben ser tenidas en consideración; (3) si se desea emplear una variable que especifique la forma del histograma, el parámetro de asimetría se comporta mejor que skewness. Estas conclusiones han sido retomadas en procedimientos y cálculos realizados con posterioridad.

Tomando en consideración tan sólo el conjunto de variables extraídas de la MCNG, se puede observar que no todas ellas se muestran igualmente discriminantes en las clasificaciones, de tal manera que de las 8 propuestas por Haralick (1973) se ha intentado determinar cuáles de ellas contribuyen más. Siguiendo los resultados apuntados por algunos autores (Ruiz et al., 2002, Maillard, 2003) se ha procedido a realizar clasificaciones con grupos de 4, 6 y 8 variables de textura de la MCNG calculadas sobre las 4 imágenes de trabajo anteriormente detalladas, a una resolución homogénea de 10 bits y un vecindario de trabajo de $25 \times 25$ píxeles. El grupo llamado 4 MCNG agrupa las variables varianza, homogeneidad, contraste y correlación de dicha matriz; el grupo 6 MCNG engloba la media, varianza, homogeneidad, contraste, momento de diferencia inverso y correlación y el grupo 8 MCNG suma la entropía y el segundo momento a las 6 anteriores. Los resultados de fiabilidad global en \% y del estadístico kappa son los que muestra la tabla 7-2 en la que se puede apreciar que el grupo de 6 variables es el que mejor se comporta en 3 de los casos y en el cuarto proporciona resultados casi idénticos al grupo de 8 variables. Por ello se considera que es rentable, desde la perspectiva de acierto y del número de variables, emplear las 6 analizadas y no el total de las 8 .

Otra variable analizada ha sido el intervalo de datos existente en el vecindario de trabajo, ya que ensayos previos mostraban una cierta posibilidad de mejora con este parámetro. Por ello se ha probado con él, junto a otras variables de la MCNG y otras variables del histograma, como energía y kurtosis, sobre el mosaico de Valencia y la imagen de Menorca a $1.7 \mathrm{~m}$ ambas y con un vecindario de $25 \times 25$. De la tabla 7-3 se puede deducir que el comportamiento de la variable intervalo de datos es complementaria a energía y kurtosis, por lo que se considera importante su inclusión en los cálculos globales. 


\begin{tabular}{|l|c|c|c|c|c|c|c|c|}
\cline { 2 - 9 } \multicolumn{1}{c|}{} & \multicolumn{2}{c|}{ AYORA } & \multicolumn{2}{c|}{ ESPADAN } & \multicolumn{2}{c|}{ MENORCA } & \multicolumn{2}{c|}{ VALENCIA } \\
\cline { 2 - 9 } \multicolumn{1}{c|}{} & F. global & Kappa & F. global & Kappa & F. global & Kappa & F. global & Kappa \\
\hline 4 MCNG & 68.01 & 0.634 & 57.71 & 0.481 & 65.62 & 0.594 & 74.92 & 0.703 \\
\hline 6 MCNG & 80.02 & 0.772 & 73.97 & 0.671 & 77.14 & 0.729 & 82.02 & 0.785 \\
\hline 8 MCNG & 78.37 & 0.759 & 67.61 & 0.613 & 76.84 & 0.731 & 78.85 & 0.751 \\
\hline
\end{tabular}

Tabla 7-2. Fiabilidades globales para cada grupo de variables de la MCNG sobre las 4 imágenes.

\begin{tabular}{|l|c|c|}
\cline { 2 - 3 } \multicolumn{1}{c|}{} & MENORCA & VALENCIA \\
\hline 6 MCNG + Intervalo de datos & 77.76 & 82.60 \\
\hline 6 MCNG + Energía + Kurtosis & 79.47 & 82.30 \\
\hline
\end{tabular}

Tabla 7-3. Fiabilidades globales para cada grupo de variables sobre las dos imágenes.

\subsubsection{Eficiencia de otras variables de textura: Filtros Wavelet, Gabor y Laws}

Algunos autores han propuesto otras variables para caracterizar las texturas en imágenes, en concreto las obtenidas de los bancos de filtros Gabor y de los filtros de Laws. Trabajos previos como los de Ruiz et al. (2001, 2004), han permitido ponerlas en práctica sobre algunos entornos y posteriormente se han ampliado a las 4 áreas de trabajo. El objetivo de este ensayo ha sido determinar en qué medida los grupos de variables reseñados y detallados en el capítulo "Metodología" permiten una discriminación de las diversas clases y su comparación con las variables de la MCNG de la imagen pancromática y con las variables wavelet.

En concreto, las variables de Laws calculadas son las resultantes de aplicar 7 filtros de $7 \times 7$ píxeles, con un post-procesado de 7 y 11 píxeles para Menorca y Espadán y 15 píxeles para Ayora y Valencia. Además de ellos, se empleó el factor densidad de bordes (edgeness) obtenido con una distancia de 3 píxeles, resultando 8 imágenes a partir de la pancromática inicial. Por lo que respecta a los filtros de Gabor, éstos se han aplicado con desviaciones de $2.86,5.73$ y 11.44 y frecuencias de $0.3536,0.1768$ y 0.0884 respectivamente, definidos en las 6 direcciones principales, las cuales posteriormente fueron promediadas para eliminar el factor de orientación y quedar 3 bandas.

El mejor grupo de variables obtenidas de la MCNG consiste en sus 6 variables más discriminantes (media, varianza, homogeneidad, contraste, momento de diferencia inverso y correlación) calculadas con un vecindario de $25 \times 25$ píxeles. Por lo que respecta al grupo de variables wavelet, se ha aplicado la transformada con la función Coiflet24 hasta el nivel 3 y de cada imagen de detalle se han obtenido las mismas 6 variables de textura. 
Estas características texturales se han extendido al mosaico de Ayora y al de Espadán, ambos a $1 \mathrm{~m}$ y 8 bits por píxel; y a la imagen de Menorca a $2.4 \mathrm{~m}$ y 11 bits y a la imagen de Valencia a $5 \mathrm{~m}$ y 11 bits por píxel. Aparte de reflejar las fiabilidades globales de acierto en las áreas internas a las diversas superficies, también se muestran en la tabla 7-4 los porcentajes de acierto en las áreas frontera entre diferentes tipologías de cubiertas. Estos resultados pueden ser expresados en forma gráfica tal y como muestra la figura 7-3 de tal manera que permite una interpretación algo más inmediata de ellos.

\begin{tabular}{|l|c|c|c|c|c|c|c|c|}
\cline { 2 - 9 } \multicolumn{1}{c|}{} & \multicolumn{2}{c|}{ AYORA } & \multicolumn{2}{c|}{ ESPADAN } & \multicolumn{2}{c|}{ MENORCA } & \multicolumn{2}{c|}{ VALENCIA } \\
\cline { 2 - 9 } \multicolumn{1}{c|}{} & Interior & Frontera & Interior & Frontera & Interior & Frontera & Interior & Frontera \\
\hline MCNG & 71.17 & 28.64 & 65.97 & 45.74 & 74.74 & 31.45 & 84.25 & 43.16 \\
\hline WAVELET (WV) & 65.47 & 30.10 & 63.75 & 45.18 & 66.41 & 33.19 & 79.28 & 43.95 \\
\hline GABOR & 61.73 & 30.95 & 65.70 & 44.04 & 68.37 & 23.89 & 68.14 & 43.71 \\
\hline ENERGIA & 57.35 & 40.24 & 67.44 & 51.42 & 70.71 & 37.05 & 62.96 & 54.48 \\
\hline MCNG+WV & 78.16 & 26.91 & 73.42 & 53.44 & 80.05 & 31.49 & 87.24 & 45.95 \\
\hline MCNG+GABOR & 76.56 & 27.96 & 71.03 & 51.72 & 76.60 & 30.01 & 86.45 & 45.14 \\
\hline MCNG+ENERGIA & 78.03 & 36.00 & 73.92 & 51.85 & 75.65 & 31.92 & 85.82 & 44.48 \\
\hline $\begin{array}{l}\text { MCNG+WV+GABOR+ } \\
\text { ENERGIA }\end{array}$ & 82.06 & 34.56 & 76.18 & 57.51 & 81.41 & 30.77 & 88.41 & 45.76 \\
\hline
\end{tabular}

Tabla 7-4. Fiabilidades del productor para cada grupo de variables sobre las dos imágenes (en amarillo y magenta las mejores fiabilidades para áreas internas y bordes).

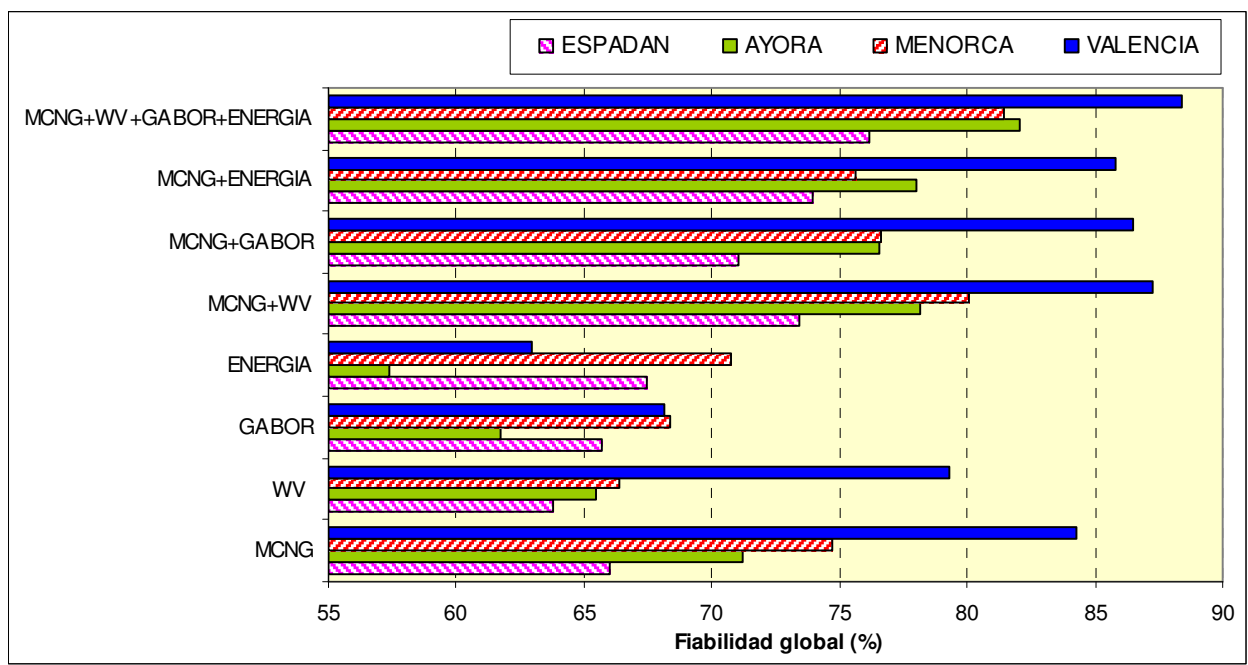

Figura 7-3. Fiabilidades del productor para cada grupo de variables sobre la imagen de Valencia.

Los resultados de la tabla 7-4, expresados en forma de fiabilidad global al hacer clasificaciones y evaluarlas en las áreas interiores o bien en las áreas frontera, reflejan ciertos aspectos dignos de reseñar: (1) el comportamiento de los diversos grupos de variables no es constante en todas las imágenes; (2) considerados de forma individual, el grupo que mejor se comporta es el de la MCNG, seguido por el de wavelet y filtros de 
energía. (3) En cuanto a las diversas agrupaciones, la mejor es la unión de todas las variables, seguida de la unión de MCNG con wavelet y MCNG con energía. (4) Si bien las fiabilidades en las áreas frontera son bajas, resulta llamativo comprobar como las variables de energía son las que mejor asignan los píxeles a las clases correspondientes en dichas áreas donde las influencias de los elementos vecinos es mayor, reduciendo el llamado "efecto frontera". Esto es debido, precisamente, al procesado específico que se hace para reducir el efecto de bordes (Ruiz et al., 2001). En la figura 7-4 se adjuntan dos fragmentos de la clasificación de todas las variables para la zona forestal de Ayora.

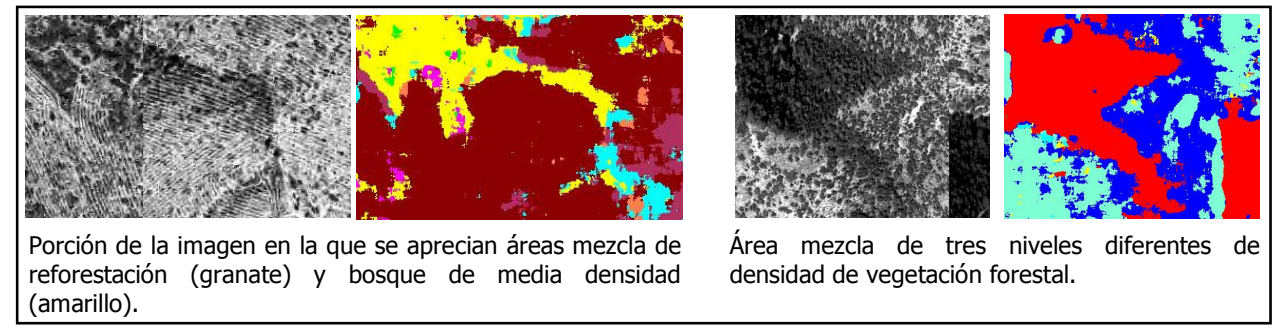

Figura 7-4. Fragmentos de la clasificación con todas las variables en la zona forestal.

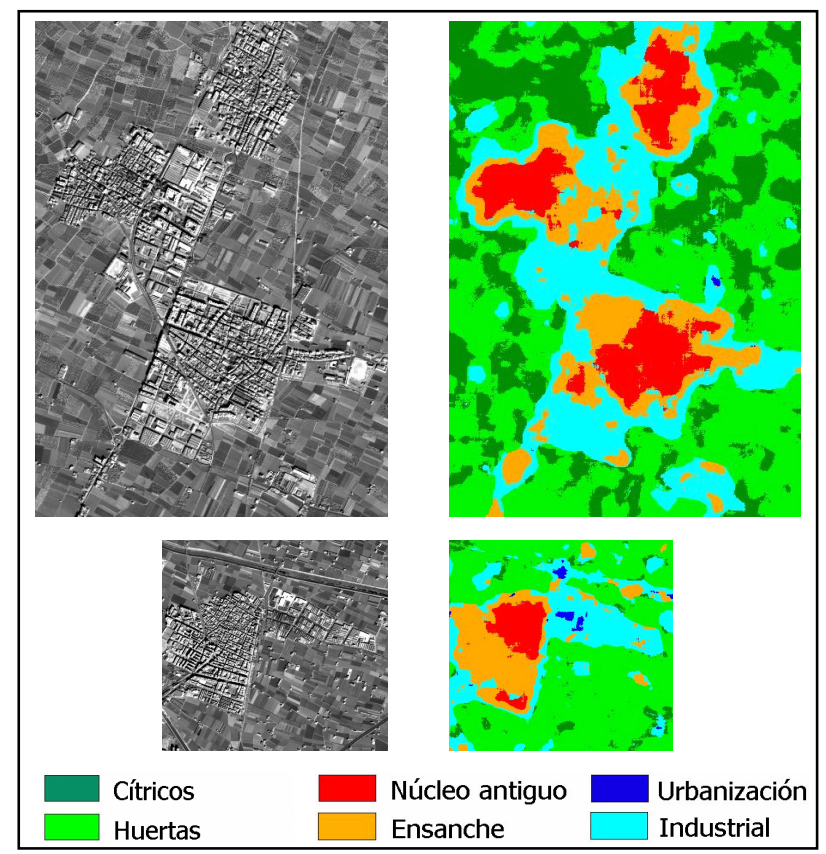

Figura 7-5. Fragmentos de la imagen de Valencia clasificada.

En la figura 7-5 se detallan algunos fragmentos de la clasificación de todas las variables de textura sobre la imagen de Valencia remuestreada a $5 \mathrm{~m}$. Se aprecia cómo se definen bien los núcleos urbanos antiguos, así como las áreas de ensanche urbanístico y 
las áreas industriales. La discriminación entre cultivos citrícolas y hortícolas es algo menos clara, quizás por similitudes entre algunas de las especies cultivadas.

En casi todas las imágenes se comienza a apreciar el efecto de los bordes debido a la interferencia entre píxeles vecinos realmente pertenecientes a clases diferentes. En la figura 7-6 se muestra una transición entre bosque de alta densidad (verde claro) y cereal (rojo) aparecen hasta 3 franjas asignadas a clases diferentes y sin evidente sentido. Este es unos de los inconvenientes del análisis de texturas, que debe ser minimizado para obtener mejores resultados.

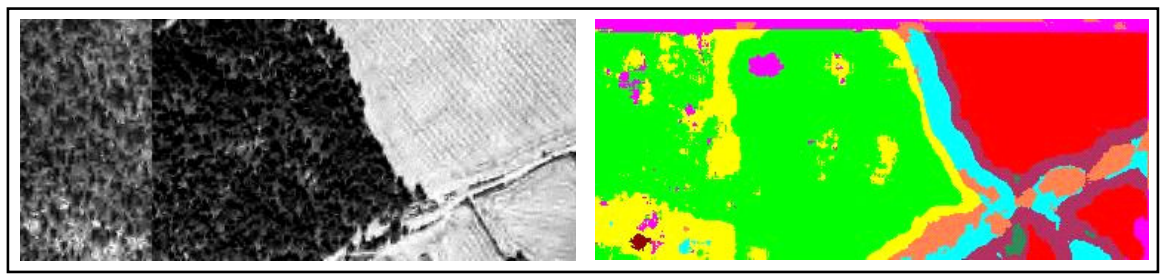

Figura 7-6. Efecto de bordes en un fragmento de la imagen de Ayora clasificada.

\subsection{Análisis de parámetros metodológicos}

\subsubsection{Determinación de la resolución espacial óptima}

El objetivo de este ensayo es comprobar o evaluar la fiabilidad del método de selección de la resolución óptima en texturas basado en el cálculo de la varianza local (Cao y Lam, 1997) para su empleo en los problemas de clasificación por texturas. Se ha implementado este método mediante un programa en IDL que calcular la media de la imagen de varianza obtenida en cada resolución y cada vecindario. A continuación se detallan los resultados de los ensayos realizados sobre diferentes imágenes o subimágenes de ellas (parte de ellos publicados en Fdez.-Sarría et al., 2005).

a) Cada imagen presenta una determinada variabilidad en las tipologías de las superficies que se refleja en desiguales comportamientos en los análisis texturales. Por ello se ha pensado realizar un primer ensayo sobre mosaicos homogéneos de cada una de las clases de la imagen QuickBird de Valencia con una resolución de $0.6 \mathrm{~m}$ y un vecindario de cálculo de la varianza de $3 \times 3$, que es el tamaño inicialmente planteado por Cao y Lam, 1997. Los resultados se muestran en la tabla 7-5. 


\begin{tabular}{|c|c|c|c|c|c|c|}
\cline { 2 - 7 } \multicolumn{1}{c|}{} & \multicolumn{7}{c|}{ CLASES } \\
\hline Resolución & Huerta & P. Indust. & Cítricos & N antiguo & Ensanche & Urbanizac \\
\hline $\mathbf{0 . 6} \mathbf{~ m}$ & 749 & 3320 & 1971 & 5219 & 4694 & 2327 \\
\hline $\mathbf{1 ~ m}$ & 1113 & 5307 & 2958 & 8195 & 7427 & 3753 \\
\hline $\mathbf{2} \mathbf{~ m}$ & 1719 & 8912 & 3308 & 13271 & 12317 & 6356 \\
\hline $\mathbf{3 ~ m}$ & 1968 & 10720 & 2584 & 15605 & 14778 & 7621 \\
\hline $\mathbf{4} \mathbf{~ m}$ & 2003 & 11427 & 1892 & 16175 & 15623 & 7898 \\
\hline $\mathbf{5} \mathbf{~ m}$ & 2032 & 11880 & 1581 & 16401 & 16292 & 8006 \\
\hline $\mathbf{6} \mathbf{~ m}$ & 2042 & 12060 & 1475 & 16472 & 16885 & 7918 \\
\hline $\mathbf{7} \mathbf{~ m}$ & 2020 & 12028 & 1419 & 15998 & 17056 & 7742 \\
\hline $\mathbf{8} \mathbf{~ m}$ & 2013 & 11915 & 1358 & 15405 & 17306 & 7504 \\
\hline $\mathbf{9} \mathbf{~ m}$ & 1999 & 11879 & 1334 & 14908 & 17395 & 7154 \\
\hline $\mathbf{1 0} \mathbf{~ m}$ & 1943 & 11713 & 1286 & 14100 & 17238 & 6796 \\
\hline $\mathbf{1 5} \mathbf{~ m}$ & 1787 & 10616 & 1170 & 10819 & 15502 & 5346 \\
\hline
\end{tabular}

Tabla 7-5. Varianza para cada mosaico de cada clase a diferentes resoluciones.

Se puede apreciar en la tabla anterior que no existe una homogeneidad plena en cuanto a la resolución que maximiza la varianza para cada clase, ya que la propia naturaleza de cada una de ellas condiciona la dimensión espacial del área a analizar. Dado que se ha empleado un vecindario de $3 \times 3$ píxeles, es lógico que para estudiar áreas de ensanche sea necesario un píxel de 9 metros (un vecindario equivalente de 27 metros); o que para huertas, polígonos industriales, núcleos antiguos y urbanizaciones el píxel tenga que ser de 6 metros (vecindario efectivo de 18 metros); o que para cultivos de cítricos, con un píxel de 2 metros (vecindario de 6 metros) sea suficiente ya que las dimensiones de los árboles citrícolas y su marco de plantación altamente espeso así lo permiten.

El interés de esta prueba ha sido analizar clases por separado. Pero en realidad, se han de analizar imágenes completas ya que esa es la forma de operar en las clasificaciones. Por ello los siguientes análisis se han realizado sobre imágenes naturales, con toda la heterogeneidad que se puedan presentar tanto entre las diferentes clases como dentro de ellas mismas.

b) En este segundo ensayo se ha trabajado sobre la zona urbana y peri-urbana de Valencia, en concreto con la imagen QuickBird de Valencia a $0.6 \mathrm{~m}$ de resolución nominal. Dado que analizar un solo tamaño de vecindario es un poco restrictivo, se han introducido más vecindarios de cálculo para determinar si existen o no tendencias marcadas. Los resultados son los que refleja la figura 7-7, donde se han considerado resoluciones de $0.6,1,2,3,4,5,6,7,8,9,10$ y 15 metros y vecindarios de $3 \times 3,5 \times 5$, $7 \times 7,9 \times 9,11 \times 11,15 \times 15$ y $25 \times 25$ píxeles. 


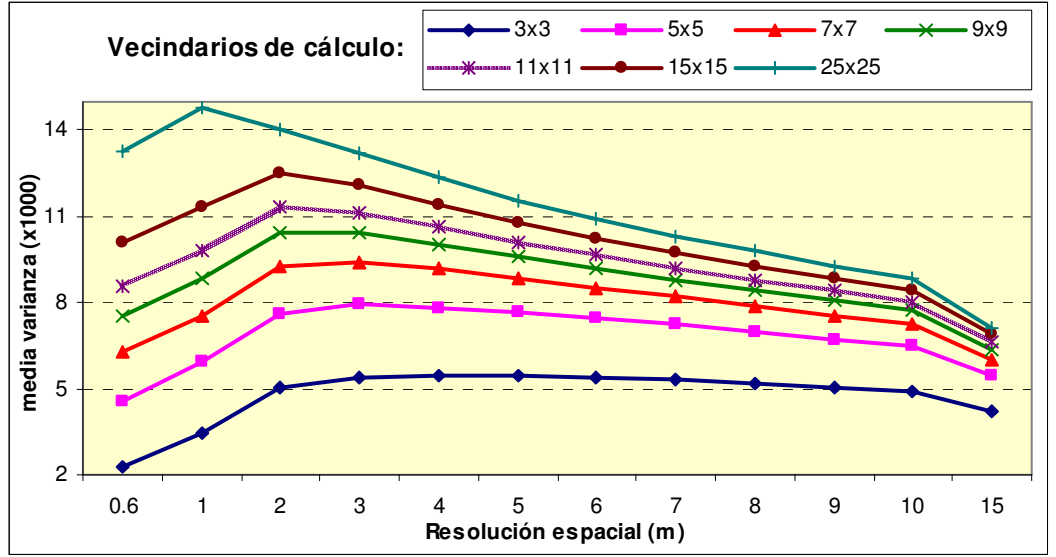

Figura 7-7. Evolución de la media de la varianza para cada resolución y vecindario.

Al analizar la imagen en su conjunto y para un mayor número de vecindarios de cálculo, se observa que se maximiza la varianza en un rango que oscila entre $4 \mathrm{~m}$, para el menor vecindario y $1 \mathrm{~m}$ para el mayor, pudiendo optar por una resolución media de 2 m como la más representativa.

c) El comportamiento de las áreas agrícolas puede presentar diferencias y por ello se trabaja con la imagen mosaico de fotogramas de Daimiel, a una resolución inicial de 0.6 m. La tabla 7-6 muestra la media de las varianzas a diferentes resoluciones de la imagen y en distintos vecindarios.

\begin{tabular}{|c|c|c|c|c|c|c|c|}
\cline { 2 - 8 } \multicolumn{1}{c|}{} & \multicolumn{7}{c|}{ VECINDARIOS } \\
\hline Resolución & $\mathbf{3 x 3}$ & $\mathbf{5 x 5}$ & $\mathbf{7 x 7}$ & $\mathbf{9 x 9}$ & $\mathbf{1 1 x 1 1}$ & $\mathbf{1 5 x 1 5}$ & $\mathbf{2 5 \times 2 5}$ \\
\hline $\mathbf{0 . 6} \mathbf{~ m}$ & 135 & 303 & 474 & 631 & 769 & 986 & 1289 \\
\hline $\mathbf{1} \mathbf{~ m}$ & 250 & 522 & 749 & 923 & 1052 & 1125 & 1454 \\
\hline $\mathbf{2} \mathbf{~ m}$ & 532 & 884 & 1082 & 1205 & 1294 & 1424 & 1629 \\
\hline $\mathbf{3} \mathbf{~ m}$ & 693 & 1000 & 1158 & 1267 & 1349 & 1476 & 1684 \\
\hline $\mathbf{4} \mathbf{~ m}$ & 727 & 988 & 1135 & 1240 & 1324 & 1455 & 1656 \\
\hline $\mathbf{5} \mathbf{~ m}$ & 721 & 960 & 1104 & 1211 & 1298 & 1431 & 1616 \\
\hline $\mathbf{6} \mathbf{~ m}$ & 699 & 929 & 1075 & 1185 & 1274 & 1407 & 1565 \\
\hline $\mathbf{7} \mathbf{~ m}$ & 647 & 872 & 1020 & 1133 & 1223 & 1351 & 1475 \\
\hline $\mathbf{8} \mathbf{~ m}$ & 628 & 855 & 1009 & 1125 & 1215 & 1338 & 1424 \\
\hline $\mathbf{9} \mathbf{~ m}$ & 589 & 816 & 971 & 1087 & 1175 & 1289 & 1334 \\
\hline $\mathbf{1 0} \mathbf{~ m}$ & 582 & 815 & 975 & 1092 & 1178 & 1281 & 1290 \\
\hline $\mathbf{1 5} \mathbf{~ m}$ & 540 & 793 & 954 & 1058 & 1117 & 1143 & 1013 \\
\hline
\end{tabular}

Tabla 7-6. Entorno agrícola de Daimiel considerando diferentes vecindarios de cálculo.

Se puede afirmar que para la totalidad del mosaico del área agrícola de Daimiel existe una homogeneidad evidente en cuanto a la mejor resolución a emplear, centrada en 3 metros por píxel, es decir, con esa resolución espacial, esta imagen tiene la suficiente 
variabilidad espacial como para poder extraer toda su información prácticamente con todos los vecindarios considerados. Los patrones espaciales de esta imagen, la mayoría de pequeñas dimensiones, así lo corroboran.

d) Para las zonas montañosas con vegetación natural se ha analizado la imagen de la Sierra de Espadán a una resolución inicial de $2 \mathrm{~m}$. Las medias de las varianzas se detallan en la tabla 7-7.

\begin{tabular}{|c|c|c|c|c|c|c|c|}
\cline { 2 - 8 } \multicolumn{1}{c|}{} & \multicolumn{7}{c|}{ VECINDARIOS } \\
\hline Resolución & $\mathbf{3 x 3}$ & $\mathbf{5 x 5}$ & $\mathbf{7 x 7}$ & $\mathbf{9 x 9}$ & $\mathbf{1 1 x 1 1}$ & $\mathbf{1 5 x 1 5}$ & $\mathbf{2 5 \times 2 5}$ \\
\hline $\mathbf{1} \mathbf{~ m}$ & 198 & 330 & 436 & 518 & 582 & 671 & 788 \\
\hline $\mathbf{2} \mathbf{~ m}$ & 360 & 542 & 648 & 715 & 761 & 820 & 888 \\
\hline $\mathbf{3} \mathbf{~ m}$ & 326 & 481 & 563 & 614 & 649 & 693 & 741 \\
\hline $\mathbf{4} \mathbf{~ m}$ & 391 & 532 & 602 & 644 & 672 & 707 & 735 \\
\hline $\mathbf{5} \mathbf{~ m}$ & 348 & 469 & 530 & 567 & 592 & 621 & 639 \\
\hline $\mathbf{6} \mathbf{~ m}$ & 362 & 473 & 529 & 562 & 583 & 605 & 612 \\
\hline $\mathbf{7} \mathbf{~ m}$ & 334 & 432 & 482 & 511 & 529 & 547 & 546 \\
\hline $\mathbf{8} \mathbf{~ m}$ & 327 & 422 & 470 & 497 & 513 & 527 & 518 \\
\hline $\mathbf{9} \mathbf{~ m}$ & 301 & 390 & 434 & 459 & 474 & 485 & 470 \\
\hline $\mathbf{1 0} \mathbf{~ m}$ & 293 & 378 & 419 & 442 & 454 & 462 & 438 \\
\hline $\mathbf{1 5} \mathbf{~ m}$ & 243 & 312 & 343 & 356 & 361 & 356 & 295 \\
\hline
\end{tabular}

Tabla 7-7. Entorno de montaña con vegetación natural de Espadán.

Se aprecia cómo para esta imagen los resultados son muy homogéneos en la resolución que nominalmente presenta. Esta imagen forestal de cubierta naturales de matorrales, arbustos o árboles permite su análisis con un píxel de $2 \mathrm{~m}$ y vecindarios mayores de $5 \times 5$ (10 metros efectivos). Los remuestreos no se considerarían necesarios salvo para permitir ver como se produce un segundo máximo para 4 metros, si bien es poco marcado.

e) Desde el punto de vista del tamaño de las diferentes texturas de una imagen, los vecindarios pequeños, como $3 \times 3,5 \times 5$ o $7 \times 7$ incluso, pueden ser insuficientes para captar la información de esa textura, ya que a veces la variabilidad de patrones es alta al combinar cubiertas forestales, otras de cultivos y otras antropizadas. Por tanto en los dos siguientes ensayos se han restringido las varianzas de cálculo a las mayores y dado que los resultados de las tablas anteriores indican un fuerte decaimiento de la varianza a resoluciones mayores a 4 metros, no se han considerado éstas. Se han ampliado con dos resoluciones no enteras $(1.7 \mathrm{~m}, 2.4 \mathrm{~m}$ ) dado que se trabaja sobre imágenes QuickBird, de las que se dispone de información multiespectral a $2.4 \mathrm{~m}$ por píxel y podría interesar combinar todos los datos disponibles.

En el primer ensayo con estas premisas se ha tomado la imagen QuickBird de Menorca a $0.6 \mathrm{~m}$ de partida. Para el segundo, a partir de la imagen QuickBird 
pancromática a $0.6 \mathrm{~m}$ se ha construido un mosaico con porciones de ella, para reducir su tamaño sin perder representatividad de las diversas cubiertas presentes en la imagen ( 6 clases). Los resultados del cálculo de la varianza local quedan reflejados en la tabla 7-8.

\begin{tabular}{|c|c|c|c|c|c|c|}
\hline & \multirow[b]{2}{*}{ Resolución } & \multicolumn{5}{|c|}{ VECINDARIOS } \\
\hline & & $9 \times 9$ & $11 \times 11$ & $15 \times 15$ & $21 \times 21$ & $25 \times 25$ \\
\hline \multirow{5}{*}{ Menorca } & $1 \mathrm{~m}$ & 5421 & 5995 & 6783 & 7484 & 7788 \\
\hline & $1.7 \mathrm{~m}$ & 6092 & 6525 & 7086 & 7580 & 7805 \\
\hline & $2.4 \mathrm{~m}$ & 6215 & 6557 & 7009 & 7431 & 7631 \\
\hline & $3 \mathbf{~ m}$ & 5981 & 6279 & 6686 & 7080 & 7269 \\
\hline & $4 \mathrm{~m}$ & 5476 & 5738 & 6109 & 6479 & 6658 \\
\hline \multirow{5}{*}{$\begin{array}{l}\text { Mosaico } \\
\text { de } \\
\text { Valencia }\end{array}$} & $1 \mathrm{~m}$ & 11601 & 13056 & 15243 & 17415 & 18414 \\
\hline & $1.7 \mathrm{~m}$ & 13944 & 15267 & 17094 & 18682 & 19335 \\
\hline & $2.4 \mathrm{~m}$ & 14654 & 15782 & 17225 & 18393 & 18863 \\
\hline & $3 \mathbf{m}$ & 14679 & 15641 & 16831 & 17778 & 18152 \\
\hline & $4 \mathrm{~m}$ & 14254 & 15006 & 15921 & 16635 & 16905 \\
\hline
\end{tabular}

Tabla 7-8. Resultados de la varianza local de niveles de intensidad para 2 imágenes a distintas resoluciones espaciales y empleando varios vecindarios.

Para las dos pruebas, parece mostrarse la resolución de $1.7 \mathrm{~m}$ como la más adecuada y sobre todo con los vecindarios mayores, que son los más empleados, como se verá en ensayos posteriores.

El ensayo de la varianza local máxima debe ser entendido como una aproximación a priori a la mejor clasificación, es decir, es un indicativo de cuál puede ser la resolución espacial que maximice los resultados de la clasificación. Por tanto, es necesario establecer algún control o contraste sobre esta rutina y determinar si la premisa anterior se cumple o no. Para dos de las imágenes anteriormente analizadas se ha comprobado esa mejor resolución espacial realizando clasificaciones con varios tamaños de píxeles. Se observa lo siguiente:

Para la imagen QuickBird del área urbana de Valencia y tras los sucesivos remuestreos se ha procedido a clasificar la imagen diferenciando entre 6 y 7 clases. Según el método de la varianza local, la mejor resolución espacial promedio para todos los vecindarios es de $2 \mathrm{~m}$. En la figura 7-8 se puede apreciar como la fiabilidad global de las dos clasificaciones aumenta de forma muy marcada hasta llegar a $2 \mathrm{~m}$, resolución a partir de la cual las fiabilidades dejan de crecer (caso de 6 clases) e incluso llegar a decaer sensiblemente (caso de 7 clases). Esto ratifica la previsión apuntada por la varianza local.

La segunda comprobación se ha realizado en la imagen mosaico de fotogramas aéreos de la zona agrícola de Daimiel. Tal y como se apunta en Fdez.-Sarría et al. (2003), se han clasificado, con un total de 12 clases, las 8 variables de textura de la MCNG 
calculadas con un vecindario de $21 \times 21$ a dos resoluciones, $0.6 \mathrm{~m}$ y $2 \mathrm{~m}$. Se ha completado la clasificación con la resolución obtenida de la mejor varianza local $(3 \mathrm{~m})$. No se han considerado otras resoluciones porque la definición de las clases con píxeles mayores genera una degradación importante en los contornos de los elementos y pérdida de nitidez global de la imagen. Los resultados obtenidos son los que se recogen en la tabla 7-9, donde se muestra que la mejor fiabilidad global se alcanza a la resolución que maximiza la varianza local.

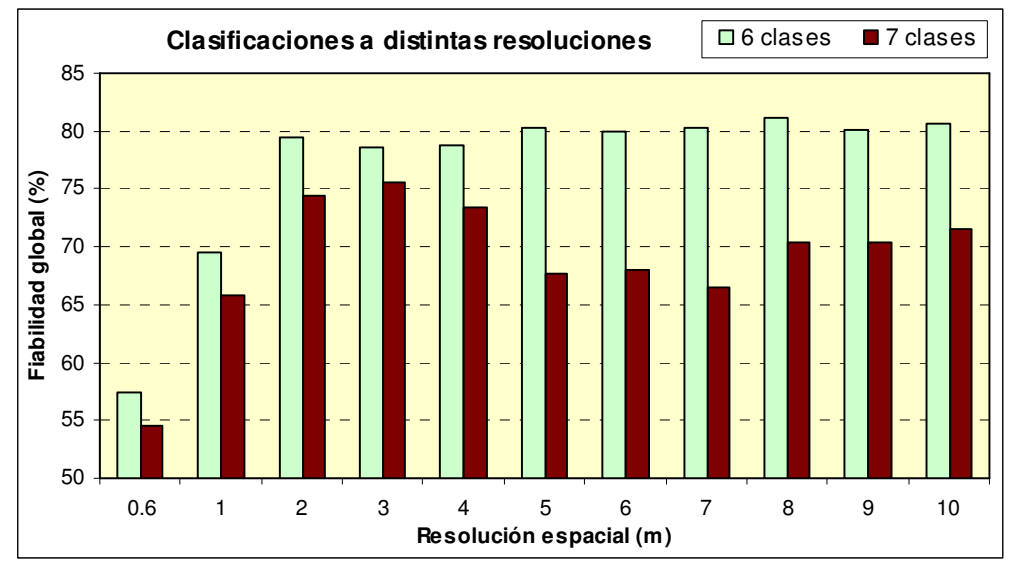

Figura 7-8. Fiabilidad global de diferentes clasificaciones a las resoluciones analizadas.

\begin{tabular}{|c|c|}
\hline Resolución & Fiabilidad global \\
\hline $\mathbf{0 . 6} \mathbf{~ m}$ & $74.36 \%$ \\
\hline $\mathbf{2} \mathbf{~ m}$ & $81.77 \%$ \\
\hline $\mathbf{3} \mathbf{~ m}$ & $82.62 \%$ \\
\hline
\end{tabular}

Tabla 7-9. Resultados de la clasificación de ámbitos agrícolas.

Con estos dos estudios comparativos se demuestra la buena previsión de acierto en las clasificaciones proporcionada por la rutina de cálculo de la varianza local.

\subsubsection{Determinación de la mejor resolución radiométrica}

La resolución radiométrica de una imagen nos indica el rango de niveles de gris que se pueden diferenciar en ella. Dada la heterogeneidad de todas las áreas analizadas, se ha estudiado cómo afecta la variación de la resolución radiométrica en los resultados de la clasificación para todas ellas, dado que esto permite optimizar los recursos de procesado de la información inicial, tal y como se ha explicado en el apartado 6.3.2. Se han calculado las 8 variables de textura propuestas por Haralick y extraídas de las MCNG correspondientes a distintas resoluciones radiométricas y han sido clasificadas. Los 
resultados, mostrados en la tabla 7-10 y la figura 7-9, nos ratifican lo que inicialmente era una intuición: cada imagen alcanza su máximo de acierto en una resolución radiométrica diferente, si bien existen matices dignos de detallar: (1) la imagen de Valencia tiene el máximo a 9 bits pero la diferencia entre 9,8 y 7 bits es inferior a 1\%, por lo cual cualquiera de ellas podría ser empleada. (2) La imagen de Menorca presenta el máximo a 11 bits, si bien la diferencia con 10, 9, 8 e incluso 7 bits es mínima. (3) La imagen mosaico de Ayora tiene su máximo en 10 bits. (4) la imagen mosaico de Espadán es la que apunta a una resolución radiométrica menor (6 bits) muy probablemente justificada por la menor heterogeneidad de una imagen en la que predominan claramente las áreas forestales de arbolado o matorral, frente a otras, como Menorca, en la que existen cubiertas más dispares.

\begin{tabular}{|l|c|c|c|c|}
\cline { 2 - 5 } \multicolumn{1}{c|}{} & M. Valencia & Menorca & M. Ayora & M. Espadán \\
\hline $\mathbf{1 1}$ bits & 70.32 & 77.61 & 74.07 & 60.99 \\
\hline $\mathbf{1 0}$ bits & 78.85 & 77.14 & 78.37 & 67.61 \\
\hline $\mathbf{9}$ bits & 80.71 & 77.39 & 77.99 & 69.21 \\
\hline $\mathbf{8}$ bits & 80.56 & 77.37 & 77.95 & 69.47 \\
\hline $\mathbf{7}$ bits & 80.21 & 77.49 & 77.43 & 69.51 \\
\hline $\mathbf{6}$ bits & 79.68 & 76.65 & 76.55 & 70.18 \\
\hline $\mathbf{5}$ bits & 75.69 & 76.54 & 76.41 & 68.29 \\
\hline
\end{tabular}

Tabla 7-10. Fiabilidad global al clasificar las 8 variables de textura de la MCNG de cada resolución.

Si la tabla 7-10 muestra unos resultados para las variables derivadas de la imagen pancromática original, es de suponer que el mismo comportamiento se repita para las derivadas de las imágenes de detalle a niveles 1,2 y 3 de la transformada wavelet discreta empleando la función Coiflet2 4 y a resoluciones entre 11 y 8 bits. Se puede ver en la tabla 7-11 cómo se repiten los máximos anteriormente reseñados.

Como cierre de estos ensayos, se puede afirmar que las imágenes de mayor variabilidad (mayor número de clases) en sus cubiertas se comportan mejor en resoluciones mayores, como Menorca, Ayora y Valencia, mientras que las más homogéneas (menos clases), como Espadán requieren una radiometría menor.

\begin{tabular}{|l|c|c|c|c|c|c|}
\cline { 2 - 7 } \multicolumn{1}{c|}{} & \multicolumn{3}{c|}{8 vbles. MCNG de TW con Coiflet 24} & \multicolumn{3}{c|}{$\mathbf{8}$ vbles. MCNG de imagen pancrom. } \\
\cline { 2 - 7 } \multicolumn{1}{c|}{} & M. Valencia & Menorca & M. Ayora & M. Valencia & Menorca & M. Ayora \\
\hline $\mathbf{1 1}$ bits & 67.34 & 60.83 & 63.96 & 70.32 & 77.61 & 74.07 \\
\hline $\mathbf{1 0}$ bits & 65.86 & 57.57 & 67.85 & 78.85 & 77.14 & 78.37 \\
\hline 9 bits & 71.72 & 56.34 & 64.12 & 80.71 & 77.39 & 77.99 \\
\hline $\mathbf{8}$ bits & 61.72 & 59.96 & 62.19 & 80.56 & 77.37 & 77.95 \\
\hline
\end{tabular}

Tabla 7-11. Fiabilidades globales en cada imagen y resolución radiométrica. 


\subsubsection{Vecindario óptimo de cálculo de variables de textura}

El cálculo de las variables de textura se realiza considerando el vecindario de un píxel y el resultado se le asigna a él. Por ello son muy importantes las dimensiones de dicho vecindario, ya que un vecindario amplio recibirá mucha influencia de píxeles vecinos que pertenecen a otra clase, mientras que uno pequeño no podrá reflejar todo el patrón de textura del elemento al que pertenece ese píxel. Esto dependerá de la naturaleza de la imagen, es decir, de los tipos de cubiertas presentes en ella, así como de la resolución espacial.

Los ensayos realizados en este sentido han buscado evidenciar cuál es ese mejor vecindario y para ello se han calculado sobre diferentes imágenes (con patrones espaciales sensiblemente diferentes) las 8 variables extraídas de la matriz de co-ocurrencias de niveles de gris propuesta por Haralick (1973), con 5 vecindarios: 9x9, 11x11, 15x15, 21x21 y $25 \times 25$. Tras ello, se han clasificado y se han analizado tanto las fiabilidades globales como las fiabilidades del productor de imágenes de las áreas de trabajo.

Para la primera prueba, en la que no se ha tenido en consideración cuál es la mejor resolución espacial, se ha trabajado con la imagen de Valencia remuestreada a $5 \mathrm{~m}$, de la que se han calculado las 8 variables de la MCNG. La tabla 7-12 muestra las fiabilidades del productor de sus 6 clases y en ella se puede apreciar como la mejor fiabilidad de productor de cada una de ellas (en amarillo) se produce a partir de vecindarios grandes (de $17 \times 17$ en adelante) y se repite más en el vecindario de $25 \times 25$. Se aprecia que las texturas de patrón espacial menor (como cítricos o construcciones de segundas residencias) se clasifican mejor con vecindarios más pequeños (17x17) mientras que otras de patrones mayores, como zonas urbanas o de expansión urbanística en forma de ensanches urbanos de ciudades consolidadas, con grandes manzanas e importantes avenidas, requieren vecindarios mayores $(25 \times 25)$. Similar comportamiento presentan las huertas al ser pequeñas parcelas con variabilidad entre ellas por lo que su textura requiere vecindarios grandes.

\begin{tabular}{|c|c|c|c|c|c|c|}
\cline { 2 - 7 } \multicolumn{1}{c|}{} & N. urbano & Urbanizac. & Ensanche & Industrial & Cítricos & Huerta \\
\hline $\mathbf{1 1 x 1 1}$ & 92.67 & 94.33 & 39.03 & 73.23 & 80.41 & 69.92 \\
\hline $\mathbf{1 7 x 1 7}$ & 95.94 & 95.90 & 55.62 & 89.87 & 79.02 & 75.01 \\
\hline $\mathbf{2 1 \times 2 1}$ & 96.21 & 94.52 & 63.33 & 95.12 & 77.66 & 76.89 \\
\hline $\mathbf{2 5 \times 2 5}$ & 96.39 & 94.28 & 74.70 & 94.77 & 76.87 & 81.64 \\
\hline
\end{tabular}

Tabla 7-12. Fiabilidades del productor de cada clase y con cada vecindario a $5 \mathrm{~m}$ de resolución.

Aparte de analizar los porcentajes de acierto de 6 clases en una imagen se han considerado las fiabilidades globales para otras 4 a diferentes resoluciones y vecindarios propuestos. Se muestran en la tabla 7-13 y figura 7-9, donde se observa que en las 4 
imágenes empleadas existe una tendencia creciente hasta el vecindario de $21 \times 21$, a partir del cual las mejorías son más suaves, obteniendo el máximo en $25 \times 25$. Se considera a éste el vecindario óptimo ya que no es excesivamente grande para las resoluciones estudiadas, pero lo suficiente como para reflejar el comportamiento conjunto de todas las texturas en cada una de las tipologías de superficies sin tener una influencia excesiva de los píxeles vecinos.

\begin{tabular}{|l|c|c|c|c|c|}
\cline { 2 - 6 } \multicolumn{1}{c|}{} & $\mathbf{9 x 9}$ & $\mathbf{1 1 x 1 1}$ & $\mathbf{1 5 x 1 5}$ & $\mathbf{2 1 x 2 1}$ & $\mathbf{2 5 x 2 5}$ \\
\hline Mosaico-Ayora 1 m & 67.56 & 72.09 & 75.90 & 79.50 & 80.60 \\
\hline Mosaico Espadan 1 m & 63.78 & 66.31 & 68.91 & 71.57 & 72.07 \\
\hline Mosaico Valencia 1.7 m & 68.01 & 72.32 & 77.12 & 81.93 & 84.32 \\
\hline Imagen Menorca 1.7 m & 66.22 & 63.31 & 71.17 & 73.64 & 78.05 \\
\hline
\end{tabular}

Tabla 7-13. Fiabilidades globales de las clasificaciones para distintos vecindarios.

Además de emplear las variables de MCNG obtenidas directamente de la imagen pancromática, se ha estudiado si el comportamiento del vecindario es similar para las variables de textura de MCNG derivadas de las imágenes de detalle obtenidas de la descomposición wavelet. Para ello, y sobre la imagen de Valencia remuestreada a $5 \mathrm{~m}$, se ha ejecutado la rutina de descomposición y extracción de los detalles de nivel 1 con la función Coiflet24, mostrando los resultados la tabla 7-14. De nuevo, el vecindario de $25 \times 25$ se perfila como el idóneo para los procesados posteriores.

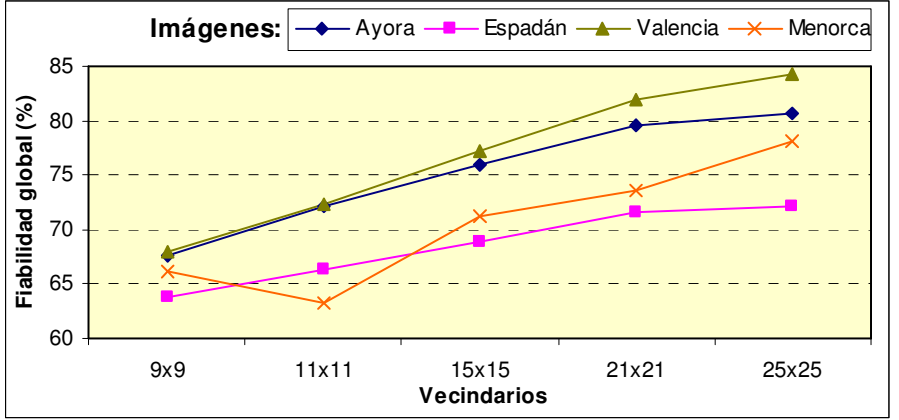

Figura 7-9. Evolución de la fiabilidad global de las clasificaciones con cada vecindario.

\begin{tabular}{|c|c|c|}
\cline { 2 - 3 } \multicolumn{1}{c|}{} & Fiabilidad & Kappa \\
\hline $\mathbf{1 1 \times 1 1}$ & 57.11 & 0.48 \\
\hline $\mathbf{1 7 \times 1 7}$ & 64.93 & 0.57 \\
\hline $\mathbf{2 1 \times 2 1}$ & 67.16 & 0.60 \\
\hline $\mathbf{2 5 \times 2 5}$ & 73.27 & 0.67 \\
\hline
\end{tabular}

Tabla 7-14. Fiabilidad global y parámetro Kappa de las variables extraídas de los detalles de nivel 1. 
Como resultado conjunto de los diversos ensayos de este apartado, y dada la heterogeneidad de los datos de partida, se puede concluir que, en nuestro caso, el mejor vecindario de cálculo de las variables de textura es el de 25×25 píxeles.

\subsubsection{Ensayos sobre el algoritmo empleado para el cálculo de la Transformada Wavelet}

Se han aplicado los algoritmos "à trous", "shift4" y "DWT" detallados en el capítulo VI, "Metodología" sobre tres imágenes a diferentes resoluciones. La implementación se ha realizado mediante filtros y álgebra de imágenes para el algoritmo à trous, mediante programación, diseño propio de los filtros bidimensionales y cálculo de texturas en IDL para el caso de DWT y mediante programación en Matlab y cálculo de variables de textura en IDL para el algoritmo shift4.

De cada imagen se han extraído 21 bandas: la imagen pancromática, 8 variables de la MCNG (vecindario de $25 \times 25$ ) de la imagen original y 4 variables de MCNG $(25 \times 25)$ de cada una de las 3 imágenes de los detalles generados mediante la transformada wavelet. En la tabla 7-15 se muestran los resultados de las clasificaciones para cada imagen y por cada método, empleando las mismas muestras de aprendizaje y evaluación y el mismo clasificador de máxima probabilidad en cada una de ellas. Se detallan las fiabilidades globales de las clasificaciones y el parámetro kappa, el cual evalúa la mejora de la clasificación frente a una asignación aleatoria. La primera fila muestra los resultados correspondientes a la imagen de la zona metropolitana de Valencia con una resolución espacial de $5 \mathrm{~m}$ por píxel, donde se han utilizado los filtros de la función Coiflet de soporte 12 para shift4 y DWT. La segunda fila muestra los resultados para la zona de montaña mixta reseñada como "Ayora". La tercera fila se corresponde a la zona de montaña con vegetación natural denominada "Espadán". En estas dos últimas imágenes se han empleado las funciones wavelet denominadas Meyer3, así como filtros obtenidos a partir de ellas.

\begin{tabular}{|l|c|c|c|c|c|c|}
\cline { 2 - 7 } \multicolumn{1}{c|}{} & \multicolumn{2}{c|}{ DWT } & \multicolumn{2}{c|}{ Algoritmo à trous } & \multicolumn{2}{c|}{ Algoritmo shift4 } \\
\hline \multicolumn{1}{|c|}{ Imagen } & F. Global & Kappa & F. Global & Kappa & F. Global & Kappa \\
\hline Valencia & 86.66 & 0.8492 & 86.10 & 0.8354 & 85.97 & 0.8294 \\
\hline Ayora & 86.36 & 0.8445 & 83.35 & 0.8104 & 84.84 & 0.8270 \\
\hline Espadán & 78.90 & 0.7326 & 77.62 & 0.7151 & 78.32 & 0.7252 \\
\hline
\end{tabular}

Tabla 7-15. Resultados de clasificación para 3 imágenes sobre las que se han aplicado 3 algoritmos.

De los resultados mostrados en la citada tabla se puede observar que la transformada DWT genera mejores fiabilidades globales que las otras dos transformadas, 
si bien la diferencia es pequeña. Los resultados desglosados por clases han mostrado que no todas las clases se comportan de la misma manera en los 3 algoritmos, si bien la mayoría de las clases presentan las mayores fiabilidades de productor en el algoritmo DWT. Todo esto, unido a la mayor facilidad de implementación desde el punto de vista computacional, hace que se haya optado por la transformada wavelet discreta tradicional aplicada mediante bancos de filtros para los ensayos posteriores.

\subsubsection{Niveles y familias empleadas en la Transformada Wavelet}

La descomposición wavelet se puede realizar en sucesivos niveles o escalas. La figura 7-10 es un ejemplo de cómo una imagen es descompuesta hasta el nivel 3 y de cómo la información de cada nivel o escala va cambiando, pasando de ser información que contiene frecuencias espaciales grandes a otras menores en el nivel 3.

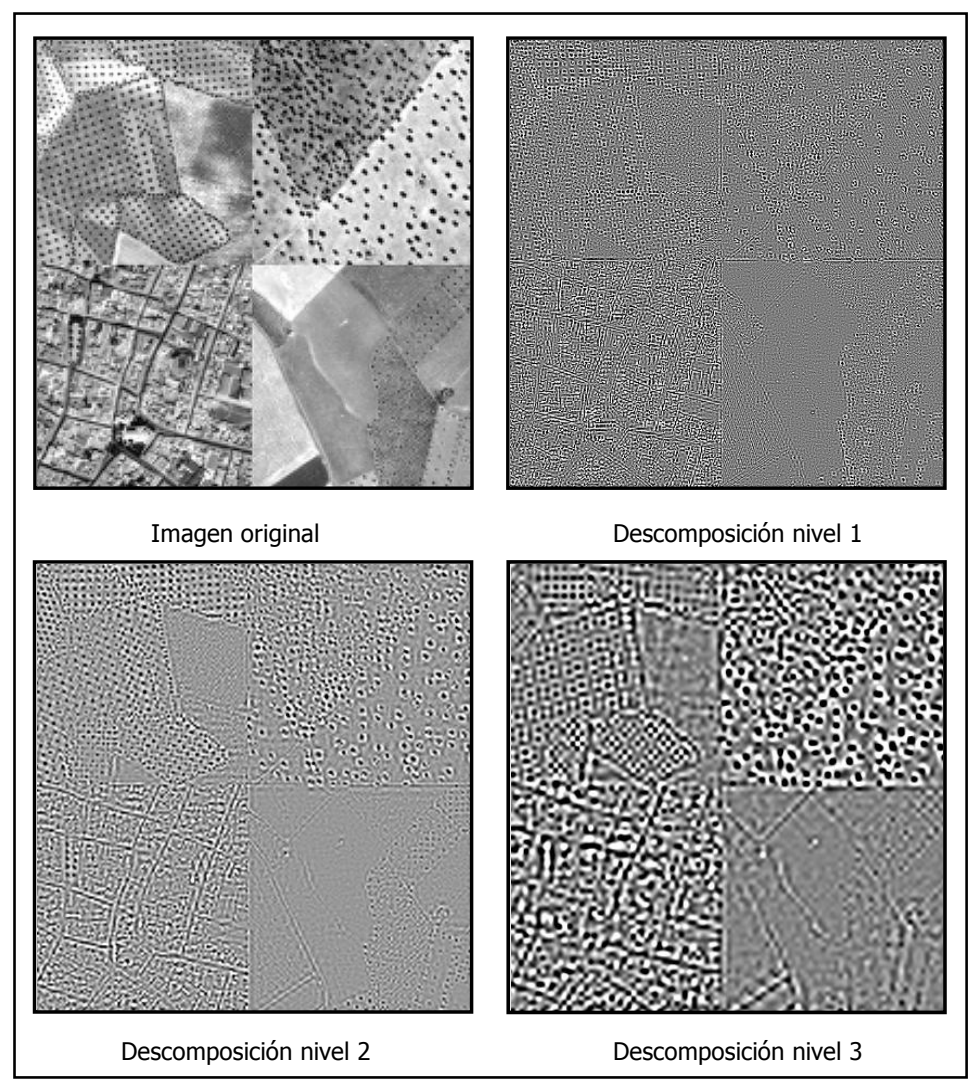

Figura 7-10. Ejemplo de la descomposición wavelet con la función Daubechies 4 hasta nivel 3. 
Entrando de lleno en ensayos específicos sobre la transformada wavelet, se pueden analizar varios parámetros de su aplicación. El nivel de la transformada, es decir, hasta qué escala se debe realizar la descomposición es uno de ellos; el otro consiste en determinar si existe una familia de funciones que genere mejores resultados al destacar de manera especial la información de detalle o de altas frecuencias. Por ello, los resultados mostrados a continuación expresan diferentes grupos de descomposición con funciones base empleadas.

Sobre los 4 entornos de trabajo (mosaico de Ayora a $1 \mathrm{~m}$ y 8 bits, mosaico de Espadán a $1 \mathrm{~m}$ y 8 bits, imagen de Valencia a $5 \mathrm{~m}$ y 11 bits, imagen de Menorca a $1.7 \mathrm{~m}$ y 11 bits) se han calculado las variables de la MCNG con vecindario de $25 \times 25$, se ha aplicado una transformación wavelet discreta hasta nivel 3 a cada imagen original y de cada una de las imágenes de detalles y fluctuaciones en cada nivel se han calculado las mismas variables de la MCNG. Posteriormente se han experimentado diversas agrupaciones de esas variables, de tal manera que se viese la evolución de la fiabilidad global al ir añadiendo variables de textura. Éstas consisten en: la propia imagen pancromática; 6 de las más discriminantes de la MCNG de cada imagen de partida y las mismas 6 variables de la MCNG de cada imagen de detalle y de cada imagen de fluctuaciones. La identificación viene detallada a continuación:

\begin{tabular}{c|l} 
Identificación & Variables \\
\hline 1 & Imagen pancromática inicial \\
2 & Vbles. MCNG de la imagen inicial \\
3 & Vbles. MCNG de los detalles a nivel 1 \\
4 & Vbles. MCNG de los detalles a nivel 2 \\
5 & Vbles. MCNG de los detalles a nivel 3 \\
6 & Vbles. MCNG de las fluctuaciones a nivel 1 \\
7 & Vbles. MCNG de las fluctuaciones a nivel 2 \\
8 & Vbles. MCNG de las fluctuaciones a nivel 3
\end{tabular}

Los resultados se muestran en las tablas 7-16 y 7-17. Se puede apreciar que casi para todas las funciones wavelet y en las cuatro áreas de trabajo, las máximas fiabilidades se logran con la agrupación de las variables extraídas de la imagen inicial y de los detalles de niveles 1,2 y 3 . Además se aprecia que las mayores fiabilidades se consiguen con las funciones wavelet de la familia Coiflet, destacando muy ligeramente la de 24 coeficientes.

En el proceso de descomposición mediante los bancos de filtros se generan imágenes de fluctuaciones que dan origen a las imágenes de detalle. Se ha intentado comprobar si la información textural se puede identificar ya en las fluctuaciones o si por contra se deben reconstruir los detalles. Para ello se determinaron las mismas 4 variables de textura de cada imagen de fluctuaciones y se agruparon junto a las de la imagen 
original sobre dos imágenes, el mosaico de Ayora y el de Espadán (tabla 7-18). Dado que las funciones Coiflet se comportan ligeramente mejor que las Daubechies, se han tomado las primeras solamente. De estos resultados se deduce que las variables de textura extraídas de las imágenes de fluctuaciones no hacen crecer la fiabilidad global, sino todo lo contrario.

\begin{tabular}{|l|r|r|r|r|r|r|r|r|}
\cline { 2 - 9 } \multicolumn{1}{c|}{ Variables } & \multicolumn{4}{c|}{ AYORA } & \multicolumn{4}{c|}{ ESPADAN } \\
\cline { 2 - 9 } & Daub4 & Daub8 & \multicolumn{1}{c|}{ Coif12 } & Coif24 & Daub4 & Daub8 & Coif12 & Coif24 \\
\hline $\mathbf{1 + 2}$ & 59.26 & 59.26 & 59.26 & 59.26 & 66.12 & 66.12 & 66.12 & 66.12 \\
\hline $\mathbf{1 + 2 + 3}$ & 59.63 & 59.31 & 61.07 & 60.29 & 67.11 & 66.56 & 72.02 & 71.28 \\
\hline $\mathbf{1 + 2 + 3 + 4}$ & 59.55 & 60.06 & 60.58 & 59.52 & 68.21 & 66.94 & 70.64 & 70.03 \\
\hline $\mathbf{1 + 2 + 3 + 4 + 5}$ & 60.98 & 61.94 & 62.03 & 62.04 & 67.40 & 66.28 & 71.45 & 71.32 \\
\hline
\end{tabular}

Tabla 7-16. Fiabilidades globales para cada grupo de variables sobre las dos imágenes.

\begin{tabular}{|l|r|r|r|r|r|r|r|r|}
\cline { 2 - 9 } \multicolumn{1}{c|}{ Variables } & \multicolumn{4}{c|}{ VALENCIA } & \multicolumn{4}{c|}{ MENORCA } \\
\cline { 2 - 9 } & Daub4 & Daub8 & Coif12 & Coif24 & Daub4 & Daub8 & Coif12 & Coif24 \\
\hline $\mathbf{1 + 2}$ & 83.97 & 83.97 & 83.97 & 83.97 & 75.53 & 75.53 & 75.53 & 75.53 \\
\hline $\mathbf{1 + 2 + 3}$ & 85.52 & 84.87 & 85.57 & 85.58 & 77.52 & 76.80 & 77.40 & 77.20 \\
\hline $\mathbf{1 + 2 + 3 + 4}$ & 85.34 & 86.11 & 85.98 & 86.90 & 76.90 & 77.05 & 77.19 & 78.02 \\
\hline $\mathbf{1 + 2 + 3 + 4 + 5}$ & 86.27 & 87.42 & 86.66 & 86.94 & 76.87 & 77.92 & 77.87 & 79.18 \\
\hline
\end{tabular}

Tabla 7-17. Fiabilidades globales para cada grupo de variables sobre las dos imágenes.

\begin{tabular}{|l|c|c|c|c|}
\cline { 2 - 5 } \multicolumn{1}{c|}{} & \multicolumn{2}{c|}{ AYORA } & \multicolumn{2}{c|}{ ESPADAN } \\
\cline { 2 - 5 } \multicolumn{1}{c|}{ Variables } & Coif12 & Coif24 & Coif12 & Coif24 \\
\hline $\mathbf{2 + 3 + 4 + 5}$ (detalles) & 60.10 & 60.46 & 65.55 & 62.63 \\
\hline $\mathbf{2 + 6 + 7 + 8}$ (fluctuaciones) & 55.06 & 55.36 & 63.10 & 63.36 \\
\hline
\end{tabular}

Tabla 7-18. Fiabilidades globales para cada grupo de variables sobre las dos imágenes.

Los valores obtenidos en las tablas anteriores se centran sobre la fiabilidad global de las clasificaciones sin entrar en desgloses por clases y sus fiabilidades de productor y usuario. Dado que puede ser interesante comprobar qué ocurre en cada clase de manera individual con algunas funciones wavelet, se detallan en la tabla 7-19 los resultados desglosados en las 6 clases de la imagen QuickBird de Valencia, para todas las variables anteriormente reseñadas (sin las fluctuaciones) y con 4 de las funciones que han demostrado tener un buen comportamiento. Se pueden apreciar los porcentajes de aciertos en cada una de ellas, así como los errores cometidos, tanto por exceso como por defecto. Se observa que no hay una función que sea mejor para todas las clases y que dentro de cada una, las diferencias entre las 4 funciones wavelet son muy pequeñas.

Ampliando el abanico de ensayos a otras funciones wavelet y a otras áreas, en concreto a la imagen de entornos agrícolas de Daimiel, remuestreada a $2 \mathrm{~m}$ por píxel, se 
han obtenido una serie de variables de textura para varias funciones. De cada imagen, tanto la pancromática original como cada una de los detalles de niveles 1,2 y 3, se han calculado 4 variables (varianza, contraste, momento de diferencia inverso y correlación) de su MCNG correspondiente, 1 factor de bordes (edgeness) y 1 energía (como filtro de Laws). En total, 24 variables, de cuya clasificación y en forma de fiabilidad global se han obtenido los resultados de la tabla 7-20. En ella se aprecia que si bien las diferencias de fiabilidad, tanto en las áreas interiores como en las fronteras, son muy pequeñas, parece apuntarse que las funciones de mayor soporte se comportan mejor que las de menor y que las funciones Coiflet permiten obtener resultados ligeramente mejores.

\begin{tabular}{|l|c|c|c|c|c|c|c|c|}
\cline { 2 - 9 } \multicolumn{1}{c|}{} & \multicolumn{2}{c|}{ Daub4 } & \multicolumn{2}{c|}{ Daub8 } & \multicolumn{2}{c|}{ Coif12 } & \multicolumn{2}{c|}{ Coif24 } \\
\cline { 2 - 9 } \multicolumn{1}{c|}{ Clases } & F. P. & F. U. & F. P. & F. U. & F. P. & F. U. & F. P. & F. U. \\
\hline Cítricos & 77.19 & 86.78 & 75.84 & 86.59 & 75.84 & 85.14 & 74.30 & 85.75 \\
\hline Ensanche & 85.30 & 89.29 & 88.35 & 90.69 & 84.67 & 91.59 & 87.74 & 91.62 \\
\hline Huerta & 87.63 & 84.18 & 87.65 & 80.55 & 86.08 & 82.33 & 87.01 & 80.54 \\
\hline N. Urbano & 86.77 & 94.88 & 88.73 & 94.17 & 91.75 & 90.21 & 90.83 & 94.14 \\
\hline Urbanización & 92.03 & 99.89 & 94.00 & 98.53 & 94.49 & 98.79 & 95.20 & 98.62 \\
\hline P. Industrial & 93.60 & 60.84 & 93.50 & 70.68 & 93.14 & 66.73 & 92.12 & 68.30 \\
\hline
\end{tabular}

Tabla 7-19. Fiabilidades del productor y usuario por clases y funciones wavelet. En amarillo y magenta las mejores fiabilidades de productor y usuario respectivamente para cada clase.

\begin{tabular}{|l|c|c|c|c|c|c|}
\cline { 2 - 7 } \multicolumn{1}{c|}{} & Haar & Daub-4 & Daub-8 & Coif-6 & Coif-12 & Coif-24 \\
\hline Interior & 81.9 & 84.5 & 85.4 & 83.8 & 86.0 & 87.2 \\
\hline Fronteras & 40.8 & 42.5 & 39.3 & 41.6 & 42.7 & 43.0 \\
\hline
\end{tabular}

Tabla 7-20. Fiabilidades globales sobre el mosaico agrícola para varias funciones wavelet.

\subsection{Verificación global de las variables y parámetros óptimos obtenidos}

A lo largo de todos los ensayos detallados en apartados anteriores se ha pretendido evidenciar la existencia de algunas variables de textura y parámetros de las imágenes y los propios de la transformada wavelet predominantes respecto a otros a la hora de clasificar por texturas una serie de imágenes. Para ello se han generado unas rutinas de trabajo que, aplicadas sobre variedad de cubiertas naturales, han proporcionado unos resultados que han permitido generar conclusiones más o menos evidentes. Pero en 
algunos de estos ensayos previos, a veces no han sido considerados los resultados de otros ensayos por lo que no se tiene en este punto un conocimiento real de la influencia de unos sobre otros, por ejemplo de la influencia de las variables de textura más discriminantes sobre el comportamiento de las funciones wavelet. Tampoco se han realizado las pruebas sobre las mismas imágenes ya que se ha trabajado con diferentes resoluciones espaciales y radiométricas. Por todo lo anterior, y de cara a dar un aspecto de homogeneidad y globalidad a los resultados y conclusiones finales, en este apartado se pretende determinar qué grupo de variables de textura tiene un mejor comportamiento al ser calculadas sobre imágenes optimizadas en su resolución espacial y radiométrica, con el mejor vecindario de cálculo, etc.; y por otro lado, verificar de qué manera influye la selección óptima de variables texturales y parámetros metodológicos sobre las diferentes familias de funciones wavelet detalladas en la metodología (figura 7-11). Todo ello se ha realizado sobre las 4 imágenes que nos definen las 4 tipologías de cubiertas superficiales. La valoración de los resultados se ha llevado a cabo mediante las matrices de confusión de las clasificaciones generadas.

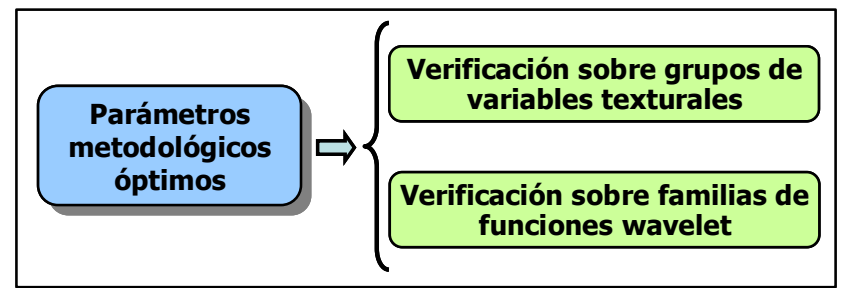

Figura 7-11. Esquema del procesado global tras la definición de parámetros y variables.

\subsubsection{Datos de partida para las pruebas}

Las imágenes empleadas en esta fase final del trabajo son las 4 siguientes, cuyas resoluciones espacial y radiométrica se han elegido a partir de los resultados de los ensayos previos y cuyas clases pueden ser observadas en el capítulo V "Datos de trabajo":

- Para áreas urbanas y peri-urbanas con presencia de cultivos hortícolas: imagen mosaico de Valencia a 1.7 m y 9 bits por píxel.

- Para zonas rurales mediterráneas, con cubiertas heterogéneas de vegetación forestal, cultivos e influencia humana: imagen de Menorca a $1.7 \mathrm{~m}$ y 11 bits por píxel.

- Para entornos forestales con vegetación natural: imagen mosaico de Espadán a 1 $\mathrm{m}$ y 6 bits por píxel.

- Para zonas de montaña mixtas de áreas agrícolas y forestales: imagen mosaico de Ayora a $1 \mathrm{~m}$ y 10 bits por píxel. 


\subsubsection{Verificación de los grupos de variables texturales}

Al igual que el ensayo realizado en el apartado 7.2 sobre grupos de variables de textura que pueden generarse a partir de una imagen pancromática y teniendo en consideración los mejores parámetros metodológicos deducidos a lo largo del presente capítulo, se ha reconstruido el mismo ensayo con la finalidad de determinar si dichos parámetros son realmente influyentes y qué grupo de variables permite una mejor clasificación sobre las imágenes reseñadas anteriormente. Se han reconstruido los bloques de variables quedando de la siguiente manera:

- Variables de textura (MCNG): Rango de datos, 6 variables de la MCNG (media, varianza, homogeneidad, contraste, momento de diferencia inverso y correlación), energía del histograma y kurtosis.

- Variables wavelet (WV): para cada imagen de detalles (niveles 1,2 y 3 ) de la transformada con la función Coiflet 24, se ha obtenido el rango de datos, 5 variables de la MCNG (media, homogeneidad, contraste, momento de diferencia inverso y correlación), energía del histograma y kurtosis.

- Variables de energía: 7 filtros de energía (media ponderada, gradiente, forma, ondulación, rugosidad, oscilación, y laplaciano del gaussiano) y el factor densidad de bordes (edgeness) obtenido con distancia de 3 píxeles.

- Variables de Gabor: 18 bandas resultantes de 6 direcciones de cálculo $\left(0^{\circ}\right.$, $30^{\circ}, 60^{\circ}, 90^{\circ}, 120^{\circ}$ y $\left.150^{\circ}\right), 3$ frecuencias $(0.3536,0.1768$ y 0.0884$)$ y 3 desviaciones típicas (1.9099, 3.81970 y 7.62940$)$.

Las fiabilidades globales de las clasificaciones expresadas como aciertos en la asignación en las áreas internas de los objetos (interior) o en su exterior (frontera) están reflejadas en la tabla 7-21.

\begin{tabular}{|l|c|c|c|c|c|c|c|c|}
\cline { 2 - 9 } \multicolumn{1}{c|}{} & \multicolumn{2}{c|}{ AYORA } & \multicolumn{2}{c|}{ ESPADÁN } & \multicolumn{2}{c|}{ MENORCA } & \multicolumn{2}{c|}{ VALENCIA } \\
\cline { 2 - 9 } \multicolumn{1}{c|}{} & Interior & Frontera & Interior & Frontera & Interior & Frontera & Interior & Frontera \\
\hline MCNG & 83.52 & 35.35 & 75.49 & 44.57 & 80.62 & 30.67 & 82.72 & 49.99 \\
\hline WAVELET (WV) & 72.67 & 32.64 & 58.63 & 39.85 & 64.47 & 38.50 & 73.07 & 46.07 \\
\hline GABOR & 63.21 & 31.04 & 61.76 & 40.78 & 63.70 & 23.86 & 72.75 & 41.21 \\
\hline ENERGÍA & 52.99 & 40.62 & 62.65 & 53.88 & 61.02 & 50.09 & 55.76 & 43.24 \\
\hline MCNG+WV & 91.20 & 37.25 & 82.54 & 49.55 & 82.51 & 37.12 & 86.07 & 55.32 \\
\hline MCNG+GABOR & 87.16 & 34.78 & 81.63 & 46.91 & 81.51 & 23.28 & 89.17 & 53.23 \\
\hline MCNG+ENERGÍA & 84.71 & 36.09 & 76.09 & 45.48 & 81.02 & 30.78 & 83.36 & 51.13 \\
\hline $\begin{array}{l}\text { MCNG+WV+GABOR } \\
\text { +ENERGÍA }\end{array}$ & 91.09 & 36.41 & 81.87 & 48.95 & 82.10 & 28.68 & 88.67 & 55.93 \\
\hline
\end{tabular}

Tabla 7-21. Fiabilidades globales para cada grupo de variables. 
Como se aprecia en los resultados anteriores, se pueden obtener algunas conclusiones importantes sobre los grupos de variables a la hora de discriminar las texturas presentes en las imágenes:

$1^{\text {a- }}$ De forma individual, el mejor grupo de variables es el de MCNG, seguido por las de wavelet, Gabor y energía, tal y como ya se apuntaba en el apartado 7.2.2.

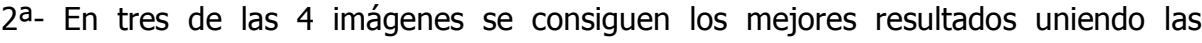
variables de la MCNG y las de wavelet, mientras que en la $4^{a}$ imagen (Valencia) dicha combinación es bastante próxima al máximo.

$3^{a}$ - La agrupación de todas las variables se aproxima bastante al máximo, pero es ligeramente inferior. Esta es una pequeña diferencia respecto a los resultados de la tabla 7-4 del apartado 7.2.2, donde se apreciaba que la unión de todas las variables proporcionaba las mejores fiabilidades. Ahora se ha comprobado que si se eligen correctamente las resoluciones, los parámetros de cálculo y las variables estadísticas, se puede reducir el número de características texturales para obtener un resultado sensiblemente mejor.

4a- En lo que respecta a la asignación temática en los bordes de los objetos, las variables de energía, de nuevo, son las que tienen una mayor capacidad de discriminar las clases de pertenencia de los píxeles en casi todos los casos.

\subsubsection{Verificación de todas las familias de funciones wavelet}

En los ensayos de apartados anteriores se ha experimentado con algunas familias de funciones wavelet que suelen ser las más empleadas y las de mejor comportamiento, sobre varias imágenes a diferentes resoluciones, pero existen muchas más. En este punto del trabajo se ha ampliado el grupo de funciones a otras menos comunes pero que pueden tener un buen comportamiento por sus características matemáticas. Ello se ha realizado teniendo en consideración los resultados de los ensayos previos en cuanto a nivel óptimo de transformación, información más útil extraíble de ella, variables texturales más discriminantes y mejores resoluciones en las imágenes y vecindarios de cálculo. De esta forma, y trabajando con las imágenes referidas previamente, se han analizado 11 familias de funciones wavelet y dos bloques de variables, las derivadas de la MCNG de la imagen inicial y las de los detalles de la transformada wavelet. Sobre esa información se han realizado las clasificaciones oportunas con un objetivo básico: Determinar cuál es la función wavelet que consigue mejores fiabilidades globales en una clasificación para los dos grupos de variables que la prueba anterior ha mostrado como óptimas. Se han definido las siguientes características de textura: 
- $\quad$ De cada imagen pancromática inicial se han considerado 9 variables:

- Intervalo de datos

- 6 variables de la MCNG (media, varianza, homogeneidad, contraste, momento de diferencia inverso y correlación)

- Energía del histograma

- Kurtosis

- $\quad 24$ variables, 8 de cada imagen de detalles (niveles 1,2 y 3):

- Intervalo de datos

- 5 variables de la MCNG (media, homogeneidad, contraste, momento de diferencia inverso y correlación)

- Energía del histograma

- Kurtosis

Tras clasificar los distintos grupos de características se ha obtenido la tabla 7-22, en la que se aprecian de forma conjunta las fiabilidades globales de todas ellas. En amarillo se resaltan las mejores fiabilidades globales para todas las variables de cada imagen y en magenta para las variables wavelet.

\begin{tabular}{|l|c|c|c|c|c|c|c|c|c|c|c|c|}
\cline { 2 - 14 } \multicolumn{1}{c|}{} & \multicolumn{3}{c|}{ VALENCIA } & \multicolumn{3}{c|}{ MENORCA } & \multicolumn{3}{c|}{ AYORA } & \multicolumn{3}{c|}{ ESPADAN } \\
\hline Wavelet & 9 PAN & 24 WV & TODAS & 9 PAN & 24 WV & TODAS & 9 PAN & 24 WV & TODAS & 9 PAN & 24 WV & TODAS \\
\hline BL-6 & 82.72 & 72.74 & 85.94 & 80.62 & 60.97 & 81.62 & 83.52 & 71.70 & 89.03 & 75.49 & 50.38 & 81.77 \\
\hline SHAN-7 & 82.72 & 75.84 & 85.91 & 80.62 & 66.91 & 79.65 & 83.52 & 76.03 & 87.36 & 75.49 & 75.35 & 81.48 \\
\hline MEY-3 & 82.72 & 72.90 & 85.98 & 80.62 & 63.94 & 81.45 & 83.52 & 74.36 & 88.50 & 75.49 & 75.72 & 81.40 \\
\hline DB-4 & 82.72 & 75.18 & 85.49 & 80.62 & 63.90 & 79.99 & 83.52 & 69.53 & 89.23 & 75.49 & 57.25 & 83.15 \\
\hline DB-8 & 82.72 & 73.83 & 86.00 & 80.62 & 66.90 & 80.91 & 83.52 & 73.09 & 89.64 & 75.49 & 52.49 & 82.25 \\
\hline SYM-8 & 82.72 & 75.31 & 85.98 & 80.62 & 63.99 & 81.09 & 83.52 & 70.78 & 89.26 & 75.49 & 58.44 & 83.01 \\
\hline SYM16 & 82.72 & 74.74 & 85.72 & 80.62 & 65.79 & 83.27 & 83.52 & 73.18 & 90.53 & 75.49 & 58.57 & 82.95 \\
\hline Coif-6 & 82.72 & 68.84 & 83.26 & 80.62 & 60.03 & 80.16 & 83.52 & 60.43 & 85.55 & 75.49 & 52.38 & 82.54 \\
\hline Coif-12 & 82.72 & 74.67 & 85.47 & 80.62 & 63.97 & 80.65 & 83.52 & 70.84 & 90.15 & 75.49 & 57.00 & 83.82 \\
\hline Coif-18 & 82.72 & 73.34 & 85.48 & 80.62 & 65.75 & 81.97 & 83.52 & 68.33 & 87.71 & 75.49 & 57.28 & 84.82 \\
\hline Coif-24 & 82.72 & 73.07 & 86.07 & 80.62 & 64.47 & 82.51 & 83.52 & 72.67 & 91.20 & 75.49 & 58.63 & 82.54 \\
\hline
\end{tabular}

Tabla 7-22. Fiabilidades globales para cada familia wavelet, área de estudio y grupo de variables.

Desglosada la tabla 7-22 por imágenes (figuras 7-12, 7-13, 7-14 y 7-15), se puede apreciar más claramente cómo la unión de las variables derivadas de la transformada wavelet mejora significativamente los resultados obtenidos al emplear tan sólo las derivadas de la imagen pancromática. 


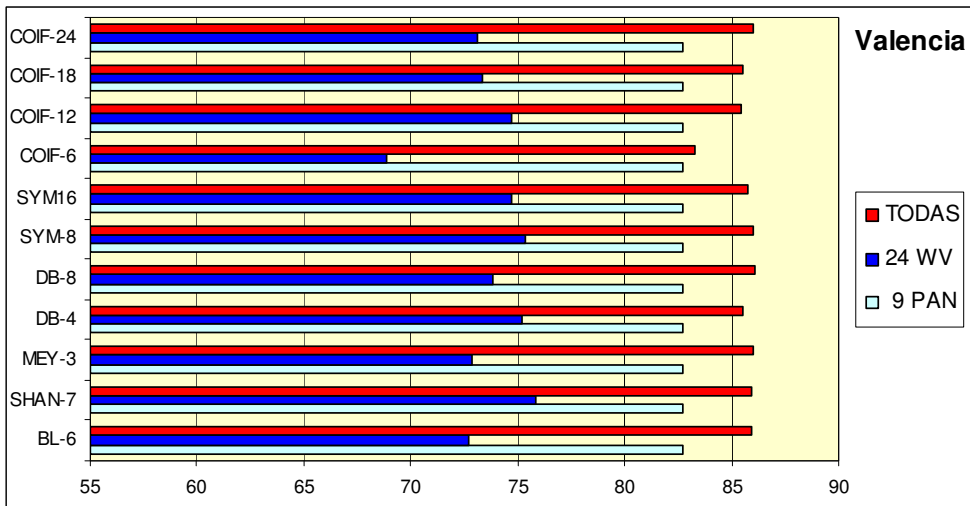

Figura 7-12. Fiabilidades globales sobre la imagen de Valencia.

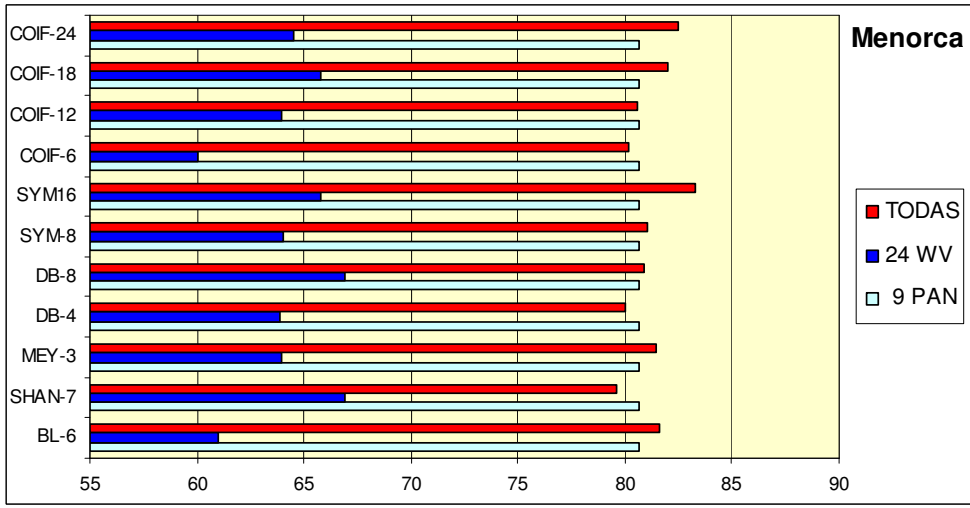

Figura 7-13. Fiabilidades globales sobre la imagen de Menorca.

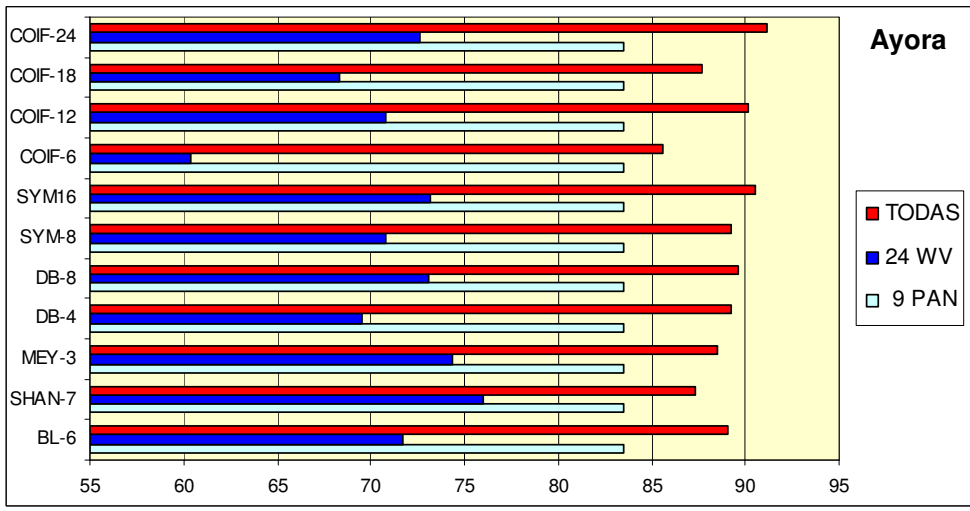

Figura 7-14. Fiabilidades globales sobre la imagen de Ayora. 


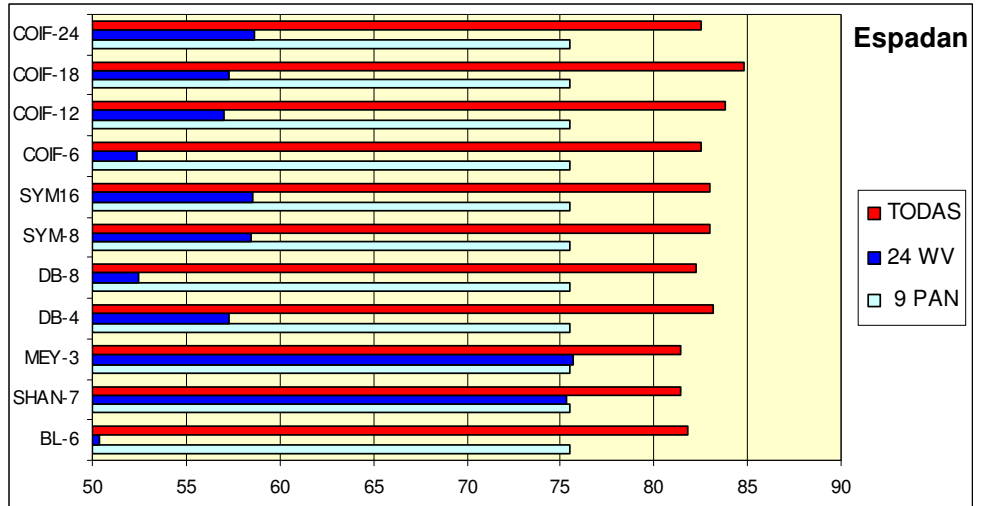

Figura 7-15. Fiabilidades globales sobre la imagen de Espadán.

De las tablas y figuras anteriores se pueden extraer algunas conclusiones, que pueden comprobarse en varios ejemplos sobre las imágenes de Valencia (figura 7-16) y Menorca (figura 7-17) en las que se puede ver el resultado de la clasificación con las variables de MCNG y las de la descomposición wavelet a nivel 3:

$1^{\text {a. }}$ Si bien las variables derivadas de la transformada wavelet, por sí solas se comportan peor que las derivadas de la imagen pancromática inicial, se aprecia que en las 4 áreas de trabajo y con todas las funciones wavelet, excepto en tres casos en el área de Menorca, las clasificaciones conjuntas con los dos grupos de variables (campo TODAS) permite lograr porcentajes de acierto realmente altos, de entre el 80 y el $90 \%$, es decir, las variables de la transformada wavelet complementan a las derivadas directamente de la imagen pancromática para obtener esos altos aciertos. De hecho, la imagen pancromática original podría ser entendida como el nivel 0 de descomposición, conteniendo información de frecuencias diferentes al resto de niveles.

$2^{\mathrm{a}}$ - No parece destacar ninguna función wavelet respecto del resto, ya que las pequeñas diferencias entre todas las fiabilidades no van más allá de 3-4 puntos porcentuales. Pese a ello, parece vislumbrarse la familia de funciones Coiflet y en concreto la de soporte 24 como la mejor al presentar 2 de los 4 máximos de fiabilidad.

$3^{3}$ - También parece apreciarse que para las funciones de una misma familia (Daubechies, Symlet o Coiflet), las fiabilidades tienden a aumentar conforme el soporte de la función, y por tanto el tamaño de los filtros asociados, se hace mayor. 

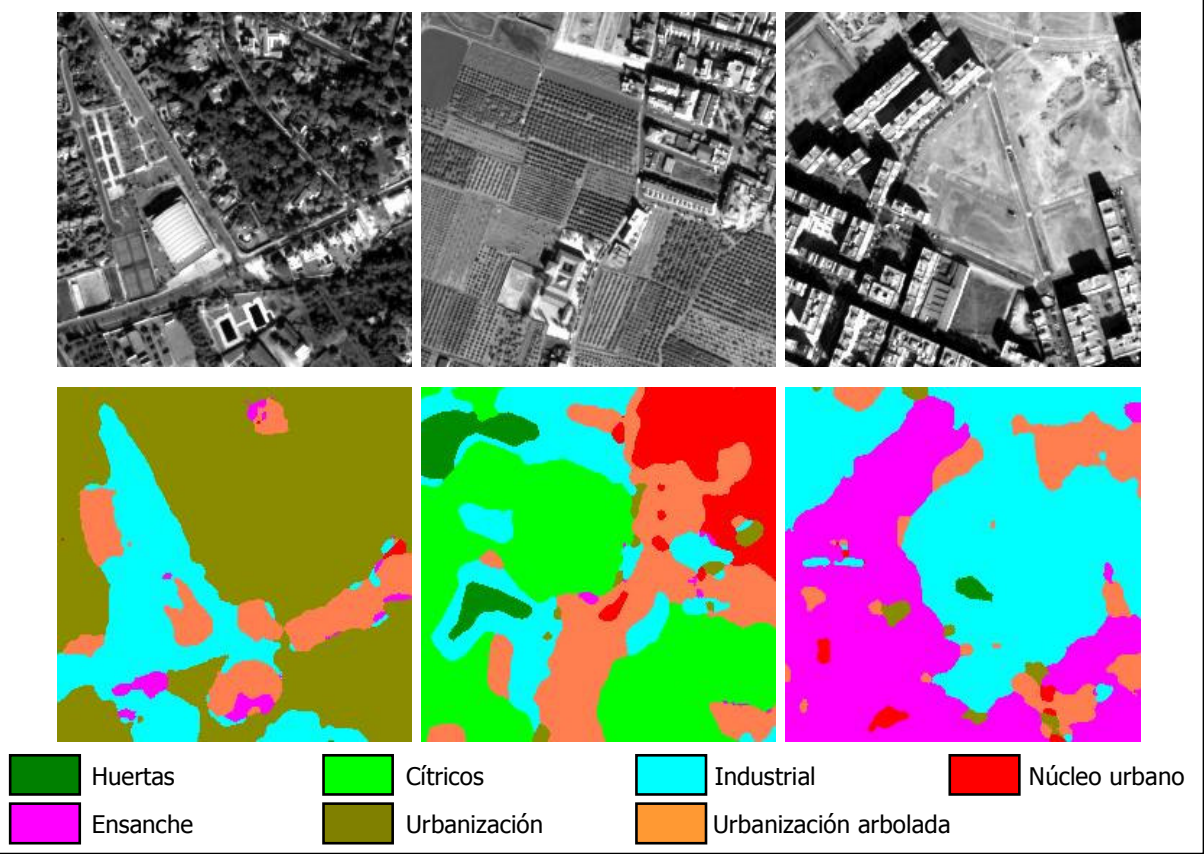

Figura 7-16. Ejemplos de las clasificaciones con todas las variables en Valencia.

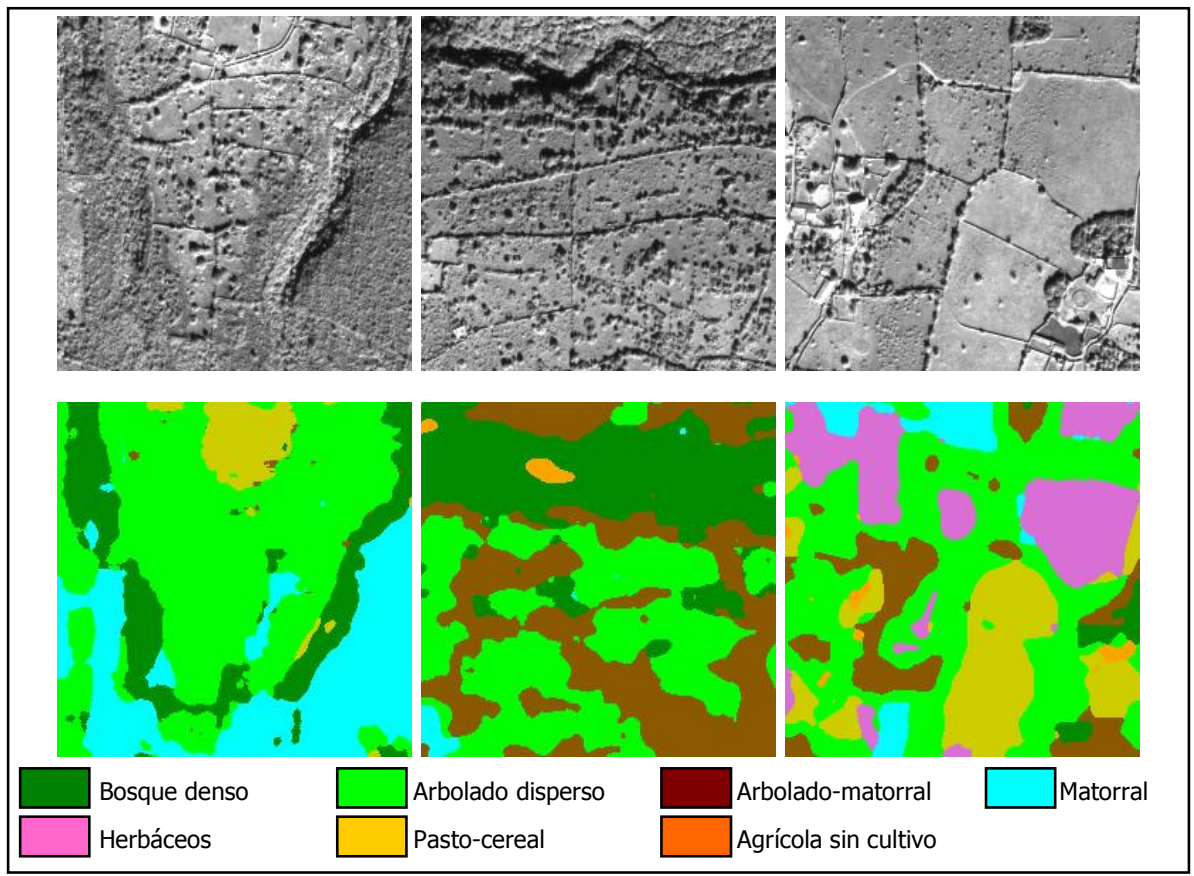

Figura 7-17. Ejemplos de las clasificaciones con todas las variables en Menorca. 


\subsection{Tratamiento post-clasificación de las zonas frontera}

El correcto tratamiento del efecto de bordes o fronteras entre las diversas texturas de las imágenes consideradas ha redundado en un sensible aumento de las fiabilidades de clasificación en dichas zonas. Tal y como se comenta en el capítulo de metodología, se han ensayado 4 diferentes procedimientos de tratamiento de bordes, todos ellos basados en una mejor definición a priori de las áreas fronterizas para sobre ellas determinar variables de textura con vecindarios más pequeños que reduzcan la influencia cruzada entre píxeles contiguos de texturas diferentes. Esos 4 procedimientos se basan en calcular segundas varianzas; en determinar bordes sobre la variable de media; en aplicar el operador de Canny para definir bordes; y en definir los bordes de la clasificación inicial. Tras definir el modelo de bordes se ha aplicado el algoritmo de trabajo de la figura 6-24 para obtener una nueva clasificación y poder ser evaluada y comparada con la inicial. Para ello se han redefinido las muestras de aprendizaje y de evaluación, sin modificar el número y tipo de clases, ajustándolas a las franjas periféricas a las texturas, tal y como se puede apreciar en la figura 7-18, donde las muestras de aprendizaje tienen colores sólidos y las de evaluación presentan una trama.

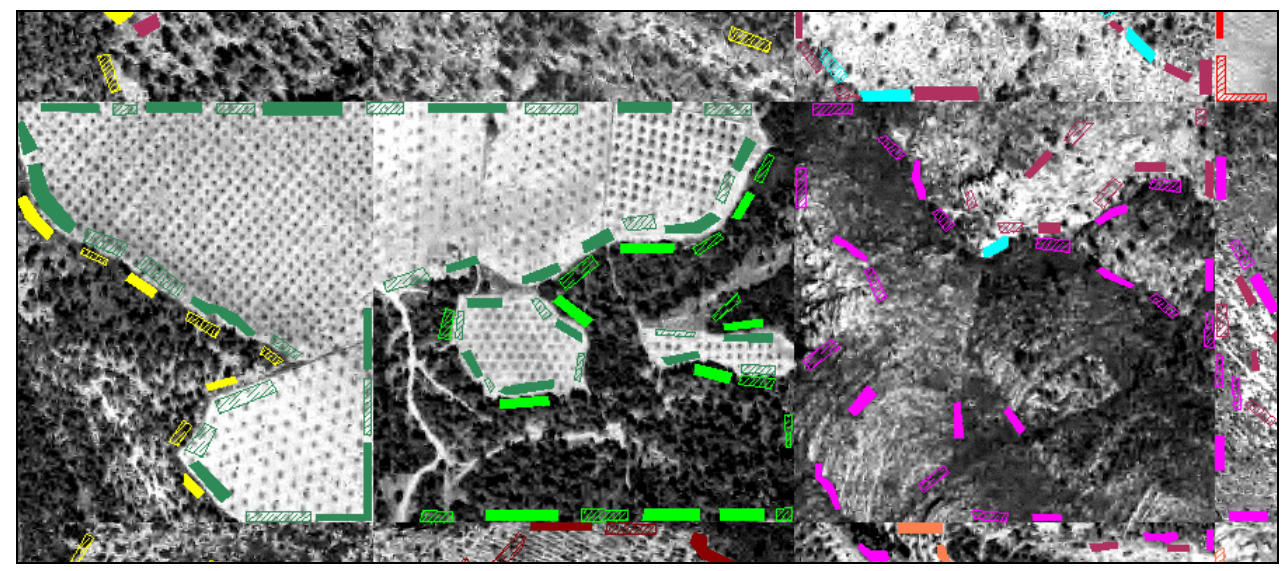

Figura 7-18. Fragmento de la imagen de Ayora con las muestras para los ensayos de bordes.

Los resultados son los que se muestran en la tabla 7-23 y figura 7-19 en las que se comparan las fiabilidades globales de la clasificación inicial (obtenida sobre las variables de textura derivadas de la aplicación de la transformada wavelet con la función Coiflet 24) 
con las resultantes de los 4 modelos anteriormente citados y propuestos para definir las áreas fronterizas.

\begin{tabular}{|l|c|c|c|c|}
\cline { 2 - 5 } \multicolumn{1}{c|}{} & \multicolumn{2}{c|}{ AYORA } & \multicolumn{2}{c|}{ ESPADAN } \\
\cline { 2 - 5 } \multicolumn{1}{c|}{} & Interior & Bordes & Interior & Bordes \\
\hline (1) Clasificación de variables de textura de la T.W. & 72.67 & 30.27 & 58.63 & 39.80 \\
\hline (2) Clasificación por segundas varianzas & 72.88 & 45.62 & 59.80 & 53.25 \\
\hline (3) Clasificación por bordes de la media & 74.02 & 42.29 & 60.14 & 49.89 \\
\hline (4) Clasificación según filtros de Canny & 67.21 & 39.04 & 57.44 & 46.88 \\
\hline (5) Clasificación por bordes de la clasificación inicial & 68.18 & 44.16 & 74.75 & 61.97 \\
\hline
\end{tabular}

Tabla 7-23. Fiabilidades globales para cada clasificación.

Como se puede advertir en esos resultados, en líneas generales se aprecia un sensible aumento en el porcentaje de acierto en las áreas fronterizas, variando entre un rango del $9 \%$ al $22 \%$. El acierto en las áreas internas se mantiene prácticamente constante, excepto en un par de casos en que disminuye apenas un $4 \%$ y algún otro que aumenta un $16 \%$. Por lo que respecta a la comparación entre los 4 modelos propuestos, quizás sea el de determinación de los bordes a partir de la clasificación inicial el que mejor se comporta, ya que excepto un decremento de un $5 \%$ en las áreas interiores de la imagen de Ayora, presenta importantes aumentos de acierto en el resto (hasta un 22\%). El modelo que peor se comporta es el de definición de bordes por el operador de Canny, al presentar un decremento en una fiabilidad y los menores incrementos en el resto. Ello puede ser debido a la imprecisión que presenta este método a la hora de analizar imágenes en las que las texturas no son demasiado homogéneas y son similares entre tipos de coberturas.

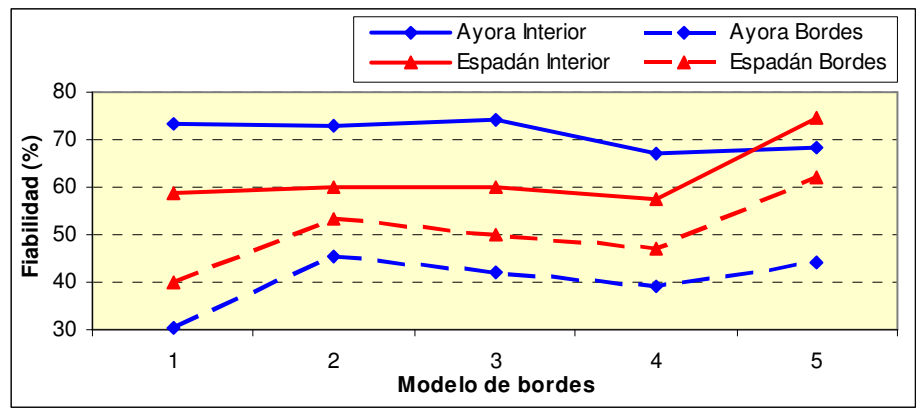

Figura 7-19. Evolución de la fiabilidad global para cada clasificación y zona.

Un ejemplo del comportamiento de los modelos de extracción de bordes analizados se puede observar en la figura 7-20. En ella se aprecia un fragmento de una imagen pancromática (a) con áreas forestales de diversas densidades y cultivos de almendros predominantemente. El resultado de la clasificación original de las variables derivadas de la transformada wavelet se observa en (b) y es importante destacar la fuerte 
indefinición en los bordes de las texturas e incluso asignaciones temáticas totalmente irreales (mucho matorral, en amarillo, y mucho suelo desnudo, en cian). Los modelos de extracción de bordes permiten tratar esas áreas de forma diferente a las internas y generan menos errores en ellas. El resultado al aplicar el modelo basado en segundas varianzas (c) permite delimitar mejor las áreas de cultivo (verde oscuro) y las de bosque (verde claro). Al aplicar el modelo de bordes de la media (d) se consigue una mejor definición de las clases en las áreas de frontera y desparecen esas "franjas" sobre las cuales la asignación temática inicial es bastante defectuosa. Los filtros de Canny generan un resultado (e) que, al igual que los anteriores, mejora al inicial si bien sigue presentando algunas asignaciones no plenamente correctas. Extrayendo los bordes de la clasificación inicial y conservando las asignaciones en las áreas internas se consigue una imagen de clasificación ( $f$ ) con un menor número de clusters o grupos de píxeles y una mayor homogeneidad en las texturas reales, así como una buena definición de los bordes.

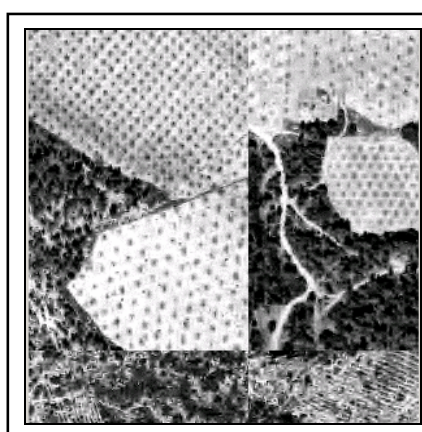

a)

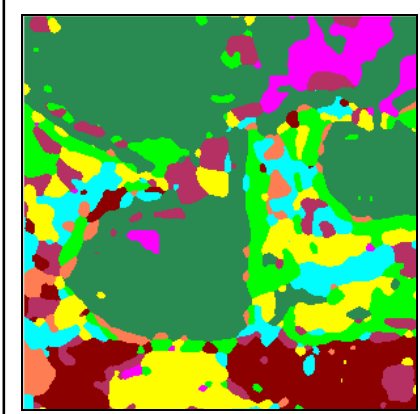

d)

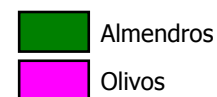

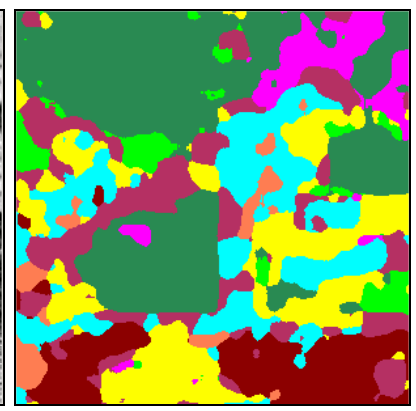

b)

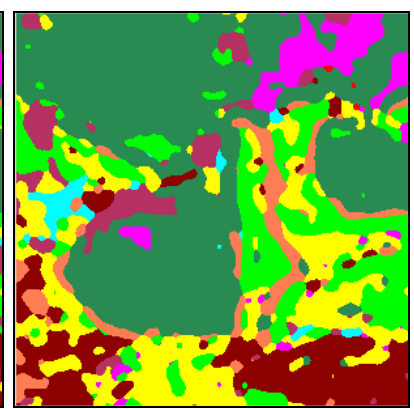

e)

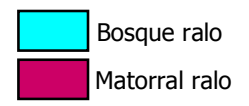

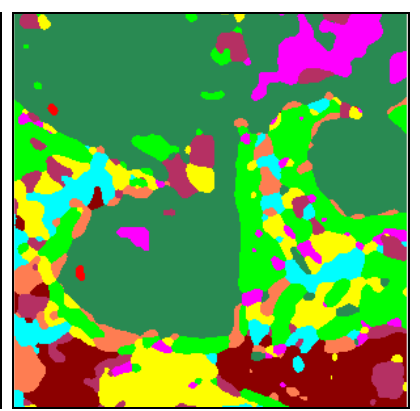

c)

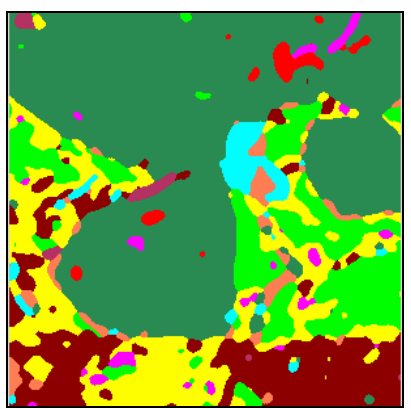

f)

Repob. forestal

Cereal

Figura 7-20. Fragmento de la imagen pancromática original (a) y comparación de la clasificación antes (b) y después de aplicar el modelo de extracción de bordes basado en segundas varianzas (c), el basado en la media (d), mediante filtros de Canny (e) y a partir de la clasificación inicial (f). 


\subsection{Discusión de los resultados}

Del conjunto de los procesos, ensayos, variaciones y pruebas realizados y detallados a lo largo de este capítulo se pueden extraer las siguientes conclusiones:

$1^{\text {a. }}$ La transformada wavelet se ha mostrado como una herramienta muy útil para el procesado de imágenes y su posterior clasificación en un conjunto de clases temáticas, ya que permite incrementar, cuando se emplea de forma conjunta con otro tipo de variables, las fiabilidades de la clasificación.

$2^{a}$. De todas las posibles formas de ser aplicada la transformada wavelet, se han ensayado tres de ellas. Frente al algoritmo à trous y al algoritmo invariante a la traslación shift4, la Transformada Wavelet Discreta (DWT) aplicada como filtros bidimensionales se ha mostrado como la más robusta al extraer mejor la información referente a las altas frecuencias de la imagen que permiten caracterizarla desde el punto de vista de las texturas.

$3^{3}$. Del conjunto de funciones wavelet definidas en la literatura específica, se ha experimentado con un total de 11 funciones, obteniendo diferencias entre ellas poco significativas, por lo que se puede afirmar lo que otros autores como Chang y Kuo, 1993 apuntaban en su trabajo con imágenes de texturas homogéneas y con 3 funciones (Haar, Daubechies16 y Battle-Lemarié), que el tipo de función aplicada no tiene una trascendencia grande, por lo menos con las funciones consideradas, y lo que sí importa es que se aplique la descomposición que la transformada wavelet implica.

$4^{a}$. Frente a las variables de texturas obtenidas por los filtros de Gabor (muchas variables) y los de energía y densidad de bordes (filtros de Laws), las variables wavelet pueden considerarse como más discriminantes y de fácil implementación en un sistema de tratamiento digital de imágenes.

5a. Dado el elevado número de variables de textura que se pueden extraer de una imagen, se han mostrado como las mejores el rango de datos, la media, varianza, homogeneidad, contraste, momento de diferencia inverso y correlación derivados de la MCNG, y la energía y kurtosis del histograma, frente a otras consideradas en el presente estudio. Se puede concluir con esto, que es necesario una razonada selección de entre todas las variables texturales posibles para evitar redundancias y correlaciones en los datos.

6a. Dada la diferente procedencia de la información geográfica existente en la actualidad y su naturaleza heterogénea, se pueden plantean algunos procesados previos y 
sencillos sobre su resolución radiométrica y espacial. Se ha demostrado que la correcta selección de esos parámetros de las imágenes permite obtener altas fiabilidades de acierto al clasificar.

7a. Un inconveniente de la clasificación por texturas es la importante presencia de elementos dispersos en las imágenes clasificadas, tal y como se puede notar en la figura 7-21, donde se aprecian dos fragmentos de imagen pancromática inicial (izquierda) y su equivalente en la clasificación (derecha). Un trabajo futuro podría consistir en investigar la potencialidad de los filtros morfológicos (que identifican pequeños clusters o agrupaciones y realizan cierres morfológicos) o de los filtros de moda, que asignan a un píxel el valor que más repite en todo un vecindario, para la corrección de este efecto.

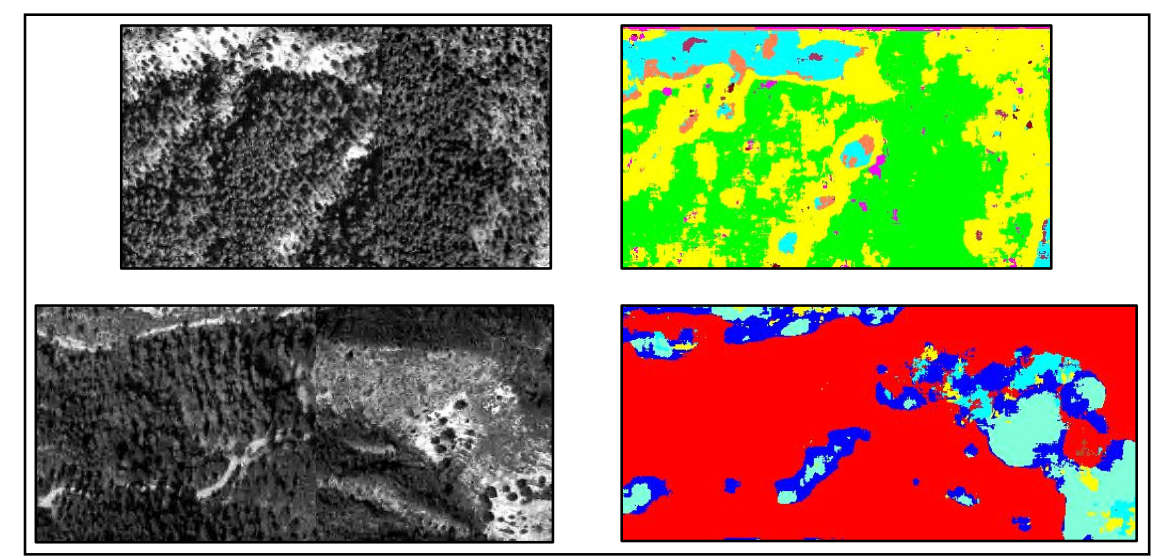

Figura 7-21. Ejemplos de la presencia de elementos dispersos en las clasificaciones.

8a. Al emplear las variables de texturas de la MCNG se aprecia un efecto de bordes o efecto frontera importante, como ocurre en la figura 7-22 o en otras reseñadas en el capítulo metodológico. Se han propuesto varias alternativas para reducir este efecto en el apartado 6.4, orientadas a un desigual procesado de las zonas definidas a priori como de bordes según las rutinas reseñadas, obteniendo en el mejor de los casos un incremento del $22 \%$ en la clasificación de las zonas frontera.

9a. No todas las características de textura son igualmente discriminantes. Por ello se muestra que una selección previa de ellas genera mejores aciertos en la clasificación, debido al hecho de que así deben ser estimados desde el mismo número de muestras menos parámetros de la función de densidad de probabilidad condicional de una clase. 


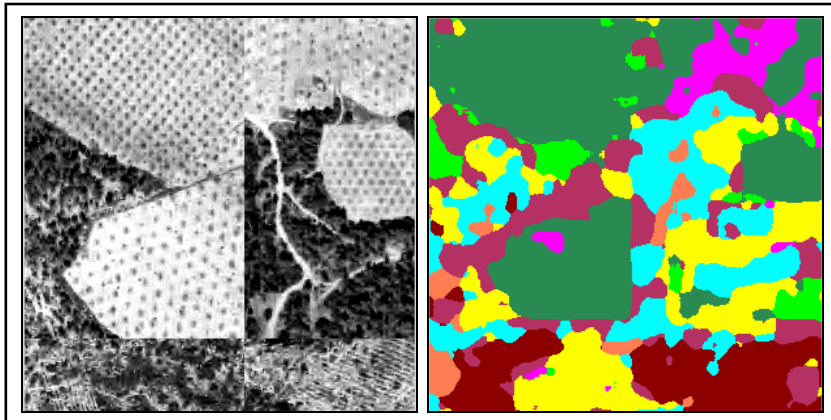

Figura 7-22. Efecto de bordes en las transiciones entre texturas.

10a. Analizando las diferencias encontradas en los resultados entre cada una de las imágenes, se puede apreciar en las figuras 7-20 y 7-21 cómo los entornos forestales propios de áreas montañosas como los de la imagen de Espadán se clasifican ligeramente peor, tanto al considerar diversos grupos de variables como diversas funciones wavelet. Esto se puede explicar por la heterogeneidad interna de cada tipo de superficie, ya que las densidades de ocupación vegetal, la morfología de cada especie, el contenido de humedad del suelo, etc. pueden generar variaciones muy importantes dentro de una misma clase. Además de ello, los límites o separaciones entre clases son difíciles de establecer aún cuando se realice una fotointerpretación minuciosa, y se puede presentar mucha yuxtaposición de áreas de diferentes clases.

$11^{\mathrm{a}}$. Las imágenes con transiciones claramente marcadas entre las clases son las que mejor se comportan. Así, en Ayora la fiabilidad llega a ser superior al $90 \%$ dado que las clases identificables son muy separables tanto visual como estadísticamente, al tratarse de cultivos con marco geométrico y clases forestales muy diferenciables entre sí, alguna de ellas propia de repoblaciones forestales. El entorno peri-urbano de Valencia con huertas, núcleos urbanos, urbanizaciones, cultivos, etc. también presenta buena separabilidad entre clases y ello se refleja en unos altos porcentajes de fiabilidad. Las imágenes propias de entornos forestales (Espadán) y mixtos entre forestal, agrícola y urbano (Menorca) tienen porcentajes de acierto muy similares y algo menores a los anteriores, explicado en gran medida por la presencia de clases con algo de similitud (varios niveles de densidad vegetal o cultivos no muy diferentes) y por tanto menos diferenciables.

$12^{\mathrm{a}}$. Dado que la transformada wavelet descompone las imágenes en sus componentes de frecuencias verticales, horizontales y diagonales ajustadas a cada escala de trabajo, parece evidente que aquellas texturas con transiciones entre sus elementos poco marcadas (como zonas forestales o de matorrales o con cultivos sin claros patrones 
geométricos) se caracterizarán peor que aquellas otras con frecuencias mayores, como pueden ser los cultivos geométricos o las áreas urbanas, por ejemplo.

13a. La descomposición de las imágenes en sucesivos niveles permite mejorar los resultados de la clasificación. La imagen pancromática inicial se puede entender como el nivel 0 de la descomposición y contiene información de frecuencias diferente a la de niveles sucesivos. De hecho, en el nivel 0 se tienen frecuencias sin diferenciar direcciones y para una escala inicial, mientras que en los siguientes se van extrayendo características direccionales a diferentes escalas, con lo que se puede estudiar la naturaleza de los elementos de la imagen a diferentes resoluciones. Los resultados muestran que el nivel óptimo de la descomposición es el nivel 3. 


\section{Capítulo VIII}

\section{Conclusiones y líneas futuras de trabajo}

El presente capítulo pretende resumir las ideas más relevantes del trabajo, así como resaltar los resultados más importantes a modo de conclusiones globales, marcando cuáles pueden ser las líneas de trabajo futuras que puedan ampliar la presente investigación.

\subsection{Conclusiones}

El trabajo desarrollado en el marco de esta línea de investigación se ha centrado en el análisis de los rasgos texturales de un conjunto de imágenes pancromáticas, algunas consistentes en fotogramas aéreos escaneados y otras provenientes directamente de satélites espaciales como QuickBird.

Se han analizado diferentes grupos de variables de textura propuestas por varios autores de cara a contrastar su aplicabilidad en imágenes reales de diversas tipologías de superficies naturales del territorio.

Se han puesto en práctica nuevas metodologías de trabajo en cuanto a su empleo sobre imágenes del territorio y que presentan propiedades interesantes a priori. Para este nuevo modelo de análisis de texturas (la transformada wavelet) se han experimentado diferentes algoritmos de aplicación con resultados ligeramente diferentes. También se ha probado a aplicar la transformada discreta con diferentes familias de funciones, cada una con parámetros específicos, y en diferentes niveles de descomposición-reconstrucción. 
A partir de los resultados obtenidos y de cara a afinar al máximo en las clasificaciones, se han ensayado posibles rutinas operacionales para intentar minimizar el error cometido en las áreas frontera de las texturas dada la importante interacción existente con las contiguas por los vecindarios de extracción de variables, sobre todo las estadísticas.

Tras la obtención de un amplio grupo de resultados para diferentes tipos de pruebas, su discusión, valoración y explotación, parecen evidentes algunas conclusiones:

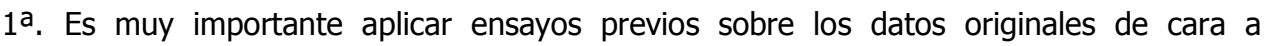
emplear una buena resolución radiométrica y espacial. Ciertas variables estadísticas de textura se derivan de la MCNG, la cual está influida por el número de niveles digitales presentes en la imagen. Por otro lado, al aplicar transformadas wavelet en forma de esquema multiresolución, el tamaño inicial del píxel condiciona en gran medida los resultados en cada uno de los niveles o resoluciones. Los porcentajes de acierto en las clasificaciones demuestran que no todas las resoluciones radiométricas y espaciales se comportan igual para discriminar texturas. Las formadas por patrones espaciales de mayores dimensiones (como áreas urbanas, cultivos de olivos, dehesas, etc.) requerirán un píxel mayor que otras (como cultivos de cítricos, cereales, áreas de matorral, etc.). En cuanto a la radiometría, aquellas superficies más homogéneas deben ser tratadas con más niveles de gris para captar mejor las menores diferencias entre ellas, como ocurre en la imagen de Menorca, mientras que otras más heterogéneas, como el área de Valencia, requieren de menos niveles de gris.

$2^{a}$. Se ha llegado a emplear un gran número de variables de textura obtenidas a partir de diferentes metodologías de análisis. Una selección previa de las variables permite estimar, desde el mismo número de muestras, menos parámetros de la función de densidad de probabilidad condicional de una clase. De los resultados obtenidos se puede concluir que la imagen pancromática no aporta información adicional decisiva en la clasificación dado que introduce información similar a la media de la MCNG. Se ha demostrado que existen unas determinadas variables, como el intervalo de valores, la media, la varianza, la homogeneidad, el contraste, el momento de diferencia inverso y la correlación derivados de la MCNG, y la energía y kurtosis del histograma, que generan mejores resultados de forma similar en todos los entornos analizados.

3a. La transformada wavelet es una potente herramienta matemática para analizar la textura de las imágenes al permitir descomposiciones y reconstrucciones en varios niveles y resoluciones, destacando componentes específicos de cada textura a cada resolución. Su relativamente fácil aplicación mediante bancos de filtros ortonormales y 
la posibilidad de interactuar con otros métodos texturales (principalmente estadísticos) permite obtener buenas fiabilidades en tareas de clasificación.

$4^{a}$. Tal y como se ha detallado en el capítulo referido a la teoría de la transformada wavelet, son varias las formas en las que ésta puede ser aplicada. Se han ensayado tres de ellas, basadas en criterios diferentes y con características dispares en cuanto a la gestión de los datos de entrada. Si bien los tres algoritmos se comportan bien y de forma bastante "pareja" entre sí, parece destacar el algoritmo clásico de transformada wavelet discreta (DWT) frente al algoritmo à trous y al algoritmo invariante a la traslación shift4. La posibilidad de aplicarse como filtros bidimensionales junto al hecho de permitir un análisis multiresolución, implica una mayor robustez del modelo clásico para extraer la información textural de la imagen.

5a. De los resultados obtenidos se puede concluir que la influencia del nivel de descomposición elegido para la transformación es importante, ya que ciertas superficies resaltan o simplifican sus características texturales a diferentes resoluciones espaciales. Por tanto, la transformada wavelet aplicada como análisis multiresolución en varios niveles es muy útil para la discriminación de texturas. En cuanto al mejor nivel, parece apuntarse que las características obtenidas de una descomposición multiresolución de nivel 3 generan los resultados de mayor fiabilidad, si bien conforme se aumenta el nivel de descomposición, la influencia en la mejora es cada vez menor, hasta llegar a ese nivel óptimo.

6a. Por lo que respecta al tipo de función wavelet elegida, los resultados son ligeramente diferentes al aplicar una u otra. De las 11 funciones empleadas en la totalidad de imágenes de ensayo, la función Coiflet24 es la que mejor resultado promedio conlleva. En cuanto a la influencia del tamaño del soporte de la función (número de momentos nulos), si bien las diferencias son mínimas, sí se aprecia que las funciones de mayor soporte, que generan filtros de mayor tamaño, permiten porcentajes de acierto en las clasificaciones ligeramente mejores.

7a. Está mas que constatado el hecho de que las variables derivadas de la MCNG de la imagen inicial son de las mejores para caracterizar una textura. Las mismas variables derivadas de las imágenes de detalles de niveles 1,2 y 3 de la transformada discreta wavelet no consiguen porcentajes de aciertos tan altos como las primeras. Pero de la unión de los dos grupos de variables se pueden llegar a obtener fiabilidades de más del $90 \%$ en algún caso, lo que permite concluir que el modelo propuesto en este trabajo permite ampliar las capacidades derivadas de la imagen pancromática inicial mediante sucesivos procesos de descomposición y extracción de la información específica de ella, implementados convenientemente mediante bancos de filtros bidimensionales. 
$8^{a}$. La mayor parte de los modelos de análisis de textura detallados en la revisión de antecedentes presentan deficiencias en el tratamiento de las zonas frontera entre texturas. Especialmente importante, por ser las variables más empleadas, es el efecto de bordes en las derivadas de la MCNG, directamente proporcional al tamaño del vecindario de cálculo. Si bien en otras variables, como las de energía definidas por Laws (1980), este efecto es ligeramente menor, se sigue requiriendo una solución, que no es sencilla y sobre todo cuando se trabaja con imágenes en las que las transiciones entre texturas no son geométricas o regulares (como ocurre con masas forestales de diferentes densidades de ocupación del suelo, por ejemplo). A fin de minimizar las consecuencias de este efecto se considera importante el predefinir las zonas frontera entre texturas y tratarlas con unos parámetros diferentes a los empleados en el resto de la imagen. Se propone una metodología que permite conseguir incrementos en los porcentajes de acierto en las asignaciones de hasta un $22 \%$ con un promedio en la mejora entorno al $15 \%$.

9a. Tras ser aplicada sobre diferentes entornos geográficos y con cubiertas desiguales, se puede concluir que la transformada wavelet por sí sola es muy útil en aquellos entornos donde la heterogeneidad de las cubiertas es grande, es decir en entornos que presenten superficies agrícolas, forestales y urbanas entremezcladas. Por contra, en entornos forestales homogéneos o agrícolas sin marcos geométricos, su acierto en la asignación es algo menor.

10a. Los métodos estadísticos generan variables que caracterizan mejor a las imágenes heterogéneas urbanas 0 de cultivos geométricos donde las variaciones entre los niveles digitales son mayores y se comportan algo peor en áreas forestales.

11a. La agrupación de las variables de la transformada wavelet y las estadísticas de la imagen pancromática permite conseguir incrementos respecto de éstas últimas de un $10 \%$ en entornos agrícolas y forestales. La transformada contribuye a diferenciar mejor las diversas superficies que no siempre presentan límites claros o concretos y separar áreas de igual tipología vegetativa pero de desigual densidad de ocupación del suelo, supliendo los problemas que otros métodos texturales, como por ejemplo los estadísticos, presentan. En otros ámbitos, de una mayor heterogeneidad en las texturas, la transformada wavelet complementa en menor medida a los métodos estadísticos clásicos, como la MCNG, ya que éstos analizan toda la variabilidad de superficies de forma muy satisfactoria.

12a. Las variables derivadas de la transformada wavelet han de ser entendidas como complementarias a otras para conseguir los mejores resultados. Las fiabilidades globales conseguidas de esa manera en las cuatro imágenes es muy alta, oscilando entre el 83 y $91 \%$. Este pequeño rango de resultados está condicionado por la mezcla 
de cubiertas naturales y patrones espaciales que se aprecian en todas las imágenes consideradas, lo que hace difícil que alguna de ellas destaque sobre el resto.

\subsection{Posibles líneas futuras de investigación}

Las diferentes funciones wavelet analizadas en este trabajo forman parte de lo que se da en llamar la $1^{a}$ generación de funciones wavelet. En los últimos años y sobre todo de la mano de autores como Donoho y Candes (1999), Lisowska (2005), se está comenzando a hablar de la $2^{a}$ generación de funciones wavelet, como aquellas que pretenden mejorar a las iniciales y solventar algunos de sus problemas, como tratamiento de bordes, no invarianza a la rotación, pobre tratamiento de imágenes con muchas frecuencias altas, etc. Dentro de este grupo se puede hablar de aquellas que tienen anisotropía y emplean marcos direccionales, como las ridgelets, curvelets, contourlets y bandelets; y otras que se basan en patrones geométricos y realizan particiones diádicas como las wedgelets y platelets. Las funciones ridgelet son constantes a lo largo de líneas y son óptimas para encontrar líneas completas en toda la imagen. Las curvelets completan a las anteriores para el caso de que los elementos a identificar sean curvas. Las contourlets pretenden representar fielmente contornos suaves y curvilíneos mediante sucesivas aproximaciones sobre los bordes en localización, dirección y escala. Las funciones bandelets analizan la regularidad de la geometría de los elementos de cada subbanda de la descomposición wavelet en diferentes direcciones y definen un umbral por encima del cual se eliminan coeficientes. Las wedgelets se basan en una reducción del ámbito de aplicación de la descomposición hasta aproximarse al elemento que se desea caracterizar. Las platelets son generalizaciones de las wedgelets con el fin de representar de forma precisa las superficies suaves y los bordes.

Todas ellas son generalizaciones de la teoría clásica, por lo que se puede decir que tienen una buena adaptabilidad a los contenidos de altas frecuencias, son escalables y se basan en criterios visuales. Son útiles para el tratamiento de curvas, superficies, bordes de texturas, tratamiento y transmisión de imágenes o vídeos, etc.

De los resultados observados en este trabajo y los analizados en la bibliografía se aprecia que el tratamiento de bordes es un problema por solucionar. Dada la buena perspectiva que presentan las funciones wavelet de $2^{a}$ generación anteriormente reseñadas para el tratamiento de las zonas frontera, se pueden ampliar las funciones utilizadas hasta ahora, que demuestran déficits, a algunas como las contourlets o 
wedgelets, implementando las transformadas correspondientes según los parámetros de cada una de ellas. Por otro lado y sin dejar el efecto frontera, se pueden desarrollar otros algoritmos operativos complementarios a los perfilados en este trabajo y que apuntan buenas perspectivas, avanzando en el empleo de filtros de bordes como Canny, Sobel, Roberts, etc., diseñando otros que permitan destacar las zonas de altas frecuencias propias de los bordes, realizando preselecciones de las áreas que a priori pueden ser más difíciles de tratar, etc.

Las imágenes de la superficie terrestre suelen presentar una heterogeneidad natural entre las diferentes cubiertas. Se ha demostrado que no todas las técnicas de análisis de textura se comportan por igual en todas ellas, por lo que se puede investigar sobre la realización de segmentaciones previas a los estudios de textura para trabajar de forma selectiva en función de las características de cada cubierta. Se podrían aplicar sobre cada zona aquellos métodos de textura que mejor se comportasen y emplear unas variables u otras para, en una fase final, agrupar todos los resultados parciales en un modelo final.

No todas las texturas presentan comportamiento similar al sufrir rotaciones, de tal manera que en muchos problemas de análisis de texturas, la información rotacional es necesaria, bien sea en forma de características específicas o bien como punto de partida para obtener otras. La aplicación práctica de la transformada wavelet bidimensional es llevada a cabo mediante bancos de filtros en filas y columnas de una imagen. Debido a la separabilidad de esos filtros, esa transformada está fuertemente condicionada por la dirección vertical y horizontal, lo cual la hace poco práctica para extraer características invariantes a la rotación. Para solventar esta limitación se podrían emplear varios filtros angulares e interpolar sus resultados. O bien podrían ser puestos en práctica otros algoritmos de transformada wavelet apuntados en la reseña teórica del capítulo IV y que la revisión bibliográfica presenta en varios trabajos, como es la transformada wavelet packet, la transformada continua o la transformada redundante wavelet frames, aplicando otras funciones de partida no separables y consideradas invariantes como la Mexican Hat, Morlet wavelets o Cauchy wavelets.

Una de las aplicaciones más demandada en la gestión de la información espacial es la detección de cambios y seguimiento de ciertas variables geográficas y ello se puede realizar mediante la transformada wavelet. Para ello se debe disponer de series multitemporales de imágenes, convenientemente corregidas de efectos radiométricos y geométricos que permitan generar señales unidimensionales para cada elemento de la imagen y a lo largo del tiempo (serie de imágenes). El empleo de técnicas basadas en la transformada wavelet permitiría destacar aquellos píxeles cambiantes y detectar el momento en el que han producido dichos cambios. 
Pero no tan solo se pueden aplicar estas técnicas a la información temporal, sino también a datos multiespectrales que recojan el comportamiento de las superficies en diferentes longitudes de onda. La combinación de características espaciales y espectrales, el desarrollo de algoritmos que permitan su tratamiento desde una perspectiva textural y aplicando la transformada wavelet, puede redundar positivamente en diferentes aplicaciones como clasificaciones (Ruiz et al., 2004), segmentaciones, extracción de ciertas variables superficiales, etc.

El problema de la clasificación de texturas consiste básicamente en la determinación de una serie de características de textura para cada píxel de la imagen y según un determinado vecindario de cálculo. A partir de ellas se realizan asignaciones mediante clasificadores, decidiendo el usuario qué texturas constituyen una clase bien definida. La mayor parte de los clasificadores empleados son probabilísticos y se suelen asumir probabilidades a priori iguales para todas las clases, así como distribuciones normales o gaussianas para las variables. Pero esto puede no ser siempre así, ya que los clasificadores que trabajan con la unidad píxel consideran valores de las variables de textura muy influenciados por los vecinos a cada píxel, por el tamaño de esos vecindarios y por la ponderación que se aplique a los valores de cada uno de ellos. Si los vecindarios son pequeños, quizás no capten bien la realidad de la textura. Si son grandes, estarán afectados por los píxeles de otras texturas. Por ello puede ser interesante realizar clasificaciones orientadas a objetos, en las que el elemento a clasificar no es un píxel, sino un objeto, un elemento de la imagen que tenga una textura homogénea y cuyas variables derivadas no estén afectadas de elementos contiguos.

La mayor parte de los ensayos realizados se han centrado en imágenes propias de áreas forestales, agrícolas o mixtas, siendo los entornos urbanos los menos frecuentes. Se ha demostrado la utilidad de las rutinas propuestas en casi todos ellos, siendo en los ámbitos urbanos empleados en donde las mejoras han sido menores. Sin embargo, y de cara a la gestión y planificación territorial, las áreas urbanas y de probable crecimiento urbano son las más importantes social, medioambiental y económicamente. Es importante mejorar en el tratamiento de estos ámbitos para lograr una mejor clasificación de las diversas unidades territoriales y de esa manera, una mayor implantación, tanto en organismos públicos como privados, de sistemas de gestión de información geográfica mediante Teledetección. 


\subsection{Agradecimientos}

Esta tesis doctoral se ha desarrollado gracias al apoyo de varios proyectos de investigación concedidos al grupo de investigación llamado Cartografía Geoambiental y Teledetección, del Departamento de Ingeniería Cartográfica, Geodesia y Fotogrametría de la Universidad Politécnica de Valencia. Los proyectos son los que siguen:

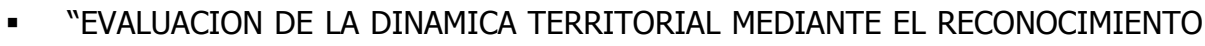
E INTEGRACION DE VARIABLES MEDIOAMBIENTALES", (1999-2001), financiado por el Vicerrectorado de I+D+I de la Universidad Politécnica de Valencia.

- "ANÁLISIS DE TEXTURAS MEDIANTE DESCOMPOSICIÓN EN WAVELETS PARA LA SEGMENTACIÓN DE IMAGENES CON FINES CARTOGRÁFICOS", (2002-2004), proyecto coordinado del Vicerrectorado de Investigación, Desarrollo e Innovación de la Universidad Politécnica de Valencia y con código: 2002-0627.

- "EXTRACCIÓN AUTOMÁTICA DE LAS CARACTERÍSTICAS GEOMORFOLÓGICAS DE LAS PLATAFORMAS CARBONATADAS DE LAS BALEARES Y VALENCIA", (20022005), financiado por la Dirección General de Investigación del Ministerio de Ciencia y Tecnología y con código: BTE2002-04552.

- "DESARROLLO Y OPTIMIZACIÓN DE MÉTODOS Y HERRAMIENTAS PARA LA EXTRACCIÓN DE INFORMACIÓN CARTOGRÁFICA NECESARIA EN LA CARACTERIZACIÓN DE SISTEMAS HIDROLÓGICOS", (2003-2006), financiado por la Dirección General de Investigación del Ministerio de Ciencia y Tecnología y con código: REN2003-04998.

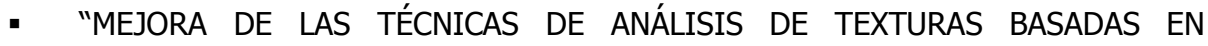
WAVELETS PARA LA CLASIFICACIÓN DE IMAGENES DE SATÉLITE DE ALTA RESOLUCIÓN", (2004-2006), proyecto coordinado del Vicerrectorado de Investigación, Desarrollo e Innovación de la Universidad Politécnica de Valencia y con código: 2004-0921.

A todos los organismos que los han sufragado y a todos los miembros del grupo de investigación, muchas gracias. 


\section{Capítulo IX}

\section{Referencias Bibliográficas}

\section{ARTÍCULOS Y COMUNICACIONES}

- ABÁSOLO, M. J. y PERALES, F. J. Wavelet analysis for a new multiresolution model for large-scale textured terrains. 11th International Conference in Central Europe on Computer Graphics, Visualization and Computer Vision, Plzen-Bory, Czech Republic. 2003.

- ABOUFADEL, E. y SCHLICKER, S. Discovering Wavelets. New York: Wiley Interscience, 1999. 125 p. ISBN: 0-471-33193-7.

- AGUSTÍ, M., VALIENTE, J. M. y CARRETERO, M. Recuperación por contenido en bases de datos de imágenes basada en wavelets: aplicación al diseño del textil. En: Proceedings of international conference on tools and methods evolution in engineering design (XIII ADM - XV INGEGRAF), Cassino, 2003. p. 1-10.

- $\quad$ ANGEL, P. y MORRIS, C. Analyzing the Mallat Wavelet Transform to delineate contour and textural features. Computer Vision and Image Understanding. 2000, vol. 80, no 3, p. 267-288.

- ANTOINE, J. P., MURENZI, R. y PIETTE, B. Image analysis with 2D continuous wavelet transform: detection of position, orientation and visual contrast of simple objects. En: MEYER, Y. (ed). Research Notes in Applied Mathematics. Marsella: Masson-Springer Verlag, 1992. p. 144-159.

- ANTONINI, M., BARLAUD, M. y MATHIEU, P. Digital image compression using vector quantization and the wavelet trasnform. En: MEYER, Y. (ed). Research Notes in Applied Mathematics. Marsella: Masson-Springer Verlag, 1992. p. 160-174. 
- $\quad$ ANYS, H. y HE, D. C. Evaluation of textural and multipolarization radar features for crop classification. IEEE Transactions on Geoscience and Remote Sensing, 1995, vol. 33, no 5, p. $1170-1181$.

- ARIVAZHAGAN, S. y GANESAN, L. Texture classification using wavelet transform. Pattern Recognition Letters. 2003, vol. 24, no 9-10, p. 1513-1521.

- ARIVAZHAGAN, S. y GANESAN, L. Texture segmentation using wavelet transform. Pattern Recognition Letters. 2003, vol. 24, no 16, p. 3197-3203.

- BATTLE, G. A block spin construction of ondelettes. Part I: Lemarié functions. Communications in Mathematical Physics. 1987, vol. 110, p. 601-615.

- BERTRAND, O., BOHORQUEZ, J. y PERNIER, J. A reversible discret wavelet transform. Application to the filtering of transient electrical brain signals. En: MEYER, Y. (ed). Research Notes in Applied Mathematics. Marsella: Masson-Springer Verlag, 1992. p. 105-109.

- BODNAROVA, A., BENNAMOUN, M. y LATHAM, S. Optimal Gabor filters for textile flaw detection. Pattern Recognition. 2002, vol. 35, nº 12, p. 2973-2991.

- BRODATZ, P. Textures-A Photographic album for artists and designers. Dover, New York, 1965.

- BURRUS, C. S., GOPINATH, R. A. y GUO, H. Introduction to Wavelets and Wavelet transforms: a primer. New Jersey: Prentice Hall, 1998. 268 p. ISBN: 0134896009.

- CAMPISI, P., NERI, A., PANCI, G. y SCARANO, G. Robust rotation-invariant texture classification using a model based approach. IEEE Transactions on Image Processing. 2004, vol. 13, no 6, p. 782-791.

- CANNY, J. A computational approach to edge detection. IEEE Transactions on Pattern Analysis and Machine Intelligence. 1986, vol. 8, no 6, p. 679-698.

- CAO, C. y LAM, N. Understanding the scale and resolution effects in remote sensing and GIS. En: QUATTROCHI, D. y GOODCHILD, M. (ed). Scale in remote sensing and GIS. $1^{\text {a }}$ edición. Boca Raton, Florida: CRC-Lewis, 1997, p. 57-72.

- CARR, J. R. y PELLON, F. The semivariogram in comparison to the co-ocurrence matrix for classification of image texture. IEEE Transactions on Geoscience and Remote Sensing. 1998, vol. 36, no 6, p. 1945-1952.

- CHANE-MING, F., MOLINARO, F. y LEVEAU, J. Wavelet techniques applied to Lidar signal to study middle atmosphere dynamics. En: International Geoscience and Remote Sensing Symposium (IGARRSS '97), Singapour, 1997, p. 581-583

- CHANG, T. y KUO, C. J. Texture analysis and classification with tree-structured wavelet transform. IEEE Transactions on Image Processing. 1993, vol. 2, no 4, p. 429-441. 
- CHAPRON, B. y BLIVEN, L. Scatterometer response interpreted by wavelet transform analysis. En: MEYER, Y. (ed). Research Notes in Applied Mathematics. Marsella: Masson-Springer Verlag, 1992. p. 110-113.

- CHIEN-CHANG, C. y CHAUR-CHIN, C. Filtering methods for texture discrimination. Pattern Recognition Letters. 1999, vol. 20, nº 8, p. 783-790.

- CHITRE, Y. y DHAWAN, A. P. M-band wavelet discrimination of natural textures. Pattern Recognition. 1999, vol. 32, p. 773-789.

- CHUN ZHU, S. Filters, Random Fields and Maximun Entropy (FRAME): towards a unified theory for texture modeling. International Journal of Computer Vision. 1998, vol. 27, no 2, p. 107-126.

- CLAUSI, D. A. Comparing and fusion of co-ocurrence, Gabor y MRF texture features for classification of SAR sea ice imagery. Atmosphere Ocean. 2001, vol. 39, no 3, p. 183194.

- CLAUSI, D. A. y YUE, B. Comparing coocurrence probabilities and Markov Random Fields for texture analysis of SAR sea ice imagery. IEEE Transactions on Geoscience and Remote Sensing. 2004, vol. 42, no 1, p. 215-228.

- CLAUSI, D. A. y DENG, H. Design-based texture feature fusion using Gabor filters and Co-ocurrence probabilities. IEEE Transactions on Image Processing. 2005, vol. 14, no 7, p. $925-936$

- COGGINS, J. M. y JAIN, A. K. A spatial filtering approach to texture analysis. Pattern Recognition Letters. 1985, vol. 3, no 3, p. 195-203.

- COHEN, A. y FROMENT, J. Image compression and multiscale approximation. En: MEYER, Y. (ed). Research Notes in Applied Mathematics. Marsella: Masson-Springer Verlag, 1992. p. 181-206.

- COLOM PALERO, R. J. Estudio e implementación de la transformada wavelet para la compresión de imágenes y vídeo. Tesis Doctoral. Directores: Sebastiá, A. y Gadea R. Universidad Politécnica de Valencia, Departamento Ingeniería Electrónica, Valencia, 2001.

- CÓRCOleS, P., PARDO, J. E., RECIO, J. A., y RUIZ, L. A. Propuesta metodológica para la optimización de la clasificación de áreas urbanas. En: Asociación Española de Teledetección (ed). Actas del X Congreso Nacional de Teledetección: Teledetección y desarrollo regional. Cáceres: 2003, p. 377-380. ISBN: 84-607-8649-8

- CROCHIERE, R. E. Sub-Band Coding. The Bell System Technical Journal. 1981, vol. 60, no 7, p. 1633-1653.

- CROISIER, A., ESTEBAN, D. y GALAND, C. Perfect channel splitting by use of interpolation / decimation / tree decomposition techniques. En: Proceedings of International Coference on Information Sciences and Systems. Patras, Greece: 1976, p. 443-446. 
- DAVID, P. M. y CHAPRON, B. Underwater acoustic, wavelets and oceanography. En: MEYER, Y. (ed). Research Notes in Applied Mathematics. Marsella: Masson-Springer Verlag, 1992. p. 114-119.

- DE LA ESCALERA, A. Visión por computador. Fundamentos y métodos. $1^{a}$ edición. Madrid: Prentice Hall, 2001. 274 p. ISBN: 84-205-3098-0.

- DELL'ACQUA, F. y GAMBA, P. Texture-based characterization of urban environments on satellite SAR images. IEEE Transactions on Geoscience and Remote Sensing. 2003, vol. $41, n^{\circ} 1$, p. 153-159.

- DHAWAN, A., CHITRE, Y., KAISER-BONASSO, C. y MOSKOWITZ, M. Analysis of mammographic microcalcifcations using gray-level image structure features. IEEE Transactions on Medical Imaging. 1996, vol. 15, no 3, p. 246-259.

- DONOHO, D. Wedgelets: nearly minimax estimation of edges. Annals of Statistics. 1999, vol. 27, no 3, p. 859-897.

- DURRIEU, M., RUIZ, L. A. y BALAGUER, A. Analysis of geostatistical parameters for texture clasification of satellite images. En: Proceedings of 25th EARSeL Symposium: Global developments in Environmental Earth Observation from Space. Oporto, Portugal. 2005.

- EPIFANIO, I. Descripción de texturas. Aplicaciones a su compresión y clasificación. Tesis Doctoral. Directores: Ayala, G. y Malo, J. Universitat de València, Dpto. de Estadística e Investigación Operativa, Facultad de Matemáticas. Valencia, 2002.

- FATEMI-GHOMI, N., PALMER, P. L. y PETROU, M. Performance evaluation of texture segmentation algorithms based on wavelets. En: Proceedings of the Workshop on Performance Characteristics of Vision Algorithms. Fourth European Conference on Computer Vision. Cambridge: 1996. p. 99-119.

- FATEMI-GHOMI, N. Performance measures for wavelet-based segmentation algorithms. Tesis Doctoral. Directores: Palmer, P. y Petrou, M. Centre for Vision, Speech and Signal Processing, University of Surrey. Surrey, 1997.

- FDEZ.-SARRÍA, A., RECIO, J. A., y RUIZ, L. A. Análisis de imágenes mediante texturas: aplicación a la clasificación de unidades de vegetación. Geofocus. 2003, vol. 1, p. 143159.

- FDEZ.-SARRÍA, A., RECIO, J. A., y RUIZ, L. A. Determinación de la resolución espacial óptima en imágenes pancromáticas para su clasificación por texturas. En: Asociación Española de Teledetección (ed). Actas del XI Congreso Nacional de Teledetección: Teledetección. Avances en la observación de la Tierra. Puerto de la Cruz, Tenerife: 2005, p. 549-552. ISBN: 84-609-6894-4.

- FDEZ.-SARRÍA, A., RUIZ, L. A., y RECIO, J. A. Study of methods based on wavelets for texture classification of high resolution images. En: Proceedings of 25th EARSeL Symposium: Global developments in Environmental Earth Observation from Space. Oporto, Portugal. 2005, p.19-27. ISBN: 90-5966-042-0. 
- FERRO, C. J. S. Scale and texture in digital image classification. Master Thesis. Director: Warner, T. Department of Geology and Geography, West Virginia University. Morgantown, 1998.

- FERRO, C. J. S. y WARNER, T. A. Scale and texture in digital image classification. Photogrammetric Engineering \& Remote Sensing. 2002, vol. 68, n 1, p. 51-63.

- FUKUDA, S. y HIROSAWA, H. A wavelet-based texture feature set applied to classification of multifrequency polarimetric SAR images. IEEE Transactions on Geoscience and Remote Sensing. 1999, vol. 37, nº 5, p. 2282-2286.

- GANESAN, L. y BHATTACHARYYA, P. A new statistical approach for micro texture description. Pattern Recognition Letters. 1995, vol. 16, no 5, p. 471-478.

- GANESAN, L. y BHATTACHARYYA, P. A statistical design of experiments approach for texture description. Pattern Recognition. 1995, vol. 28, nº 1, p. 99-105.

- GIMENEZ, F., PERIS, A. y RÓDENAS, F. Tratamiento de señales digitales mediante wavelets y su uso con Matlab. $1^{\text {a }}$ edición. San Vicente (Alicante): Club Universitario, 2004. 137 p. ISBN: 8484543870.

- GONZALEZ, R. C. y WOODS, R. E. Digital image processing. 2a edición. Upper Saddle River: Prentice-Hall, 2002. 793 p. ISBN: 0130946508.

- GONZÁlEZ-AUDICANA, M., OTAZU, X., FORS, O., SECO, A. y GARCÍA, R. Bondad de los algoritmos de descomposición Wavelet de Mallat y 'à trous' para la fusión de imágenes Quickbird. En: Asociación Española de Teledetección (ed), Actas del $X$ Congreso Nacional de Teledetección: Teledetección y desarrollo regional. Cáceres: 2003, p. 295-299. ISBN: 84-607-8649-8

- GRAPS, A. An introduction to wavelets. IEEE Computational Science and engineering. 1995, vol. 2, no 2, p. 50-61.

- GYAOUROVA, A., KAMATH, C. y FODOR, I. K. Undecimated wavelet transforms for image de-noising. Informe $\mathrm{n}^{\mathrm{O}}$ UCRL-ID-150931. Lawrence Livermore National Laboratory, University of California. Oakland, California: 2002, 12 p.

- HAACK, B. y BECHDOL, M. Integrating multisensor data and RADAR texture measures for land cover mapping. Computers \& Geosciences. 2000, vol. 26, no 4, p. 411-421.

- HARALICK, R. M., SHANMUGAN, K. y DINSTEIN, I. Texture features for image classification. IEEE Transactions on Systems, Man and Cibernetics. 1973, vol. 3, no 6, p. $610-622$.

- HARALICK, R. M. Statistical and structural approaches to texture. Proceedings of the IEEE. 1979, vol. 67, nº 5, p. 786-803.

- HARALICK, R. M. y SAPHIRO, L. G. Computer and robot vision. Reading: AddisonWesley, 1992, 672 p. ISBN: 0201108771. 
- HAVLICEK, J. P. y TAY, P. C. Determination of the number of texture segments using wavelets. Electronic Journal of Differential Equations. 2003, vol. 7, p. 61-70.

- HSIAO, R. M. y SAWCHUK, A. A. Unsupervised image segmentation using feature smoothing and probabilistic relaxation techniques. Computer Vision, Graphics and Image Processing. 1989, vol. 48, no 1, p. 1-21.

- IEEE. IEEE Standar Glossary of image processing and pattern recognition terminology. IEEE Standard 610.4-1990. New York: IEEE Press, 1990.

- JAFARI-KHOUZANI, K. y SOLTANIAN-ZADEH, H. Rotation-Invariant multiresolution texture analysis using radon and wavelet transforms. IEEE Transactions on Image Processing. 2005, vol. 14, nº 6, p. 783-795.

- JAIN, A. K. Fundamentals of digital image processing. Englewoods Cliffs: Prentice Hall, 1989. 569 p. ISBN 0133325784.

- JAMES, M. Pattern Recognition. $1^{a}$ edición. Oxford: BSP Professional Books, British Library, 1987. 139 p. ISBN: 0-632-018885-2.

- JIANG, H. Texture characterization via joint statistics of wavelet coefficient magnitudes. Informe no 1945. Computer Engineering \& Computer Science, University of MissouriColumbia. Columbia: 1999. 27 p.

- JING-WEIN, W., CHIN-HSING, C., WEI-MING, C. y CHIH-MING, T. Texture classification using non-separable two-dimensional wavelets. Pattern Recognition Letters. 1998, vol. 19 , no 13 , p. $1225-1234$.

- JONES, G. Image segmentation using texture boundary detection. Pattern Recognition Letters. 1994, vol. 15, no 6, p. 533-541.

- KARU, K., JAIN, A. K. y BOLLE, R. Is there any texture in the image? Pattern Recognition. 1996, vol. 29, no 9, p. 1437-1446.

- KASPARIS, T., CHARALAMPIDIS, D., GEORGIOPOULOS, M. y ROLLAND, J. Segmentation of textured images based on fractals and image filtering. Pattern Recognition. 2001, vol. 34, p. 1963-1973.

- LAINE, A. y FAN, J. An adaptative approach for texture segmentation by multi-channel wavelet frames. Informe no TR-93-025. Centre for Computer Vision and Visualization, University of Florida. Gainesville: 1993. 23 p.

- LAINE, A. y FAN, J. Texture classification by Wavelet Packet signatures. IEEE Transactions on Pattern Analysis and Machine Intelligence. 1993, vol. 15, no 11, p. 1186-1191.

- LARSEN, J. Wavelet packed representation of textured regions. Master Thesis. Director: Linderhed, A., Department of Electrical Engineering, Linkoping Universitet, 2001, 48 p. 
- LAWS, K. I. Rapid texture identification. En: Proceedings of the SPIE Conference on Image Processing for Missile Guidance. San Diego: 1980, p. 376-380.

- LAWS, K. I. Goal-directed texture image segmentation. Applications of Artificial Intelligence II, SPIE. 1985, vol. 548, p. 19-26.

- LeMARIE, P. G. Ondolettes à localisation exponentielles. Journal de Mathématiques Pures et Appliquées. 1988, vol. 67, no 3, p. 7-36.

- LIN, C. T. y HUANG, C. H. Texture boundary detection based on multiple and parallel cellular neural network. En: Proceedings of the 11th IEEE International Conference on Electronics, Circuits and Systems, ICECS 2004. Tel Aviv: 2004, p. 222-225.

- LISOWSKA, A. Geometrical Wavelets and their generalizations in digital image coding and processing. Tesis Doctoral. Director: Kotarski, W. Faculty of Computer Science and Material Science, Institute of Computer Science, University of Silesia. Sosnowiec, 2005.

- LIVENS, S., SCHEUNDERS, P, VAN DE WOUWER, G. y VAN DYCK, D. Wavelets for texture analysis. En: Proceedings on ICIP and its Applications. Dublin: 1997, p. 581585.

- MAILlARD, P. Comparing texture analysis methods through classification. Photogrammetric Engineering and Remote Sensing. 2003, vol. 69, no 4, p. 357-367.

- MALLAT, S. A theory for multiresolution signal decomposition: the wavelet representation. IEEE Transactions on Pattern Analysis and Machine Intelligence. 1989, vol. 11, no 7, p. 674-693.

- MALLAT, S. y ZHONG, S. Wavelet maxima representation. En: MEYER, Y. (ed). Research Notes in Applied Mathematics. Marsella: Masson-Springer Verlag, 1992. p. 207-285.

- MALLAT, S. A wavelet tour of signal processing. $2^{\text {a }}$ edición. San Diego, California: Academic Press, 1999. 637 p. ISBN: 0-12-466606-X.

- MANGIN, A. Programación en C++ Builder de algoritmos para extracción de texturas en imágenes en color mediante descriptores de texturas. Trabajo Final de Carrera. Director: Albaladejo, J. Facultad de Informática, Universidad Politécnica de Valencia. Valencia, 2001.

- MANJUNATH, B. S. y MA, W. Y. Texture features for browsing and retrieval of image data. IEEE Transactions on Pattern Analysis and Machine Intelligence. 1996, vol. 18, no 8, p. $837-842$.

- MAO, J. y JAIN, A. K. Texture classification and segmentation using multiresolution simultaneous autoregressive models. Pattern Recognition. 1992, vol. 25, no 2, p. 173188.

- MATERKA, A. y STRZELECKI, M. Texture analysis methods - a review. Informe no COST B11. Institute of Electronics, Technical University of Lodz. Bruselas: 1998. 33 p. 
- MEYER, Y. Book Review. Bullletin of the American Mathematical Society. 1993, vol. 28, n० 2, p. 350-360.

- MEYER, Y. Wavelets and applications. Meyer, Y (ed). Marsella: Masson - Springer Verlag, 1992, 450 p. Research Notes in Applied Mathematics. ISBN: 2-225-82550-5.

- MOGHADDAM H. A., ZOUJ M. J. V. y DEHGHANI M. Bayesian-based Despeckling in Wavelet Domain Using "a Trous" Algorithm. En: Proceedings of the 20th International Congress on Photogrammetry and Remote Sensing ISPRS2004: International archives of Photogrammetry, Remote Sensing and Spatial Information Sciences. Estambul: 2004, vol. XXXV, ISSN: 1682-1750.

- MOULIN, P. Multiscale Image Decompositions and Wavelets. En: Bovik, A. (ed). Handbook of image \& video processing. San Diego: Academic Press, 2000, p. 289-300.

- MULCAHY, C. Plotting and Scheming with Wavelets. Mathematics Magazine. 1996, vol. $69, n^{0} 5$, p. 323-343.

- MUNEESWARAN, K., GANESAN, L., ARUMUGAM, S. y RUBA, K. Texture classification with combined rotation and scale invariant wavelet features. Pattern Recognition. 2005, vol. 38 , p. $1495-1506$.

- MURINO, V., OTTONELLO, C. y PAGNAN, S. Noisy texture classification: a higher-order statistics approach. Pattern recognition. 1998, vol. 31, no 4, p. 383-393.

- NGUYEN, T. A tutorial on filter banks and wavelets. Informe. ECE Department, University of Wisconsin. Madison: 1995, 16 p.

- NICOLAS, J. M., DELVIGNE, J. C. y LEMER, A. Automatic identification of transient biological noises in underwater acoustics using arborescent wavelets and neural network. En: MEYER, Y. (ed). Research Notes in Applied Mathematics. Marsella: Masson-Springer Verlag, 1992. p. 120-125.

- NÚÑEZ, J., OTAZU, X., FORS, O., PRADES, A., PALÀ, V. y ARBIOL, R. Multiresolutionbased image fusion with additive wavelet decomposition. IEEE Transactions on Geoscience and Remote Sensing. 1999, vol. 37, nº 3, p. 1204-1205.

- OJALA, T., VALKEALAHTI, K., OJA, E. y PIETIKÄINEN, M. Texture discrimination with multidimensional distributions of signed gray-level differences. Pattern Recognition. 2001, vol. 34, p. 727-739.

- PAJARES, G. y DE LA CRUZ, J. M. Visión por computador. Imágenes digitales y aplicaciones. $1^{\text {a }}$ edición. Madrid: RA-MA Editorial, 2001. 764 p. ISBN: 84-7897-472-5.

- PALM, C. Color texture classification by integrative Co-ocurrence matrices. Pattern Recognition. 2004, vol. 37, p. 965-976.

- PARDO, J. E., RUIZ, L. A., PORRES, M. J., FDEZ.-SARRÍ́A, A., y URBANO, F. Caracterización de la relación entre la insolación y la regeneración vegetal tras incendios forestales en ámbitos mediterráneos. En: Universidad de Málaga (ed), Actas 
del XVI Congreso de Geógrafos Españoles: El territorio y su imagen. Málaga: 1999, p. 221-232. ISBN 84-930012-1-X.

- PÉReZ, A., LA MURA, G., PIOTRKOWSKI, R. y SERRANO, E. Procesamiento no lineal con wavelet para la eliminación del ruido en imágenes planares de medicina nuclear. En: Sociedad Cubana de Bioingeniería (ed). Memorias del II Congreso Latinoamericano de Ingeniería Biomédica. La Habana: 2001, 5 p. ISBN: 950-7132-57-5.

- PORTER, R. y CANAGARAJAH, N. A robust automatic clustering scheme for image segmentation using wavelets. IEEE Transactions on Image Processing. 1996, vol. 5, $\mathrm{n}^{0}$ 4, p. $662-665$.

- PORTILla, F. J. Representación local multiescala de imágenes. Modelado y síntesis de texturas. Tesis Doctoral. Director: Navarro, R. Departamento de imágenes y visión, Universidad Politécnica de Madrid. Madrid, 1999.

- PRASAD, L. y IYENGAR, S. S. Wavelet analysis with applications to image processing. Boca Raton: CRC Press, 1997. 279 p. ISBN: 0849331692.

- PRESS, W. H., TEUKOLSKY, S. A., Vetterling, W. T y Flannery, B. P. Numerical recipes in C: the art of scientific computing. 2a edición. Cambridge: Cambridge University Press, 1992. 994 p. ISBN: 0-521-43108-5.

- RAJPOOT, N. Texture classification using discriminant wavelet packet subbands. En: Proceedings of IEEE Midwest Synposium in Circuits and Systems. Tulsa, Oklahoma: 2002, p. 300-303.

- RANDEN, T. y HUSOY, J. H. Filter banks for texture segmentation. Piksel'n. 1993, vol. $10, n^{\circ} 3$, p. 22-29.

- RANDEN, T. y HUSOY, J. H. Multichannel filtering for image texture segmentation. Optical Engineering. 1994, vol. 33, n 8, p. 2617-2625.

- RANDEN, T. Filter and filter bank design for image texture recognition. Tesis Doctoral. Director: Husoy, J. H. Norwegian University of Science and Technology, Stavanger College. Stavanger, 1997.

- RANDEN, T. y HUSOY, J. H. Filtering for texture classification: A comparative study. IEEE Transactions on Pattern Analysis and Machine Intelligence. 1999, vol. 21, no 4, p. 291-310.

- RECIO, J. A., PARDO, J. E., RUIZ, L. A., FDEZ.-SARRÍA, A., y CóRCOLES, P. Detección y cartografiado de los procesos de expansión urbana mediante técnicas combinadas de teledetección y SIG. En: SIBSIG (ed), Actas de la IX Conferencia Iberoamericana de SIG. Cáceres: 2003.

- RECIO, J. A., RUIZ, L. A. y FDEZ.-SARRÍA, A. Use of Gabor filtres for texture classification of digital images. Física de la Tierra. 2005, vol. 17, p. 47-59. 
- RICHARDS, J. A. y JIA, X. Remote Sensing Digital Image Analysis. Berlin: Springer, 1999. 363 p. ISBN:3-540-64860-7.

- RIOU, R. y SEYLER, F. Texture analysis of tropical rain forest infrared satellite images. Photogrammetric Engineering \& Remote Sensing. 1997, vol. 63, no 5, p. 515-521.

- RUIZ, L. A. Análisis de texturas en la identificación de zonas heterogéneas en imágenes Landsat TM. En: Asociación Española de Teledetección (ed). Actas del VII Congreso Nacional de Teledetección: Teledetección aplicada a la gestión de recursos naturales y medio litoral marino. Santiago de Compostela: 1997 p. 183-186. ISBN: 84-8498-351-X.

- RUIZ, L. A., IÑÁN, I., BARIDÓN, J. E. y LANFRANCO, J. W. Combining multiespectral images and selected textural features from high resolution images to improve discrimination of forest canopies. En: Serpico, S. B. (ed). Proceedings of IV Conference on Image and Signal Processing for Remote Sensing. Barcelona: 1998, p. 124-134.

- RUIZ, L. A. Aplicación de técnicas de análisis de imagen y espectrometría infrarroja para la detección de daños en cítricos en la posrecolección. Tesis Doctoral. Directores: Moltó, E. y Juste, F. Departamento de Mecanización Agraria, Universidad Politécnica de Valencia. Valencia, 1999.

- RUIZ, L. A. y FDEZ.-SARRÍA, A. Analysis of image segmentation of multisource data in mountain environments. International archives of Photogrammetry and Remote Sensing. 2000, p. 469-475.

- RUIZ, L. A., ACOSTA, P., FDEZ.-SARRÍA, A., PORRES, M. J., y PARDO, J. E. Mejora de la eficiencia en la segmentación de imágenes por texturas mediante filtros de energía. En: Universitat de Lleida y Asociación Española de Teledetección (ed). Actas del IX Congreso Nacional de Teledetección: Medio ambiente y cambio global. Lleida. 2001, p. 477-480. ISBN: 84-9743-001-8.

- RUIZ, L. A., FDEZ.-SARRÍA, A. y RECIO, J. A. Evaluation of texture analysis techniques to characterize vegetation. En: Universidad de Valencia (ed), Man and Soil in the II Milenium. Valencia: Geoforma Ediciones, 2002, vol. 172, p. 1961-1974. ISBN 8487779-45-X

- RUIZ, L. A., FDEZ.-SARRÍA, A. y RECIO J. A. Texture feature extraction for classification of remote sensing data using wavelet decomposition: a comparative study. International archives of Photogrammetry, Remote Sensing and Spatial Information Sciences. 2004, p. 1109-1205.

- RUIZ, L. A., RECIO, J. A. y FDEZ.-SARRÍA, A. Clasificación de entornos forestales mediterráneos mediante técnicas de análisis de texturas. En: Sociedad Española de Ciencias Forestales (ed), Actas de la I Reunión de Inventario y Teledetección Forestal Juvetel 2004. Lleida: 2004, p. 187-192. ISSN: 1575-2410.

- SAITO, K. y SPENCE, R. Application of texture analysis to high-resolution optical satellite images for mapping earthquake building damage distribution -a preliminary assessment. En: Proceedings of the Second International Workshop on Remote Sensing for Post-Disaster Response. Newport Beach, California: 2004. 
- SÁNCHEZ, N. Panorama actual de las técnicas mixtas de clasificación de imágenes mediante segmentación espectral y por texturas. Aplicación a las imágenes de alta resolución espacial. Mappinginteractivo. 2003, vol. 88.

- SCHOWENGERDT, R. A. Remote Sensing. Models and methods for image processing. $2^{a}$ edición. San Diego: Elsevier, Academic Press, 1997. 522 p. ISBN: 0-12-628981-6.

- SERRANO, E. P. Introducción a la transformada wavelet y sus aplicaciones al procesamiento de señales de emisión acústica. En: Actas E-GLEA 2, $2^{\circ}$ Encuentro del Grupo Latinoamericano de Emisión Acústica, 10 Iberoamericano. Buenos Aires: 2004, p. $171-185$.

- ShATADAL, P., JAYAS, D. S. y BULLEY, N. R. Fourier and spatial domain analysis of image texture. En: Proceedings of Automated Agriculture for the 21st Century. Chicago: 1991, p. 36-41.

- SHEARER, S. A. y HOLMES, R. G. Plant identification using color co-ocurrence matrices. Transactions of the American Society of Agricultural Engineers. 1990, vol. 33, no 6, p. 2037-2044.

- SIMARD, M., DEGRANDI, G. y THOMSON, K. P. B. Adaptation of the wavelet transform for the construction of multiscale texture maps of SAR images. Canadian Journal of Remote Sensing. 1999, vol. 24, no 3, p. 264-285.

- SKRETTING, K. y HUSOY, J. H. Texture classification using sparse frame based representations. EURASIP Journal on Applied Signal Processing. 2006: vol. 2006, artículo 52561, $11 \mathrm{p}$.

- SLEZAK, E., BIJAOUI, A. y MARS, G. Structures identification from galaxy counts- Use of the wavelet transform-. En: MEYER, Y. (ed). Research Notes in Applied Mathematics. Marsella: Masson-Springer Verlag, 1992. p. 175-180.

- SMITH, M. J. T. y BARNWELL, T. P. A procedure for building exact reconstruction filter bank for subband coders. En: Proceedings IEEE International Conference in Acoustic Speech and Signal Processing. San Diego, California: 1984, p. 27.1.1-27.1.4.

- STEFANOV, W., RAMSEY, M. y CHRISTENSEN, P. Monitoring urban land cover change: an expert system approach to land cover classification of semiarid to arid urban centers. Remote Sensing of Environment. 2001, vol. 77, nº 2, p. 173-185.

- STOLLNITZ, E. J., DEROSE, T. D. y SALESIN, D. H. Wavelets for computer graphics: A primer, part 1. IEEE Computer Graphics and Applications. 1995, vol. 15, no 3, p. 76-84.

- STOLLNITZ, E. J., DEROSE, T. D. y SALESIN, D. H. Wavelets for computer graphics: A primer, part 2. IEEE Computer Graphics and Applications. 1995, vol. 15, no 4, p. 75-85.

- STRAND, J. y TAXT, T. Local frequency features for texture classification. Pattern Recognition. 1994, vol. 27, no 10, p. 1397-1406. 
- STRANG, G. y NGUYEN, T. Wavelets and filter banks. 2a edición. Wellesley: WellesleyCambridge Press, 1997. 520 p. ISBN: 0-9614088-7-1.

- STRELA, V., NIELS, P., STRANG, G., TOPIWALA, P. y HEIL, C. The application of multiwavelet filterbanks to image processing. IEEE Transactions on Image Processing. 1999, vol. 8, no 4, p. 548-563.

- SUTTON, R. N. y HALL, E. L. Texture measures for automatic classification of pulmonary disease. IEEE Transactions on Computers. 1972, vol. C-21, p. 667-676.

- TOPIWALA, P. N. Wavelet image and video compression. Topiwala, P. N. (ed). $1^{\mathrm{a}}$ edición. Boston: Kluwer Academic Publishers, 1998. 438 p. ISBN: 0-7923-8182-3.

- TORRENCE, C. y COMPO, G. P. A practical guide to wavelet analysis. Bullletin of the American Meteorology Society. 1998, vol. 79, no 1, p. 61-78.

- TSOLMON A. Wavelet-based analysis for object separation from laser altimetry data. Master Thesis. International Institute for Geo-information Science and Earth Observation (ITC). Enschede: 2003, 60 p.

- TUCERYAN, M. Moment-based texture segmentation. Pattern Recognition Letters. 1994, vol. 15, no 7, p. 659-668.

- TURIEL, A. Relevance of multifractal textures in static images. Electronic Letters on Computer Vision and Image Analysis. 2003, vol. 1, no 1, p. 35-49.

- UM, G., YE, C. y LEE, K. A hierarchical stereo matching algorithm using wavelet representation based on edge and area information. En: Proceedings of International Geoscience and Remote Sensing Symposium. Singapore: 1997, vol. 8, p. 588-590.

- UNSER, M. Texture classification and segmentation using wavelet frames. IEEE Transactions on Image Processing. 1995, vol. 4, no 11, p. 1549-1560.

- VAN DE WOUWER, G. Wavelets for multiscale texture analysis. Tesis Doctoral. Directores: Van Dyckt, D. y Scheunders, P. Universitaire Instelling Antwerpen. Antwerpen, 1998.

- VAN DE WOUWER, G., SCHEUNDERS, P. y VAN DYCK, D. Statistical texture characterization from discrete wavelet representations. IEEE Transactions on Image Processing. 1999, vol. 8, no 4, p. 592-598.

- VETTERLI, M. y KOVACEVIC, J. Wavelets and subband coding. Englewood Cliffs: Prentice Hall PTR, 1995. 488 p. ISBN: 0130970808.

- WALKER, J. S. A primer on Wavelets and their scientific applications. $1^{\text {a }}$ edición. Boca Raton: Chapman \& Hall/CRC, 1999. 155 p. ISBN: 0-8493-8276-9.

- WU, D. y LINDERS, J. A new texture approach to discrimination of forest clearcut, canopy and burned area using airbone C-band SAR. IEEE Transactions on Geoscience and Remote Sensing, 1999, vol. 37, no 1, p. 555-563. 
- XIONG, Z. y RAMCHANDRAN, K. Wavelet Image Compression. En: Bovik, A. (ed). Handbook of image \& video processing. San Diego: Academic Press, 2000, p. 495-512.

- ZHANG, J. y TAN, T. Brief review of invariant texture analysis methods. Pattern Recognition. 2002, vol. 35, no 3, p. 735-747.

- ZHANG, N. y CHAISATTAPAGON, C. Effective criteria for weed identification in wheat fields using machine vision. Transactions of the American Society of Agricultural Engineers. 1995, vol. 38, no 3, p. 965-974.

- ZHANG, Y. Optimisation of building detection in satellite images by combining multiespectral classification and texture filtering. ISPRS Journal of Photogrammetry \& Remote Sensing. 1999, vol. 54, p. 50-60.

- ZHOU, S., VENKATESH, Y. V. y KO, C. C. Texture retrieval using tree-structured wavelet transform. En: Proceedings of International Conference on Computer Vision, Pattern Recognition and Image Processing (CVPRIP). Atlantic City: 2000.

\section{RECURSOS EN WEB}

- ABOUFADEL, E. y SCHLICKER, S. The Discovering Wavelets web site. Grand Valley State University. http://faculty.gvsu.edu/aboufade/web/dw.html

- An introduction to Wavelets. Institute of Electrical and Electronics Engineers, Inc. http://www.amara.com/IEEEwave/IEEEwavelet.html

- BERND, G. Multiresolution \& Wavelets. 1998. http://www-inst.eecs.berkeley.edu/ ee290t/sp04/lectures/lec5.pdf

- CRISTÓBAL, G. Bioimaging \& Vision Modelling (BioVis). Instituto de Óptica (CSIC) Group Imaging \& Vision Dept. http://www.iv.optica.csic.es/pub.html

- FISHER, R. CVonline: Geometric Feature Extraction Methods. 2005. http://homepages.inf.ed.ac.uk/rbf/CVonline/feature.htm

- GRAPS, A. Amara's Wavelet Page. http://www.amara.com/current/wavelet.html\#overview

- $\quad$ GUO, H. Java Wavelet Demo. Digital Signal Processing, Rice University. http://www-dsp.rice.edu/software/EDU/engine.shtml

- HALL-BEYER, M. The GLCM Tutorial Home Page. http://www.fp.ucalgary.ca/mhallbey/tutorial.htm

- $\quad$ MALLAT, S. $A$ wavelet tour of signal processing. http://www.cmap.polytechnique.fr/ mallat/book.html 
- MASSACHUSETTS INSTITUTE OF TECHNOLOGY. Vision Texture. Massachusetts: 1995. http://vismod.media.mit.edu/vismod/imagery/VisionTexture/vistex.html

- MASSACHUSETTS INSTITUTE OF TECHNOLOGY. Wavelets, Filter Banks and Applications. Mitopencourseware. http://ocw.mit.edu/OcwWeb/Mathematics/18327Wavelets--Filter-Banks-and-ApplicationsSpring2003/CourseHome/index.htm

- NASS, P. The Wavelet Transform. http://www.eso.org/projects/esomidas/doc/user/98NOV/volb/node308.html

- POLIKAR, R. The Wavelet Tutorial. Rowan University. http://users.rowan.edu/ polikar/WAVELETS/WTtutorial.html

- ROOMS, F. Wavelets and other transforms. http://telin.rug.ac.be/ frooms/links/wavelets.shtml

- SCHNITER, P. Johnston's QMF Banks. http://cnx.rice.edu/content/m10932/2.1/

- SEPPÄLÄ, O. From Fourier Transform to Wavelets. 2001. http://citeseer.ist.psu.edu/cache/papers/cs/23964/http:zSzzSzzeus. hut.fizSzteachingzSz S-114.240zSzk2001zSzreportszSzSeppala wavelet.pdf/from-fourier-transform-to.pdf.

- THE MATHWORKS. Mathtools.net. http://www.mathtools.net/Java/Wavelets/

- TORRENCE, C. y COMPO, G. P. A practical guide to Wavelet Analysis. University of Colorado. http://atoc.colorado.edu/research/wavelets/

- VIDAKOVIC, B. Jacket's Wavelets. http://www2.isye.gatech.edu/ brani/wavelet.html

- WARD, L. Introduction to Wavelets and their Applications. Harvey Mudd College. http://www.math.hmc.edu/faculty/ward/wavelets/

- Wavelet.org. École Polytechnique Fédérale de Lausanne. http://www.wavelet.org/ 


\section{Capítulo X}

\section{Anejos}

\subsection{Ficha de trabajo de campo}

FICHA DE CAMPO
RECONOCIMIENTO CUBIERTA VEGETAL - CARACTERÍSTICAS DE LOS
DEPÓSITOS SUPERFICIALES

Lugar de trabajo: Código:

Punto de muestreo $\mathrm{n}^{\mathrm{O}}$ :

Coordenadas UTM:

Fotografía aérea:

X:

Serie:

Serie:

Superficie de muestreo:

Orientación local aproximada: Fecha: $\mathrm{Y}$ :

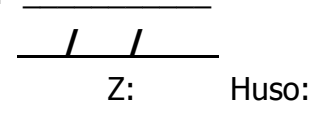

Año: No:

Año: $\quad$ No: $\mathrm{m}^{2} \quad$ Pendiente aproximada: Litología aflorante:

CARACTERIZACIÓN DE LA CUBIERTA VEGETAL

Valoración de la cubierta ocupada según estratos:

\begin{tabular}{|c|c|c|c|c|c|c|c|}
\hline \multicolumn{2}{|c|}{ Estrato } & (1) & (2) & (3) & (4) & (5) & (6) \\
\hline \multicolumn{8}{|l|}{ Arbóreo } \\
\hline \multicolumn{8}{|l|}{ Arbustivo } \\
\hline \multicolumn{8}{|l|}{ Herbáceo } \\
\hline $\begin{array}{l}(1) \\
(2) \\
(3) \\
(4) \\
(5) \\
(6)\end{array}$ & $\begin{array}{l}\text { No } \\
\text { Estr } \\
\text { Forr } \\
\text { Entr } \\
\text { Entr } \\
\text { Ocu }\end{array}$ & $\begin{array}{l}\text { gún inc } \\
\text { cubie } \\
\text { lero sic } \\
0 \\
0 \\
75 \%\end{array}$ & $\begin{array}{l}\text { IO con } \\
\text { uy pe } \\
\text { ativo }\end{array}$ & $\begin{array}{l}\text { estra } \\
\text {, insi } \\
\text { nenor }\end{array}$ & $\begin{array}{l}\text { ción } \\
\text { ante } \\
5 \%\end{array}$ & & \\
\hline
\end{tabular}


Especies que ocupan una mayor superficie:

\begin{tabular}{|c|c|c|}
\hline Arbóreas & Arbustivas & Herbáceas \\
\hline & & \\
\hline
\end{tabular}

CARACTERÍSTICAS DE LOS DEPÓSITOS SUPERFICIALES Y LOS SUELOS Afloramientos rocosos y pedregosidad

\begin{tabular}{|l|l|l|l|l|}
\hline Afloramientos rocosos & & $\begin{array}{l}\text { \% de roca } \\
\text { aflorante }\end{array}$ & $\begin{array}{l}\text { Nivel de } \\
\text { pedregosidad }\end{array}$ & \\
\hline $\begin{array}{l}\text { Sin afloramientos rocosos en los } 60 \\
\text { cm superiores }\end{array}$ & & $\begin{array}{l}\text { Sin guijarros o } \\
\text { menos de } 10 \%\end{array}$ & \\
\hline Roca blanda o muy fisurada & & & $10-20 \%$ & \\
\hline $\begin{array}{l}\text { Roca bastante blanda o } \\
\text { medianamente alterada o fisurada }\end{array}$ & & & $20-30 \%$ & \\
\hline Roca algo fisurada & & $30-50 \%$ & \\
\hline Roca poco fisurada o poco alterada & & & $50-80 \%$ (piedras) & \\
\hline Roca no fisurada o roca dura & & & $80 \%$ (con bloques) & \\
\hline
\end{tabular}

Estado de la superficie del suelo

\begin{tabular}{|l|l|l|l|}
\hline \multicolumn{1}{|c|}{$\begin{array}{c}\text { Presencia de horizonte } \\
\text { humífero }\end{array}$} & \multicolumn{1}{c|}{ Tipo de erosión } & \\
\hline Profundo $(>5 \mathrm{~cm})$ & & Laminar & \\
\hline Medio $(3-5 \mathrm{~cm})$ & & En surcos (rills) & \\
\hline Somero $(1-3 \mathrm{~cm})$ & & Regueros & \\
\hline & & Barraqueras & \\
\hline
\end{tabular}

Profundidad y textura del suelo

\begin{tabular}{|l|l|l|l|}
\hline \multicolumn{1}{|c|}{ Profunfidad (cm) } & \multicolumn{1}{|c|}{ Textura } & \\
\hline$>80$ & & Franca o media & \\
\hline $80-60$ & & & \\
\hline $60-40$ & & Muy limosa & \\
\hline $40-30$ & & Muy arenosa & \\
\hline $30-20$ & & Muy arcillosa & \\
\hline$<20$ & & & \\
\hline
\end{tabular}

Defensas antrópicas

\begin{tabular}{|l|l|l|l|}
\hline \multicolumn{1}{|c|}{ Acciones generales } & & \multicolumn{1}{c|}{ Acciones puntuales } & \\
\hline Bancales en buen estado & & Reposición de surcos & \\
\hline Bancales algo degradados & & Canalizaciones artificiales & \\
\hline Bancales muy degradados & & Otras & \\
\hline Restos de bancales & & & \\
\hline
\end{tabular}

\section{Otras observaciones}

1. Labrados en el sentido de la pendiente

2. Labrado en sentido perpendicular a la pendiente

3. Incendios recientes

4. Otros 


\subsection{Coeficientes de los bancos de filtros}

En este apartado se adjuntan los coeficientes de los diversos filtros de descomposición y reconstrucción derivados de las distintas funciones wavelet empleadas en los ensayos y cuya descripción detallada se encuentra en el capítulo VI "Metodología".

\begin{tabular}{|c|c|c|}
\hline & $n$ & $h_{1}(n)$ \\
\hline \multirow[t]{4}{*}{$p=2$} & 0 & 0.4829629131450 \\
\hline & 1 & 0.8365163037380 \\
\hline & 2 & 0.2241438680420 \\
\hline & 3 & -0.1294095225510 \\
\hline \multirow[t]{6}{*}{$p=3$} & 0 & 0.3326705529500 \\
\hline & 1 & 0.8068915093110 \\
\hline & 2 & 0.4598775021180 \\
\hline & 3 & -0.1350110200100 \\
\hline & 4 & -0.0854412738820 \\
\hline & 5 & 0.0352262918820 \\
\hline \multirow[t]{8}{*}{$p=4$} & 0 & 0.2303778133090 \\
\hline & 1 & 0.7148465705530 \\
\hline & 2 & 0.6308807679300 \\
\hline & 3 & -0.0279837694170 \\
\hline & 4 & -0.1870348117190 \\
\hline & 5 & 0.0308413818360 \\
\hline & 6 & 0.0328830116670 \\
\hline & 7 & -0.0105974017850 \\
\hline \multirow[t]{10}{*}{$p=5$} & 0 & 0.1601023979740 \\
\hline & 1 & 0.6038292697970 \\
\hline & 2 & 0.7243085284380 \\
\hline & 3 & 0.1384281459010 \\
\hline & 4 & -0.2422948870660 \\
\hline & 5 & -0.0322448695850 \\
\hline & 6 & 0.0775714938400 \\
\hline & 7 & -0.0062414902130 \\
\hline & 8 & -0.0125807519990 \\
\hline & 9 & 0.0033357252850 \\
\hline \multirow[t]{8}{*}{$p=6$} & 0 & 0.1115407433500 \\
\hline & 1 & 0.4946238903980 \\
\hline & 2 & 0.7511339080210 \\
\hline & 3 & 0.3152503517090 \\
\hline & 4 & -0.2262646939650 \\
\hline & 5 & -0.1297668675670 \\
\hline & 6 & 0.0975016055870 \\
\hline & 7 & 0.0275228655300 \\
\hline
\end{tabular}

\begin{tabular}{|c|c|c|}
\hline & $n$ & $h_{1}(n)$ \\
\hline & 8 & -0.0315820393170 \\
\hline & 9 & 0.0005538422010 \\
\hline & 10 & 0.0047772575110 \\
\hline & 11 & -0.0010773010850 \\
\hline$p=7$ & 0 & 0.0778520540850 \\
\hline & 1 & 0.3965393194820 \\
\hline & 2 & 0.7291320908460 \\
\hline & 3 & 0.4697822874050 \\
\hline & 4 & -0.1439060039290 \\
\hline & 5 & -0.2240361849940 \\
\hline & 6 & 0.0713092192670 \\
\hline & 7 & 0.0806126091510 \\
\hline & 8 & -0.0380299369350 \\
\hline & 9 & -0.0165745416310 \\
\hline & 10 & 0.0125509985560 \\
\hline & 11 & 0.0004295779730 \\
\hline & 12 & -0.0018016407040 \\
\hline & 13 & 0.0003537138000 \\
\hline$p=8$ & 0 & 0.0544158422430 \\
\hline & 1 & 0.3128715909140 \\
\hline & 2 & 0.6756307362970 \\
\hline & 3 & 0.5853546836540 \\
\hline & 4 & -0.0158291052560 \\
\hline & 5 & -0.2840155429620 \\
\hline & 6 & 0.0004724845740 \\
\hline & 7 & 0.1287474266200 \\
\hline & 8 & -0.0173693010020 \\
\hline & 9 & -0.0440882539300 \\
\hline & 10 & 0.0139810279170 \\
\hline & 11 & 0.0087460940470 \\
\hline & 12 & -0.0048703529930 \\
\hline & 13 & -0.0003917403730 \\
\hline & 14 & 0.0006754494060 \\
\hline & 15 & -0.0001174767840 \\
\hline$p=9$ & 0 & 0.0380779473640 \\
\hline & 1 & 0.2438346746130 \\
\hline
\end{tabular}

\begin{tabular}{|c|c|c|}
\hline & $n$ & $h_{1}(n)$ \\
\hline & 2 & 0.6048231236900 \\
\hline & 3 & 0.6572880780510 \\
\hline & 4 & 0.1331973858250 \\
\hline & 5 & -0.2932737832790 \\
\hline & 6 & -0.0968407832230 \\
\hline & 7 & 0.1485407493380 \\
\hline & 8 & 0.0307256814790 \\
\hline & 9 & -0.0676328290610 \\
\hline & 10 & 0.0002509471150 \\
\hline & 11 & 0.0223616621240 \\
\hline & 12 & -0.0047232047580 \\
\hline & 13 & -0.0042815036820 \\
\hline & 14 & 0.0018476468830 \\
\hline & 15 & 0.0002303857640 \\
\hline & 16 & -0.0002519631890 \\
\hline & 17 & 0.0000393473200 \\
\hline$p=10$ & 0 & 0.0266700579010 \\
\hline & 1 & 0.1881768000780 \\
\hline & 2 & 0.5272011889320 \\
\hline & 3 & 0.6884590394540 \\
\hline & 4 & 0.2811723436610 \\
\hline & 5 & -0.2498464243270 \\
\hline & 6 & -0.1959462743770 \\
\hline & 7 & 0.1273693403360 \\
\hline & 8 & 0.0930573646040 \\
\hline & 9 & -0.0713941471660 \\
\hline & 10 & -0.0294575368220 \\
\hline & 11 & 0.0332126740590 \\
\hline & 12 & 0.0036065535670 \\
\hline & 13 & -0.0107331754830 \\
\hline & 14 & 0.0013953517470 \\
\hline & 15 & 0.0019924052950 \\
\hline & 16 & -0.0006858566950 \\
\hline & 17 & -0.0001164668550 \\
\hline & 18 & 0.0000935886700 \\
\hline & 19 & -0.0000132642030 \\
\hline
\end{tabular}

Tabla 10-1. Coeficientes de los filtros de la familia de funciones Daubechies del apartado 6.3.6.3.

\begin{tabular}{|l|cccccc|}
\hline PB D & -0.0157 & -0.0727 & 0.3849 & 0.8526 & 0.3379 & -0.0727 \\
\hline PA D & 0.0727 & 0.3379 & -0.8526 & 0.3849 & 0.0727 & -0.0157 \\
\hline PB S & -0.0727 & 0.3379 & 0.8526 & 0.3849 & -0.0727 & -0.0157 \\
\hline PA S & -0.0157 & 0.0727 & 0.3849 & -0.8526 & 0.3379 & 0.0727 \\
\hline
\end{tabular}

Tabla 10-2. Coeficientes de los filtros de la familia de funciones Coiflet6 (apartado 6.3.6.4). 


\begin{tabular}{|l|rrrrrrrrrl|}
\hline PB D & -0.0007 & -0.0018 & 0.0056 & 0.0237 & -0.0594 & -0.0765 & 0.4170 & 0.8127 & 0.3861 & -0.0674 \\
& -0.0415 & 0.0164 & & & & & & & & \\
\hline \multirow{2}{*}{ PA D } & -0.0164 & -0.0415 & 0.0674 & 0.3861 & -0.8127 & 0.4170 & 0.0765 & -0.0594 & -0.0237 & 0.0056 \\
& 0.0018 & -0.0007 & & & & & & & & \\
\hline \multirow{2}{*}{ PB S } & 0.0164 & -0.0415 & -0.0674 & 0.3861 & 0.8127 & 0.4170 & -0.0765 & -0.0594 & 0.0237 & 0.0056 \\
& -0.0018 & -0.0007 & & & & & & & & \\
\hline \multirow{2}{*}{ PA S } & -0.0007 & 0.0018 & 0.0056 & -0.0237 & -0.0594 & 0.0765 & 0.4170 & -0.8127 & 0.3861 & 0.0674 \\
& -0.0415 & -0.0164 & & & & & & & & \\
\hline
\end{tabular}

Tabla 10-3. Coeficientes de los filtros de la familia de funciones Coiflet12 (apartado 6.3.6.4).

\begin{tabular}{|l|rrrrrrrrrr|}
\hline \multirow{2}{*}{ PB D } & -0.0000 & -0.0001 & 0.0005 & 0.0011 & -0.0026 & -0.0090 & 0.0159 & 0.0346 & -0.0823 & -0.0718 \\
& 0.4285 & 0.7938 & 0.4052 & -0.0611 & -0.0658 & 0.0235 & 0.0078 & -0.0038 & & \\
\hline \multirow{2}{*}{ PA D } & 0.0038 & 0.0078 & -0.0235 & -0.0658 & 0.0611 & 0.4052 & -0.7938 & 0.4285 & 0.0718 & -0.0823 \\
& -0.0346 & 0.0159 & 0.0090 & -0.0026 & -0.0011 & 0.0005 & 0.0001 & -0.0000 & & \\
\hline \multirow{2}{*}{ PB S } & -0.0038 & 0.0078 & 0.0235 & -0.0658 & -0.0611 & 0.4052 & 0.7938 & 0.4285 & -0.0718 & -0.0823 \\
& 0.0346 & 0.0159 & -0.0090 & -0.0026 & 0.0011 & 0.0005 & -0.0001 & -0.0000 & & \\
\hline \multirow{2}{*}{ PA S } & -0.0000 & 0.0001 & 0.0005 & -0.0011 & -0.0026 & 0.0090 & 0.0159 & -0.0346 & -0.0823 & 0.0718 \\
& 0.4285 & -0.7938 & 0.4052 & 0.0611 & -0.0658 & -0.0235 & 0.0078 & 0.0038 & & \\
\hline
\end{tabular}

Tabla 10-4. Coeficientes de los filtros de la familia de funciones Coiflet18 (apartado 6.3.6.4).

\begin{tabular}{|l|rrrrrrrrrr|}
\hline \multirow{3}{*}{ PB D } & -0.0000 & -0.0000 & 0.0000 & 0.0001 & -0.0003 & -0.0006 & 0.0013 & 0.0038 & -0.0057 & -0.0152 \\
& 0.0251 & 0.0393 & -0.0962 & -0.0666 & 0.4344 & 0.7822 & 0.4153 & -0.0561 & -0.0813 & 0.0267 \\
& 0.0161 & -0.0073 & -0.0016 & 0.0009 & & & & & & \\
\hline \multirow{4}{*}{ PA D } & -0.0009 & -0.0016 & 0.0073 & 0.0161 & -0.0267 & -0.0813 & 0.0561 & 0.4153 & -0.7822 & 0.4344 \\
& 0.0666 & -0.0962 & -0.0393 & 0.0251 & 0.0152 & -0.0057 & -0.0038 & 0.0013 & 0.0006 & -0.0003 \\
& -0.0001 & 0.0000 & 0.0000 & -0.0000 & & & & & & \\
\hline \multirow{3}{*}{ PB S } & 0.0009 & -0.0016 & -0.0073 & 0.0161 & 0.0267 & -0.0813 & -0.0561 & 0.4153 & 0.7822 & 0.4344 \\
& -0.0666 & -0.0962 & 0.0393 & 0.0251 & -0.0152 & -0.0057 & 0.0038 & 0.0013 & -0.0006 & -0.0003 \\
& 0.0001 & 0.0000 & -0.0000 & -0.0000 & & & & & & \\
\hline \multirow{3}{*}{ PA S } & -0.0000 & 0.0000 & 0.0000 & -0.0001 & -0.0003 & 0.0006 & 0.0013 & -0.0038 & -0.0057 & 0.0152 \\
& 0.0251 & -0.0393 & -0.0962 & 0.0666 & 0.4344 & -0.7822 & 0.4153 & 0.0561 & -0.0813 & -0.0267 \\
& 0.0161 & 0.0073 & -0.0016 & -0.0009 & & & & & & \\
\hline
\end{tabular}

Tabla 10-5. Coeficientes de los filtros de la familia de funciones Coiflet24 (apartado 6.3.6.4).

\begin{tabular}{|l|llllllll|}
\hline PB D & -0.0758 & -0.0296 & 0.4976 & 0.8037 & 0.2979 & -0.0992 & -0.0126 & 0.0322 \\
\hline PA D & -0.0322 & -0.0126 & 0.0992 & 0.2979 & -0.8037 & 0.4976 & 0.0296 & -0.0758 \\
\hline PB S & 0.0322 & -0.0126 & -0.0992 & 0.2979 & 0.8037 & 0.4976 & -0.0296 & -0.0758 \\
\hline PA S & -0.0758 & 0.0296 & 0.4976 & -0.8037 & 0.2979 & 0.0992 & -0.0126 & -0.0322 \\
\hline
\end{tabular}

Tabla 10-6. Coeficientes de los filtros de la familia de funciones Symlet 8 (apartado 6.3.6.5).

\begin{tabular}{|l|rrrrrrrrrl|}
\hline \multirow{2}{*}{ PB D } & -0.0034 & -0.0005 & 0.0317 & 0.0076 & -0.1433 & -0.0613 & 0.4814 & 0.7772 & 0.3644 & -0.0519 \\
& -0.0272 & 0.0491 & 0.0038 & -0.0150 & -0.0003 & 0.0019 & & & & \\
\hline \multirow{2}{*}{ PA D } & -0.0019 & -0.0003 & 0.0150 & 0.0038 & -0.0491 & -0.0272 & 0.0519 & 0.3644 & -0.7772 & 0.4814 \\
& 0.0613 & -0.1433 & -0.0076 & 0.0317 & 0.0005 & -0.0034 & & & & \\
\hline \multirow{2}{*}{ PB S } & 0.0019 & -0.0003 & -0.0150 & 0.0038 & 0.0491 & -0.0272 & -0.0519 & 0.3644 & 0.7772 & 0.4814 \\
& -0.0613 & -0.1433 & 0.0076 & 0.0317 & -0.0005 & -0.0034 & & & & \\
\hline \multirow{2}{*}{ PA S } & -0.0034 & 0.0005 & 0.0317 & -0.0076 & -0.1433 & 0.0613 & 0.4814 & -0.7772 & 0.3644 & 0.0519 \\
& -0.0272 & -0.0491 & 0.0038 & 0.0150 & -0.0003 & -0.0019 & & & & \\
\hline
\end{tabular}

Tabla 10-7. Coeficientes de los filtros de la familia de funciones Symlet 16 (apartado 6.3.6.5). 


\begin{tabular}{|l|llllllll|}
\hline PB D & -0.057884 & -0.139930 & 0.1825920 & 0.658911 & 0.658911 & 0.1825920 & -0.139930 & -0.057884 \\
\hline PA D & 0.057884 & -0.139930 & -0.1825920 & 0.658911 & -0.658911 & 0.1825920 & 0.139930 & -0.057884 \\
\hline PB S & -0.057884 & -0.139930 & 0.1825920 & 0.658911 & 0.658911 & 0.1825920 & -0.139930 & -0.057884 \\
\hline PA S & -0.057884 & 0.139930 & 0.1825920 & -0.658911 & 0.658911 & -0.1825920 & -0.139930 & 0.057884 \\
\hline
\end{tabular}

Tabla 10-8. Coeficientes de los filtros de la función Battle-Lemarié 6 (apartado 6.3.6.6).

\begin{tabular}{|l|ccccccl|}
\hline PB D & -0.150052 & 0.000000 & 0.450150 & 0.707100 & 0.450150 & 0.000000 & -0.150052 \\
\hline PA D & 0.150052 & 0.000000 & -0.450150 & 0.707100 & -0.450150 & 0.000000 & 0.150052 \\
\hline PB S & -0.150052 & 0.000000 & 0.450150 & 0.707100 & 0.450150 & 0.000000 & -0.150052 \\
\hline PA S & -0.150052 & 0.000000 & 0.450150 & -0.707100 & 0.450150 & 0.000000 & -0.150052 \\
\hline
\end{tabular}

Tabla 10-9. Coeficientes de los filtros de la función Shannon 7 (apartado 6.3.6.7).

\begin{tabular}{|l|rrrrrrrl|}
\hline \multirow{2}{*}{ PB D } & -0.0243218 & 0.0636672 & 0.0306212 & -0.1326970 & -0.0350483 & 0.444095 & 0.743750 & 0.444095 \\
& -0.0350483 & -0.1326970 & 0.0306212 & 0.0636672 & -0.0243218 & & & \\
\hline \multirow{2}{*}{ PA D } & 0.0243218 & 0.0636672 & -0.0306212 & -0.1326970 & 0.0350483 & 0.444095 & -0.743750 & 0.444095 \\
& 0.0350483 & -0.1326970 & -0.0306212 & 0.0636672 & 0.0243218 & & & \\
\hline \multirow{2}{*}{ PB S } & -0.0243218 & 0.0636672 & 0.0306212 & -0.1326970 & -0.0350483 & 0.444095 & 0.743750 & 0.444095 \\
& -0.0350483 & -0.1326970 & 0.0306212 & 0.0636672 & -0.0243218 & & & \\
\hline \multirow{2}{*}{ PA S } & -0.0243218 & -0.0636672 & 0.0306212 & 0.1326970 & -0.0350483 & -0.444095 & 0.743750 & -0.444095 \\
& -0.0350483 & 0.1326970 & 0.0306212 & -0.0636672 & -0.0243218 & & & \\
\hline
\end{tabular}

Tabla 10-10. Coeficientes de los filtros de la función Meyer 3 (apartado 6.3.6.8).

\subsection{Listado de rutinas programadas}

Para la puesta en práctica de los ensayos descritos en el capítulo metodológico se han desarrollado diversas rutinas en dos lenguajes de programación diferentes, en código fuente de Matlab y el lenguaje IDL, fuente del programa ENVI sobre el cual se ha trabajado en gran parte. Dado que sería de gran extensión adjuntar dicho código en el presente documento impreso, se incluye de forma digital en el CD adjunto, cuya estructura y descripción de contenidos es el que se detalla a continuación.

\section{RUTINA EN LENGUAJE DE MATLAB}

\begin{tabular}{|l|l|}
\hline descomposicion.m & $\begin{array}{l}\text { Aplicación de la descomposición wavelet directa, extracción } \\
\text { de tendencias y fluctuaciones, detalles y aproximaciones y } \\
\text { reconstrucción de la imagen inicial. }\end{array}$ \\
\hline
\end{tabular}




\section{RUTINAS EN LENGUAJE IDL}

\begin{tabular}{|c|c|}
\hline energia.pro & $\begin{array}{l}\text { Calcula la energía global de la imagen y una imagen de } \\
\text { energía derivada de la original empleando un vecindario de } \\
3 \times 3 \text {. }\end{array}$ \\
\hline desv_energ_kurt.pro & $\begin{array}{l}\text { Calcula de forma conjunta las imágenes de desviación media, } \\
\text { energía y kurtosis de la imagen original empleando un } \\
\text { vecindario de } 3 \times 3 \text {. }\end{array}$ \\
\hline imagen_asimetria.pro & $\begin{array}{l}\text { Calcula la imagen de asimetría a partir del histograma de } \\
\text { una imagen de entrada. }\end{array}$ \\
\hline asimetria.pro & Calcula el parámetro de asimetría de toda una imagen. \\
\hline desc_recons.pro & $\begin{array}{l}\text { Realiza la descomposición y reconstrucción de la imagen } \\
\text { original según la transformada wavelet y usando un banco } \\
\text { de filtros específicos para cada familia de funciones. } \\
\text { Determina los modelos de tendencias, fluctuaciones, } \\
\text { aproximaciones y detalles. Calcula las variables de textura de } \\
1^{\text {er }} \text { y } 2^{\circ} \text { orden. }\end{array}$ \\
\hline remuestreo.pro & $\begin{array}{l}\text { Aplica un remuestreo sobre una imagen, generando otras de } \\
\text { tamaño diferente especificando las nuevas dimensiones del } \\
\text { píxel. }\end{array}$ \\
\hline resize.pro & $\begin{array}{l}\text { Aplica un remuestreo a una imagen mediante un factor } \\
\text { especificado. }\end{array}$ \\
\hline remuestreo_varianza & $\begin{array}{l}\text { Aplica remuestreos a una imagen generando otras nuevas, } \\
\text { calculando sobre éstas las imágenes de varianza y calculando } \\
\text { las estadísticas de las últimas. }\end{array}$ \\
\hline sumar_imagenes.pro & Suma varias imágenes en una nueva de salida. \\
\hline variables_textura.pro & $\begin{array}{l}\text { Calcula las variables de textura de la MCNG en un vecindario } \\
\text { concreto. }\end{array}$ \\
\hline convolucion.pro & $\begin{array}{l}\text { Realiza la convolución de una imagen mediante un filtro } \\
\text { especificado. }\end{array}$ \\
\hline estadisticas.pro & Calcula las estadísticas básicas de una imagen. \\
\hline
\end{tabular}



entrada. Llama a la rutina canny.pro elaborada por Harvey Rhody (rhody@cis.rit.edu) ${ }^{1}$.

1. Escrita en febrero de 2001 por Harvey Rhody. Parte de un programa escrito en C por Mike Heath, University of South Florida (heath@csee.usf.edu). A su vez, éste empleó algunas partes de código escrito en la Michigan State University. 